تقييم وتطوير مبادرة الإفصاح - تعديلات معيار عرض القوائم المالية IAS1

كمدل لعلاج مشاكل الإفصاح المحاسبي - دراسة اختبارية

$$
\text { د/ محمد وداد الأرضي }
$$

أستاذ مساعد المحاسبة - كلية التجارة وإدارة الأعمال -جامعة حلوان

القسب الأول: منهجية البحث:

ملخص البحث:

الغرض: تهدف الدراسة لنقييم مكونات مبادرة الإقصاح - تعديلات المعيار المحاسبي الدولي الأول عرض

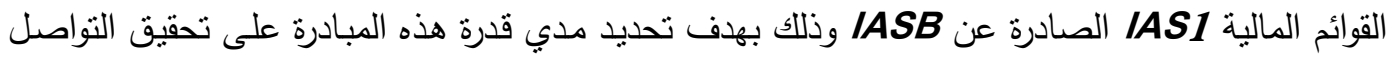

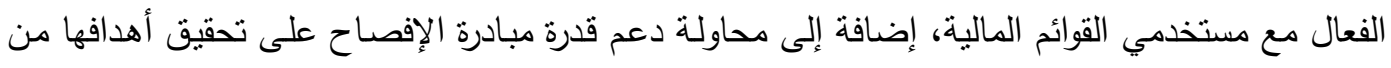
خلال اقتتراح تعديلات لبعض فقرات IAS1 التي لم ترد بمبادرة الإفصاح. تصميم / المنهجية: للتحقق من صحة فروض الدراسة قام الباحث بإعداد قائمة استقصاء مكونة من ستة

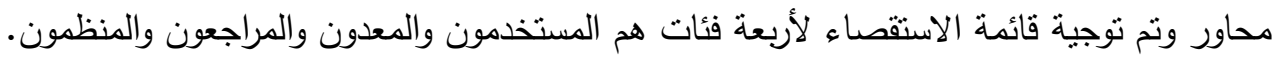

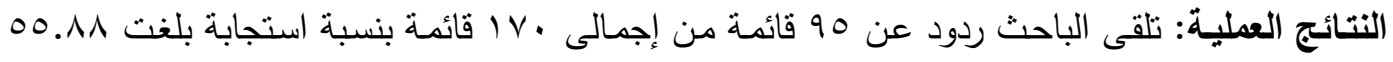

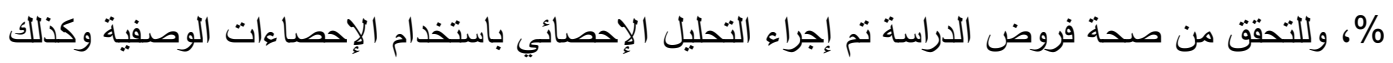

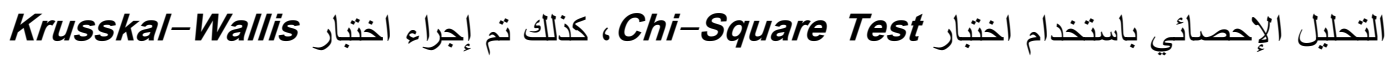

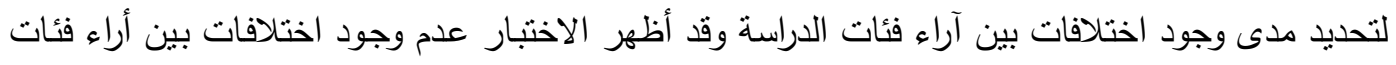

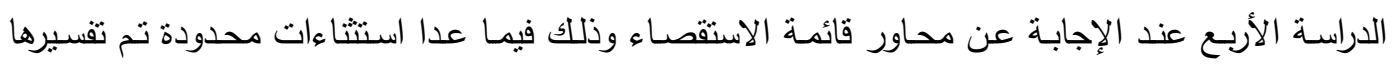

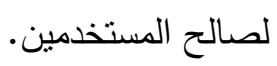

الأصالة//القيمة: تمنل الدراسة مساهمة بالأدب المحاسبي من خلال محاولة تقييم مكونات مبادرة الإفصاح

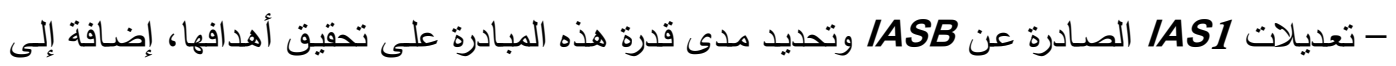

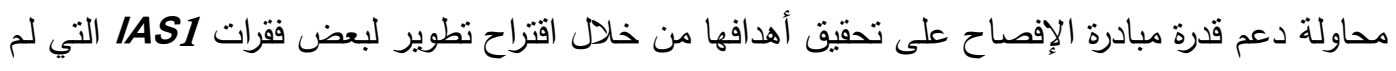
ترد بمبادرة الإقصاح. الكلمـات الأفتاحية: مبادرة الإفصساح، الإفصـاح، العرض، قائمسة المركز المالي، قائهة الدخل، السياسات المحاسبية، الإيضاحات. 
(1/1

تمنل القوائم المالية للشركات ضامن رئيسي لرفاهية واستمرار أسواق المال نظرا لما تحتويه

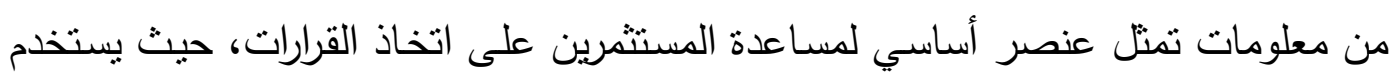

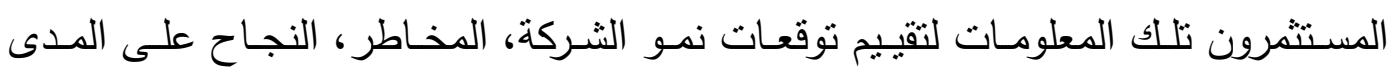

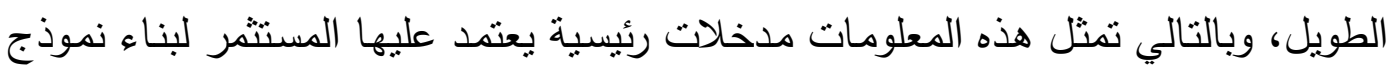
القرار الخاص به وهو ما يحتم أن يكون الإفصاح في القوائم المالية معبراً عن واقع الأعمال

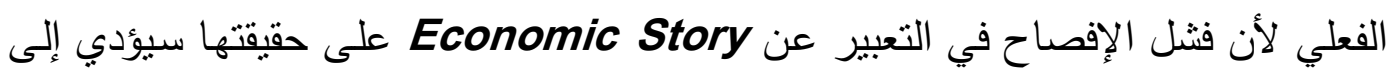

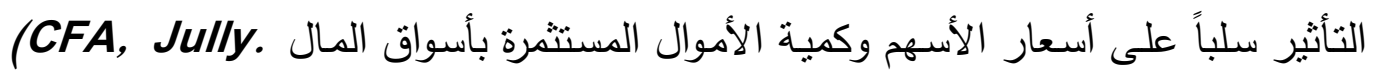

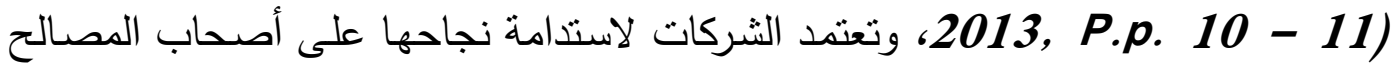
بشكل كامل، لذا فإن من مصلحة تلك الثركات أن توفر تقارير ذات جودة عالية من أجل الته

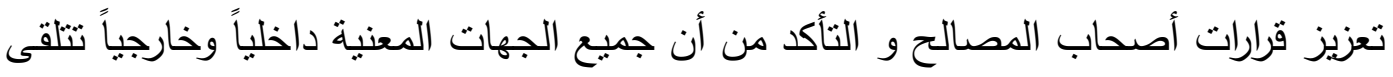

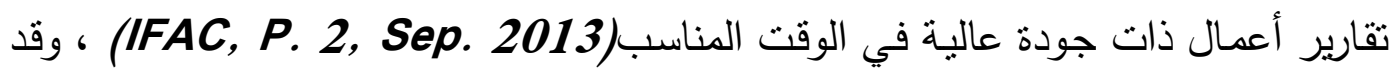
بات الإفصاح يمثل طليعة الجهود التتظيمية المستخدمة لتحسين مستوى جودة أسواق المال

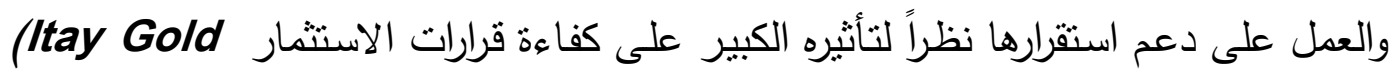
.stein, Liyan Yang, April 18. 2017, P.p. 1 - 2)

وتجدر الإثـارة أن آلية اعتبار الإفصساح أداة لرفع مستوى جودة أسواق المال تم اعتمادها

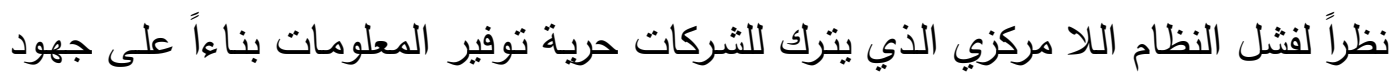
المستثرين، وهو النظام الذي أثبت فثله وهو ما تطلب إعداد تنظيم بكفل للمستثمرين

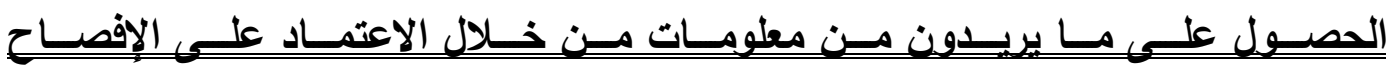

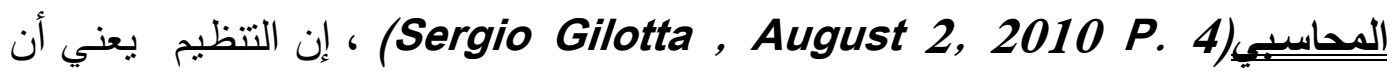

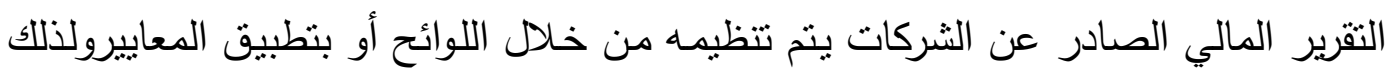

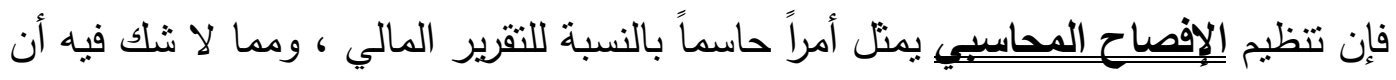

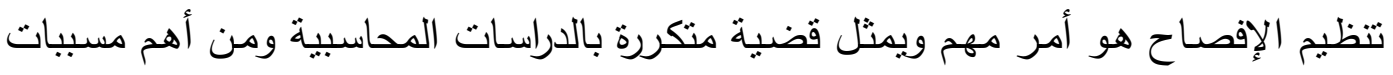

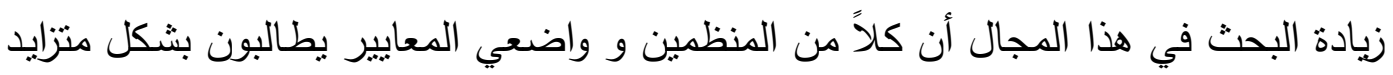

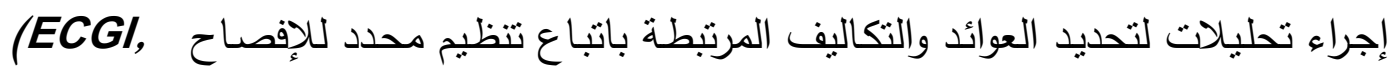
.Christian Leuz, Peterwys oscki, 2016, P.p. 8 -9) 


\section{1/ 1/}

يُعرف الإفصـاح بأنه التوفير العمدي للمعلومات المالية أو غير المالية سواء كان إفصـاح

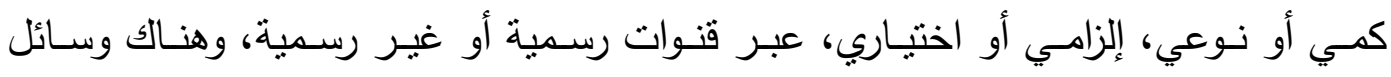

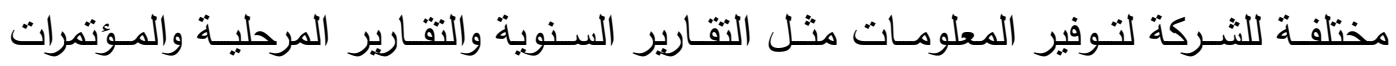
والنشرات الصحفية والمواقع الإكترونية، ويعتبر التقرير المالي تقنية مهمة جداً للإفصـاح

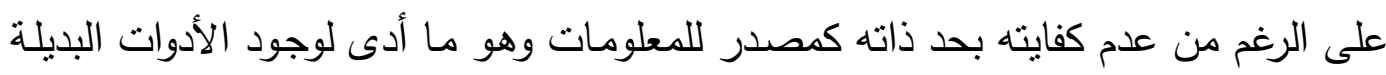

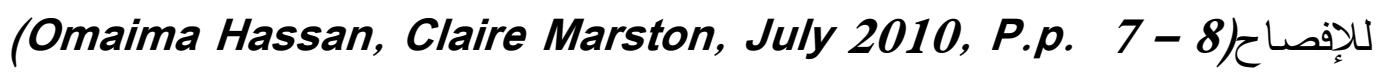

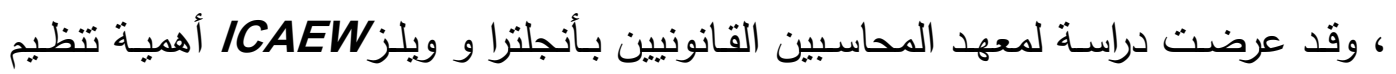

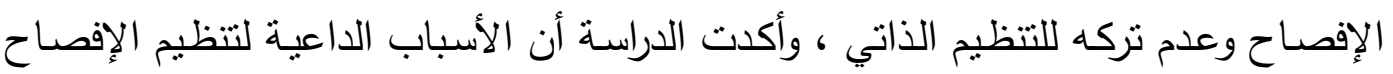

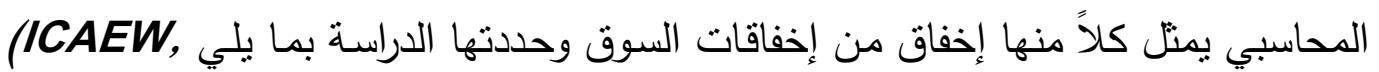
: Dec. 2013, P. 18) (1) انخفاض إنتاج السلعة العامة: حيث أن فوائد الإفصساح لا يمكن أن تقتصر على من يدفعون تكلفته، لذا فإنه بمثابة سلعة عامة ولذا يكون هناك ميل إلى خفض الإنتاجية (المعلومات) إذا ما نرك أمر الإنتاج حصراً

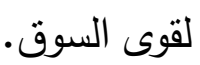

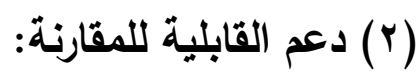

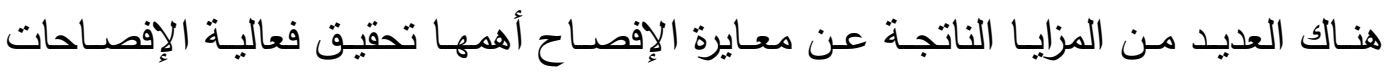

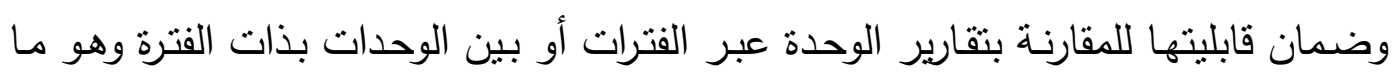
برتبط بتنظيم الإفصاح بشكل إلزامي.

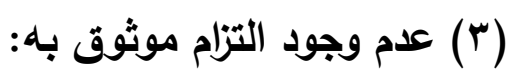
استفادة المستخدمين من الإفصاح الموفر لهم تتتج من إدراكهم بوجود التزام على الوحدات

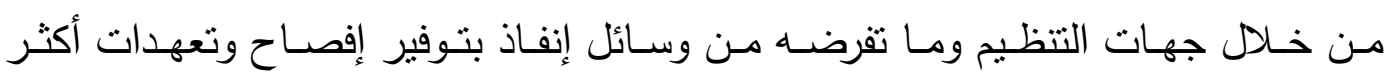
مصداقية. ( ) ( ) تباين المعلومات: في غياب تتظيم للإفصاح يمكن القول بأنه من السهل بالنسبة للمشاركين بالأسواق أن يحققوا

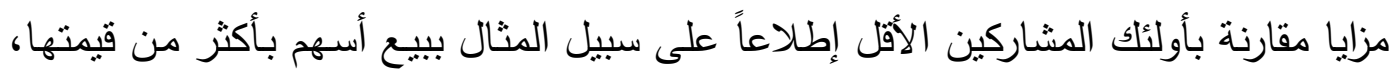
بشراء أسهم بأقل من قيمتها أو حتى عن طريق ارتكاب التنيال صريح. 
وكل ما سبق هي حجج لتتظيم الإفصاح تؤكد على انتظار مجتمع الاستثمار تتظيم دقيق

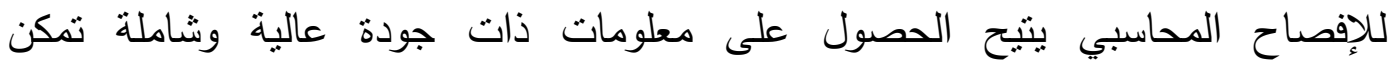
المستخدمين من فهم طبيعة عمل الوحدة وتقييم مدى استدامة نموذج الأعمال الخاص بالوحدة وقدرتها على نوليد تدفقات نقدية مستقبلية، وتوفير هذه المعلومات يتطلب من المنظمين وواضعي المعايير إدراك أن الإفصاح ليس بديلاً للاعتراف بمعنى أن الإفصاح يهدف لتوفين إندير معلومات إضافية للعناصر

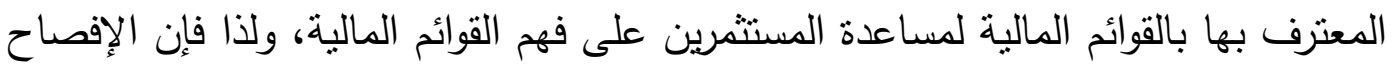

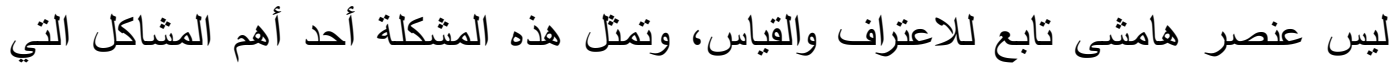

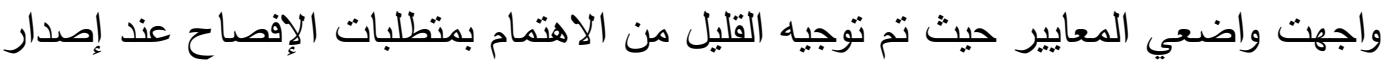

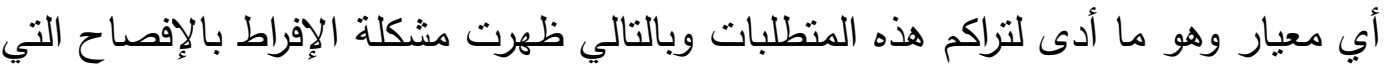

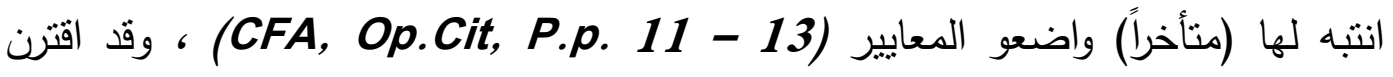
صدور القوانين ثم المعايير المنظمة للإفصاح بالكثير من الدراسات التي أوضحت أدأدواراً

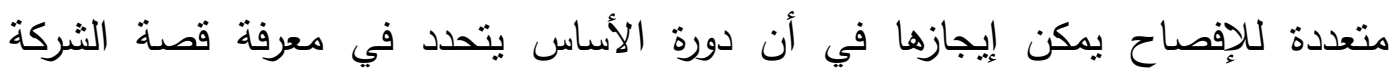

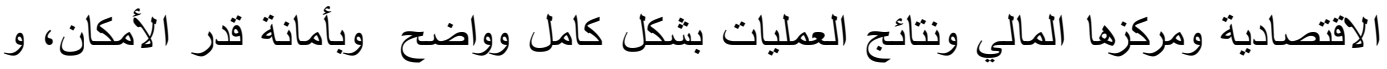

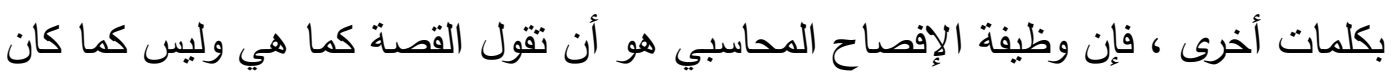

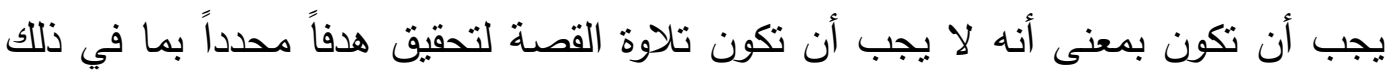

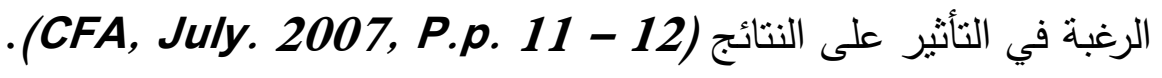

إلا أن هذا الدور المنوط بالإفصـاح المحاسبي قد تعرض للكثير من الانتقادات حيث أكد Russ Golden

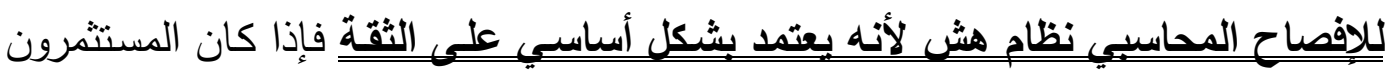

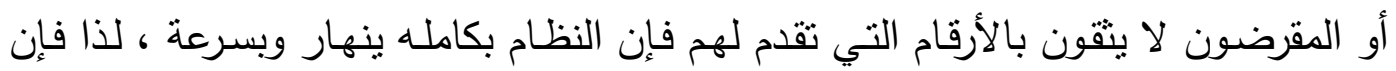

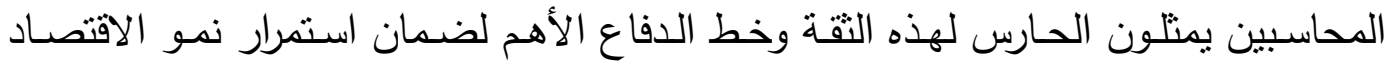
As Accounting, professionals, You are the وإيجاد فرص عمل (FASB, Russ Golden, Augst 31, guardians of that trust 2017,Pp.1-3) ، كما تضمنت الاتنقادات الموجهة للإفصساح المحاسبي النأكيد على 
وجود قلق متزايد في السنوات الأخيرة إزاء مشكلة الإقراط بالإفصاح وهو ما بظهر حاجة

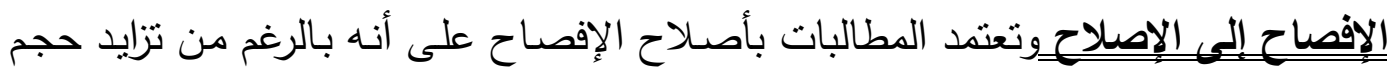

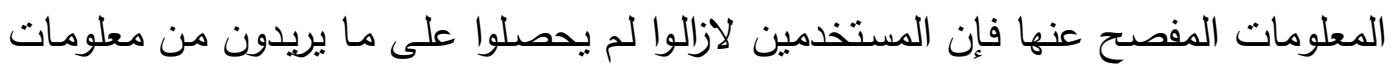

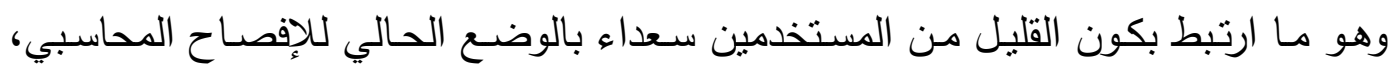

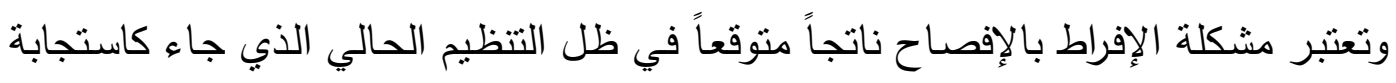
لإخفاق السوق في تتظيم الإفصاح المحاسبي(8) 2 - 2 (ICAEW, Op.Cit, P.p.).

وفي دراسة بعنوان Louder than words تم تحديد مشكلتين أساسيتين بالإفصـاح الحالي هما الإفراط في التفاصيل، إضافة لكون التقارير لا تعبر عن واقع الأعمال الحقيقي،

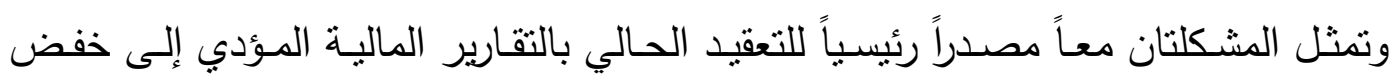

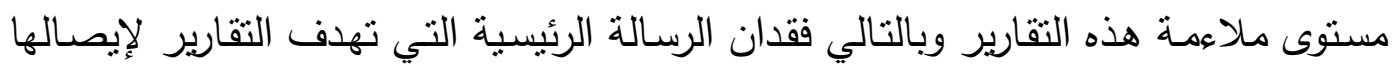

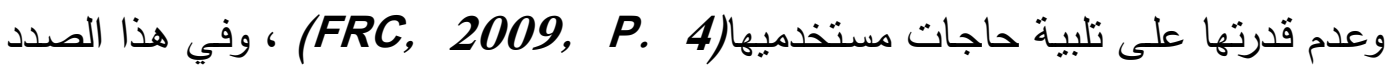
تجدر الإثشارة إلى أن الإفصاح المحاسبي يمر بدورات من الأوقات الجيدة والأخرى السيئة

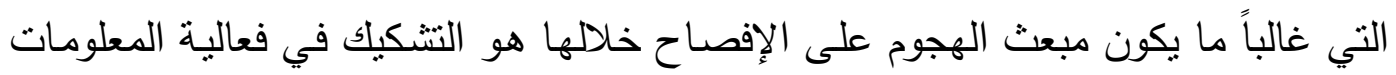

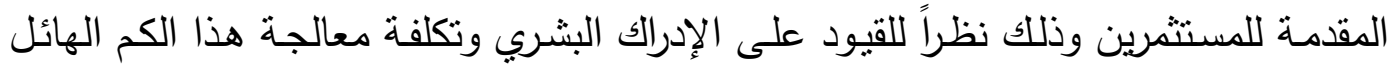

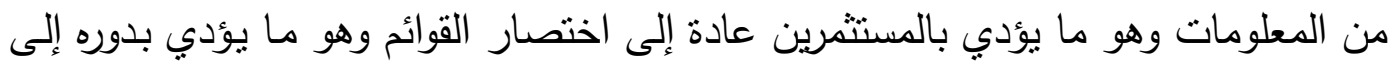

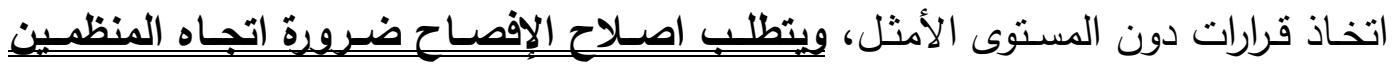

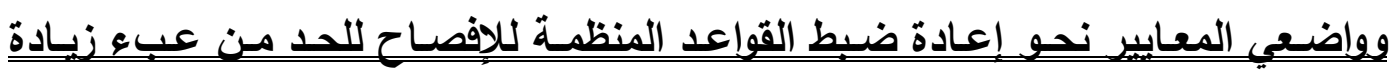
المعلومـات بهـف تحسن قرارات المستثمرين والحـا مـن إتباع المستثمرين الأقل خبرة

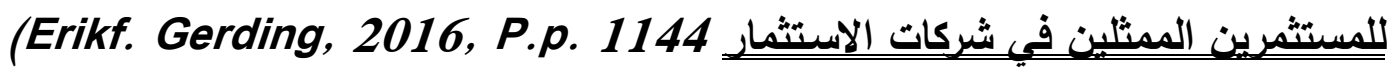

وفي ذات الصدد فقد أكد المعهذ الأسكتلندي للمحاسبين القانونيين ICAS أن هناك استياءاً

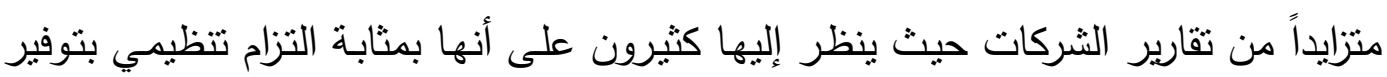

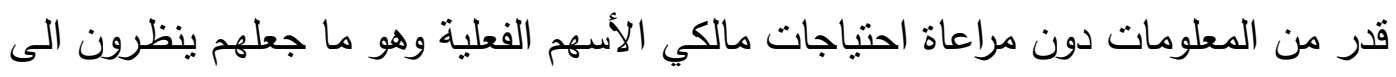

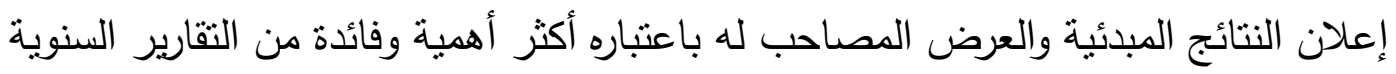

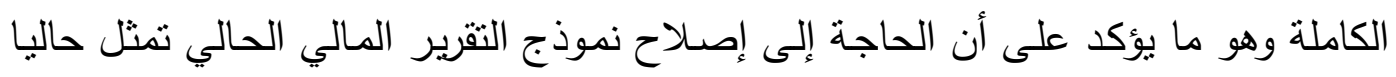




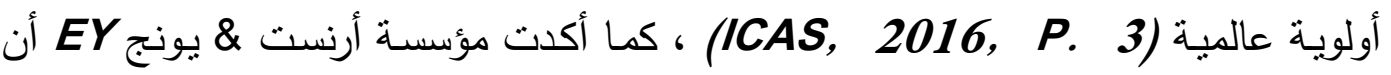

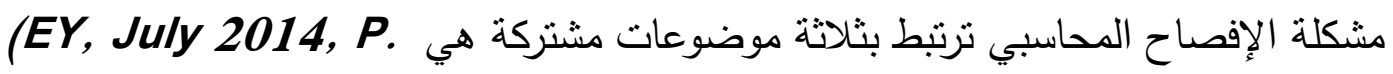

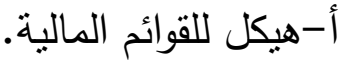
ب-مستوى تفصيل المعلومات.

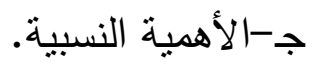

وتمثل العناصر الثلاثتة مكونـات معيـار المحاسبة الدولي الأول العرض بـالقوائم المالبـة

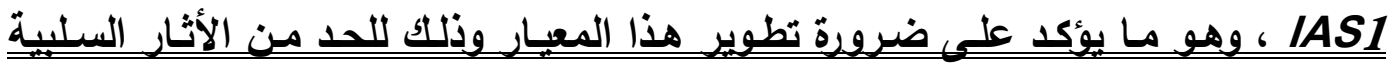
الناتجـة استمرار مـا برتبط بتطييق العناصر السـابقة من مشـاكل تؤدي مجتمعـة إلى مـا

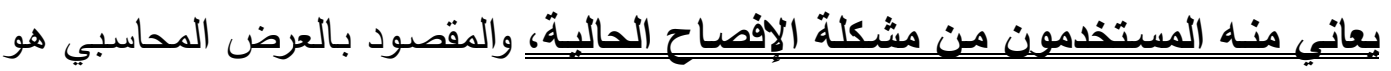
عمليـة إدراج العناصـر في القوائم الماليـة ، والهدف الرئيسي للعرض كمـا تم تحديده في في

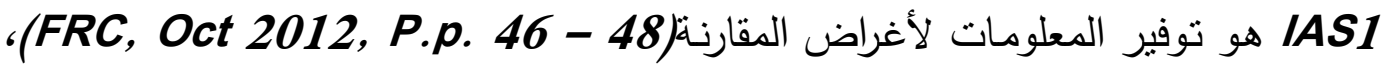

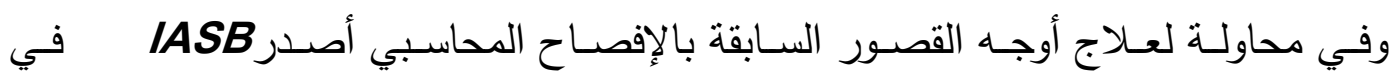

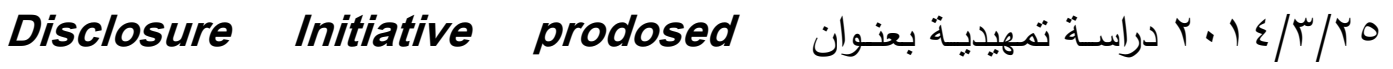
amendments to IAS1

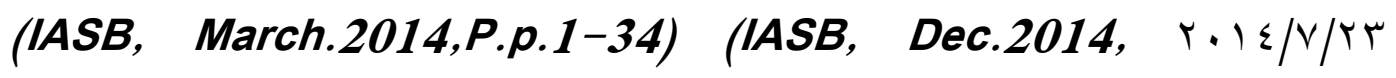

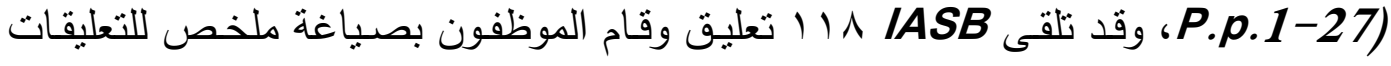

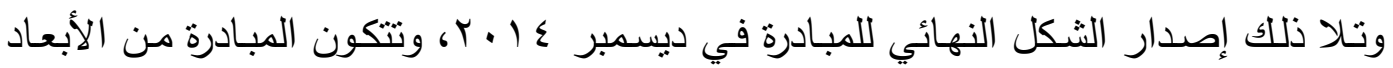
التالية(IASB, May 2013, P.p. 1-44)

\section{IAS1 - - إلعديل}

r- - إصدار مرشد مهنى يحكم تطبيق الأهمية النسبية.

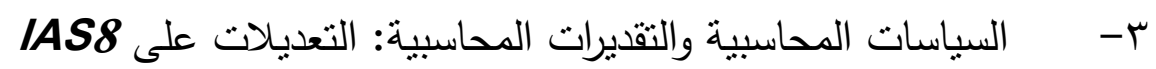

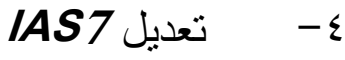

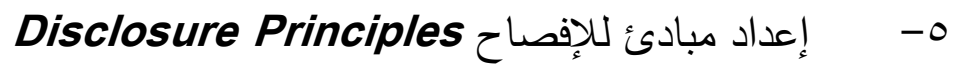
؟- مراجعة مستويات الإفصاح بالمعايير الحالية. 


\section{ويناعاً عليه تتحدد مشكلة البحث:}

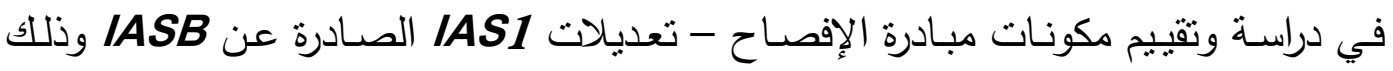

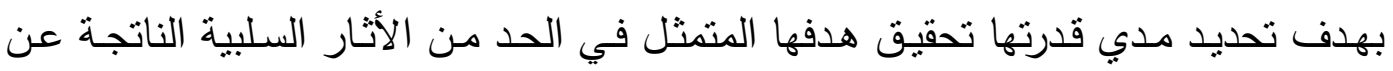

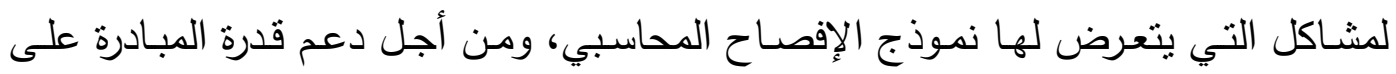

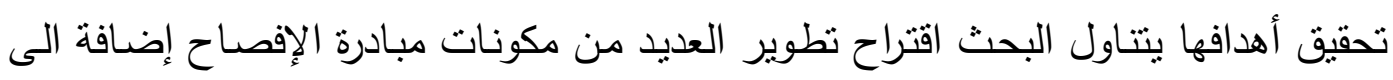

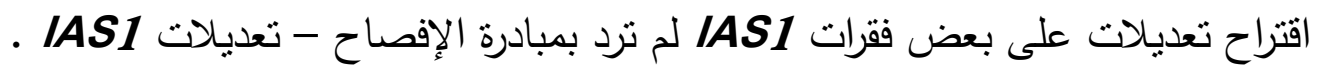

\section{1/ 1/ الدراسات السابقة:} أولًَا: الاراسات السابقة التي تتاولت مشاكل الإفصاح المحاسبي

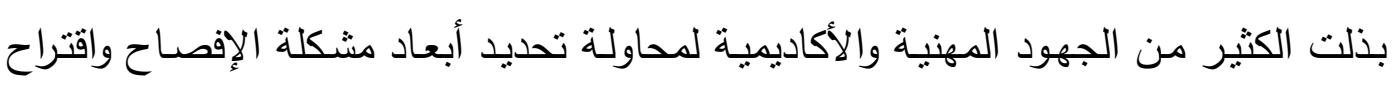
الحلول لها، ويعرض الباحث فيما يلي لبعض هذه الدراسات. 1 - دراسة FRC

(FRC, 2009, Op. Cit, P.p. 1 - 64)

أكدت الدراسة أن القدرة على جذب اهتمام قارئ التقارير المالية ترتبط بإتباع أفضل الطرق

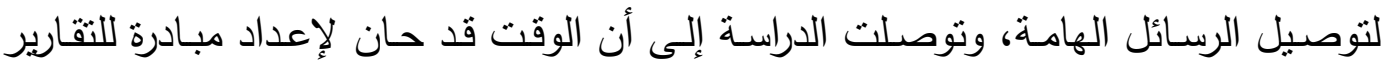

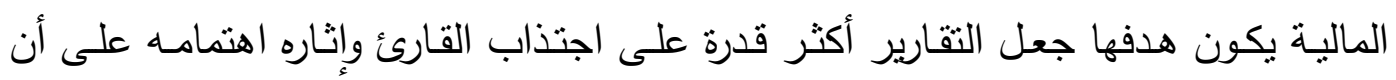

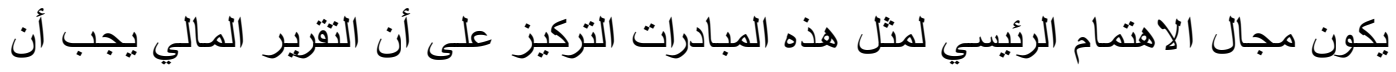

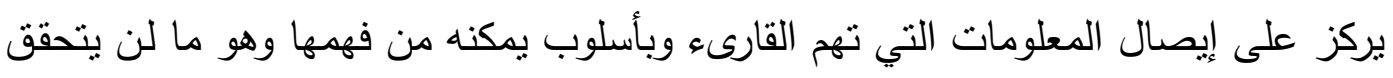

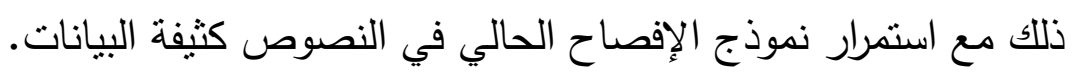

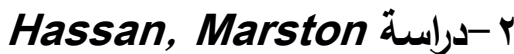

(Omaima Hassan, Claire Marston, Op. Cit, P.p. 1-58)

أكدت الدراسـة على أن أهية الإفصساح نتشأ من كونـه وسيلة أساسية للتواصل بين الإدارة

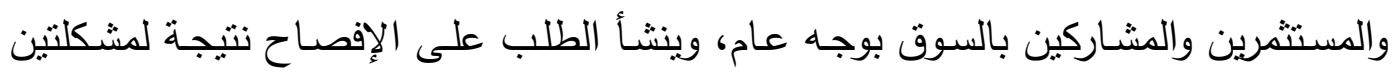

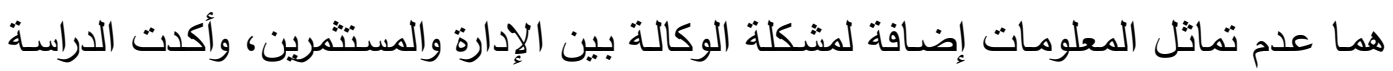
أن تطوير الإفصاح المحاسبي سيمثل أداة هامة لخفض آثار هذه المشاكل. لإدأل 
3- الدراسة المشتركة لمعه المحاسبين الأسكتلندي ICAS ومعهر المحاسبين القانونيين في نيوزيلندا

(ICAS, NZICA, 2011, P.p. 1 - 142)

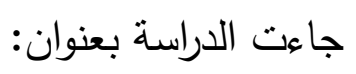

\section{Losing the excess baggage - reducing disclosure in financial}

statements to whats important

تمت الدراسة المشتركة بين المعهدين بطلب من IASB لكلا المجلسين بمراجعة منطلبات

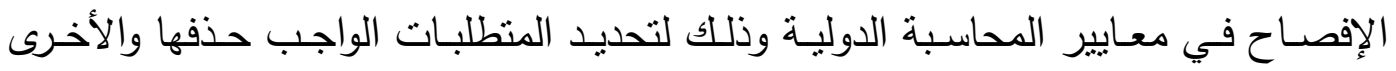

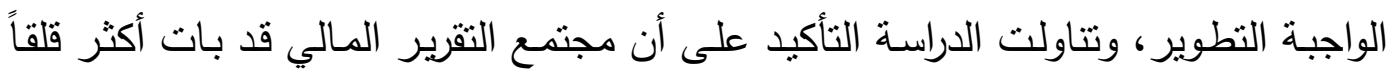

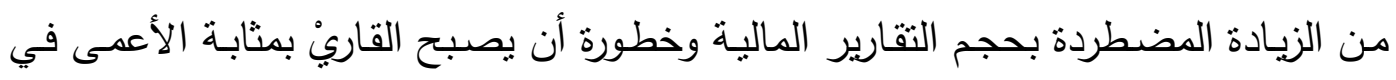

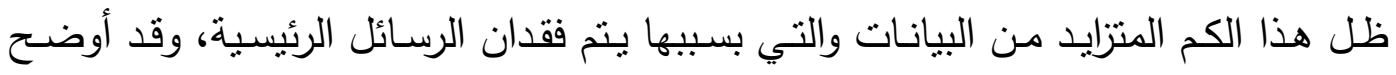

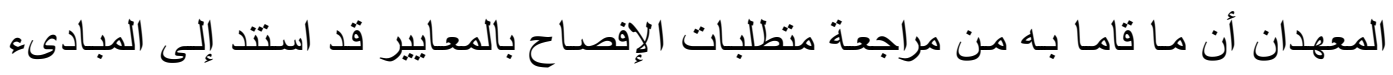

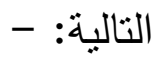

1- وجود تراكم بمنطلبات الإفصـاح بالمعايير نتيجة الإصدار المنوالي لها دون القيام بأي مراجعة للموازنة بين منطلبات الإفصاح وأهميتها للمستخدمين. r- برورة النظر للإفصاح في سباق تلبية حاجات المستخدمين وهو ما لا يمنع تقديم

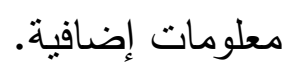

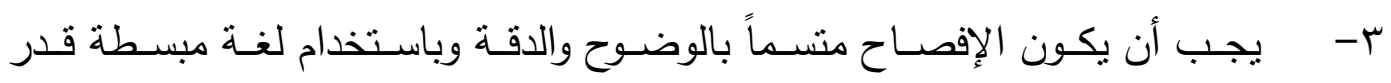

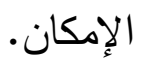

؟- - الإفصاح يجب أن يساعد الإدارة على تلاوة القصة عن أداء الوحدة ومركزها المالي واتجاهات العمل بها. - - - مدم تكرار الإفصاحات.

وبناءاً على المبادىء السابقة تتاولت الدراسة مراجعة منطلبات الإفصـاح لـ بـ معيار وتم

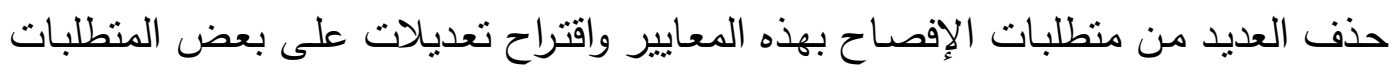

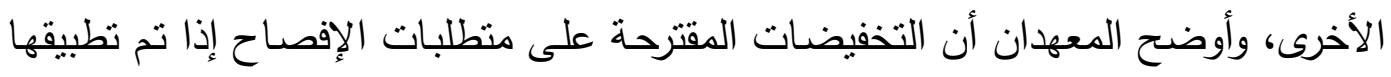

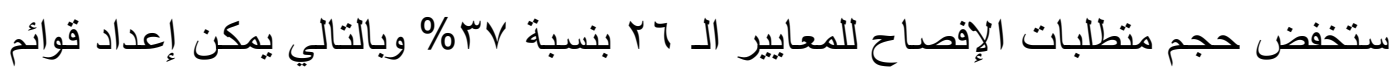


مالية ذات أحجام أقل تحتوي على معلومات هامة وكمية أقل من التفاصيل غير الهامة مما

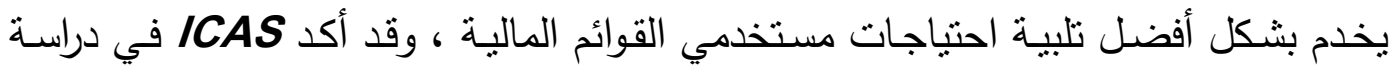

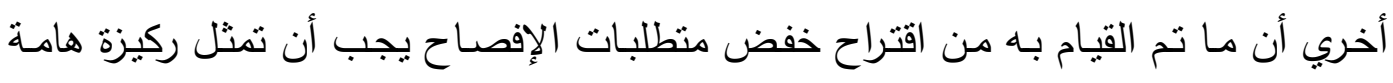

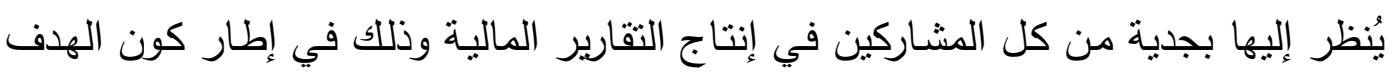

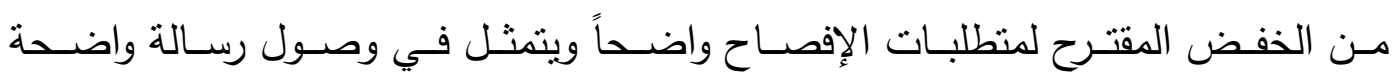
للمستخدمين حول ماضي الثركة وحاضرها ومستقبلهار 8 - 7 . 7 (ICAS, 2010, P.p.

ع -دراسة مجلس التقرير المالي FRC:

(FRC, Op. Cit, Oct. 2012, P.p. 1 - 64)

Thinking about disclosure in a broder context جاءت الدراسة بعنوان تناولت الدراسة التأكيد على ضرورة الحد من تطبيق الدنهج التدريجي بالإفصاح نظراً لآثاره

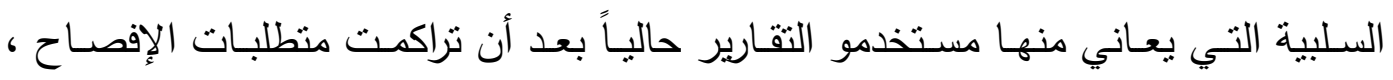

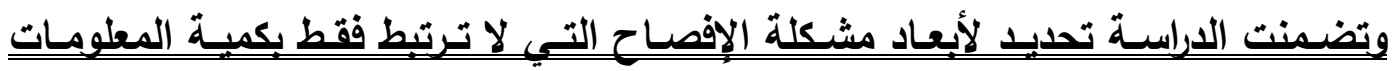

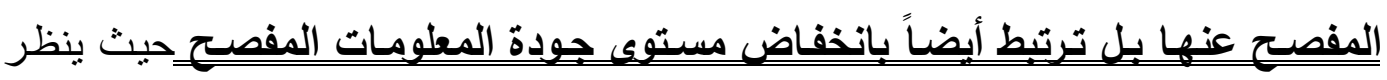
Distointed غالبية المستخدمين لما يتم توفيره من إفصاحات باعتبارها مجموعة مفككة collection من الإفصاحات التي يتم توفيرها بناء على منطلبات مصادر تنظيمية مختلفة وهو ما أدى لكون هدف الثقارير المالية Seems to have been forgotten

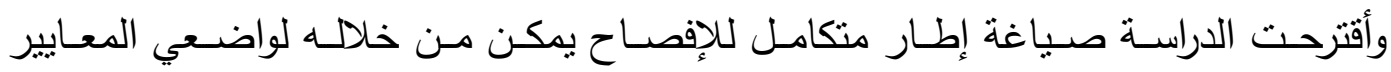

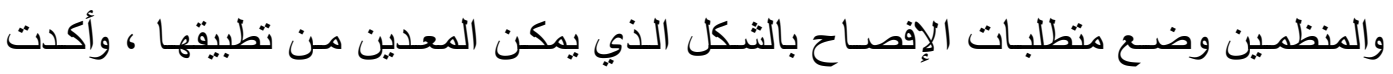

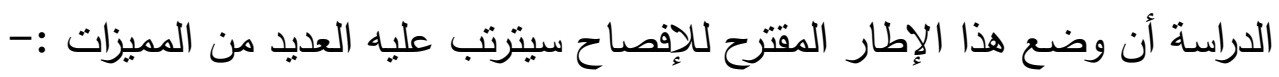
1- - زيادة قدرة المعلومات المفصح عنها على تلبية حاجات المستخدمين. ץ- - بمان أن المنظمين هم فقط من يعدل أو يضيف لمتطلبات الإفصاح.

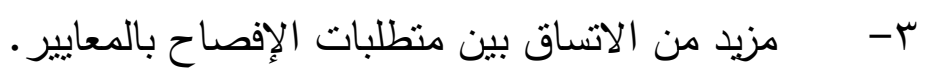

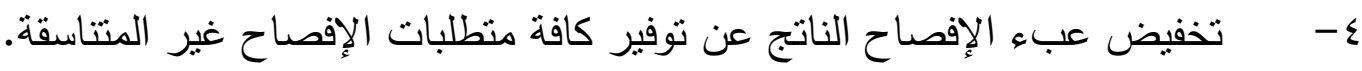
- - - القضاء على التكرار بالإفصاحات.

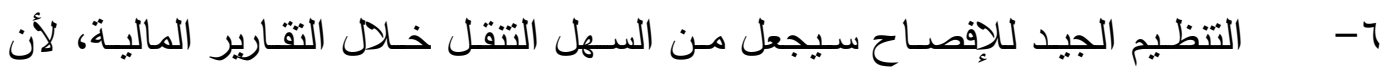
المعلومات التي تهدف لتحقيق أهداف محددة ستوضع بنفس القسم بالتقرير المالي.

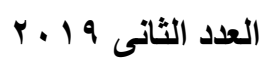
$-T \leq Y$. مجلة المحاسبة والمراجعة 


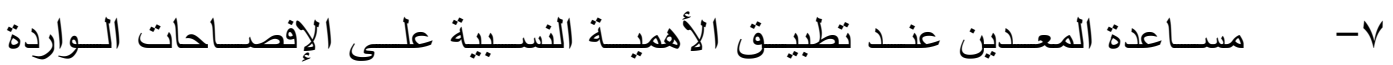
بالإيضاحات.

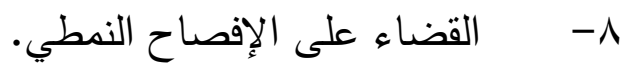

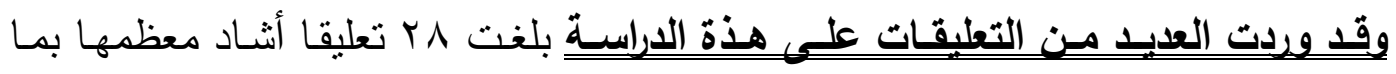

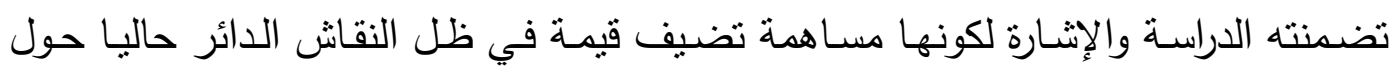
تطوير الإفصاح، وقد تضمنت التعليقات مطالبة IASB عند وضع الحلول لمشكلة الإفصاح

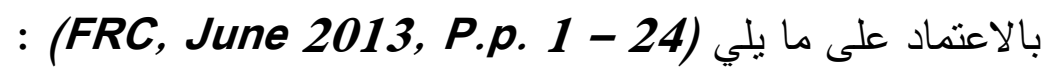

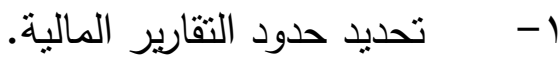
r - إعداد معايير للمكان الذي سيتم الإفصاح به.

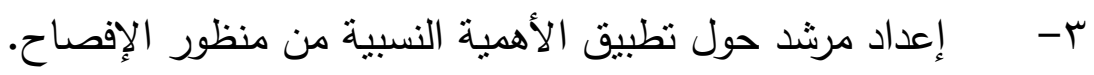
ع - إعداد بيان صريح حول الإفصاح عن المعلومات غير الهامة.

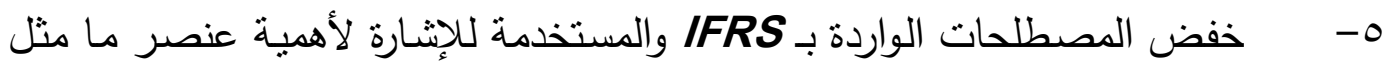

Significant، Key،Critical 7- تحديث IAS1 بما يؤدي لفصل منطلبات العرض عن منطلبات الإفصاح.

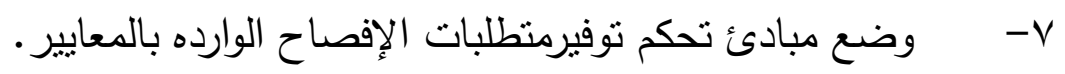

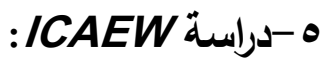

(ICAEW, Op. Cit, P.p. 1 - 92)

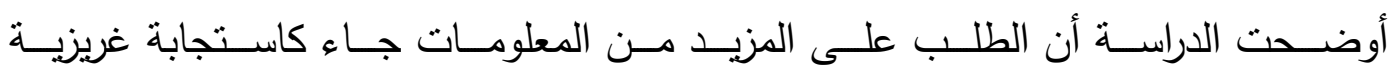
Instinctive Response العقود الأخيرة ، وهذه المشاكل غالبا ما يكون رد الفعل التتظيمي المرتبط بها تفعيل الآلية

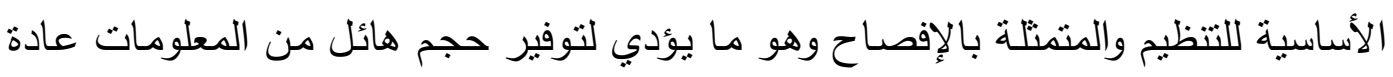

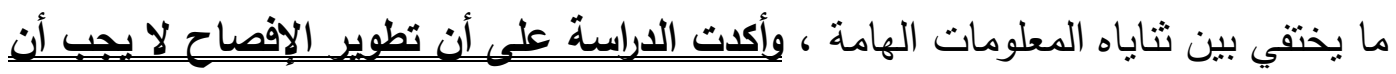

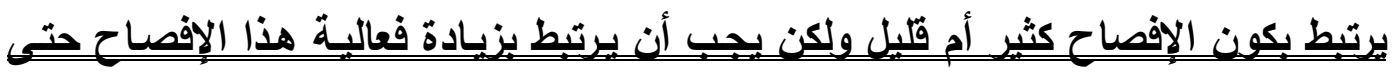
لو كان إحراز النتائج المرجوة لن بتحقق سريعاً. 
ثانبا: الاراسات السابقة التي تناولت ضرورة تطوير العرض المحاسبي؛

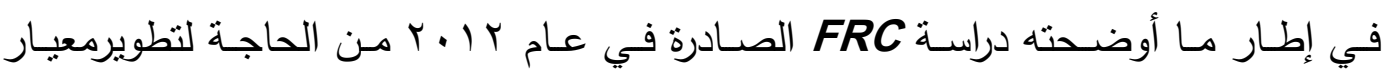

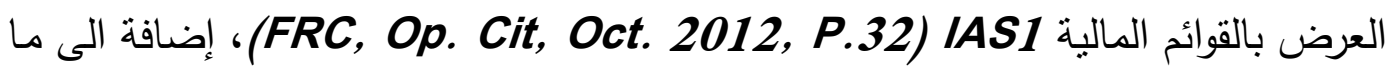
تضمنته دراسة EY والتي حددت ثلاثة أبعاد لمشكلة الإفصاح هي(EY, Op.Cit, P. 4): أ-هيكل للقوائم المالية. ب-مستوى تفصيل المعلومات. ج-الأهمية النسبية. وكون الجوانب الثلاثة تمثل عناصر معيار العرض بالقوائم المالية IAS1 مما يحتم ضرورة

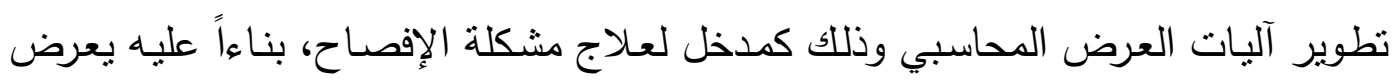

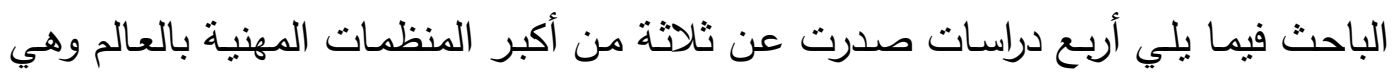

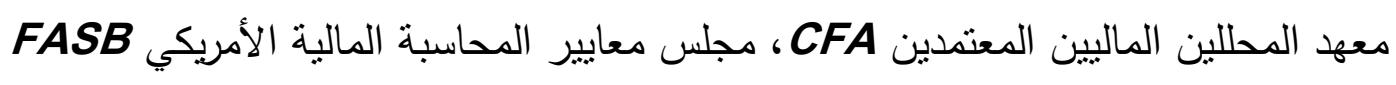

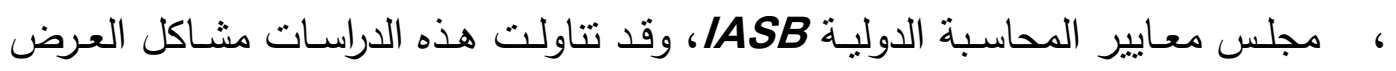
المحاسبي وإمكانيات وآليات نطويره .

1-الاراسـة التمهيدية الصـادرة عن IASB في ؟ + . ب لتعديل المعيار المحاسبي الأول العرض بالقوائم المالية. (IASB, March 2006, P.p. 1 - 104)

أوضح IASB أن التعديلات على IAS1 تهدف إلى تعزيز فائدة المعلومات الواردة بالقوائم

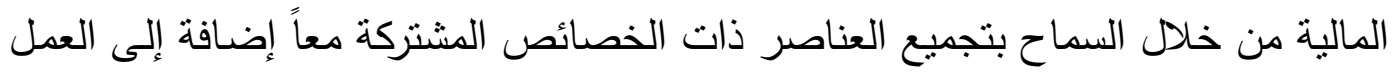

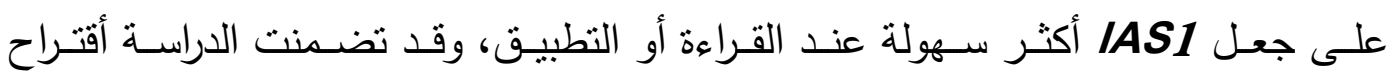
التعديلات التالية:-

أ-تقديم قائمة المركز المالي في بداية الفترة ضمن الثكل الكامل للقوائم المالية.

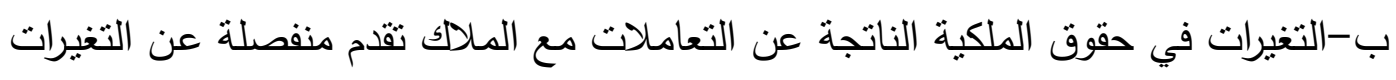
التي لم تتم من الملالك في قائمة التغير بحقوق الملكية.

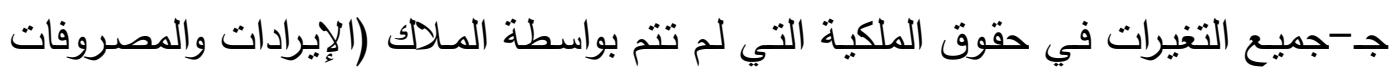

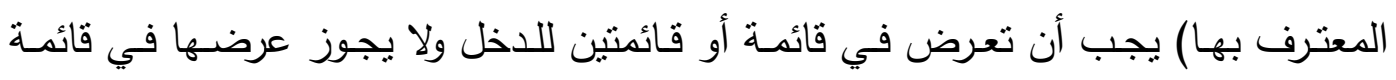
التغير بحقوق الملكية. 
د -عرض التوزيعات الخاصة بكل سهم بقائمة التغير بحقوق الملكية أو بالملاحظات.

r بورقة المناقثة المشتركة بين IASB وFASB

(FASB, IASB, 2008, P.p. 1 - 168)

Preliminary Views on Financial Statements جاءت بعنوان Presentation ، وقد تتاولت الدراسة بيان أهمية العرض المحاسبي لأنه يتعلق بكيفية تقديم المعلومات في القوائم المالية ، والتأكيد على أن هذه الدراسة المشتركة هدفها الأساسي لداسي

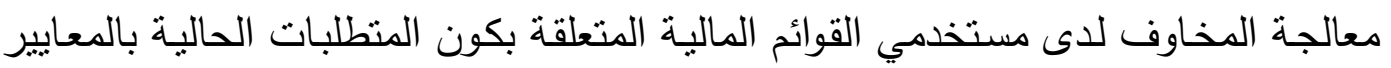
تتيح استخدام طرق متعددة للعرض، إضافة إلى أن المعلومات في القوائم المالية غالباً ما ينت

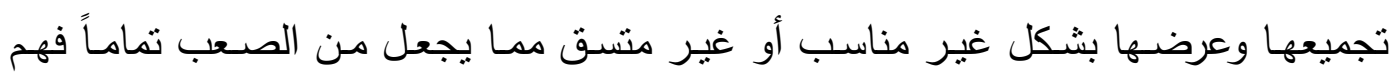

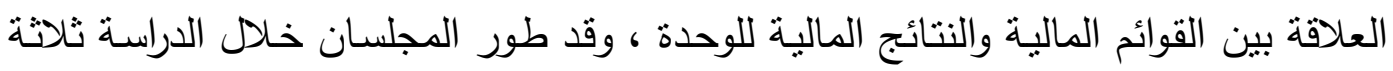

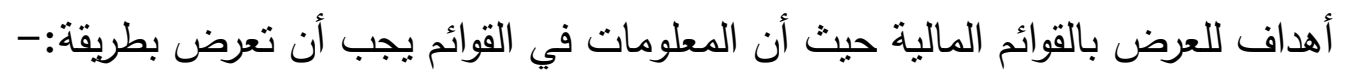
أ-تقدم صورة مالية منماسكة عن أنشطة الوحدة Portrays Cohesive financial pictures ب-تفصيل المعلومات إلى الحد الذي تكون به المعلومات مفيدة للتنبؤ بالتدفقات المستقبلية

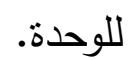

Liquidity and جالتساعد المستخدمين على تقييم مستوى سيولة الوحدة ومرونتها المالية finaical flezibility

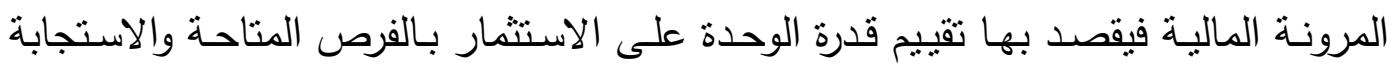

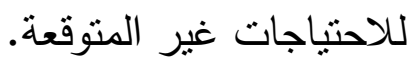

وتتاولت الدراسة تقديم مقترح بتقسيم أنشطة الوحدة إلى نشاطين رئيسيين هما: أ- نشاط الأعمال ويقسم إلى نشاط نتغيلي واستثماري.

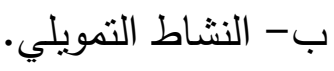
وأكدت الدراسة على الحاجة لإعداد القوائم المالية بما يظهر الأنشطة الثناث السابقة تثغيلي

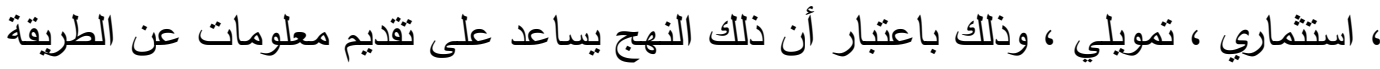

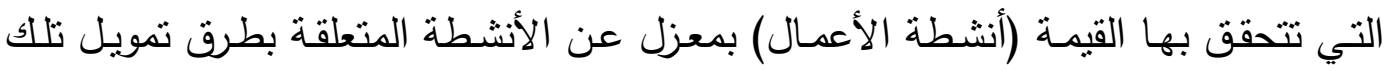


الأعمال (النشاط التمويلي)، وقدمت الدراسـة نموذج للقوائم المالية المقترحة مـع بيان أدلة التصنيف الواجب إنباعها لتصنيف العناصر داخل كل قائمة فيما بين الأنشطة الثثلاثة وذلك

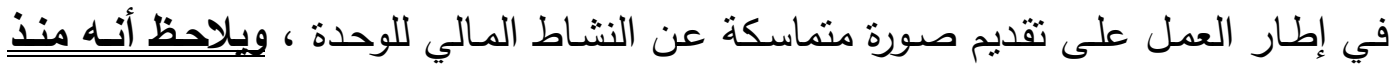

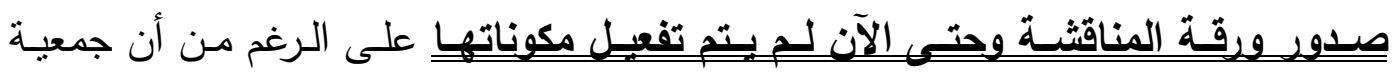
المحاسبة الأمريكية AAA في تقييمها لهذه الدراسة أكدت على أن بها العديد من السمات

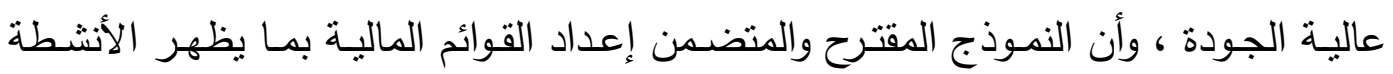

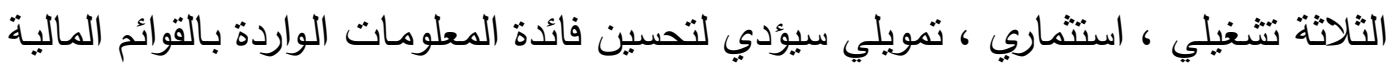

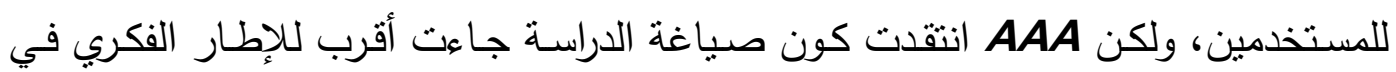

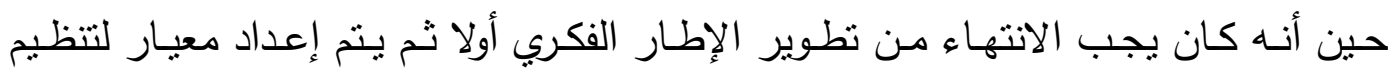
Allen, العرض(AAA, June 23, 2009, P.p. 1 - 1 - كما أكدت دراسنة

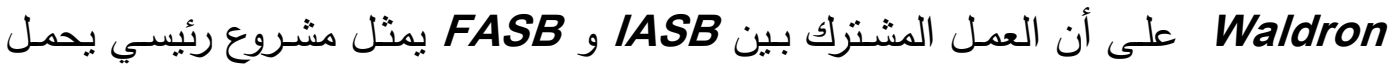
(Janes Allen, Mathew وعداً كبيراً نحو دعم الثفافية وتلبية احتياجات المستثمرين

Waldron, 2011, P.p. 10 - 11)

ب-دراسة معهد المحلين الماليين المعتمدين CFA: (CFA, July. 2013, Op. Cit, P.p. 8 - 40)

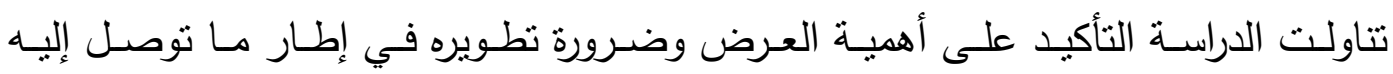

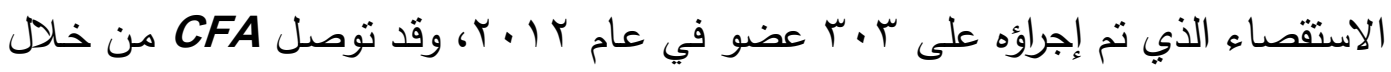
الاستقصاء الى أن أولويات المستثمرين عند إدخال تحسينات على التقارير المالية تتحدد

أ-زيادة التركيز على المسائل ذات الأهمية:

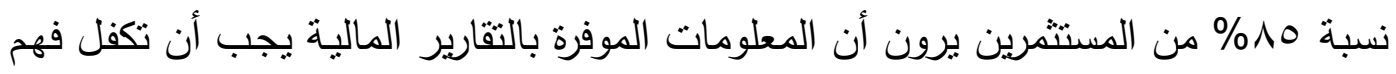

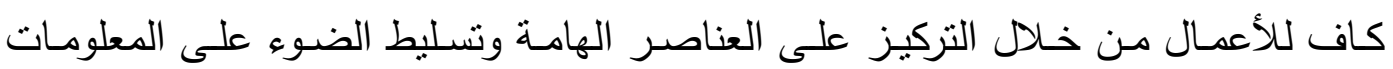

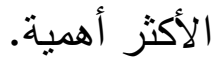

ب-تحسين العرض في القوائم المالية: نسبة rی \% من المستثمرين أكدوا على ضرورة تحسين العرض بالقوائم المالية بهدف جعل

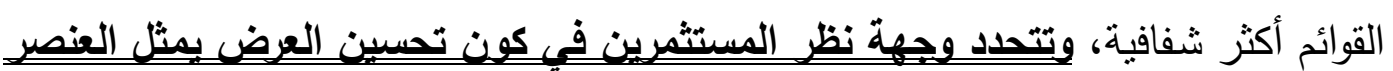
- rol - 


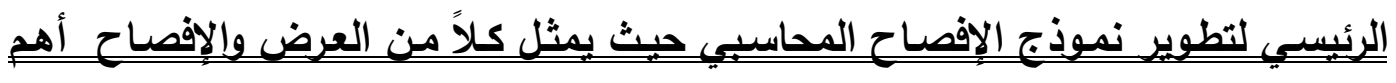
آليات الوحدة لتحقيق التواصل الفعال مـع المستخدمين، ويرى المستثمرون إمكان تطوير

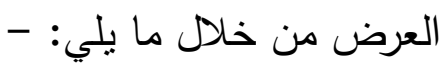
1 -التفصيل: مطلوب تفصيل كاف في القوائم المالية 2-النظر للمستقبل: إدراج معلومات مستقبلية 3-التماسك: لابد من تطبيق هذا المبدأ خلال القوائم المالية ومن خلاله سيكون المستثمرون قادرين على تتبع المعاملات خلال القوائم المالية. 4-استخدام الطريقة المباشرة بقائمة التنققات النقدية.

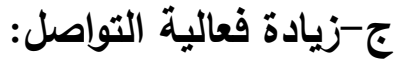

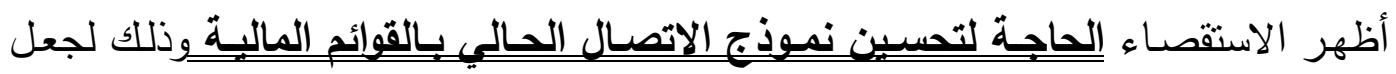

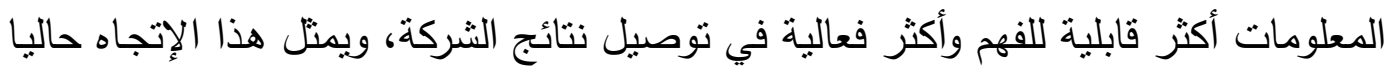
مساحة مشتركة بين المستتمرين والمعدين فيما يتعلق بأولويات التحسين بـالقوائم المالية،

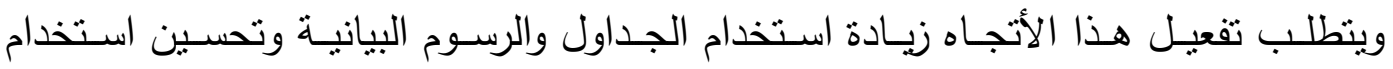
الإثـارات المرجعيـة والقضـاء على التكرار وذلك بهدف دعم التواصل الفعـال بين الوحدة

ع - عراسة مجلس معايير المحاسبة المالية الأمريكي (FASB, August. 11. 2016, P.p. 1 - 74)

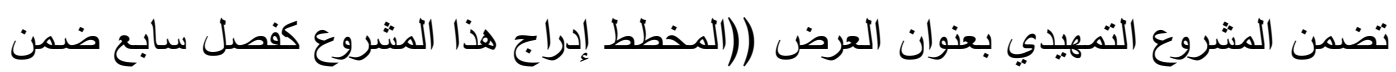

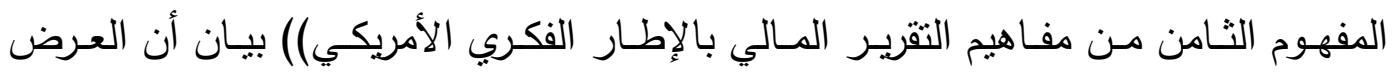

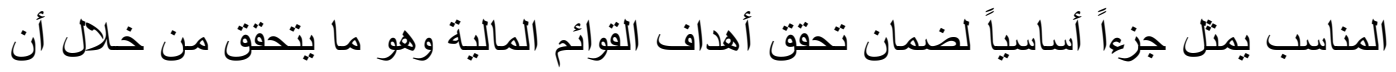
تكون المعلومات المعروضة بالقوائم المالية أداة مساعدة لمقدمي الموارد في:

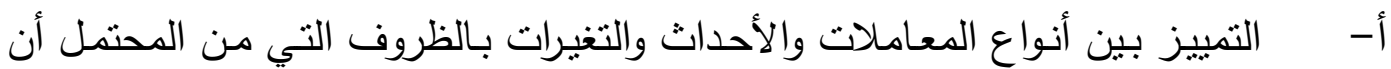

ب-تقدير مبالغ وتوقيت التدقات النقدية المستقلية وتقييم احتمالية حدوثها. ج-فهم موارد الوحدة والمطالبات على هذه الموارد. - ror - 
وقد أوضـح FASB أن العرض بـالقوائم الماليـة هو بمثابـة رسم صسورة بالكلمـات والأرقام Depicitions in words and numbers

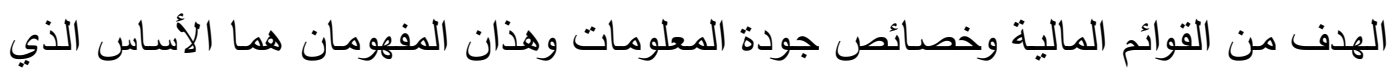

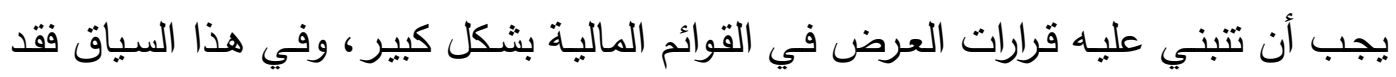

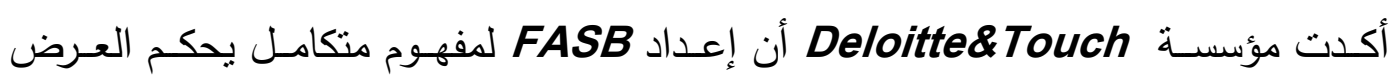

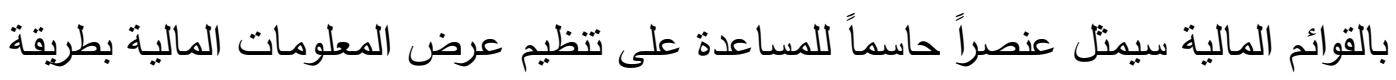

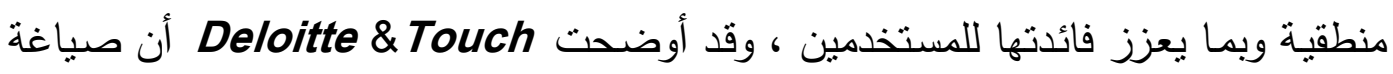

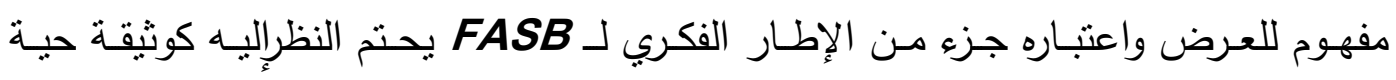
بحيث يتم تطويره باستمرار في ضوء التطورات في بيئة التقرير المالي(Deloitte, Nov. 9. 2016, P.p. 1 - 1 (

تقييم الاراسات السابقة

يعتقد الباحث أن مشـاكل الإفصـاح المحاسبي التي توصـلت إليهـا الدراسـات السـابقة قد ارتبطت فيما بينها بخط عريض واضح يؤكد على وجود المشاكل التالية:

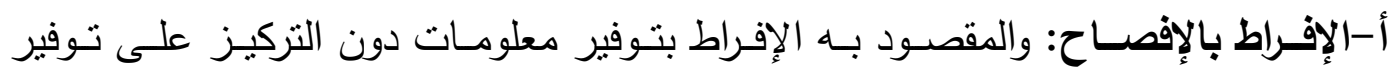

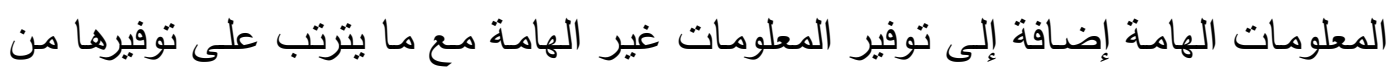
حجب المعلومات الهامة وصعوبة حصول المستخدمين عليها.

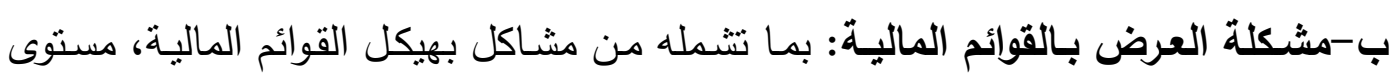
تفصيل المعلومات، ضوابط تطبيق الأهمية النسبية ج-انخفاض مستوى جودة ما يتم توفيره من مطلومات: حيث لا يتلبي التقارير الاحتباجات الفعلية لمستخدميها. د-مشكلة عدم تماثل المطلومات: وهي مشكلة رئيسية يعاني منها المستثمرون، وتتشأ هذه

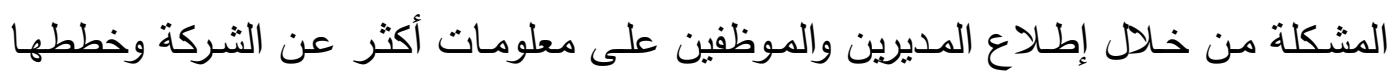

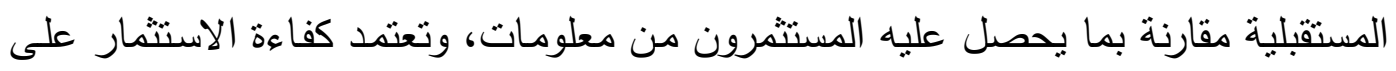
ما يحققه الإفصاح المحاسبي من خفض مستوى تباين المعلومات الذي يعتبر أحد المسببات

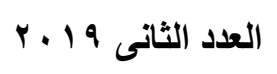

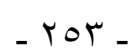

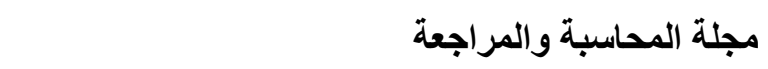


الهامـة للضجيج بسوق المال هذا الضجيج الذي ينتج عنه خفض دقة ما ينت اتخاذه من قرارات (Youchaotan, Yuyuliu, 2017, P.p. 2010, 211).

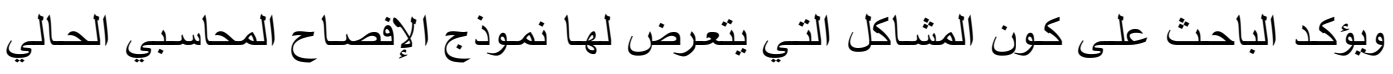

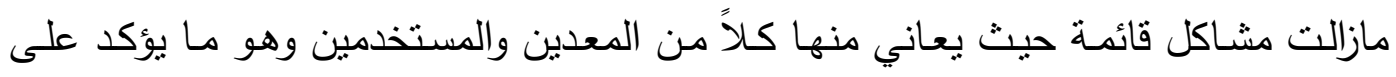

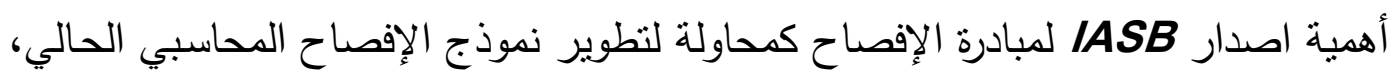

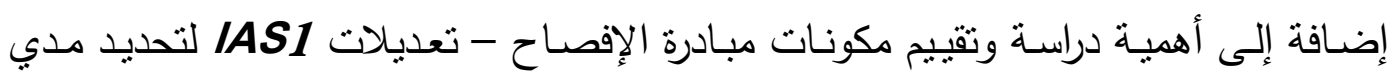

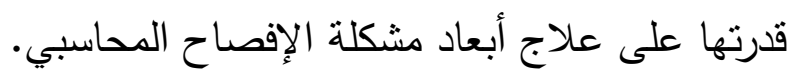

\section{ع 1 ا: هذف البحث:}

يهدف البحث إلى تقييم مسنوى جودة مكونات مبادرة الإفصاح - تعديلات IAS1 الصادرة

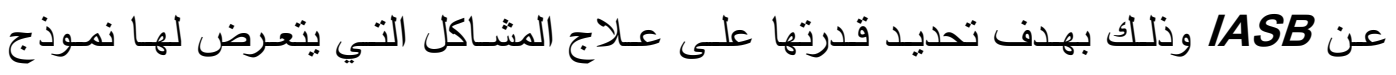

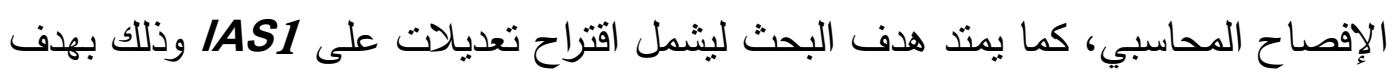
دعم قدرة مبادرة الإفصاح - تعديلات IAS1 على تحقيق أهدافها.

$$
\text { 1/ 1: أهبة البحث: }
$$

تتضح أهمية البحث من خلال ما يلي:

1-يتتاول البحث تحديد للمشاكل التي ترنبط بتطبيق المعيار المحاسبي الدولي الأول عرض

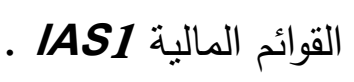

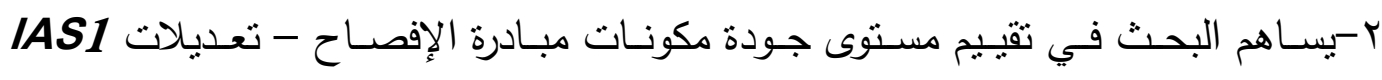

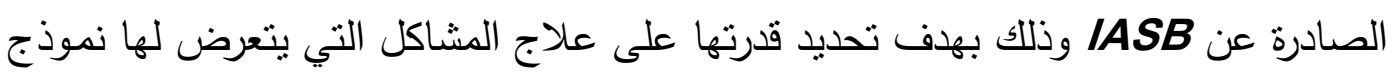

$$
\text { الإفصاح المحاسبي. }
$$

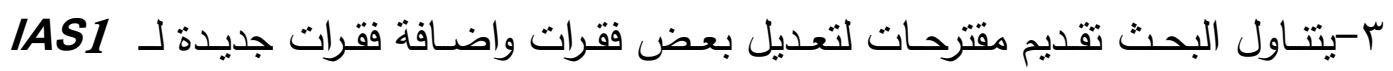
بهدف دعم قدرة مبادرة الإفصاح - تعديلات IAS1 على تحقيق أهدافها.

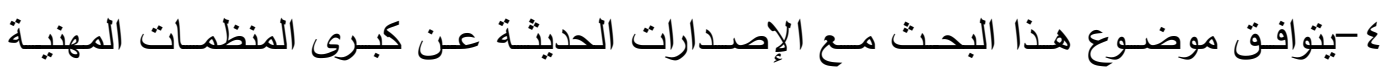

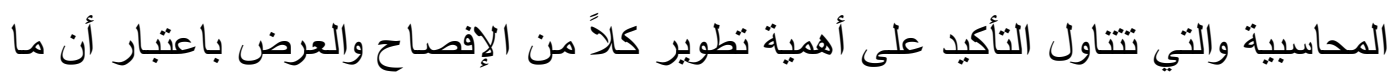
يتعرضان له من مشاكل تحد كثيراً من قدرة مستخدمي القوائم المالية على الاستفادة منها. 


\section{1/ 1/: فروض البحث:

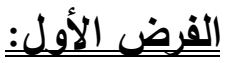

تتضح الحاجة لتطوير نموذج الإفصاح المحاسبي في إطار تعدد أبعاد مشكلة الإفصاح من المنال

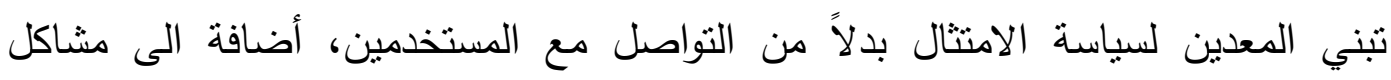

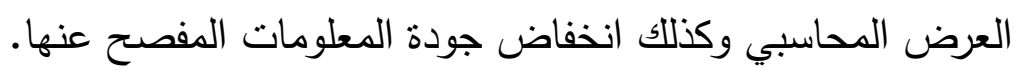

الفرض الثاني: - (الفي

يمثل إصدار IASB لمبادرة الإفصاح - تعديلات IAS1 استجابة تنظيمية للأزمة المالية العالمية تهدف إلى إيجاد حلول لمشاكل نموذج الإفصاح المحاسبي. الفرض الثالث:

يجب أن يستند التطوير المقترح على مبادرة الإفصاح - تعديلات IAS1 على مجموعة من المبادئ التي تكفل الحد من التعقبد الحالي بالتقارير المالية، ودعم مستوى التواصل الفعال

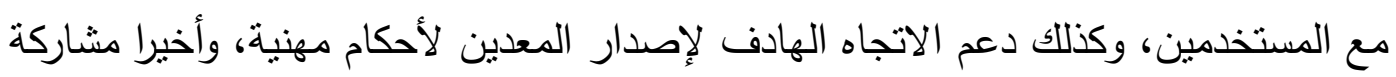

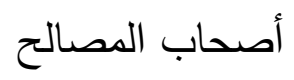

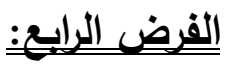
تمثل التعديلات المقترحة على مبادرة الإفصاح - تعديلات IAS1 المرتبطة بقائمة المركز

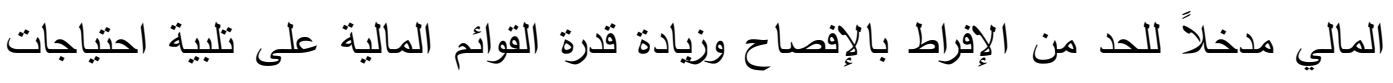
مستخدميها.

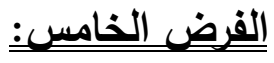
تمثل التعديلات المقترحة على مبادرة الإفصاح - تعديلات IAS1 المرتبطة بقائمة (قائمتي) الأرباح أو الخسائر والدخل الثامل الآخر مدخلا للدد من الإفراط بالإفصاح وزيادة قدرة القوائم المالية على تلبية احتياجات مستخدميها. |لقفرض السادس: تمتل التعديلات المقترحة على مبادرة الإفصاح - تعديلات IAS1 المرتبطة بالإيضاحات مدخلا للحد من الإفراط بالإفصاح وزيادة قدرة القوائم المالية على تلبية احتياجات مستخدميها. 


\section{الفرض السبع:}

تمتل التعديلات المقترحة على مبادرة الإفصاح - تعديلات IAS1 المرتبطة بالإفصاح عن

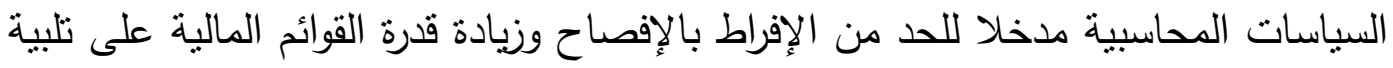

احتياجات مستخدميها.

الفرض الثامن

التعديلات الواردة ضمن مبادرة الإفصاح- تعديلات IAS1 تمثل تعديلات محدودة النطاق

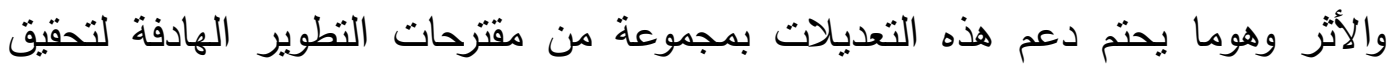
الأهداف المرجو تحققها من إصدار المبادرة.

القفرض التاسيع

تؤدي التعديلات المقترحة على فقرات IAS1 التي لم تزد ضمن مبادرة الإفصاح- تعديلات IAS1 وزيادة قدرة القوائم المالية على تلبية احتياجات مستخدميها.

لتحقيق أهداف البحث واختبار فروضه نم تقسيم البحث إلى سبعة أقسام وذللك على النحو 1/V

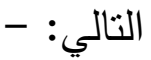
القسم الأول: منهجية البحث القسم الثاني: إصدار مبادرة الإفصاح

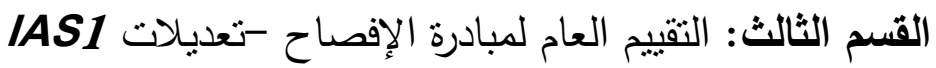
القسم الرابع: المبادئ التي يستند عليها التطوير المقترح على مبادرة الإفصاح- تعديلات

القسم الخامس: تقييم وتطوير مبادرة الإفصاح-تعديلات IAS1 القسم السادس: الدراسة الاختبارية

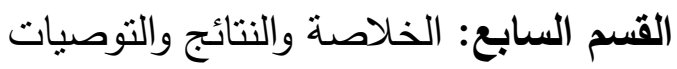
القسم الثاني: إصدار مبادرة الإفصاح: يتناول الباحث فيما يلي أحد أكثر المحاولات لعلاج مشاكل نموذج الإفصاح الحالي اكتمالاً ودقة وهي مبادرة الإفصاح Disclosure Initiative الصادرة عن IASB ، حيث سيتم 
عرض مكونات المبادرة ويلي ذلك تقييم هذه المكونات واقتراح مقترحات للنطوير وذلك في

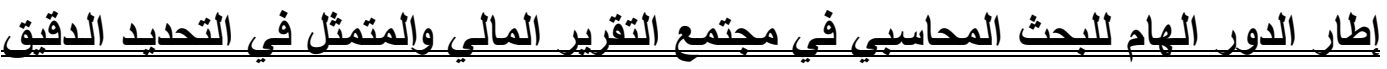
للمشاكل التي بعاني منها التقرير المالي في ضوع التجاهات كافة فئات المستخدمين وكنللك المعدين ، ويلي ذلك الدور الرئبسي للبحث المحاسبي والمتمثل في اقتراح وصبياغة الحلولي فئي (James Guthrie, Leed. Parker, الأكثر كفاءة وقدرة على علاج المشاكل القائمة . 2016, P.p. $2-3)$

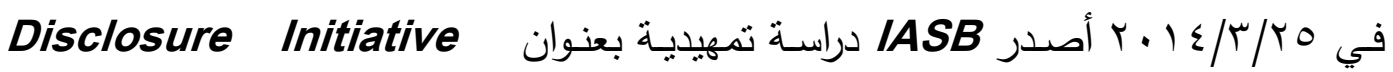
prodosed amendments to IAS1

$$
\text { ت. تنهي في }
$$

(IASB, March.2014, Op. Cit, P.p.1-34) (IASB, Dec.2014, Op.

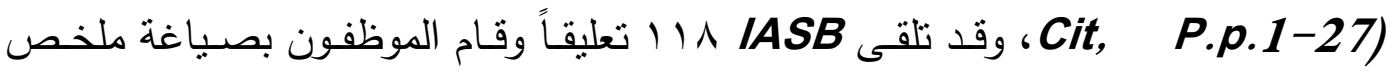

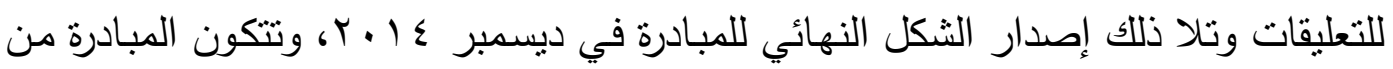
- : (IASB, May 2013, Op. Cit, P.p. 1-44) العناصر التالية IAS1 - إ تعديل

r- إصدار مرشد مهني يحكم تطبيق الأهمية النسبية.

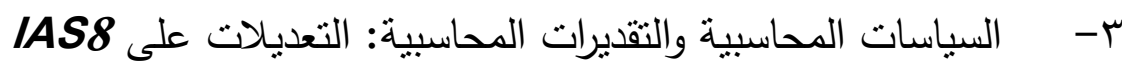
ع Disclosure Principles - - - إعداد مبادئ للإفصاح 7- راجعة مستويات الإفصاح بالمعايير الحالية.

ويعتقد الباحث أن المتغيرات المؤدية لتحرك IASB لإصدار هذه المبادرة تنثلت فيما يلي :

المتغير الأول: محاولة إيجاد حلول لمشاكل نموذج الإفصاح المحاسبي السابق عرضها:

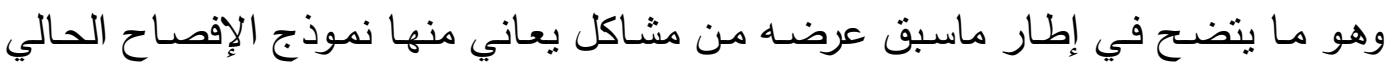

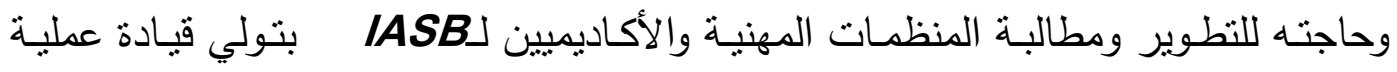
· التطوير 
المتغير الثاني: حاجة مجتمع التقرير المالي لمبادرة تمثل إطاراً شاملاً للإفصاح:

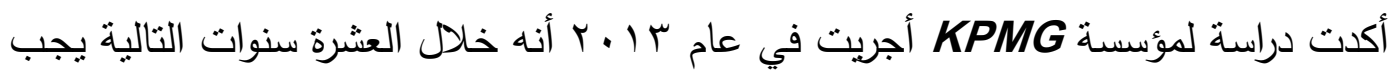

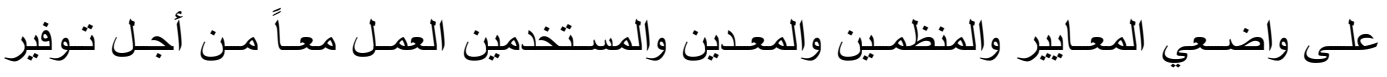
المعلومـات الهامـة ، ويتطلب النجاح بهذا المجال تبني مبادرات هامـة حول العـالم فمثناً

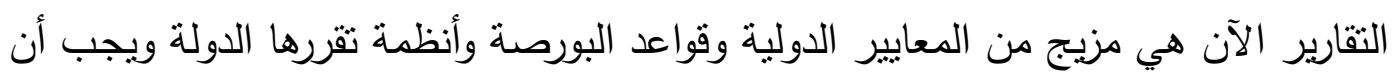

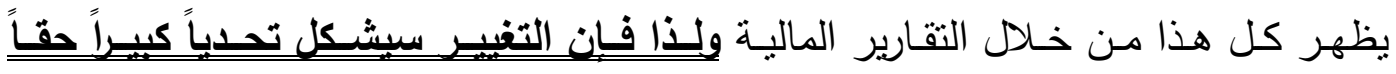
(KPMG, 2013,P.19)

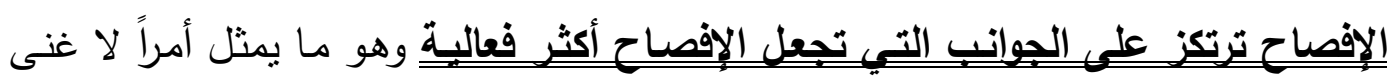

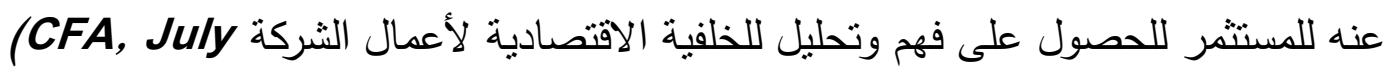
. 2013, Op. Cit, P.p. 1 - 9)

المتفير الثالث: الاستجابة التنظيمية للأزمة المالية العالمية:

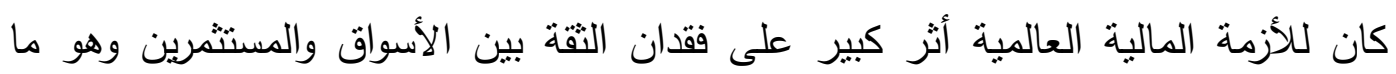

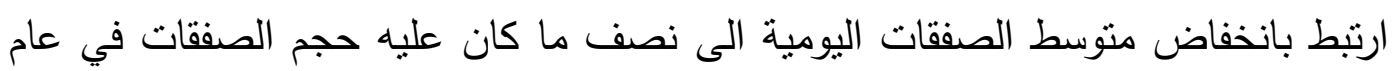

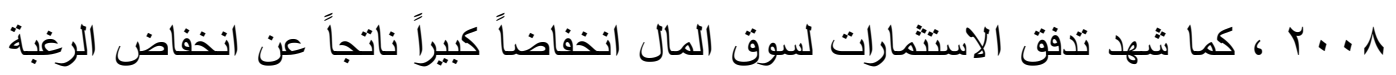

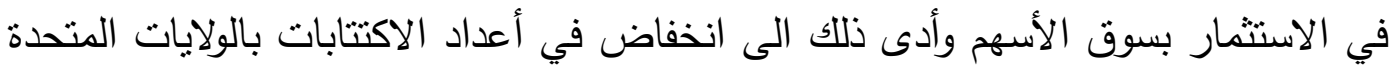

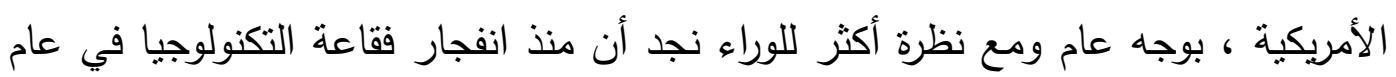

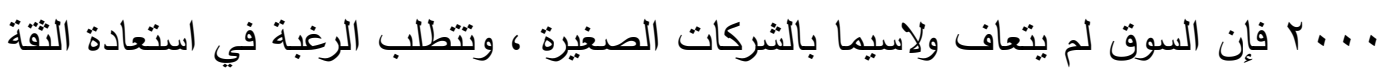

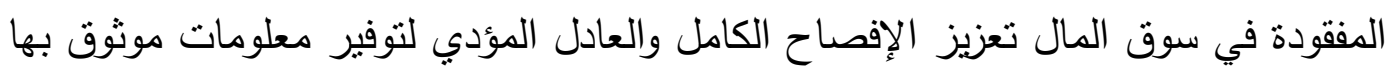

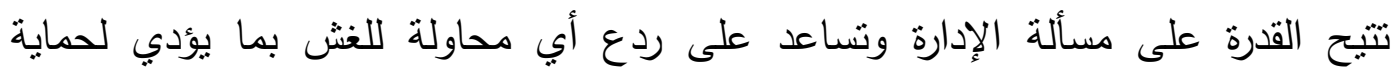

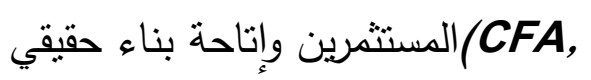
July 2013, Op. Cit, P.p. 23 - 25 اؤوس الأموال

وقد تتاولت دراسـة لـ Bertomeu, Magee بيان أن أوقات الأزمات تمثل لحظات هامـة لتتظيم مهنة المحاسبة، وهو ما يتضح بمجرد البحث في التاريخ الحديث لتنظيم أسواق المال

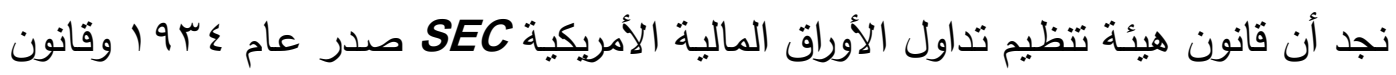

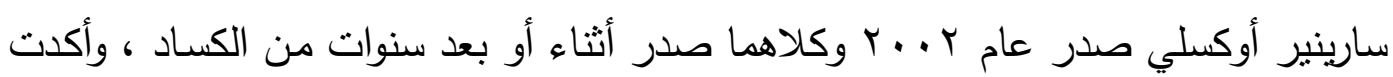

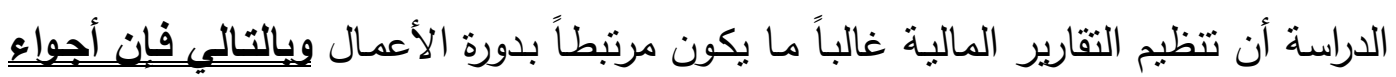


الأزمـة تستـدعي غالبـاً استجابِة تنظيمبة لمحاولـة علاج القصور المحاسبي وهو ما أكد عليه David Twediee الرئيسي السابق لـ IASB في اجتماع جمعية المحاسبية الأمريكية AAA

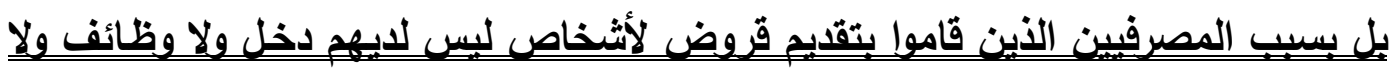

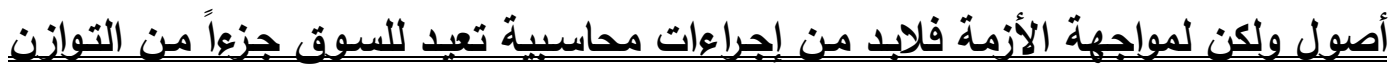

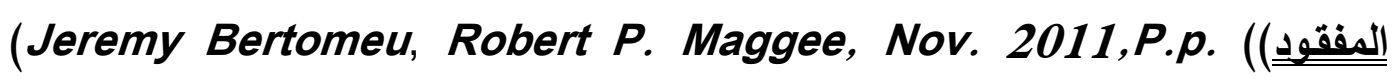
(214 - 211 ، ويدعم الرأي السابق القائم على كون الأزمات المالية تمثل محركاً محفزاً

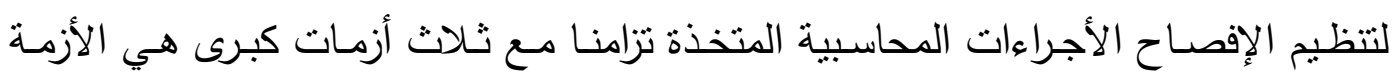

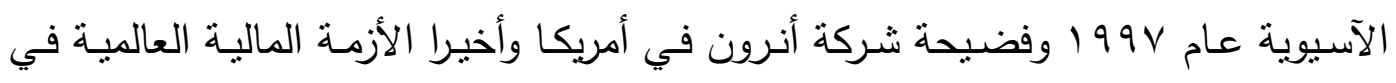
A . . ا حيث أنه في أعقاب هذه الأحداث قام واضعوا المعايير والهيئات الرقابية بتغييرات

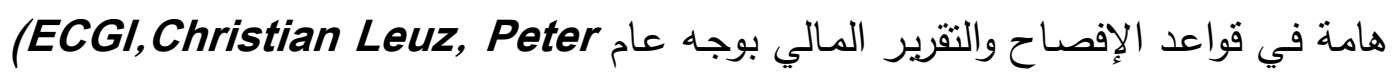

Wsocki, Op. Cit, P.p. $1-2)$

ويناء على ما سبق بعتق الباحث أن أجواء الأزمة المالية العالمية وما صاحبها من دعوات

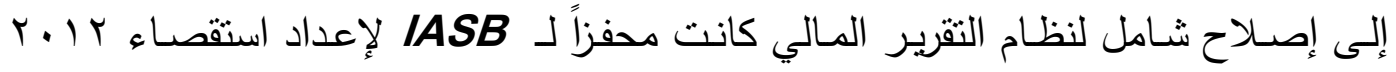

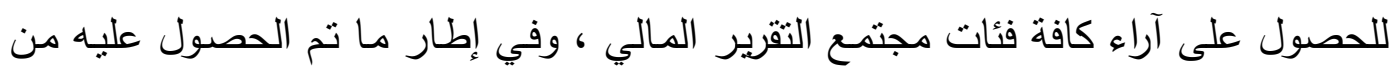

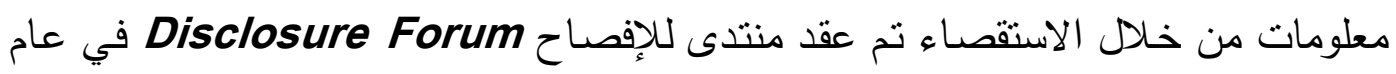

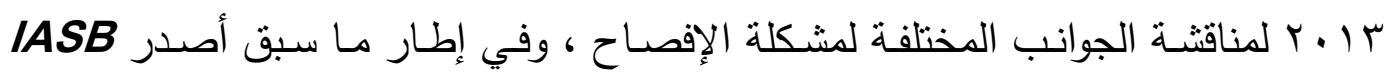

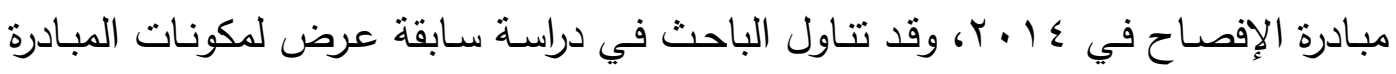

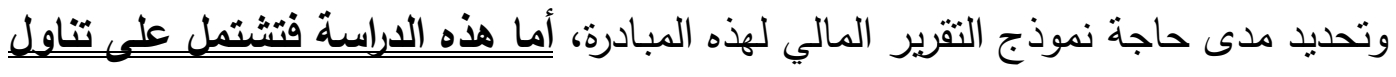
تقييم وتطوير مبادرة الإفصاح وذللك فيما بتعلق بما تضمنته مبادرة الإفصاح من تعديلات على IAS1، ويتم عرض التقييم والتطوير المقترح من خلال الأقسام التالية:-

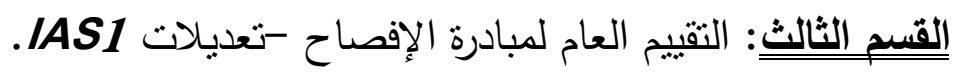

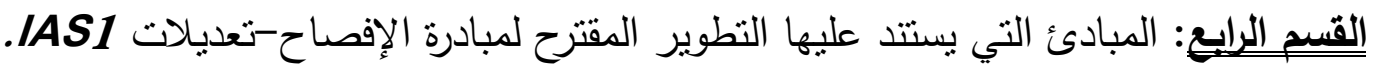

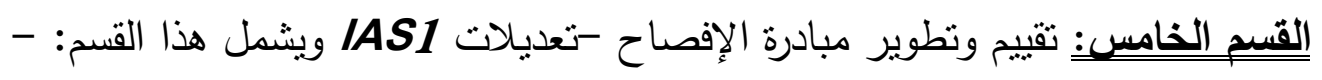
أولاً: تقييم وتطوير فقرات IAS1 الواردة ضمن مبادرة الإفصاح-تعديلات IAS1 
ثُانبـاً: التعديلات المقترحة على فقرات بـ IAS1 لـم ترد ضمن مبادرة الإفصـاح-

$$
\text { IAS1 تعديلات }
$$

ثالثاً: التعديلات على IAS1 المرتبطة بإصدارIASB الإطار الفكري للتقرير المالي في

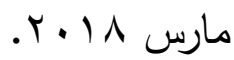

\section{القسم الثالث: التقييم العام لمبادرة الإفصاح -تعديلات IAS1:}

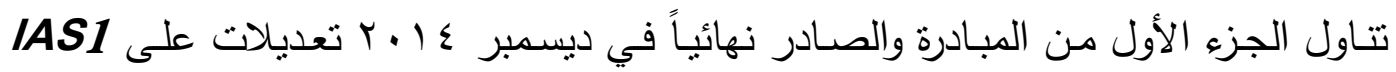

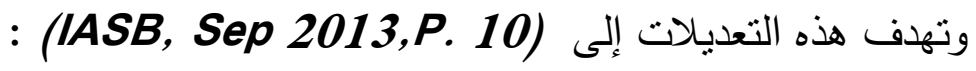

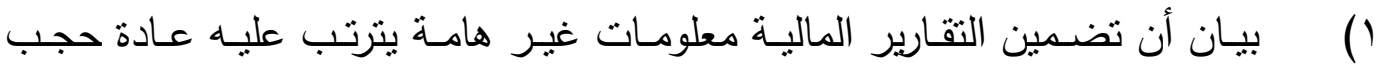
المعلومات الهامة.

r إيضاح أن تقييم الأهمية النسبية يطبق على المجموعة الكاملة للقوائم المالية شاملة

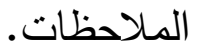

؟) إزالة اللغة التي ترتب عليها تفسير وجود منهج محدد الملاحظات.

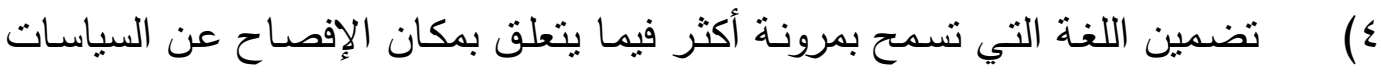

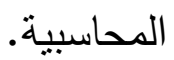
0) النظر في إضـافة منطلبات للمطابقة فيما يتعلق بصـافي الديون إذا تم الإفصـاح عنها.

وقد ورد لـ IASB العديد من التعليقات منها التعليقات الإيجابية وبعضها كانت تعليقات تتنقد بعض مكونات مبادرة الإفصاح -تعديلات IAS1، ويعرض الباحث فيما يلي عرض موجز لمكونات هذه التعليقات، ويلاحظ أنه لم يصدر أي تعليق من جمعية المحاسبين والمراجعين

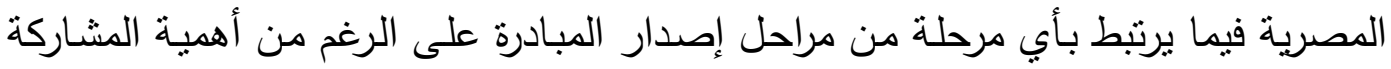

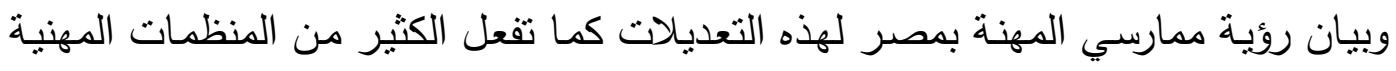
بدول العالم المختلفة بما فيها منظمات مهنية عربية وأفريقية.

\section{أولاً: التعلبقات الإيجابية على مبادرة الإفصاح- تعدبلات IAS1 ا-معهل المحاسبين القانونيين بانجلترا وويلز ICAEW:}


(ICAEW, 2014, P.p. 1 - 8)

رحب ICAEW بالمبادرة باعتبارها استكثافاً لآفاق تحسين الإفصاحات في IFRS، وأكد ICAEW

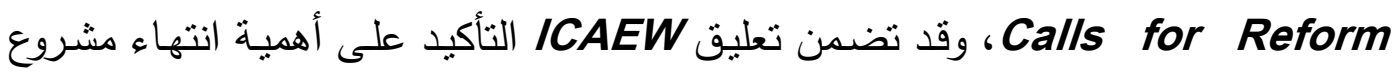
المبادرة ومشروع الإطار الفكري من أجل إعادة دعم مستوى الثقة بالثقرير المالي.

r-مجلس معايير المحاسبة الاسترالي AASB: (AASB, August. 5. 2014, P.p. 1-11) أكد مجلس معايير المحاسبة الاسترالي IAASB أنه يدعم بقوة مشروع مبادرة الإفصاح في مرحلته الأولى، وذلك باعتبار أن التعديلات المقترحة على IAS1 تمثل خطوة في الاتجاه

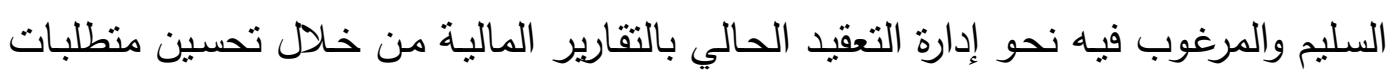

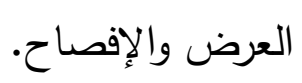

r-الهيئة الأوربية لتنظيم أسواق المال ESMA: (ESMA, June 23, 2014, P.p. 1 - 7)

أوضـت الهيئة الأوربيـة لنتظيم أسواق المـال ESMA تأييدها تعديل متطلبـات الإفصـاح

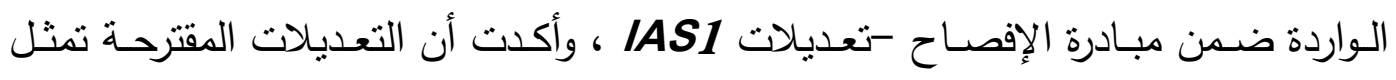

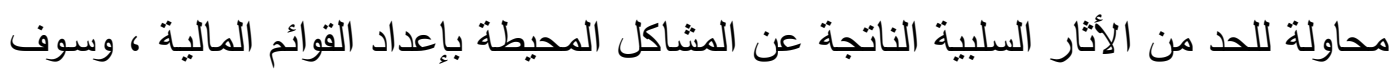
تؤدي هذه التعديلات إلى تحسين نوعية المعلومات المالية على الددى القصير .

\section{؛ -مؤسسة Delloite}

(Deloitte, July. 21, 2014, P.p. 1 - 5)

أيدت مؤسسة Delloitte مبادرة الإفصاح باعتبارها تمثل إدراكاً دقيقاً لمشكلة الإفصاح الزائد المنتشر على نطاق واسع كما إنها تمثل مدخلاً للحفاظ على وظيفة التقرير المالي كأداة

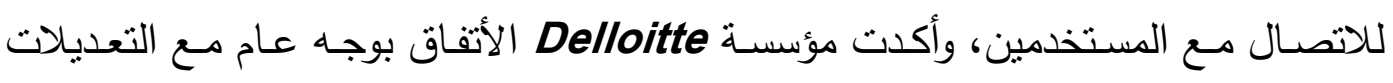
المقترحة المرتبطة بإناحة الفرصة للمعدين لإصدار أحكام مهنية وهو ما يمثل خطوة نحو تحقيق تواصل أكثر وضوحاً مع مستخدمي التقارير المالية. 


\section{هوأسسة أرنست \& يونج العالمية EY:}

(EY, July 23. 2014, P.p. 1 - 6)

أوضـح EY أن التعديلات المقترحة تبدو عمومـاً منسقة مـع الفهم العـام لـ IAS1 إضـافة

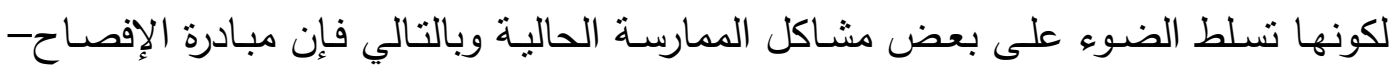
تعديلات IAS1 تمثل الخطوة الأولى نحو تحسين منطلبات العرض والإفصاح وهو ما يجعل

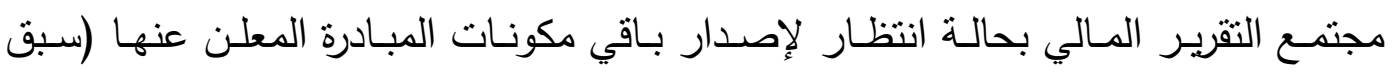
بيانها).

\section{ثُانباً: التعلبقات المتضمة لانتقاد مبادرة الإفصاح- تعليلات IAS1:}

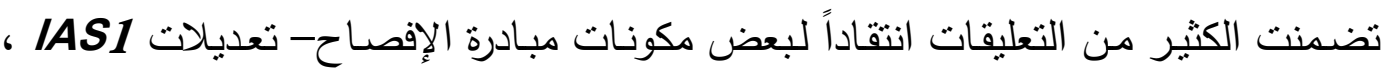
ويعرض الباحث هذه الانتقادات فيما يلي :-

ا-معه المحللين الماليين المعتمدين CFA :

(CFA, August. 28. 2014, P.p. 1 - 14)

برى CFA أن المشروع بركز على بعض الجوانب المحدودة المتعلقة بالعرض والإفصاح في

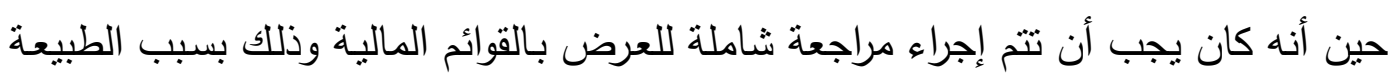

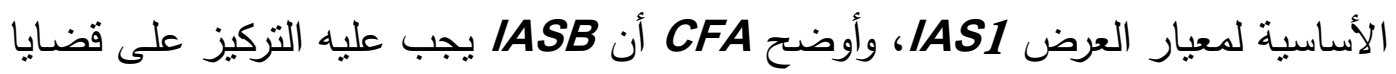

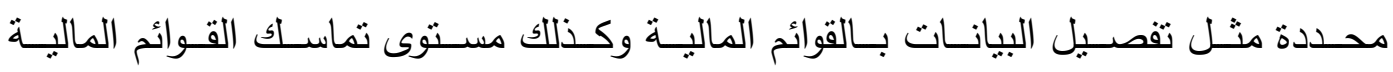

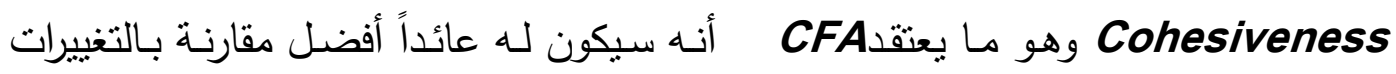

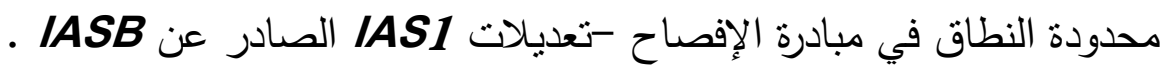

:KPMG بؤسوسة

(KPMG, July. 23. 2014, P.p.1 - 7)

أوضحت مؤسسة KPMG أن التعديلات الواردة بمبادرة الإفصاح -تعديلات IAS1 تمثل

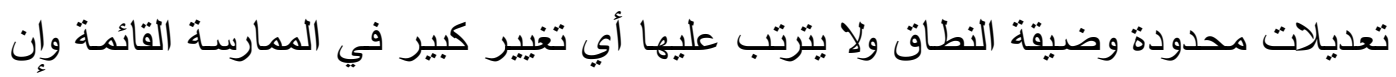

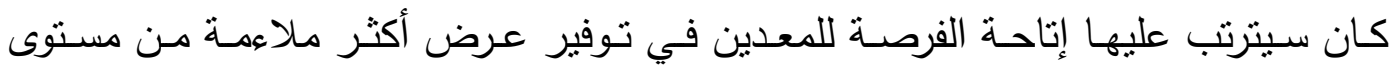


العرض الحالي، إلا أن هذه التعديلات لابد من استكمالها واعتبارها خطوة أولى نحو بناء مبادرة للإفصاح أوسع نطاقاً.

\section{r-معهد المحاسبين الإيرلندي CAI}

(CAI, July 2014, P.p.1 - 6)

يعتقد CAI أن التعديلات على IAS1 جـاءت كاسـتجابة (محدودة) للمخـاوف المحيطـة بالممارسـة والمرتبطة بكون متطلبات الإفصـاح الواردة بـ IAS1 تمنع المعدين من إصدار

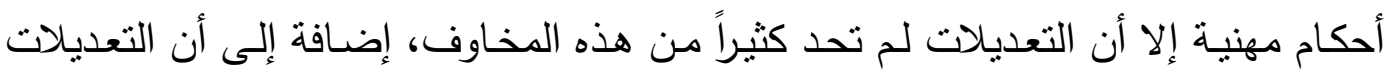

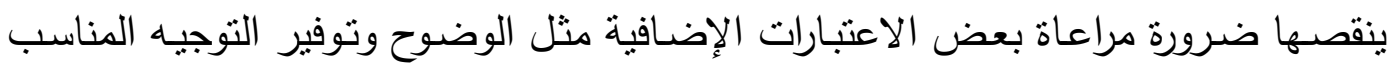
لكيفية إجراء تعديلات محددة في الممارسة العملية.

ع -المجموعة الاستثارية الأوربية للتقرير المالي EFRAG (EFRAG, July. 22. 2014, P.p.1 - 6) يعتقد EFRAG أن مبادرة الإفصاح هي واحدة من أهم المشاريع الدولية لـ IASB الهادفة

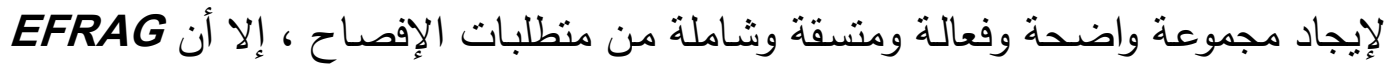
يعتقد إن المبادرة لم تؤدي إلا لتعديلات طفيفة على IAS1 في حين أن التعديلات الأساسية

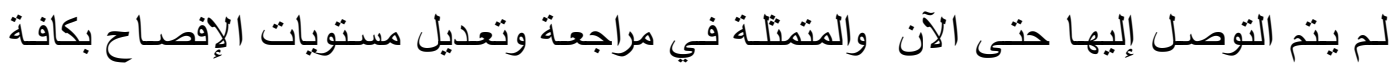
المعايير، وأكدGFRAG أن ما صدر من تعديلات مخيب للآمال ويُفقد

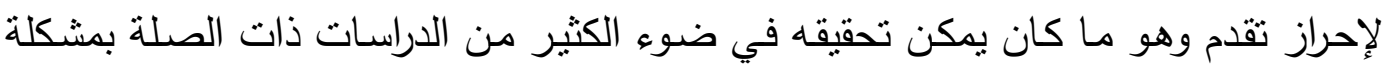
الإفصاح التي قام بها EFRAG وغيره من هيئات معايير المحاسبة الإقليمية والوطنية.

وإضافة الى ماسبق فقد أصدر IASB بياناً يوضح فيه طبيعة التعليقات الواردة على إصدار

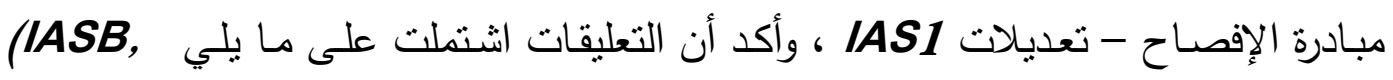
: Oct. 2014, P.p.1 - 11) (IASB, Sep. 2014, P.p.1 - 19) ( ) (إن التعديلات محدودة وأثزها على الممارسة سيكون ضعيفاً.

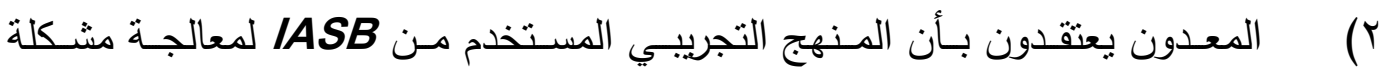
الإفصاح يعتبر منهج غير مناسب. $-4 \pi$ - 
r) التعديلات المتعلقة بالأهمية النسبية لم تتضمن آليات تحديد ما هو هام وما هو غير هام فيما يتعلق بالإفصاح.

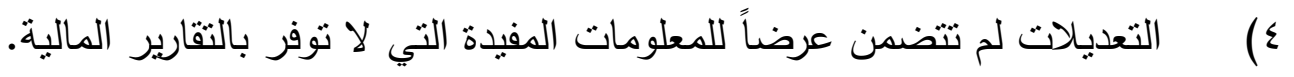

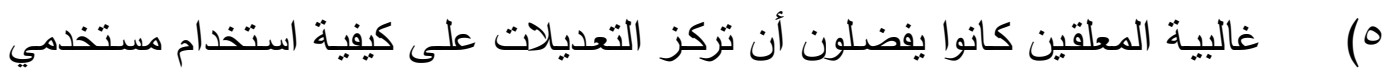

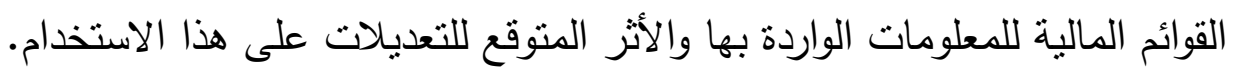
التعديلات لم توفر إطاراً كافياً يحكم إصدار المعدين للأحكام المهنية.

وفي إطار ما سبق بعتقد الباحث أن مبادرة الإفصساح والمنضمنة تعديلات IAS1 تمثل

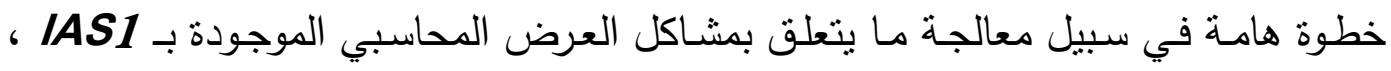

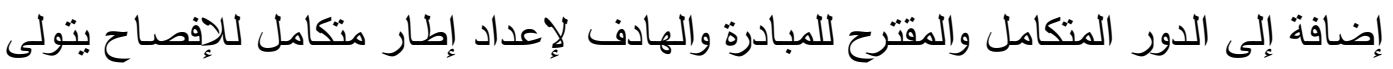
تتظيم وترشيد الإفصاح المحاسبي وتوفير آليات لمساعدة المعدين على إصدار أحكام مهنية

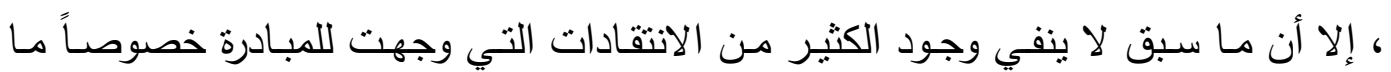

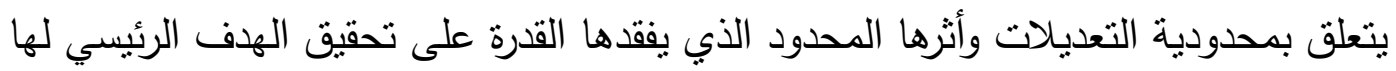

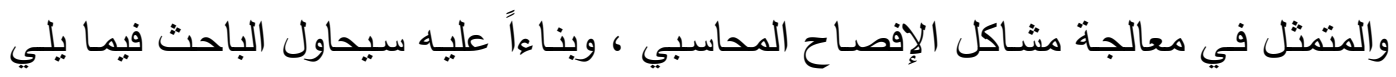

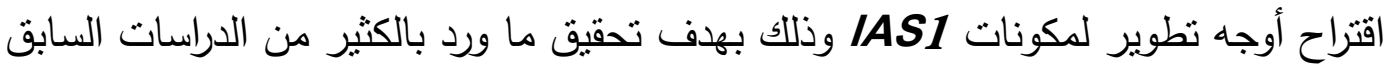
عرضها من أن التقارير المالية يجب أن نوفر معلومات عما حدث بطريقة موجزة وصريحة

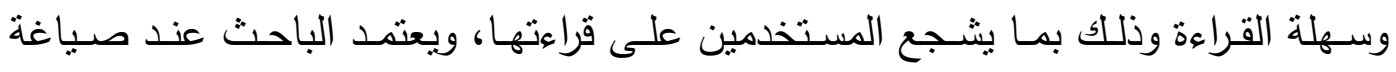

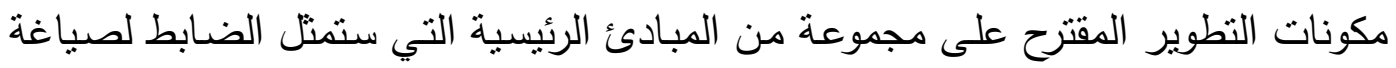

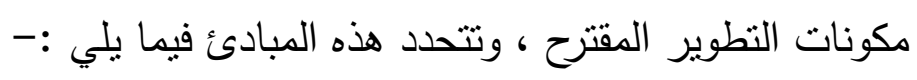

القسم الرابع: المبادئ التي بستتد عليها التطوير المقترح على مبادرة الإفصاح - تعديلات

يعرض الباحث فيما يلي لمجموعة من المبادئ التي سيتم صياغة التطوير المقترح في

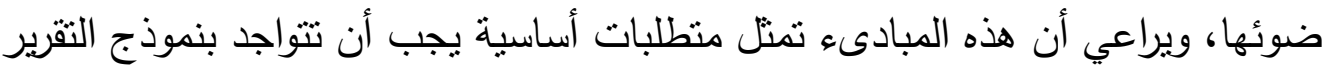

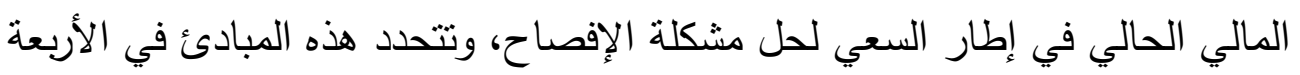
مبادىء التالية: أوولاً: مبادى ع الحد من التعقبد: 
باتت النقارير المالية بوضعها الحالي معقدة للغاية مما يفقد المستخدم القدرة على الربط

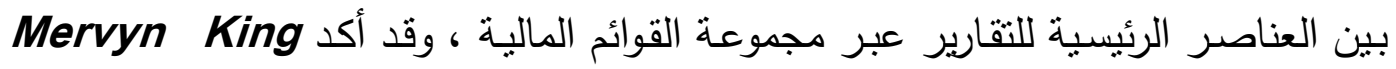
رئيس المجلس الدولي للتقارير المتكاملة IRRC أن نموذج التقرير المـالي الحالي صار مثل

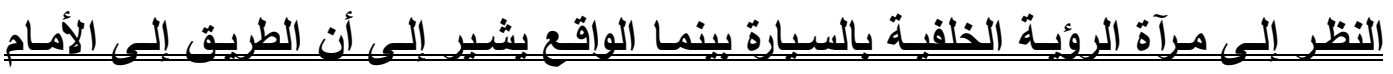

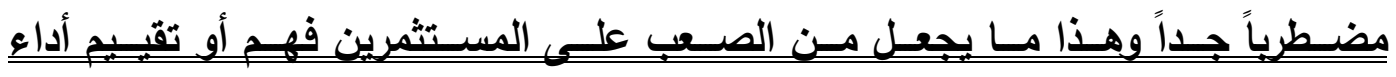
الثركة (KPMG, 2013, P. 8) ، وقد توصلت دراسة Miller إلى أن مستوى التعقيد

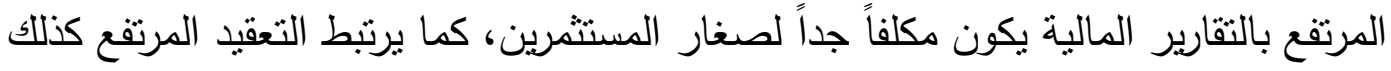
بانخفاض حجم التذاول بسوق المال بالنسبة لصغار المستثرين مع آثار محدودة على كبار المستثرين(Brian P. Miller, 2010, P.2109) ، وتتحدد مكونات التعقيد بالتقارير المالية فيما يلي(12-11 ( ) التعقيد الناتج عن التعقيد المتأصل في المعاملات. r) التعقيد الناجم عن تعقيد المعايير . (1)

ويعتقد الباحث أن محاولة التعامل مع هذا التعقيد تقتضي أن يتم إدراك أن المشكلة الرئيسية

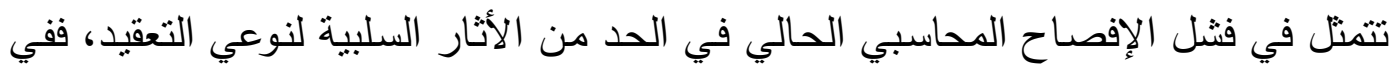

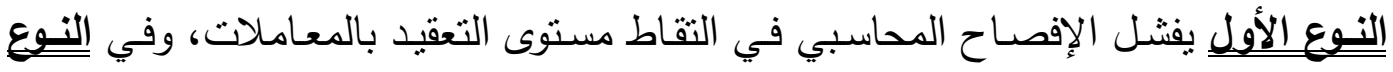

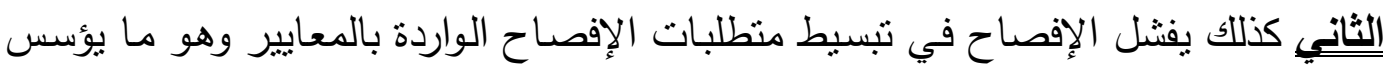

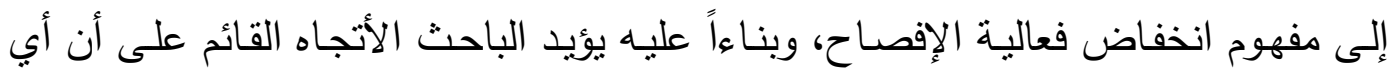

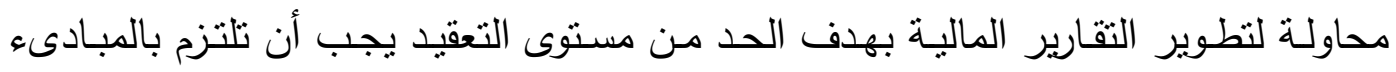
التالية (FRC, 2009, Op.Cit, P.p 15 - 15 () الاستهاف Targeted بأن تركز أي محاولة للنطوير على جوانب الأهمية، وأن يتم التركيز على توفير معلومات ملائمة للمستخدمين تعبر حقيقة عن واقع المعاملات.

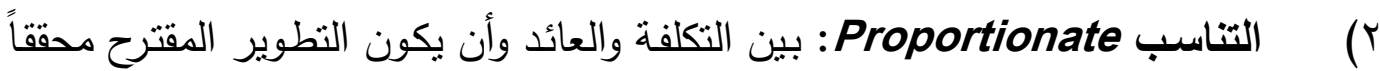
لعوائد للمستخدمين تفوق تكلفة نوفير هذا النطوير.

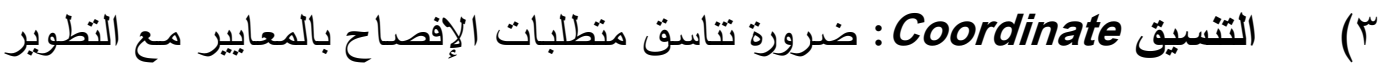
المقترح ومع منطلبات الإفصاح المطلوبة من جهات تتظيمية أخرى لذات المعاملة. 
الوضـوح Clear : يجب أن تكون التعديلات المقترحة بسيطة وسهلة الاستخدام،

تتم صياغة التعديل صباغة واضحة.

تتاح الفرصة للمعدين على استخدام المبادئ والأحكام المهنية.

يتم استخدام المصطلحات المحددة بدقة وتتاسق استخدامها.

وسيلتزم الباحث بهذه المحددات عند صياغة النطوير المقترح على مكونات مبادرة الإفصـاح

IAS1 تعديلات

Effective Communication ثنانبا: مبادئ التواصل الفعال سبق بيان فثل التقرير المالي في أداء دوره كوسيلة للتواصل الفعال مع المستخدمين الذين

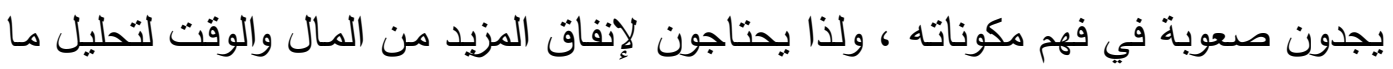
ورد بالقوائم المالية ، إضافة لكون التواصل غير الفعال لا يشمل التوصيل السيئ للمعلومات

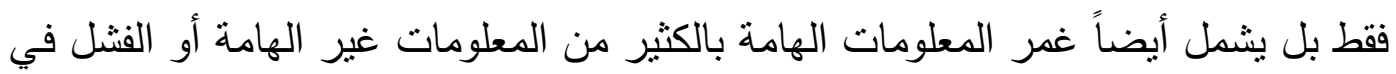

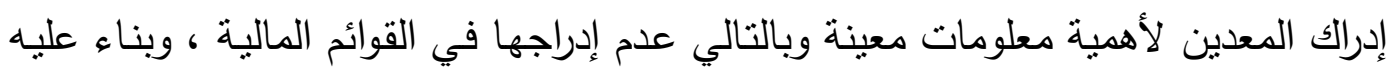

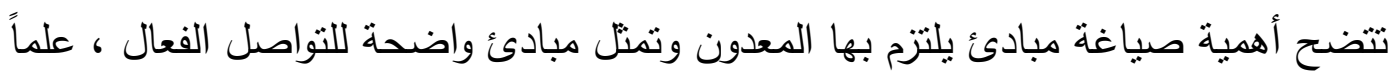

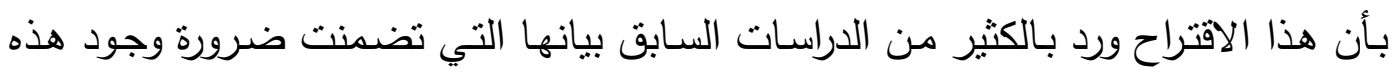

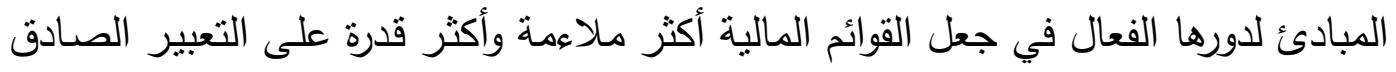

(IASB, March 2017, P.p. 19 -26)

ويعرض الباحث فيما يلي لمجموعتين من مبادئ الاتصال الفعال، المجموعة الأولى صدرت

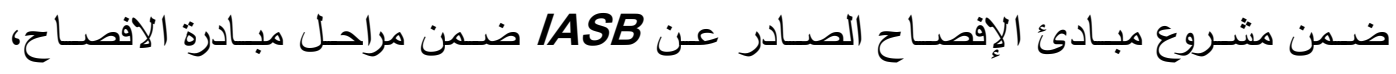
والمجموعـة الثانبـة هي مبـادئ التواصـل الفعـال الصـادرة ضـمن النسـخة النهائيـة للإطـار

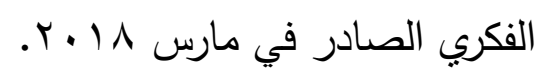

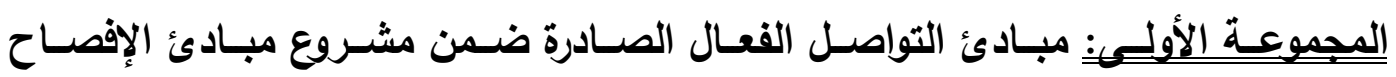
:Disclosure Principles

أكد IASB على ضرورة وجود مبادئ تحكم عمل المعدين وتساعد الوحدات على توصيل

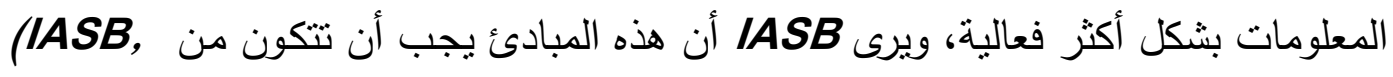

-:March 2017, Op.Cit, P.p. 20 - 21) 
( ) أن تكون المعلومات المفصح عنها خاصة بالوحدة، ومصاغه وفقاً لظروفها، وهو ما

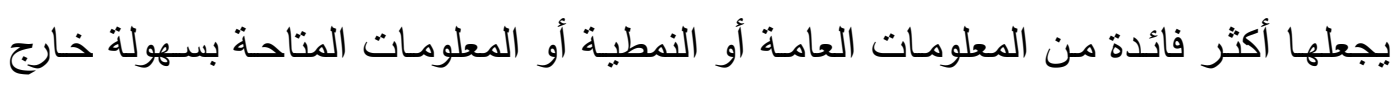

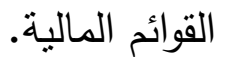
أن تصف المعلومات ببساطة ما تتجه لعرضه وبشكل مباشر كلما كان ذلك ممكناً وبدون فقدان أي معلومات هامة، وبدون أب زيادة غير ضرورية في حجم القوائم المالية.

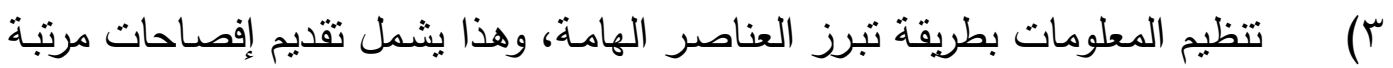

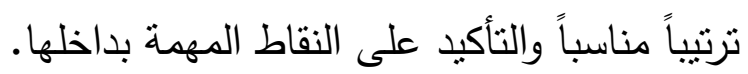

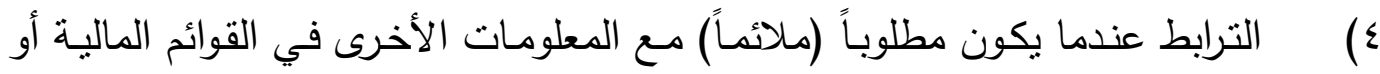

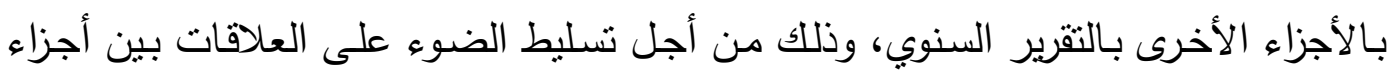
المعلومات وتحسينها ضمن القوائم المالية. 0) عدم تكرار المعلومات دون داع في أجزاء مختلفة بالقوائم المالية أو بالتقرير السنوي.

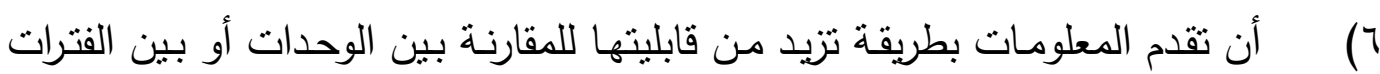
لذات الوحدة دون المساس بفائدة المعلومات.

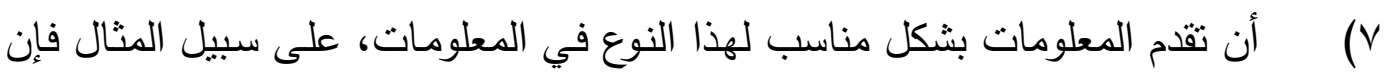

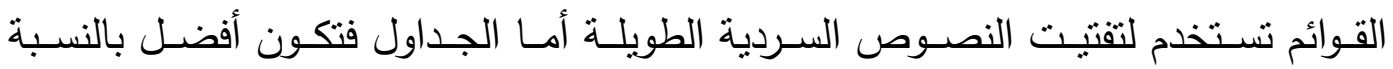
للمعلومات كثثفة البيانات مثل تحليل آجال الاستحقاق.

وأوصى IASB باستخدام الحكم المهني عند تطبيق هذه المبادئ في حالة احتباج الوحدة

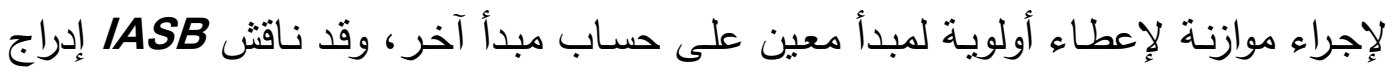

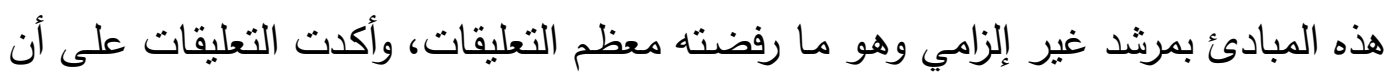

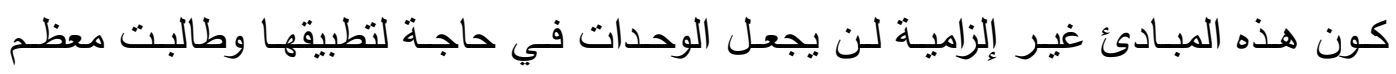

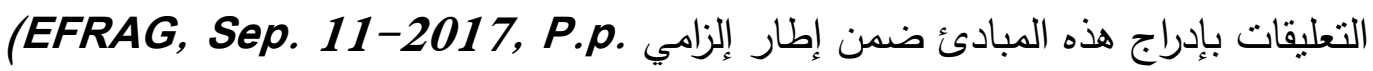
(ICAEW, Oct. 2. 2017, P.p. 3 - 4) (IASB, الدراسة أمنلة للنواصل غير الفعال في القوائم المالية لمساعدة المعدين على تجنبها -:March 2017, Op.Cit, P.p. 19 -20)

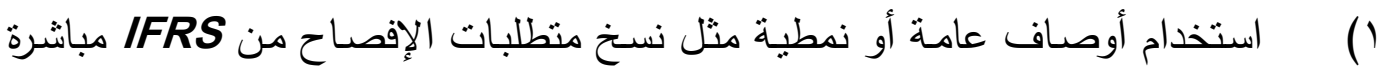

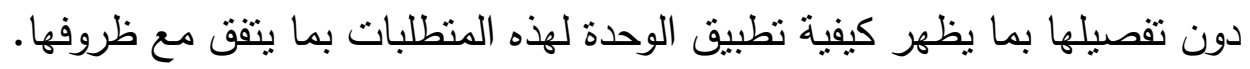

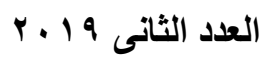
- rTV مجلة المحاسبة والمراجعة 
ب استخدام أوصـاف غير واضحة على سبيل المثال المصطلحات الفنية بدون شرح

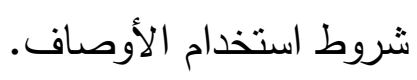

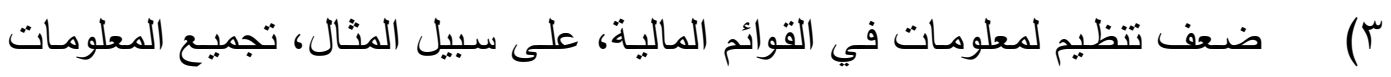
بشكل غير مناسب أو عدم توفير صفحة محتويات أو مساعدات أخرى.

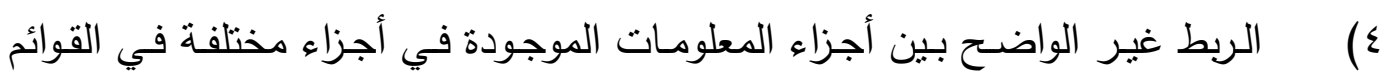

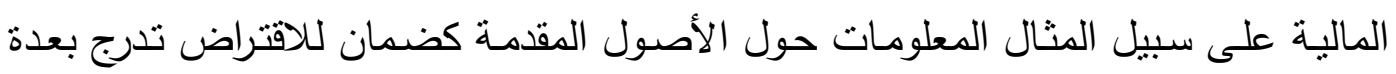
ملاحظات بدون أي إثنارات مرجعية أو أي ربط بين تلأك الإفصاحات.

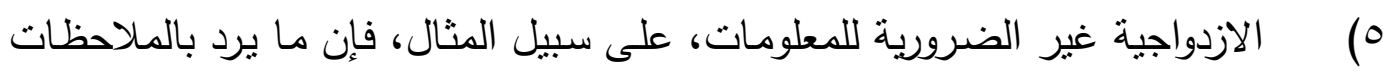
حول المخزون بعيد ذات ما ذكر في القوائم المالية دون أي معلومات إضافية.

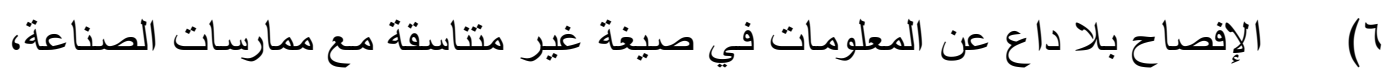

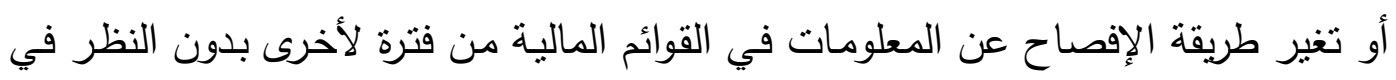

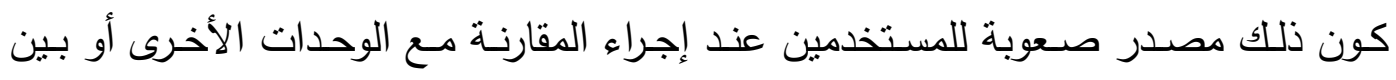
الفترات المختلفة لذات الوحدة.

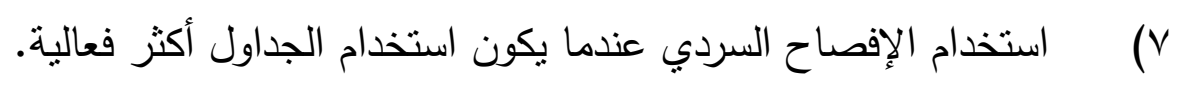

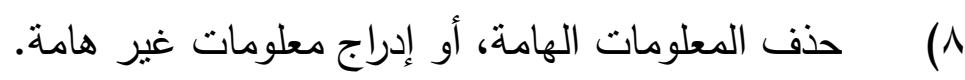

المجموعة الثانبة: مبادئ التواصل الفعال الواردة بالإطار الفكرى للتقرير المالي:

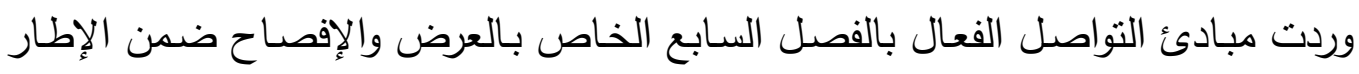

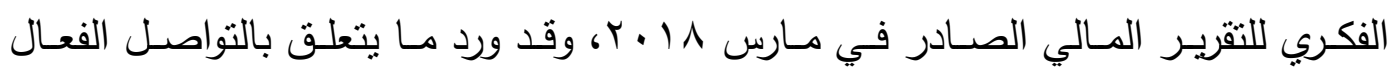
(IASB, March 2018, P.p 74 - بالفقرات 7.

( ) التركيز على تحقيق مبادئ وأهداف العرض والإفصاح بدلاً من التركيز على القواعد.

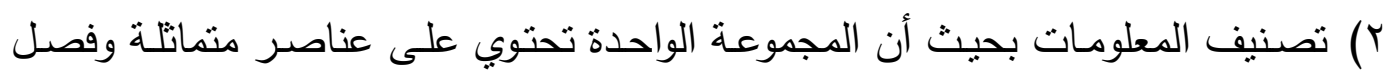
العناصر غير المتماتلة. r) تجميع المعلومات بطريقة لا يترتب عليها أن يتم غمر المعلومات الهامة بالتفاصيل غير

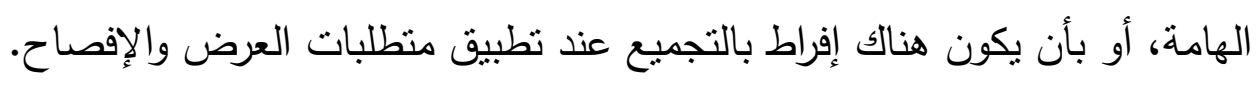


ع) المعلومات المرتبطة بالوحدة أكثر فائدة من المعلومات التوصيفية الواردة بالمعايير والتي يشار لها دائماً بالمعلومات النمطية. 0) تكرار المعلومات بأجزاء مختلفة بالقوائم المالية عادة ما يكون أمر غير ضرالئة ضروري ويترتب عليه جعل القوائم المالية أقل قابلية للفهر.

وبأستعراض مجموعتي مبادئ التواصل الفعـال يتضـح إن البندين الرابع والخامس بمبادئ الاتصـال الفعـال بالإطـار الفكري هما فقط من سبق عرضـهـ بالمبادئ الواردة بالمجموعـة

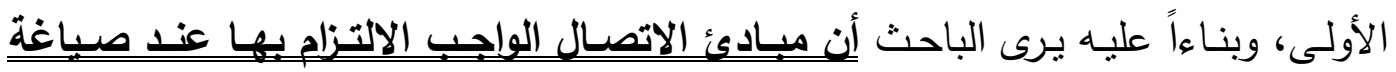

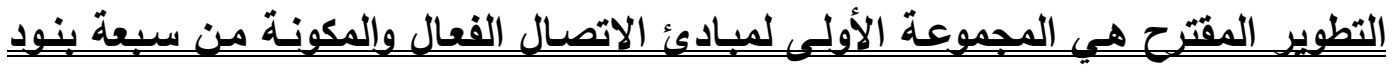

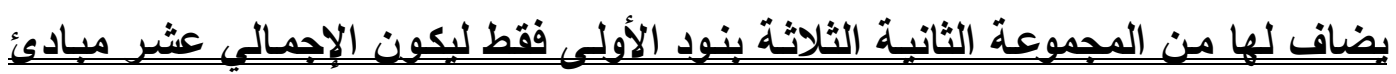

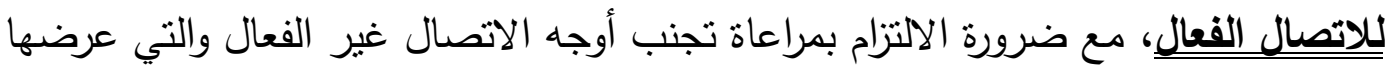
IASB

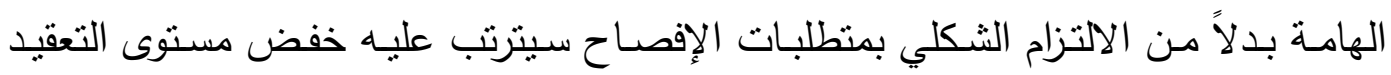
بالتقارير المالية ومساعدة المستتمرين على الحصول على فهم كامل للأعمال.

ثُالثا: دعم الاتجاه الهادف لإصدار المعدين لأحكام مهنية: أكد IASB أن بعض الفقرات بـ IAS1 تجعل من الصعب على لعلى المعدين إصدار أحكام

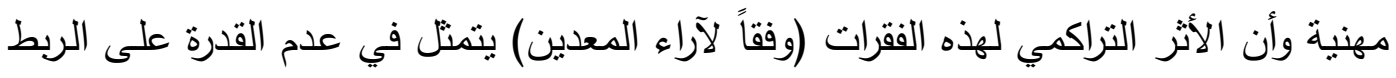

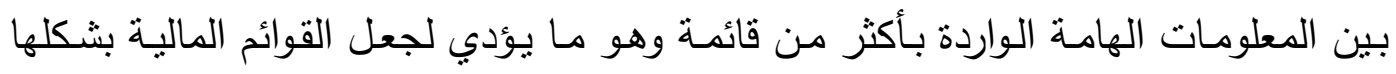
الحالي مفككة Disjointed (IASB, May 2013, Op.Cit, P.p. 18-19)

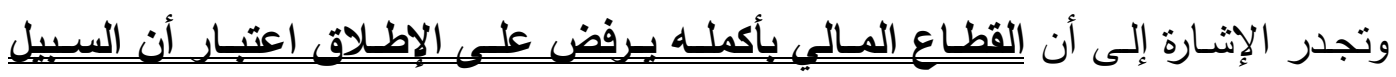

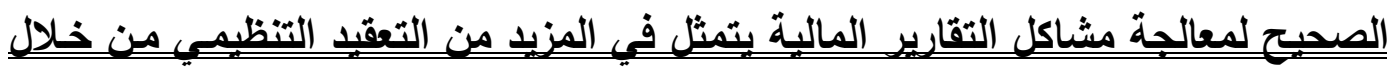

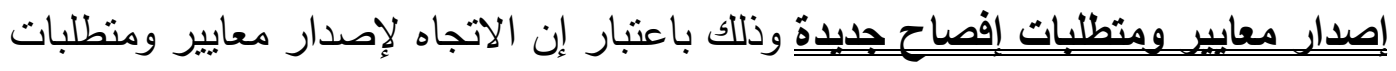

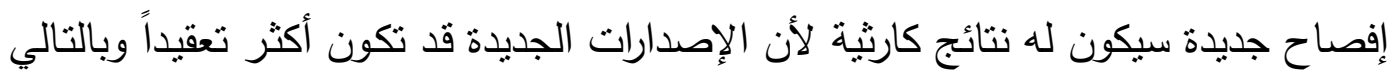

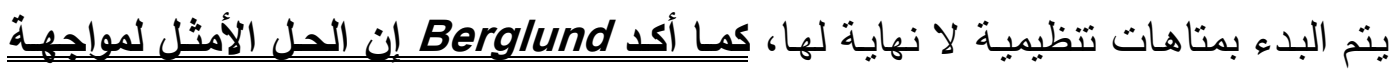

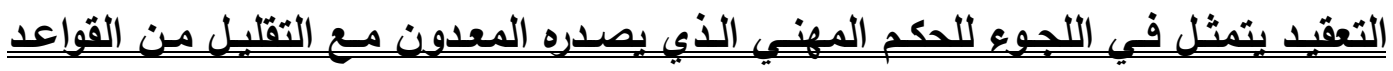
المطبقة (متطلبات الإفصاح الثابتة)(108) - 107 (Tom Berglund, 2014, P.p. 
، وفي ذات الصدد برى FRC أن إتاحة الفرصة للمعدين لإصدار الحكم المهني الموضوعي

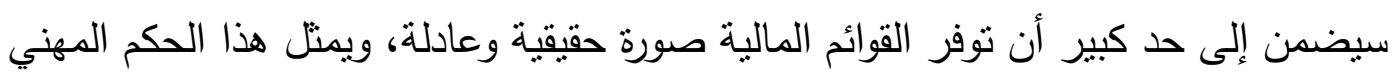

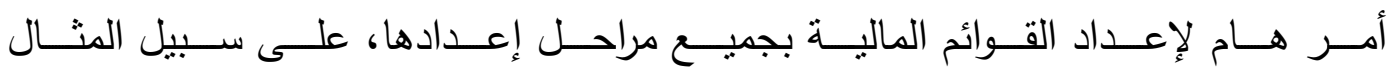

:(FRC, June2014,P.p.1-2)

أ-حين يكون هناك اختيار بين سياسات محاسبية مسموح بها في ظل IFRS

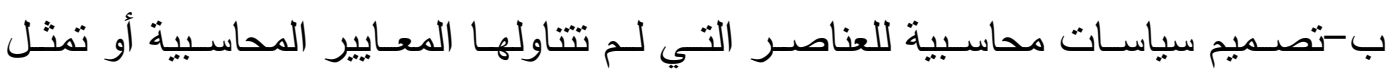

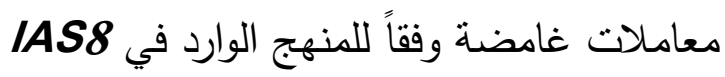
ج-النظر فيما هو هام وما هو غير هام. دماته

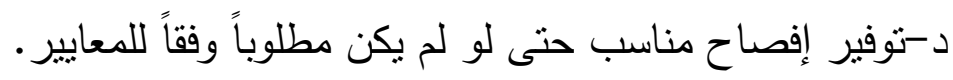

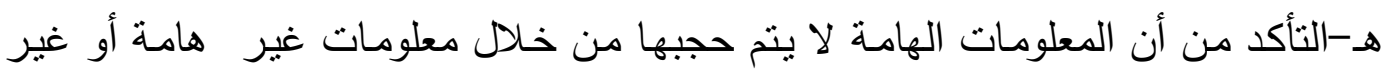

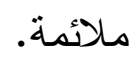
و -تقييم القوائم المالية والتأكد من أنها وبشكل عام توفر رؤية حقبقية وعادلة.

بناءاً عليه يعتقد الباحث بضرورة تقيم وإعداد مقترحات تطوير IAS1 في إطارالأعتماد

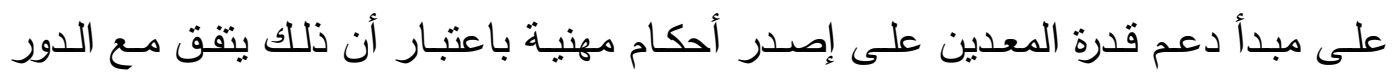

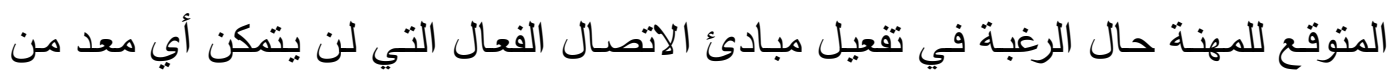

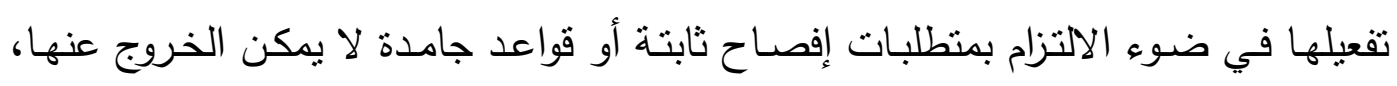

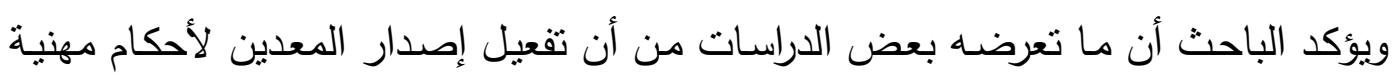

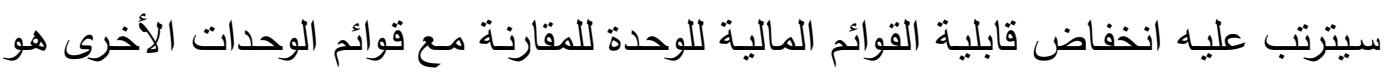

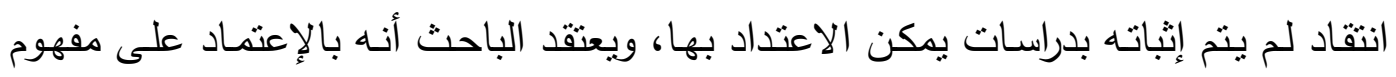
التكلفة / العائد فإن العائد من الاعتماد على إصدار المعدين لأحكام مهنية سيفوق كثيراً أي تكاليف ناتجة عن تبني هذا الاتجاه.

رابعا: مشاركة أصحاب المصالح لتقييم مكونات التطوير المقترح على مبادرة الإفصاح تعديلات IAS1: تصنيا: يتمثل أصحاب المصالح في الفئات التي يرى IASB أنهم أطراف مهمة في سلسلة إعداد

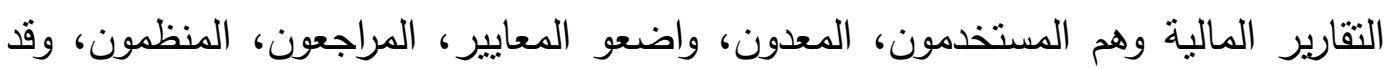

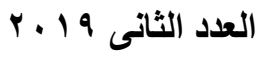
- TV. مجلة المحاسبة والمراجعة 


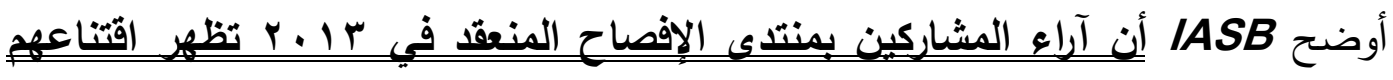
لكون كل طرف منهم بساهم (كمسب) في أحل أو أكثر من مشاكل الإفصاح وهو ما يؤكد

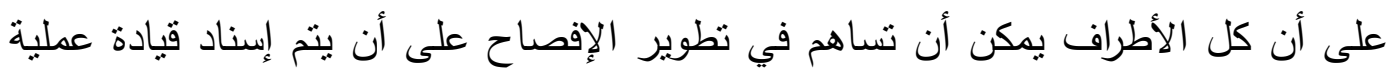

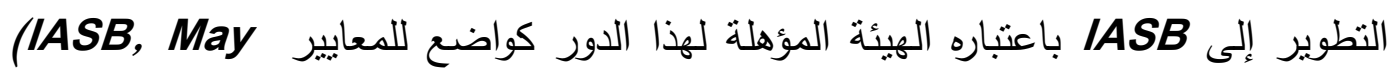
2013, Op.Cit, P. 11)

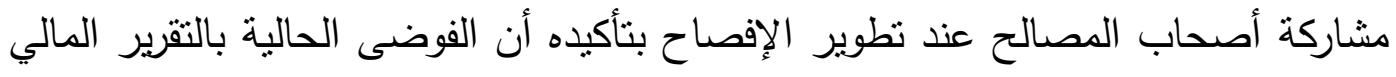

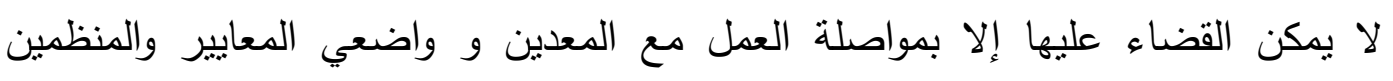

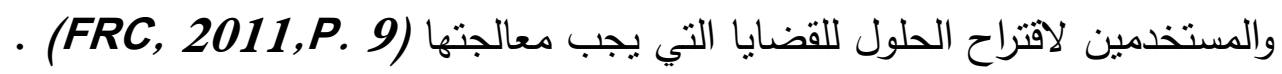

كما أنشار Russell G. Golden رئيس مجلس معايير المحاسبة المالية FASB إلى ما يقوم بـ FASB من تواصل مع أصحاب المصالح للحصول على آرائهم وتفهم أولوياتهم

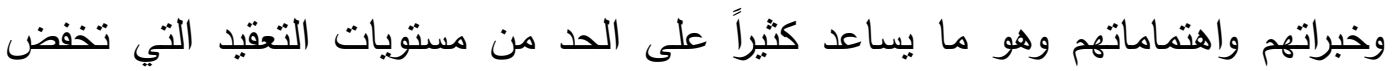

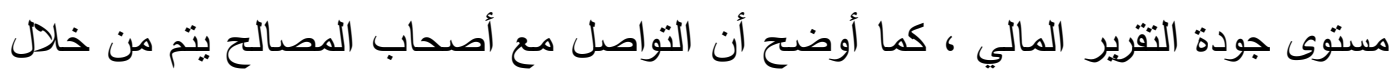

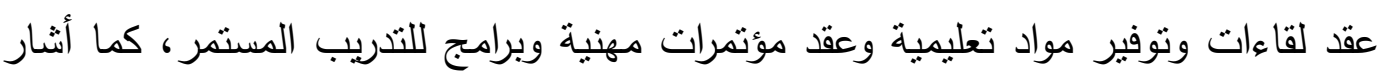
Golden الجديدة من خلال إنثاء بوابة الكترونية تضمن التواصل الفعال مع كافة أصحاب المصالح

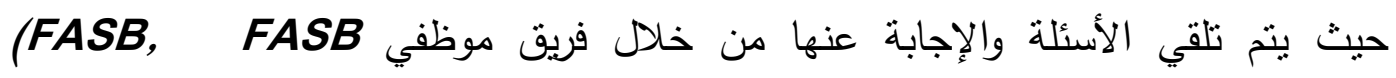

. Russell G. Golden, August. 31, 2017,P.p. 1 - 11)

ويؤكد الباحث على الاعتماد على هذا المبدأ القائم على مشاركة كافة أصحاب المصالح وذلك من خلال عرض مقترحات التطوير على الفئات التالية: -معدون - مستخدمون مراجعون - منظمون، للحصول على أراؤهم وتقييمهم لمقترحات النطوير .

القسم الخامس: تقييم و تطوير مبادرة الإفصاح - تعليلات IAS1: يتتاول الباحث عرض التقييم والنطوير المقترح لمبادرة الإفصاح -تعديلات IAS1 من خلادل

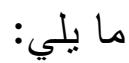
أولاً: تقييم ومحاولة تطويرفقرات IAS1 الواردة ضمن مبادرة الإفصاح -تعديلات IAS1

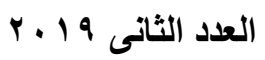
مجلة المحاسبة والمراجعة 
ثابِياً: التعديلات المقترحة على فقرات بـ IAS1 لم ترد ضمن مبادرة الإفصساح-تعديلات

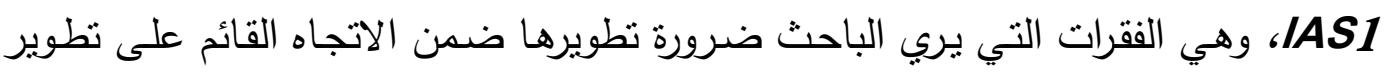
العرض المحاسبي باعتباره أحد أهم أدوات النواصل مع المستخدمين.

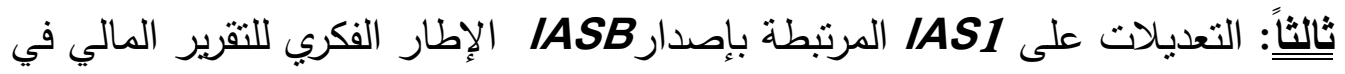

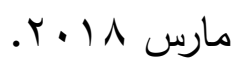

أولاً: تِقيم وتظوير فقرات IAS1 الواردة ضمن مبادرة الإفصاح-تعديلات IAS1 تتكون التعديلات على معيار IAS1 الواردة ضمن مبادرة الأفصاح مما يلي (الثكل الكامل للتعديلات ملحق ()) : تعديلات متعلقة بالأهمية النسبية والتجميع. - - معديلات على قائمة المركز المالي. تعديلات على قائمة (قائمتي) الأرباح أو الخسائر والدخل الثنامل الآخر . تعلى

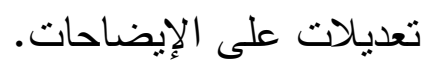
تعديلات على الإفصاح عن السياسات الدحاسبية. تعديلات على المجموعة الكاملة للقوائم المالية.

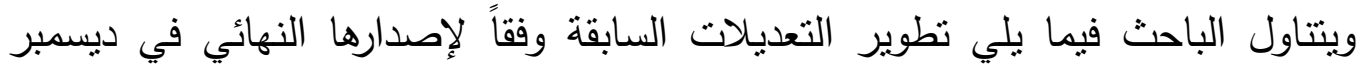

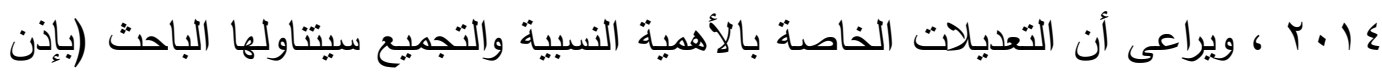

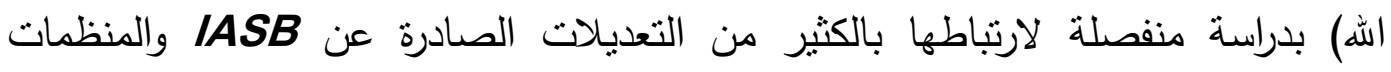

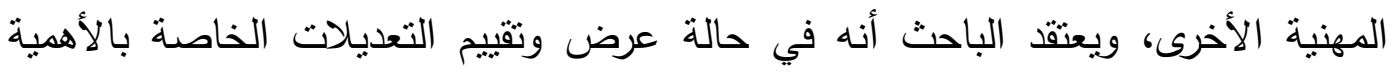
النسبية ضمن هذا النطوير المقترح فإن النطوير سيخرج من سياقه نظراً لأن الدراسات

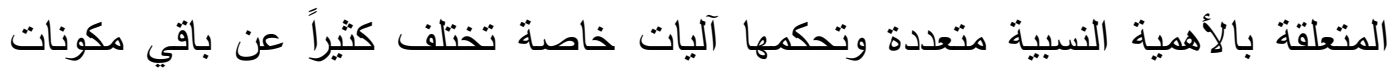
التطوير، ويراعي أن التعديلات أسفلها خط هي التعديلات الواردة بمبادرة الإفصاح-

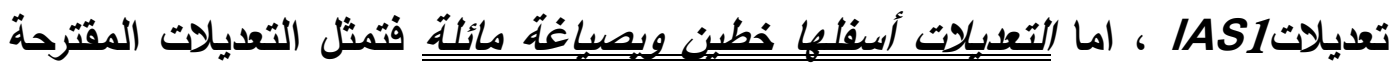
من الباحث

1/أولاً: التعدبلات المرتبطة بقائمة المركز المالي: تناولت مبادرة الإفصاح -تعديلات IAS1 فيما يتعلق بقائمة المركز المالي الفقرات التالية:

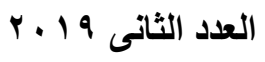
- TVY . مجلة المحاسبة والمراجعة 
كعدأدني، يجب أن تتشمل قائمة المركز المالي بنوداً مستقلة تعرض المبالغ النالية:

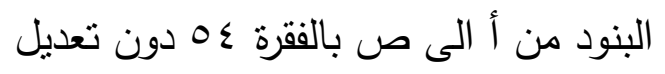

ثم بنهاية الفقرة ؟0 تمت إضافة ما يلي:

هذه البنود المستقلة يجب أن بتم تفصيلها عندما يكون هذا العرض ملائماً لفهـ المركز

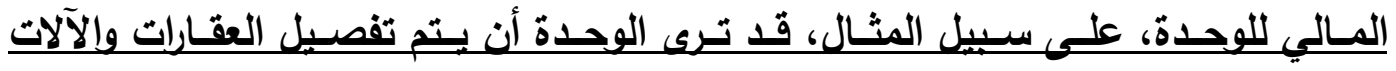

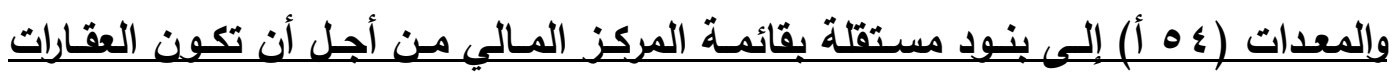
والآلات والمعدات لها القدرة على صنع الفارق في القرارات المتخذة بواسطة مستخدمين القوائم المالبة. الإصدار النهائي: تم حذف عبارة كحد أدنى فقط أما السطور أسفلها خط بنهاية الفقرة فقد نم حذفها ولم تضاف للإصدار النهائي.

تقييم وتظوير الفقرة ؟ 0؛ 1

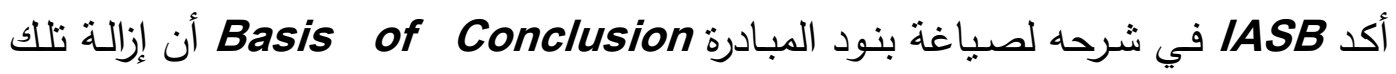
العبارة جاء لمعالجـة سوء الفهم المرتبط بصياغتها التي توحى بوجود الزام على المعدين

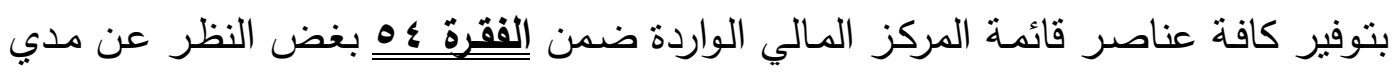
أهميتها، وقد أكد IASB أن الهدف من التعديل هو حث المعدين على تطبيق الأهميـة

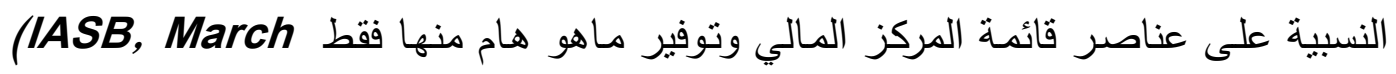
2014, Op. Cit, P. 18)

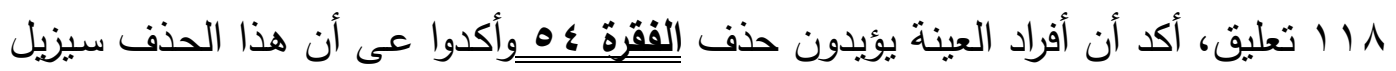

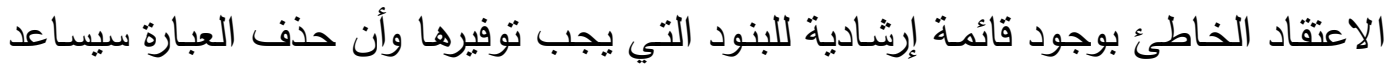

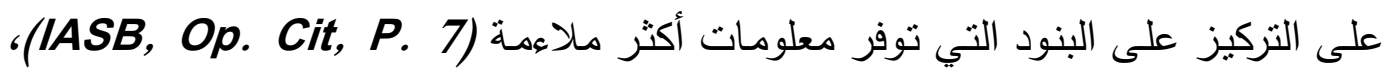

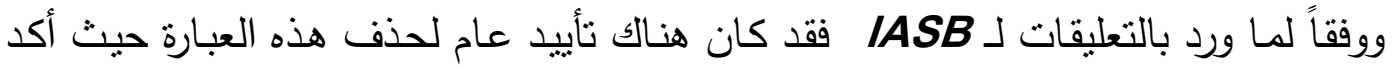

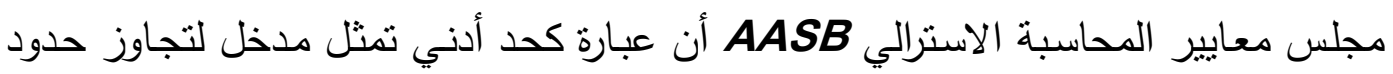




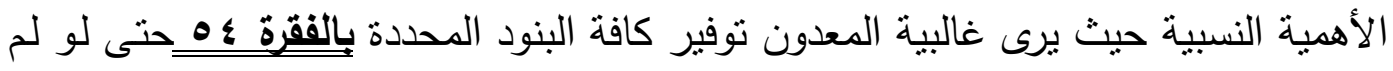

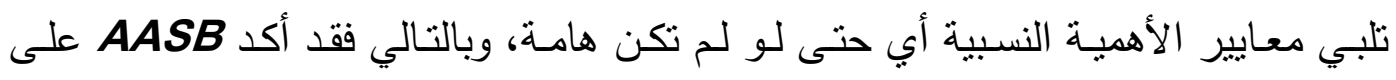

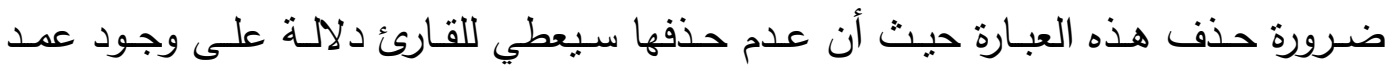

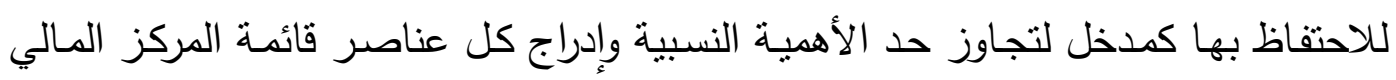

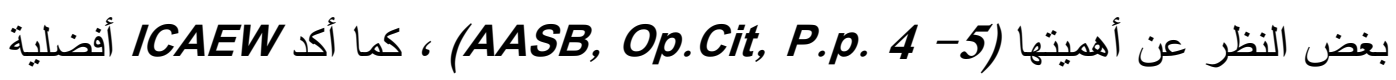

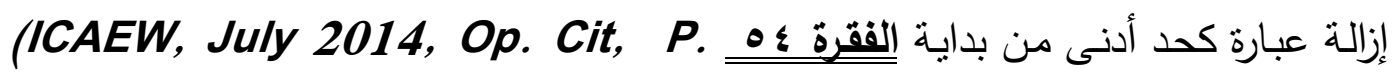

بناء على ماسبق واتساقاً مـع المبادئ السابق بيانها كدعائم للتطوير المقترح وخصوصاً ما

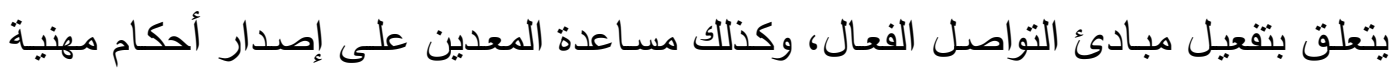

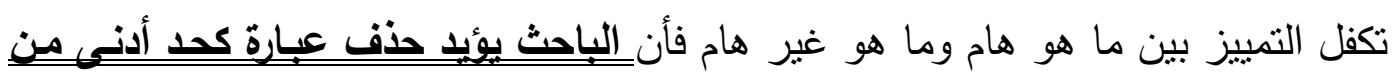
نصى الفقرة عـــ

的 يعتقد الباحث أن الأثر المنتظر من حذف عبد عبارة كحد أدنى لن يتحقق مع استمرار عبارة يجب أن تثـل التي ستحد كثيراً من قدرة المعدين على تحديد العناصر الهامة والتركيز

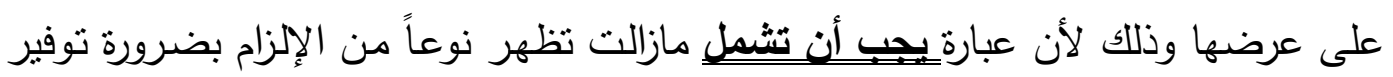

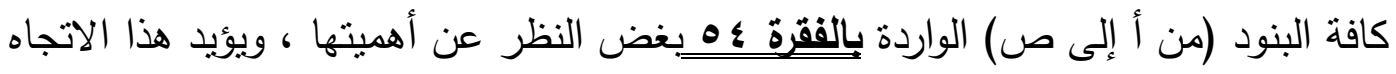
مؤسسة EY التي أكدت خطأ الاعتقاد بكون حذف عبارة كحد أدنى قد حل المشكلة وألفرة وأصبح

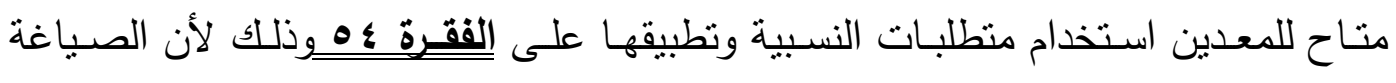

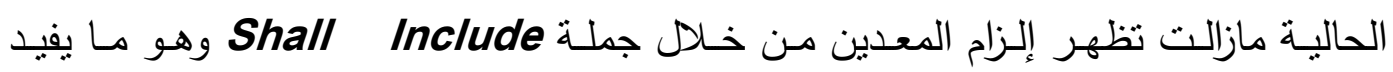

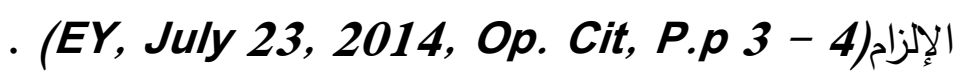

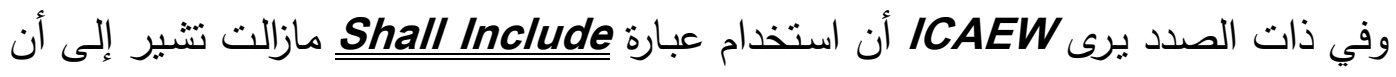

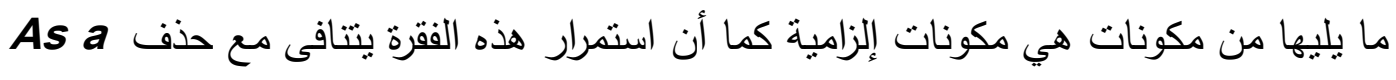

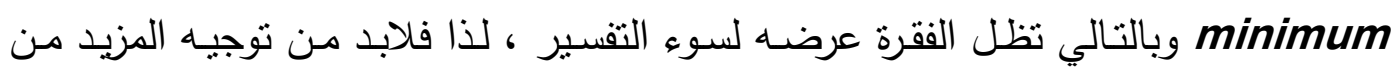
الاهتمام للصياغة الواضحة التي تكفل تحقيق الهدف وهو تفعيل متطلبات الأهمية النسبية

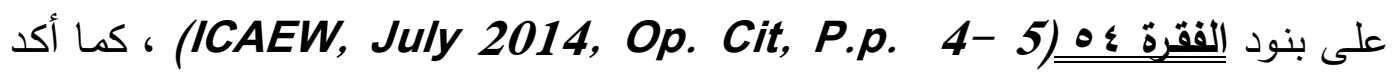


معهد المحاسبين الإداريين IMA أن تأييد حذف عبارة كحد أدنى من الفقرة ؛هـصطدام بكون الصياغة الباقية تحتوي على Shall Include والتي تمثل بدورها إلزام بتوفير كافة

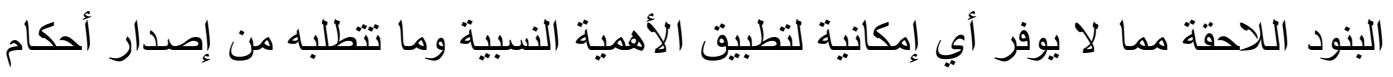
مهنية لاستبعاد العناصر غير الهامة ، وأكد

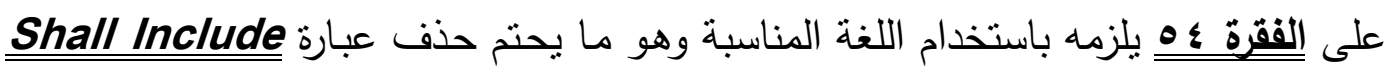
. (IMA, July. 7. 2014, p.p 3-4)

بناء على ماسبق يؤيد الباحث ضرورة حذف عبارة يجب أن نتمل Shall Include لأنها

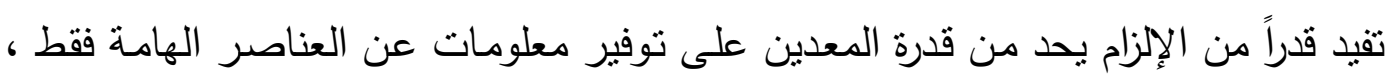

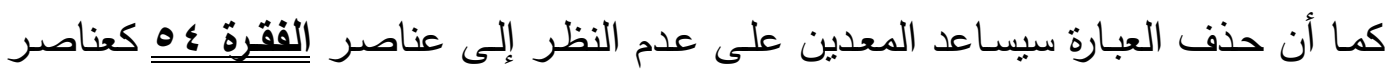

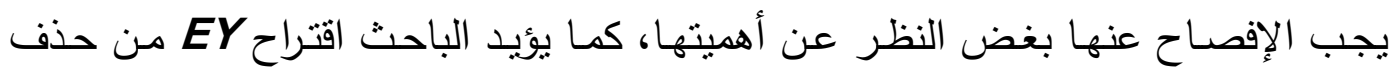
عبارة Would Normally Include وأن يحل محله Shall Include تشتمل) وهو ما يعتقد الباحث بكونه لا يحمل أي صيغة إلزام ويتيح للمعدين تطبيق أحكام

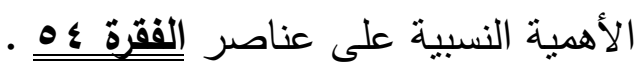

بَ: إضافة ما يفيد صراحة أن عرض عناصر المركز المالي يرتبط بكونها عناصر هامة:

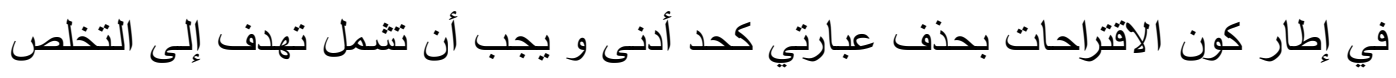

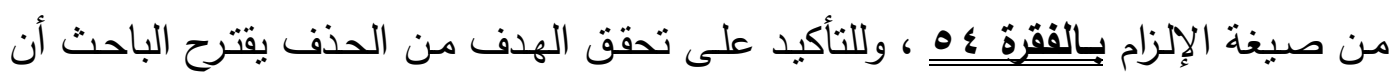

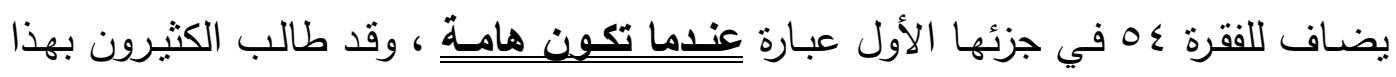

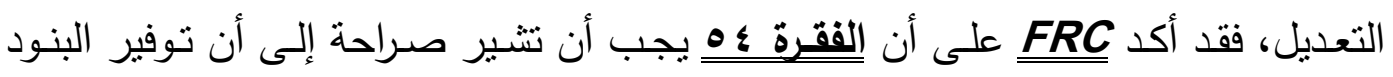
المنصوص عليها بالقرة يكون فقط إذا كانت هامة (FRC, July 7. 2014, P. 7)

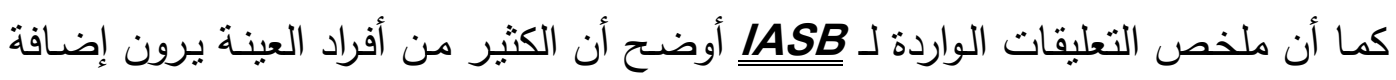
When Material ICAEW النسبية ولا يتم عرضها إلا إذا كانت هامة(ICAEW, July 2014, Op. Cit, P. 5)

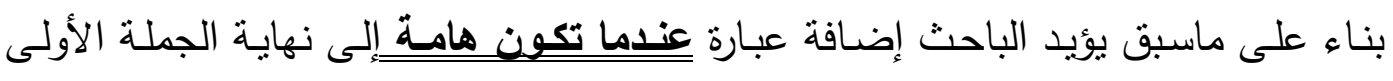

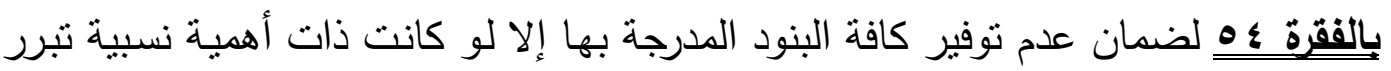


عرضـها، وهو مـا يعتقد الباحث بأنه سيمنل حافز للمعدين والمراجعين على تخطي مـا

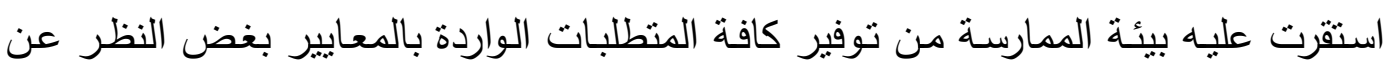

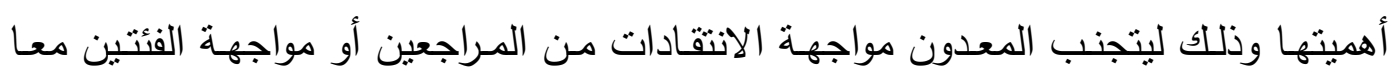
للاعاوى القضائية.

عَع-الفقرة الخاصة بالتفصيل الواردة بالإصدار الأولى بنهايـة الفقرة ؛ه والتى تم حذفها

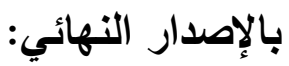
وردت هذه الفقرة بالإصدار الأولي بنهاية الفقرة ؛ه بغرض إتاحة الفرصة للمعدين لتفصيل

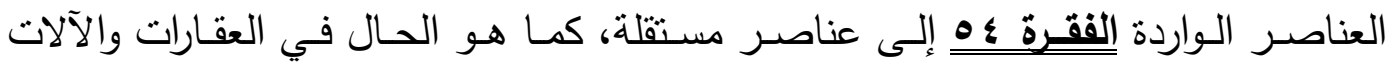
والمعدات فيجوز عرض كلاً منهما بشكل منفصل حالـة تحقق منطلبات الأهميـة النسبية إضافة لضرورة أن يكون هذا العرض أكثر مناسبة لفهم المستخدمين للمركز المالي، إلا أن

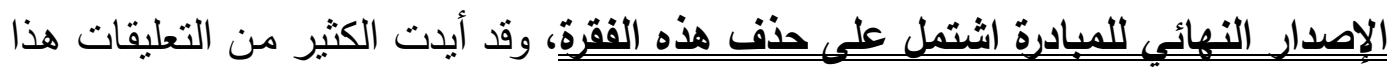

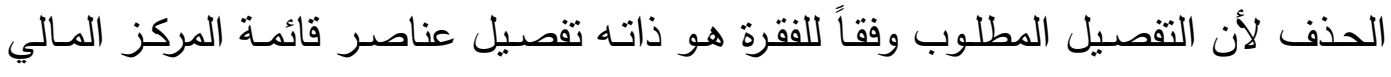

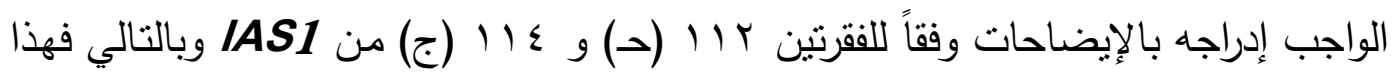

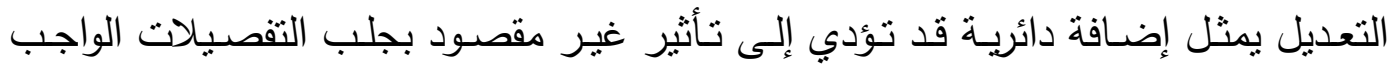

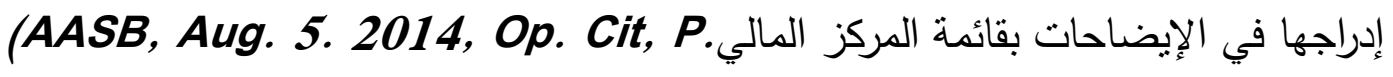

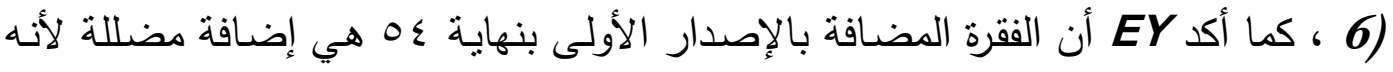

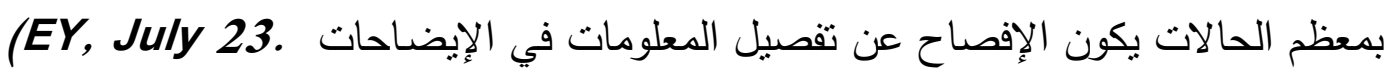
. 2014, Op. Cit, P.3)

إلا أن الباحث بـرى أن حذف العبارة جاء حذفاً متسرعاً وأن الأفضل كان إعادة صياغة الفقرة لضمان تفعيل إتاحة الفرصة للمعدين لإصدار حكم مهني حول مكان إدراج التفاصيل

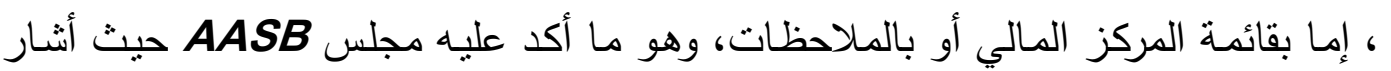

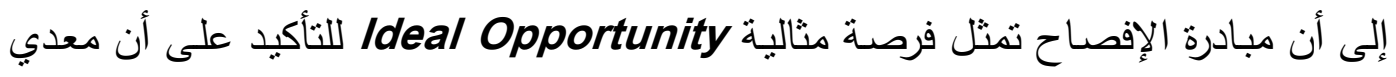

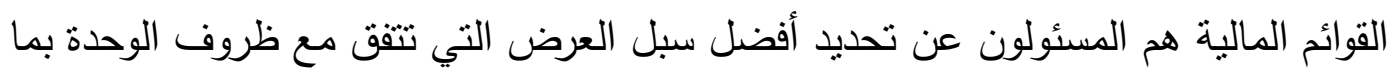

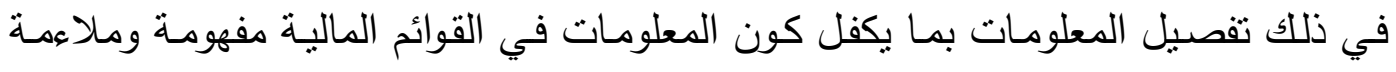

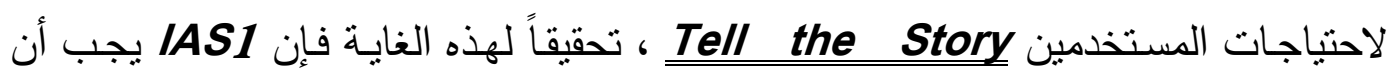


يحتوي على السماح للمعدين بإدراج التفصيل إما بالقوائم المالية أو بالإيضاحات وفقاً لروئية

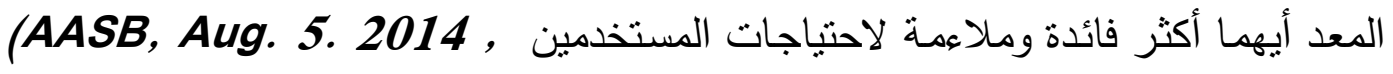
عالى ضرورة بقاء الفقرة مع تعديلها بما يتيح إمكانية

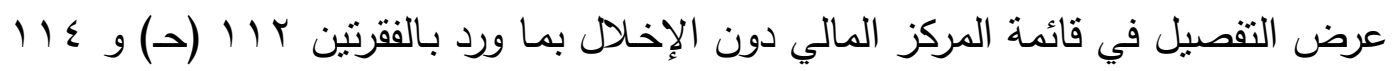

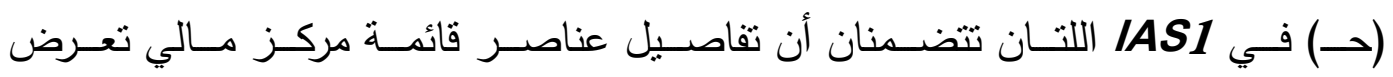
(FRC, July. 7. 2014, أن يتم تعديل الفقرة لتكون كما يلي لئل :Op. Cit, P. 7) هذه البنول المستقلة يجب أن يتم تفصبيليا عندما يكون هذا العرض هو الأسلوب الأكثر

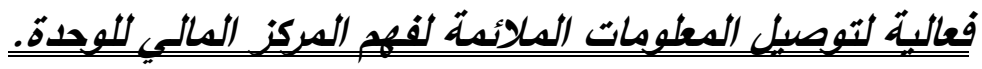

ويؤيد الباحث هذا التعديل الذي يتيح قدراً من التفصيل لعناصر الفقرة ؛ه طالما أن هذا

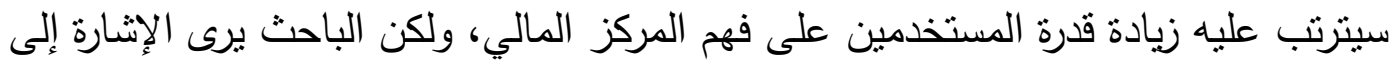

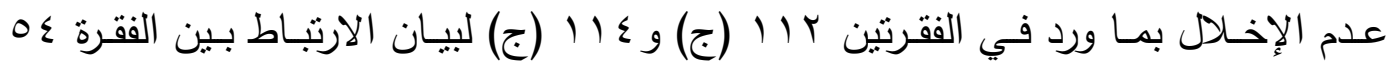
والفقرتين وذللك لضمان وضوح حاجة المُعد إلى إصدار حكم مهني حول رؤيته لمكان إدراج التفاصيل هل بقائمة المركز المالى بالإيضاحات.

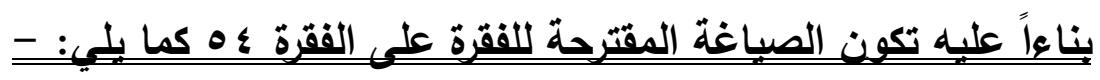
عادة ما تثتـل قائمة المركز المالي على بنود مستقلة تعرض المبالغ الثالية عندما تكون هامة : -

البنود من أ الى ص بالفقرة ؟0 دون تعديل

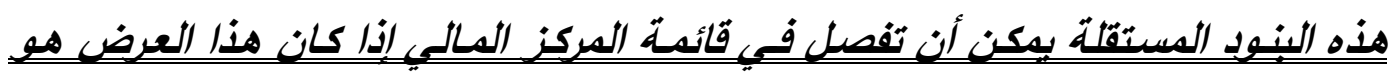

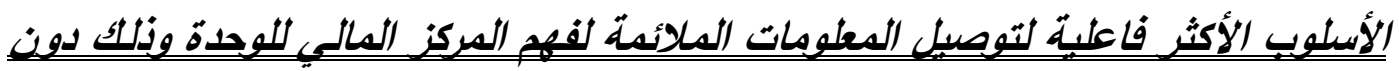

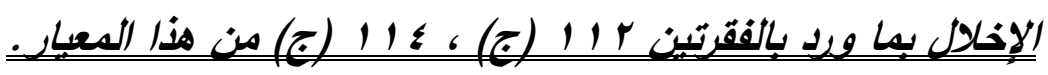

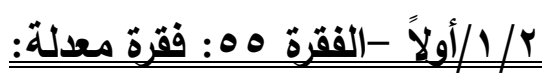
الإصدار الأول:

لم تعدل الفقرة هــ

الإصدار النهائي: 
تقوم المنشأة بعرض بنود (بمـا في ذلك تفصيل البنود المينـة في الفقرة " ؛ه") وعناوين

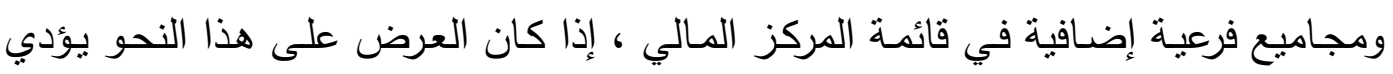
إلى فهم المركز المالي للمنشأة.

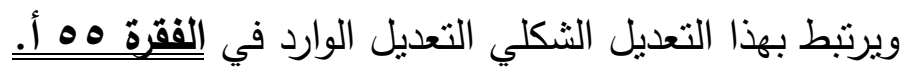

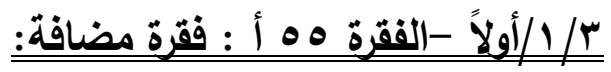
فقرة غير موجودة بـ الإلا IAS1 وتم إضافتها كما يلي: -

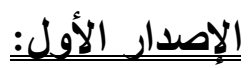
عندما تقوم المنثأة بعرض مجاميع فرعية وفقاً للفقرة "هه" يجب أن تكون هذه المجاميع الفرعية : أ- مكونة من مبالغ لبنود يتم قياسيا وفقاً لمعايير التقرير المالي الدولية. وب- بتتم عرضـها وعنونتها على نحو يجعل البنود المكونـة للمجموع الفرعي واضحة ومفهومة. و ج- تكون متسقة من فترة لأخرى. الإصدار النهائي: تم الموافقة على إضافة الفقرة لـ IAS1 على أن يضاف البند (د) لثروط عرض المجاميع

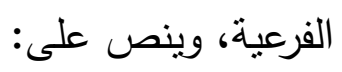
د-لا يتم إيرلهها أكثر من المجاميع الفرعية والمجاميع المطلويـة في قائمـة المركز المـالي وفقاً لمعايير التقرير المالي الدولية.

تقبيم وتطويرالفقرة هـ أذ أوضـ FASB في إطـار دراسته حول العرض أن المعايير تتضـمن عدداً محدوداً مـن فئس

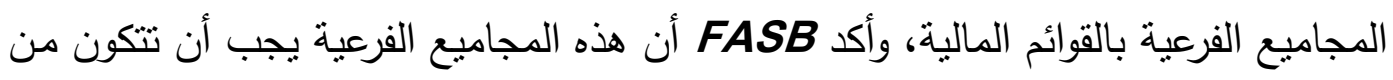

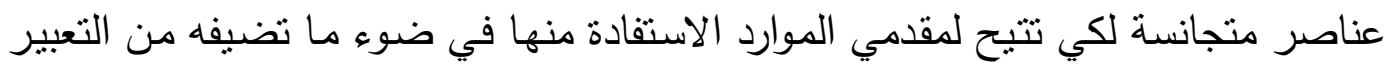

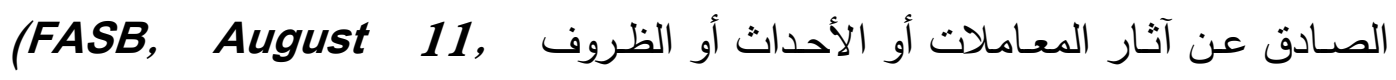

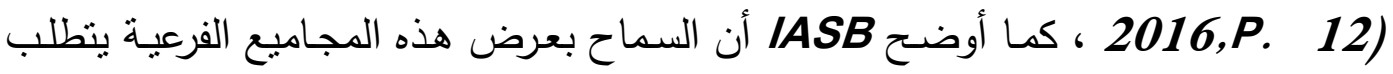

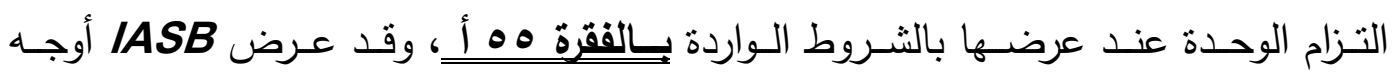


المخاوف لدى بعض المستخدمين من التوسع في استخدام هذه المجاميع الفرعية، وحددت (IASB, March 2017, Op. Cit, P.p. 49 - 51)(IASB, هذه الدخاوف بما يلين -:Dec 2104, Op. Cit,P.p. 18 - 19) أ-الصعوبة في فهم كيفية حسابها. ب-عدم وضوح كيفية ارتباطها بالمبالغ الأخرى فى القوائم المالية. جـ-صعوبة المقارنة بين الفترات لأن الوحدة قد لا تستمر باحتسابها.

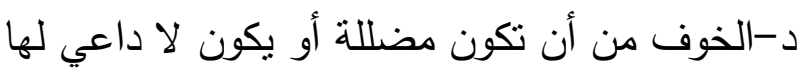

إلا أن IASB يـرى أن استخدام الثـروط الواردة بـالفقرة هـ أ يمثل رداً على معظم هذ

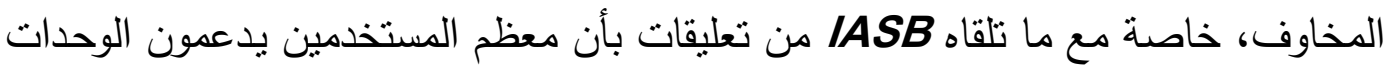

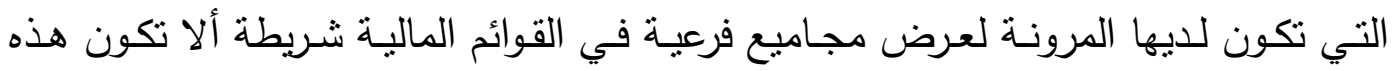

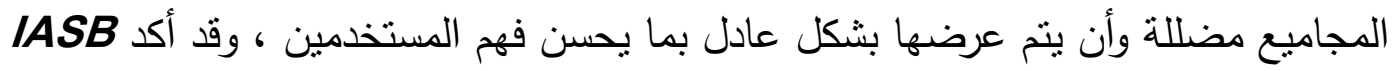

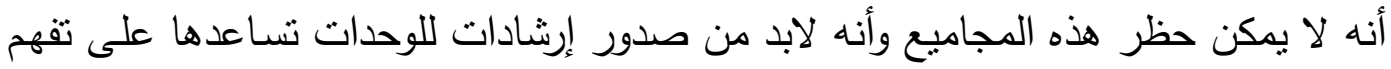

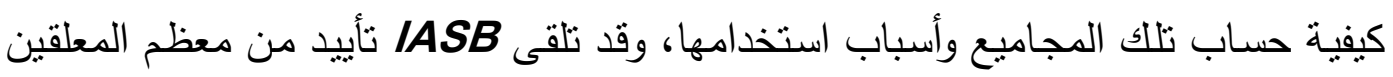

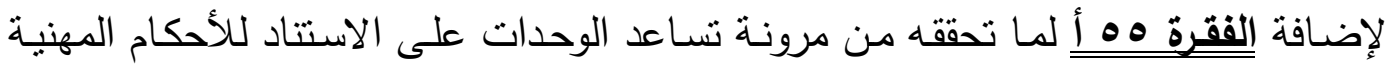

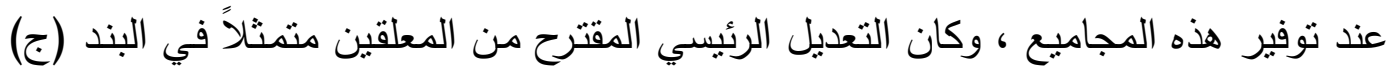

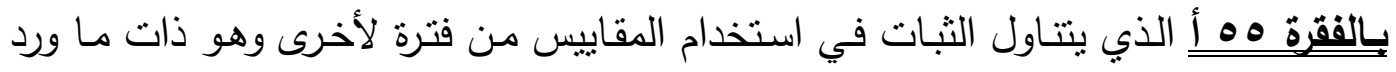

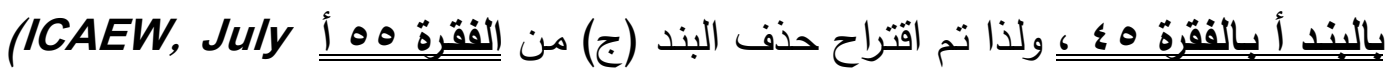
(AASB, Aug. 5, 2014, Op. Cit, P.p.7 - 2014, Op. Cit, P.p.5-6) (CAI, July 2014, Op. Cit, P. 3) (EFRAG, July 22. 2014, Op. 8) . Cit, P. 5)

وقد عرضت دراسة IASB بعنوان Disclosure principles أنه عند استخدام المجاميع (IASB, March 2017, Op. Cit, P.p.56 الفرعية يجب الالتزام بالمنطلبات التالية $-:-57)$

أن تعـرض برمـوز مســاوية أو أقلـل مـن العناصـر الرئيسية أو المجـاميع الفرعيـة

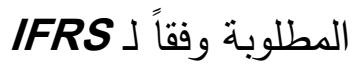




$$
\begin{aligned}
& \text { أن تكون مصحوبة بشرح في الإيضاحات حول: - } \\
& \text { أ-كيف تقدم معلومات عن مركز وأداء وتدفقات الوحدة. } \\
& \text { ب-أية معلومات إضافية أخرى تساعد على فهم المجاميع. }
\end{aligned}
$$

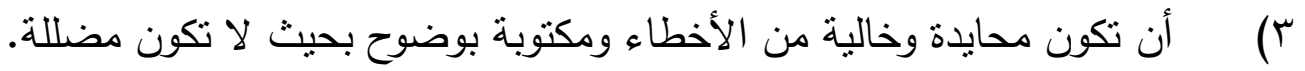

$$
\text { ع) أن أن أن أكون مصحوبة بمعلومات مقارنة. }
$$

0 العرض المستمر بما يدعم القابلية للمقارنة.

وبناءاً على ما سبق يرى الباحث إجراء التعديلات التالية على الفقرة هـ أ (علماً بأن ذات

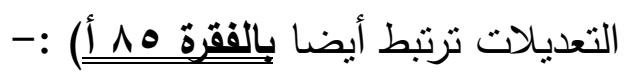

( ) مذف البند (ج) بالإصدار الأولي ويحل محله البند (د) الوارد بالإصدار النهائي.

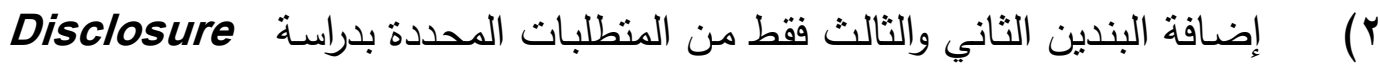
Disclosure principles principle

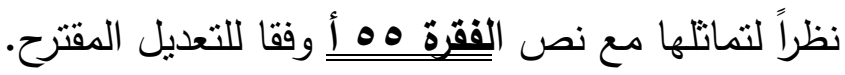

بناعاً علبه تكون الصباغة المقترحة للفقرة هـ أ كما بإي:

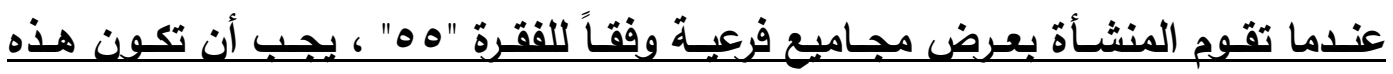

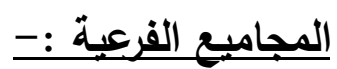

(أ) مكونة من مبالغ لبنود يتم قياسيا وفقاً لمعابير التقرير المالي الدولية.

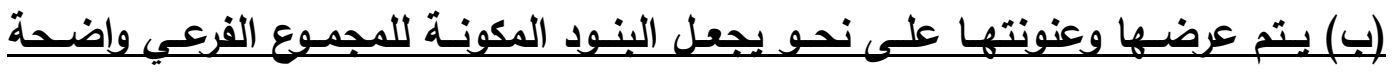
ومفهومة. (ج) لا يتم إيلزانها أكثر من المجاميع الفرعية المجامبع المطلويـة في قائمة المركز المالي وفقاً لمعاييز التقريز المالي الدولية. د) أن تكون مصحوية بشرح في الإيضاحات حول:1- -كيف تقلم معلومات عن مركز وأداء وتدققات الوحيدة. r r أبية معلومات إضافية اخرى تساعد على فهم المجامبع.

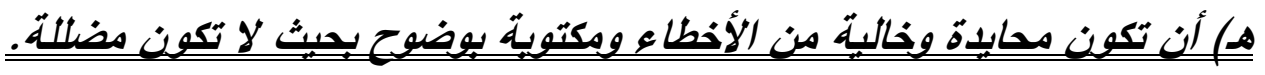


ويعتقد الباحث أن هذه التعديلات ستساعد جدياً على اتساق وثبات عرض الدجاميع الفرعية وقابليتها للمقارنة مع ما يترتب على ذللك من دعم مسنوى ملاعمة المعلومات وكذللك قابليتها

بأولاً: التعدبلات المرتبطة بقائمة (قائمتي) الأرياح أو الخسائر والاخل الثامل الآخر: -

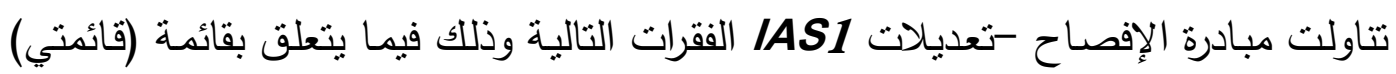

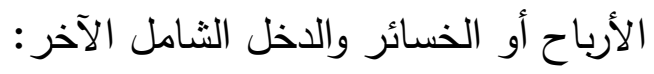

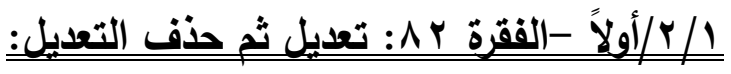
الإصدار الأول:

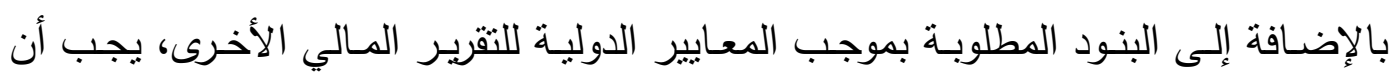

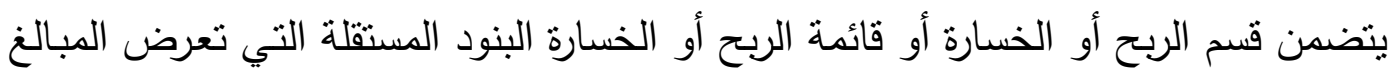
التالية للفترة: - التفن

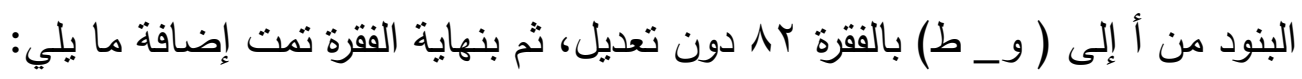

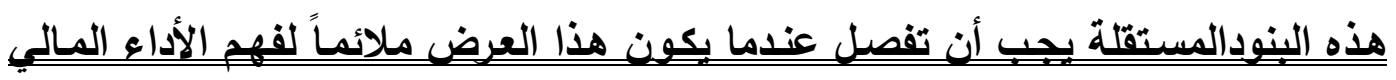
للوحدة

الإصدار النهائي: تم حذف التعديل المقترح وظلت الفقرة كما هي دون تعديل.

\section{تقبيخ وتطوير الفقرة Y A:}

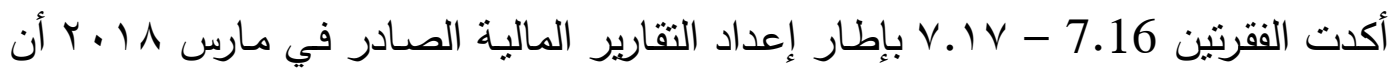

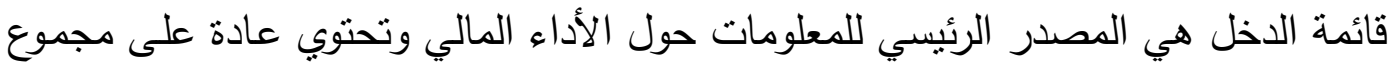

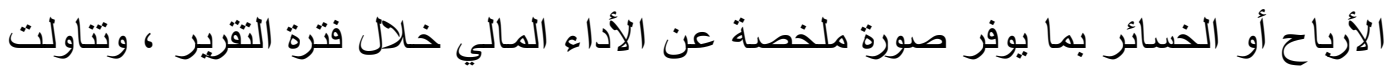

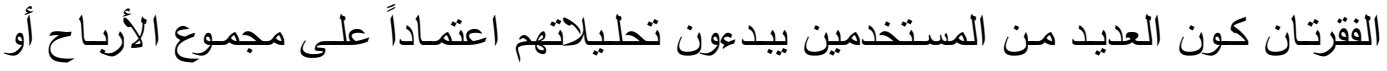

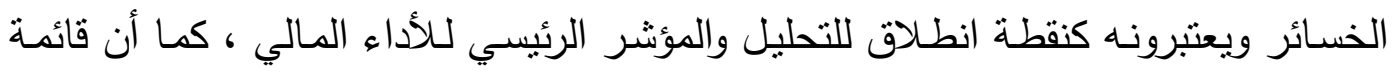
الدخل هي المصدر الرئيسي للمعلومات عن جميع الإيرادات والمصروفات ويجوز استثناء

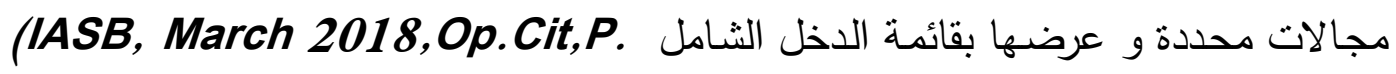
- rNI - 
(76) ، وفيما يتعلق بالتعديل على الفقرة به فإن الإصدار النهائي للفقرة تضمن إصدارها

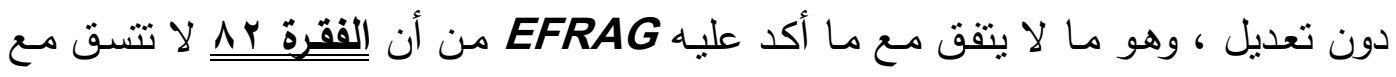

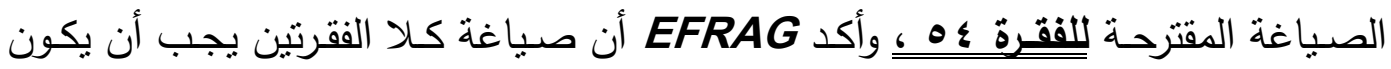

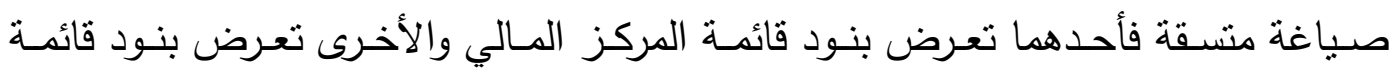
(EFRAG, July 22. 2014, Op.Cit, P. 7) الدخل

وبناءاً عليه يقترح الباحث التعديلات التالية على الفقرة به لتنكون متسقة مع صياغة الفقرة $-: \underline{\underline{0 \leqslant}}$

بدايـة الفقـرة بـ عبارة (بالإضـافة إلى البنود المطلوبـة بموجب المعـيير الدوليـة للتقرير المالي الأخرى) وهي عبارة لم ترد في الفقرة ؛ـهـ ولذا ولضمان انساق الفقرتين يقترح

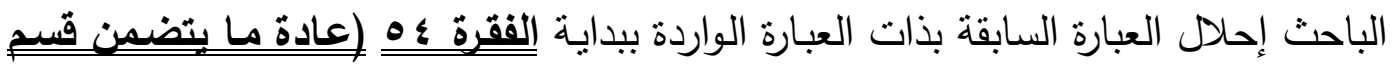

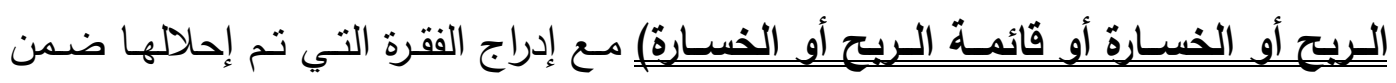

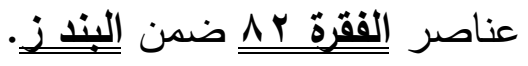

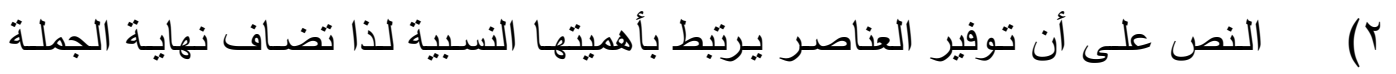

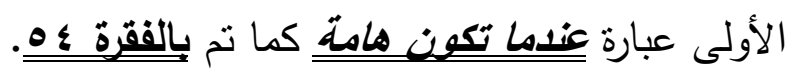

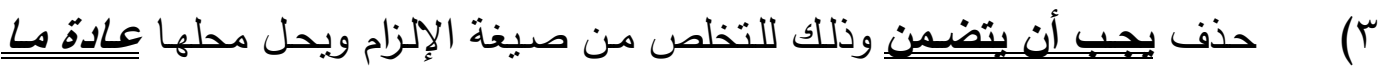
بشتىل.

ع) عقب العناصر المقترحة كمكونات للقائمة يتم إضـافة ذات العبارة المقترحة بنهاية

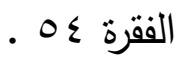

بناعاً عليه تكون الصبياغة المقترحة للفقرة ب م كما بلي.

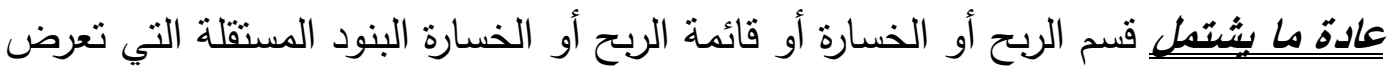
المبالغ التالية للفترة عندما تكون هامئة : -

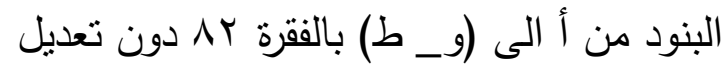

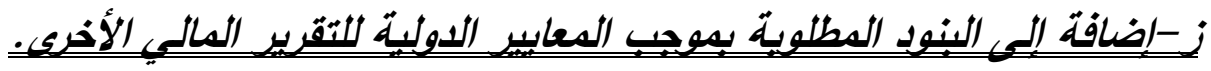

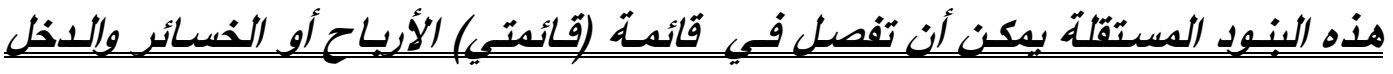
الشامل الآخر إذا كان هذا العرض هو الأسلوب الأكثر فاعلبة لتوصيل المعلومات الملائمة - TAY - 


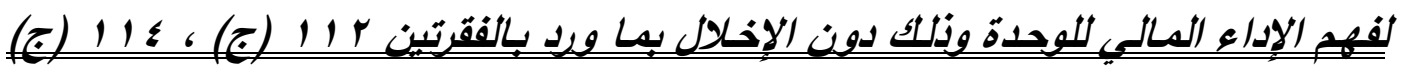
من هذا المعيار.

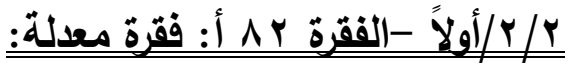 الإصدار الأول:}

يجب أن يعرض قسم الدخل الثامل الآخر البنود المستقلة للمبالغ للإخل الثشامل الأخرفي

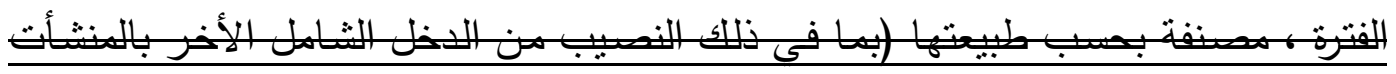

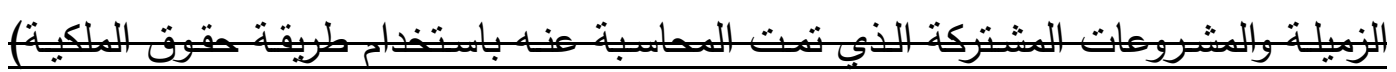

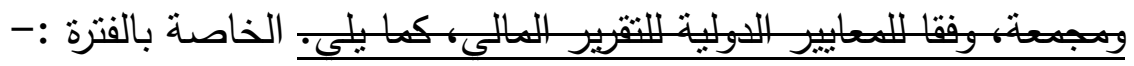

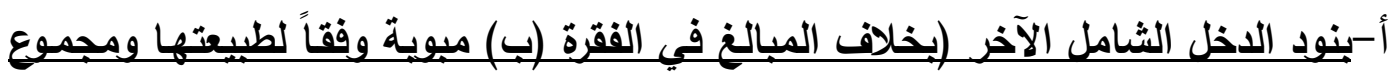
تثلك التي: - أ- (ا) بنود لن يعاد تصنيفها لاحقاً ضمن الربح أو الخسارة.

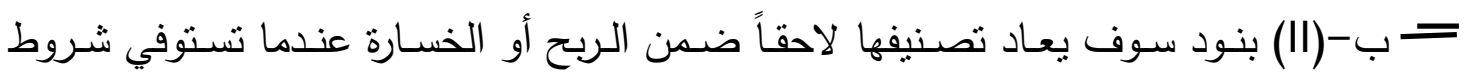
محددة. ب-نصبب المنشأة في الاخل الثامل الآخر من الثركات الثقبقة والمشروعات المشتركة والتي يتم المحاسبة عنها باستخذام طريقة حقوق الملكية ، مع فصل البنود وفقاً لمعاييز التقرير المالي الدولية الأخرى بين: (ا) لن بتم إعادة تبوينها لاحقاً إلى الأرياح أولئي الخسائر. سوف بتم إعادة تبويسها لاحقاً إلى الأرياح أو الخسائر عند تحقق شروط محددة. إلإصدار النهائي: تم إصدار ذات التعديل الوارد بالإصدار الأولى.

\section{تقيبي وتطويرالفقرة}

يعرض قسم الدخل الثـامل صافي تأثير التغيرات المعترف بها على حقوق الملكية خـال

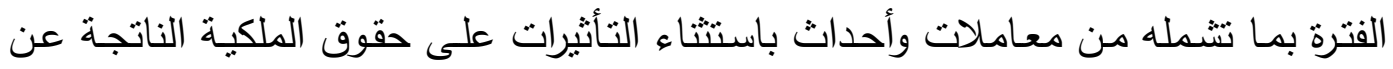
استثمارات الملاك والتوزيعات لهم، وتعكس هذه المعلومات قدرة الوحدة على استخدام الموارد 
(FASB, August, 11, 2016, المتاحة لها بما في ذلك قدرتها على توليد تدفقات نقدية

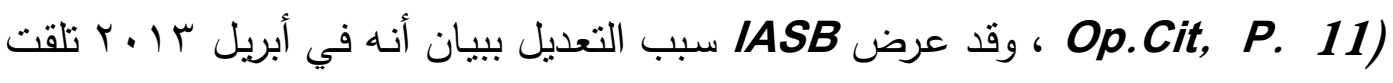

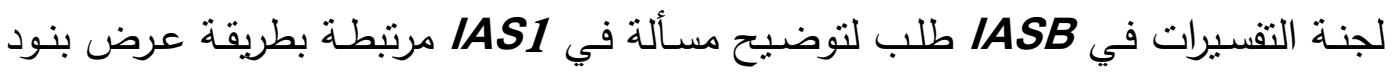
الدخل الثامل من الثركات الزميلة والمشاريع المشتركة عند استخدام طريقة حقوق الملكية ،

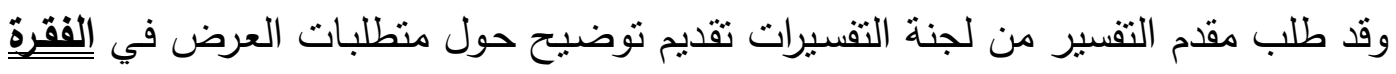

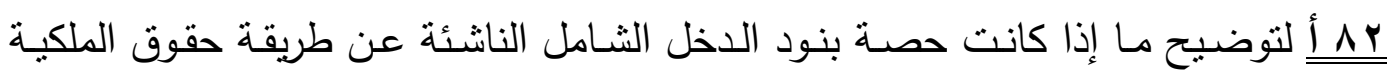

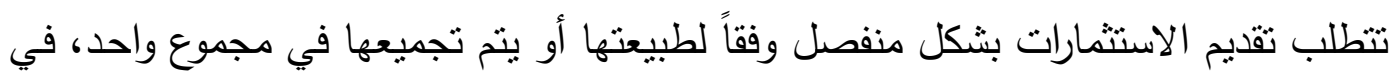

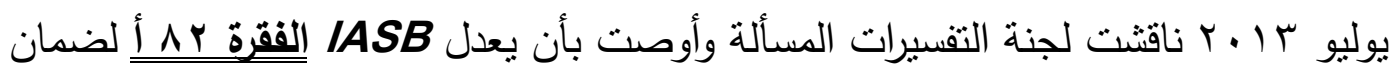

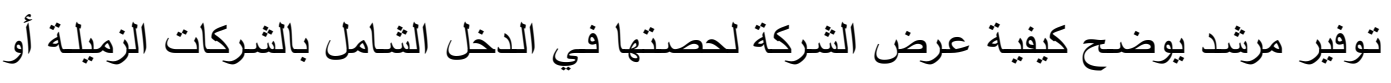

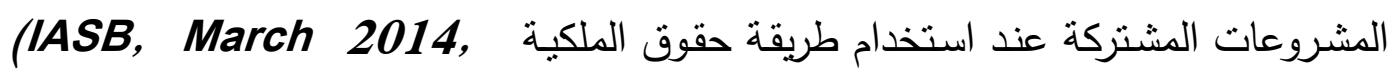
-:Op.Cit, P. 22) أ-ما إذا كانت تللك البنود ستضاف أو لن تضاف في وقت لاحق كربح أو خسارة و ب-العرض كبند واحد داخل تلك التصنيفات.

وقد أكد IASB أن العرض المقترح بالتعديل سيكون أكثر إفادة للمستخدمين وأن عدم اقتراح

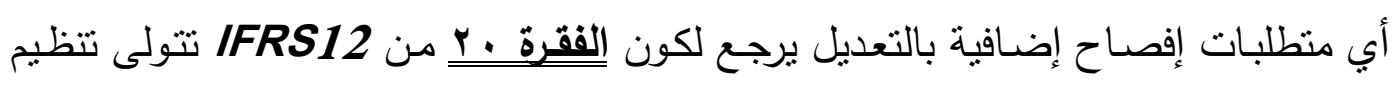

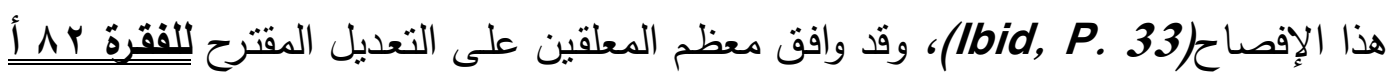
وأظهروا دعم هذه التعديلات لكونها ستحسن من مستوى شفافية التقرير المالي، كما أنها ولها

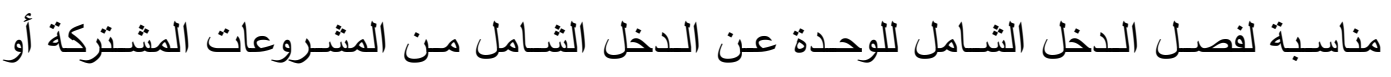
الزميلة(IASB, Sep 2014, Op.Cit, P. 16)، كما أيد كلاً من CFA, AASB) هـذة التعـيلات ، وأكـدوا على دورهـا فـي دعـ شـفافية التقريـر ، Deloitte ، FRC (AASB, Op.Cit, P. 10)(CAF, Aug. 28. 2014, Op.Cit, P. 13) المالي (FRC, July. 7, 2014, Op.Cit, P.p 11 - 12) (Deloitte, July 21. 2014, Op.Cit, P. 5)

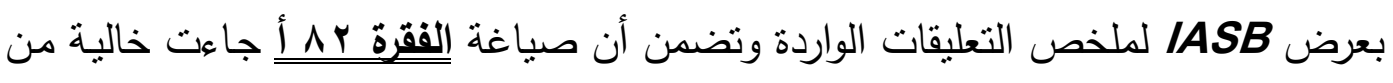

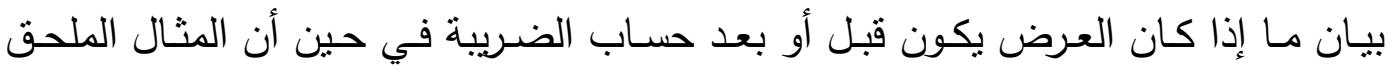

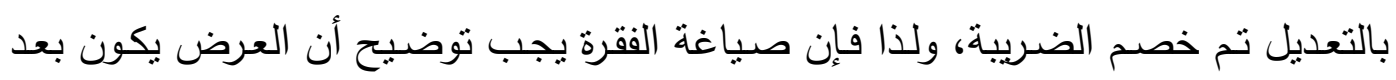




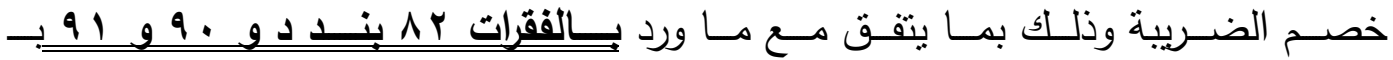
(AASB, Aug. 5. 2014, Op.Cit, P.. 10) (IASB, Sep 2014, .IAS1 وبناءاً عليه يقترح الباحث إضافة عبارة بعد حساب الضريبة للاتفاق OPB. Op. Cit, P. 17)

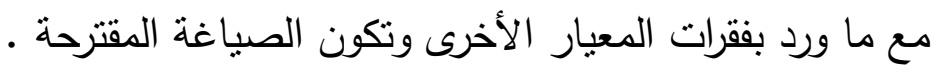

بناعاً تكون الصباغة المقترحة للققرة ب 1 أ كما بليِ. يجب أن يعرض قسم الدخل الثـامل البنود المستقلة للمبالغ التالية الخاصــة بـالفترة بعد

$$
\text { مساب الضربيية : }
$$

أ-بنود الدخل الثنامل الآخر (بخلاف المبالغ في الفقرة (ب) ميوية وفقاً لطيعتها ومجموع تثلك التي: (ا) بنود لن يعاد تصنيفها لاحقاً ضمن الربح أو الخسارة. بنود سوف يعاد تصنيفها لاحقاً ضمن الربح أو الخسارة عندما تسنوفي شروط الخارة محددة.

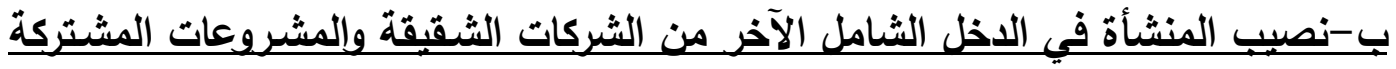

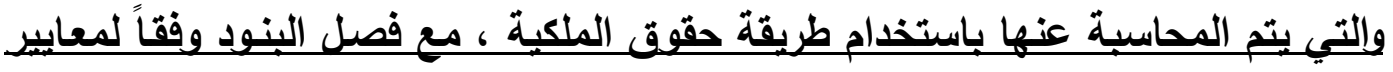
التقرير المالي الدولية الأخرى بين: (ا) لن بتم إعادة تبويبها لاحقاً إلى الأربياح أو الخسائر.

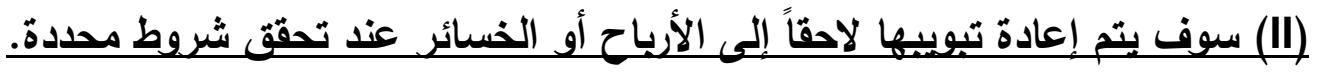

$$
\begin{aligned}
& \text { ب/ץ/ أولاً -الفقرة هم: فقرة معدلة: } \\
& \text { الإصدار الأول: } \\
& \text { الإصدار النهائي: }
\end{aligned}
$$

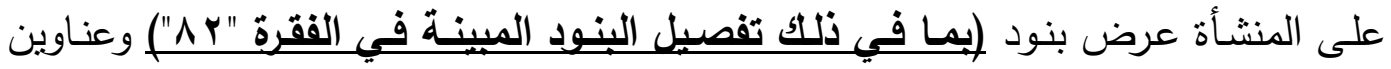

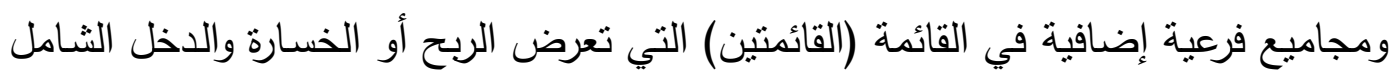
الآخر إذا كان ذلك العرض ملائماً لفهم الأداء المالي للمنشأة.

ويرتبط التعديل الثكلي بالفقرة هـ بالتعديل الوارد بالفقرة هـ أ. 


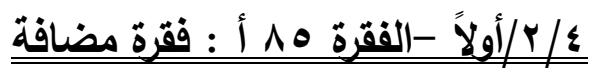
الإصدار الأول: عند عرض الوحدة للمجاميع الفرعية وفقاً للفقرة هـ ، فإن هذه المجاميع الفرعية بحب أن

IFRS أ-تكون مكونة من عناصر يمكن التحقق منها وقياسيها وفقاً لـ

ب-تكون موصوفة بطريقة تجعها مفهومة.

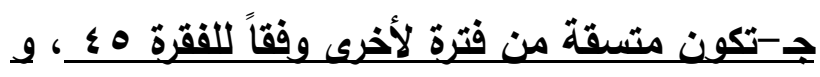

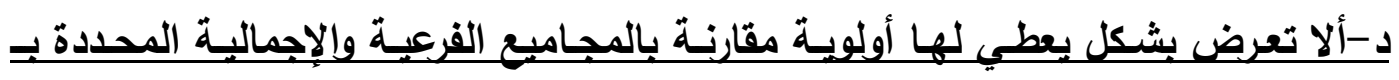
.IFRS

الإصدار النهائي:

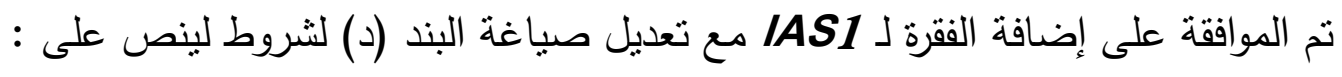

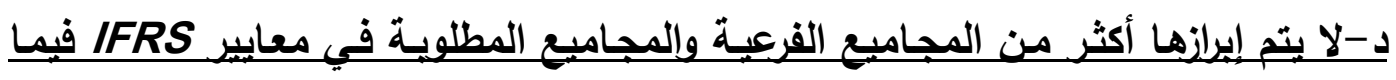
يتعلق بقائمة الأربياح أو الخسائر والدخل الثشامل الآخر.

\section{تقييم وتطوير الفقرة هم أ :}

تتتاول الفقرة توفير مقاييس فرعية بقائمة الدخل وهو ذات الأمر الذي تم تتاوله بـالفقرة هـ أ

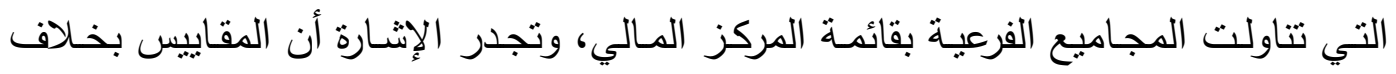

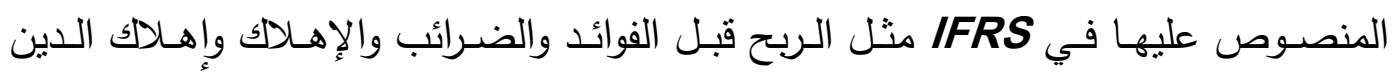
EBITAA

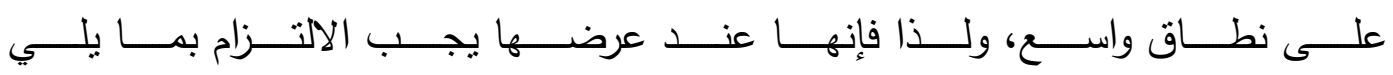
:(EFRAG,Oct,12,2017,P.p.19-20)

$$
\begin{aligned}
& \text { أ-تعريفها بوضوح. } \\
& \text { ب-توضيح الغرض منها. } \\
& \text { ج-الثبات في العرض. } \\
& \text { د-الاستتاد إلى معلومات IFRS عند حسابها. } \\
& \text { هـ-تقهم المستخدمون لسبب حسابها. } \\
& \text { - YAT - }
\end{aligned}
$$

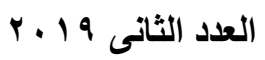

$$
\begin{aligned}
& \text { مجلة المحاسبة والمراجعة }
\end{aligned}
$$


و -ألا يترتب عليها حجب أو إعاقة فهم معلومات IFRS.

وقد أيدت معظم التعليقات السابق عرضها فيما يتعلق بـالفقرة هـ أ إجراء ذات التعديلات

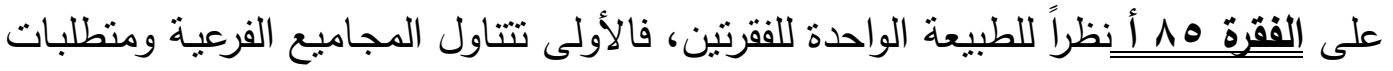

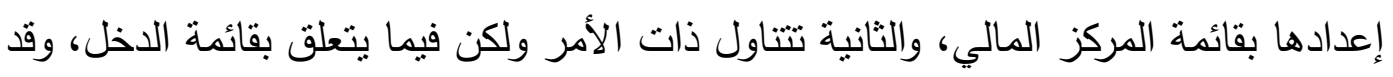

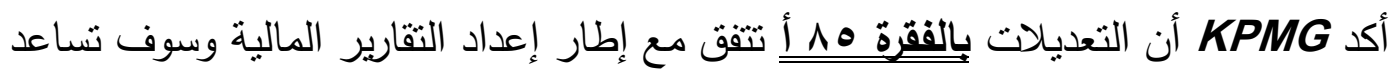

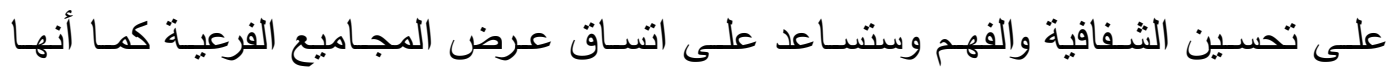

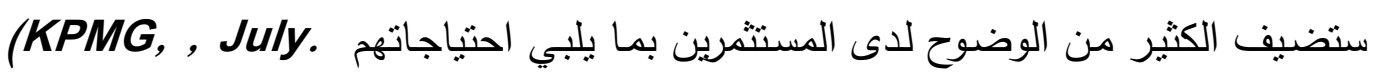
IASB أن تأييد غالبية المعلقين للتعديلات بالفقرة : 10 أ-تقدم منهجية تمنع عرض المجاميع التي لاهي لا داعي لها ب-لا تتجع عرض Non-GAAP Measures التي قد تعطي صورة أكثر إيجابية مقارنة بالمعلومات المطلوبة بموجب المعايير الدولية للإبلاغ المالي

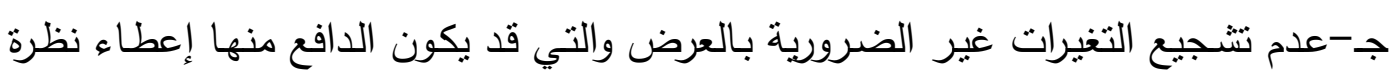
متفائلة للأداء المالي.

وقد تضمن عرض التعليقات تأكيد IASB على أن الكثير من التعليقات تضمنت الحاجة

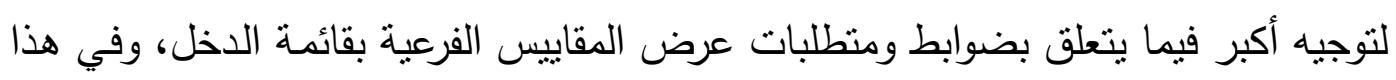

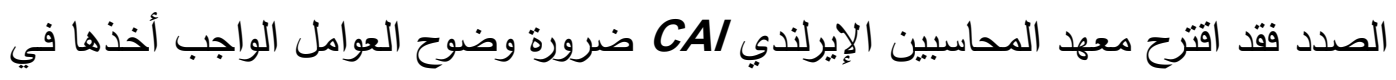

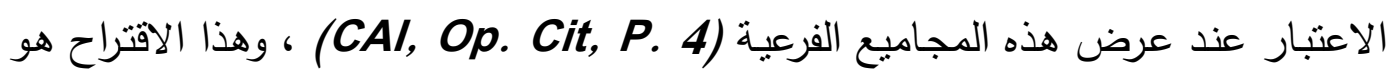

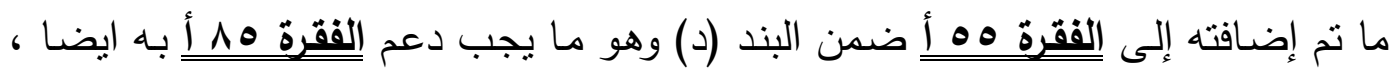

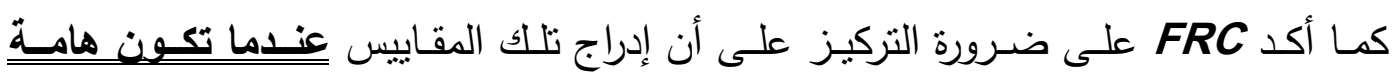
(FRC, July 7, 2014, Op. Cit, P.7)

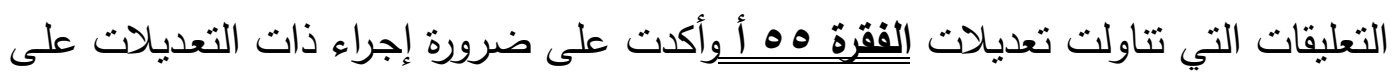

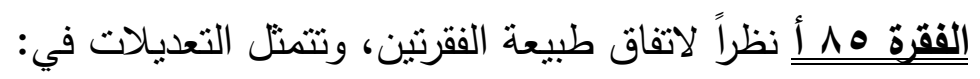

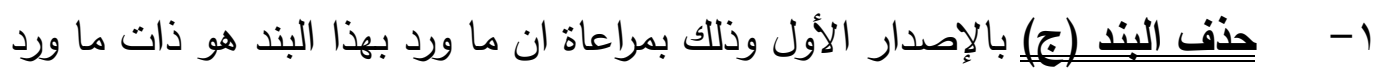

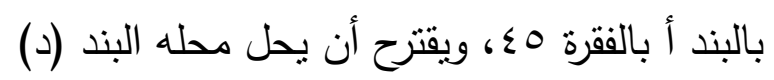

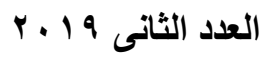
- YAV -

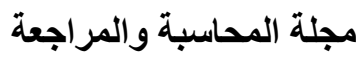


r - - إضافة البندين (د) و (هـ) السابق إضافتهما للققرة هـ أ وذلك بهدف دعم منطلبات إعداد المجاميع الفرعية.

\section{بناء علبه تكون الصباغة المقترحة للفقرة ه1 أ كما بلي :-}

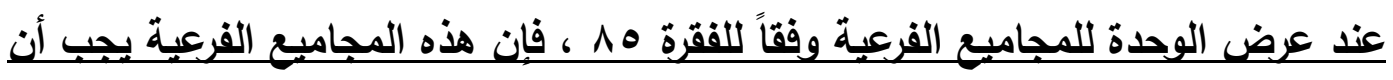

أ- تكون مكونة من عناصر بمكن التحقق منها وقياسها وفقاً لـ IFRS. ب- تكون موصوفة بطريقة تجطلها مفهومة.

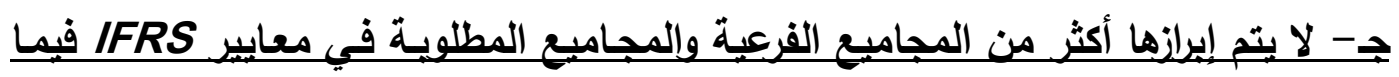

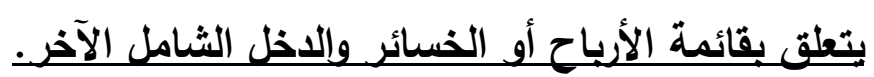

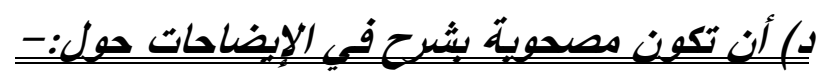
1- -كيف تقلم معلومات عن مركز وأداء وتدفقات الوحيدة.

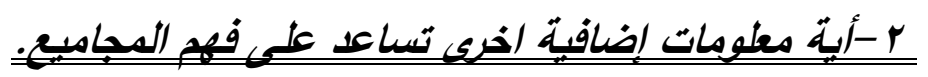
هـ أن تكون محابِة وخالية من الأخطاء ومكتوية بوضوح بحيث لا تكون مضلية.

ويعتقد الباحث أن هذه التعديلات ستكفل إلى حد كبير اتساق عرض هذه المجاميع الفرعية

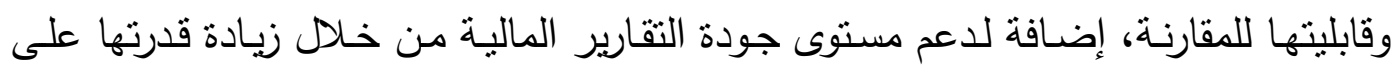
تلبية احتباجات مستخدميها.

$$
\text { الإصد/ب/أولاً -الفقرة هـ ب ب : فقرة مضافة: }
$$

يجب على المنثـأة عرض البنود في قائمسة (قائمتي) الربح أو الخسـارة واللاخل الثـامل

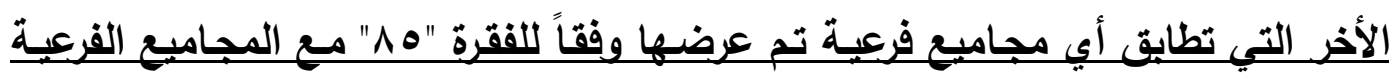
والأجماليات المطلوية وفقا للمعايير الدولية للتقرير المالي لهذئة القوائم. 
تم الموافقة على إضافة الفقرة لـ IAS1

$$
\text { تقييم وتطوير الفقرة هم ب: }
$$

أكد مجلس معايير المحاسبة الاسترالي أن التطابق المطلوب بـالفقرة هـ بـ يوفر معلومات

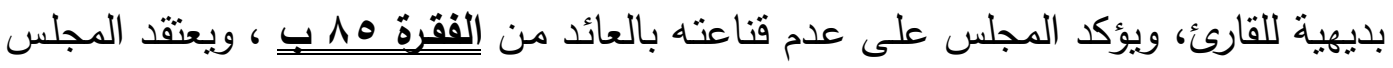
ضرورة تعديلها بما يتيح للوحدة القدرة على إصدار حكم مهني حول الحاجة للمطابقة علما باليا

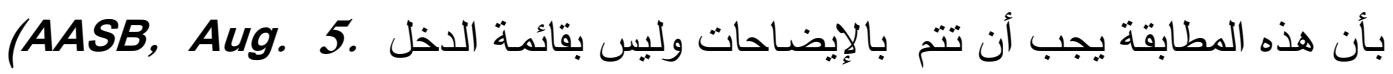
2014, Op. Cit, P.p. 8 - 9) (ICAEW, July 2014, الفعال مع المستخدمين تحتم عرض هذا التوافق في الإيضاحات

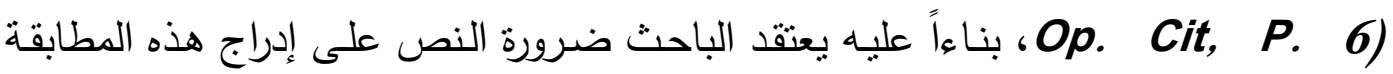

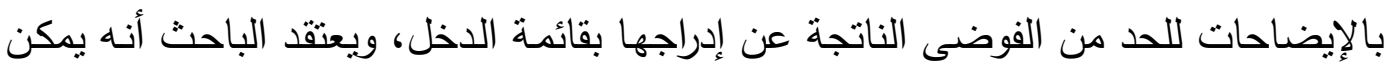
تحقيق هذا الهذف من خلال استبدال الصياغة الحالية :

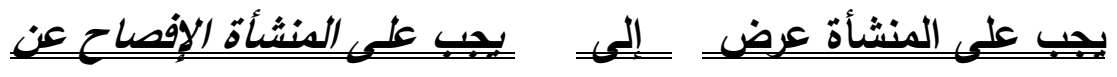

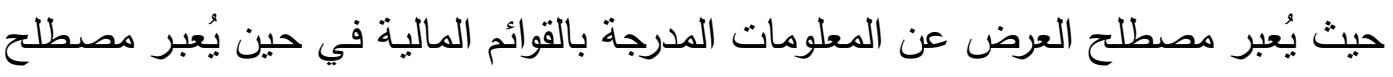

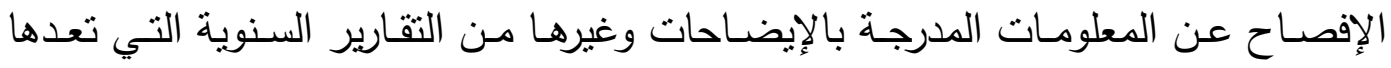
الإدارن(IASB, March 2014, Op. Cit, P.17)

بناءاً علبه تكون الصباغة المقترحة للفقرة ه1 ب كما بلي ؛ يبب على المنشأة الافصاح عن البنود في قائمة (قائمتي) الربح أو الخسارة واللخل

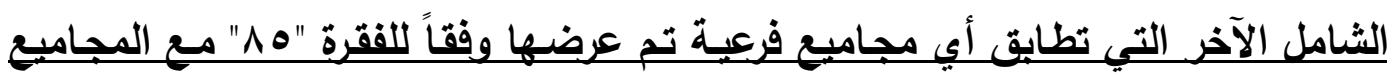
الفرعية والإجماليات المطلوية وفقا للمعايير الدولية للتقريـ المالي لهيذة القوائع.

بَ/ أولًا: التعديلات المرتبطة بالإيضاحات:

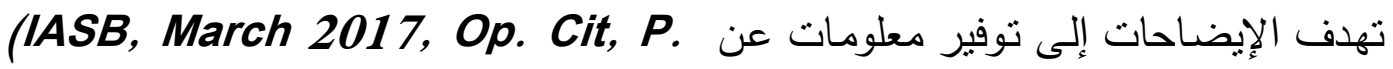

أ-طبيعة العناصر المعترف بها وغير المعترف بها والمخاطر الناشئة عنها. 
ب-الأساليب والافتراضات والأحكام والتغيرات في تلأك الأساليب، الافتراضات والأحكام التي تؤئز على المبالغ المعروضة أو المفصح عنها. ج-المعاملات والأحداث التي حدثت بعد نهاية الفترة إذا كانت ضرورية لنح لتحقيق هدف القوائم

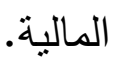
د-معلومات مستقبلية حول المعاملات أو الأحداث المحتملة أو المستقبلية. هـ-معلومات مقارنة حول الفترات السابقة. وقد تتاولت التعديلات الواردة بمبادرة الإفصاح-تعديلات IAS1 فيما يتعلق بالإيضـاحات

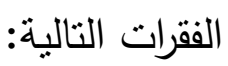

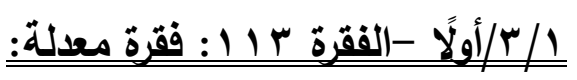
الإصدار الأول:

يجب على المنشأة أن تعرض الإيضاحات بطريقة منظمة ما أمكن ذلك عمليا .ويجب على لئح

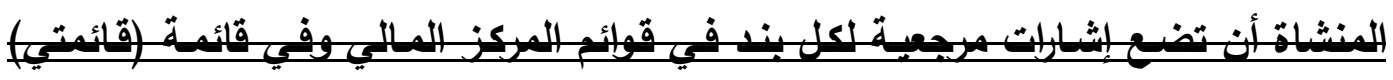

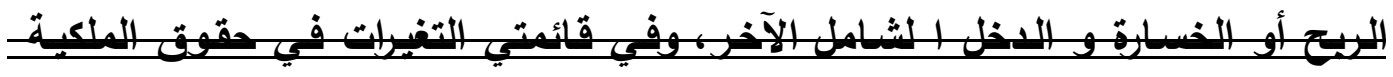

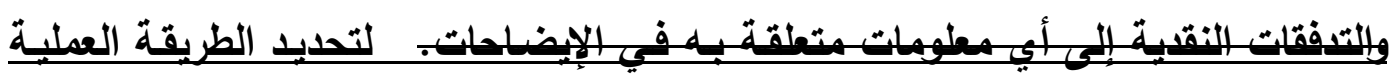
يب على المنشأة أن تأخذ في الاعتبار الأثر على قابلية القوائم المالبة للفهِ والمقارنة.

الإصدار النهائي: يجب على المنشأة أن تعرض الإيضـاحات بطريقة منظمة، مـا أمكن ذللك عملياً، لتحديد الطريقة العملية يجب على المنثأة أن تأخذ في الاعتبار الأثر على قابلية القوائم المالبية للفهـ والمقارنـة.ويجب على المنشأة أن تضع إثـارات مرجعية لكل بند في قائمسة المركز

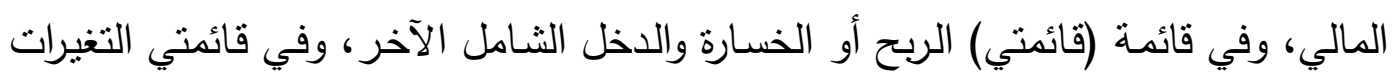
في حقوق الملكية والتدفقات النقدية إلى أي معلومات متعلقة به في الإيضاحات.

\section{تقييم وتطوير الفقرة س 11:}

يلاحظ أنه بالإصــار الأولِى تم حذف مـا يتعلق بالإثـارات المرجعيـة التي نتشير لإدراج

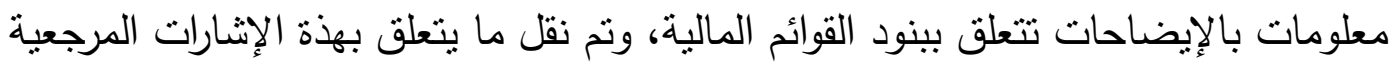

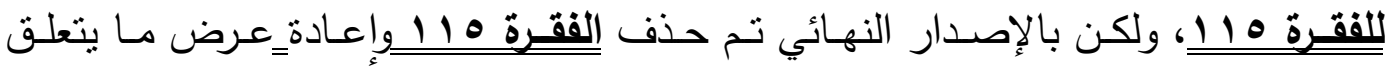


بالإثـارات المرجعية للفقرة س ال1ه وقد أكد CFA على الحاجة إلى دعم وتعزيز استخدام

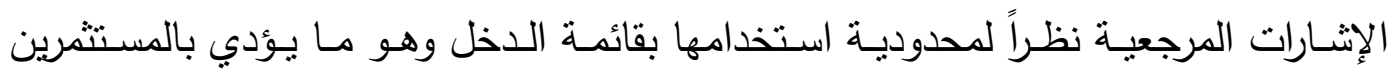
لمواجهة صعوبة في التوفيق بين معلوماتها والمعلومات الواردة بالإيضاحات

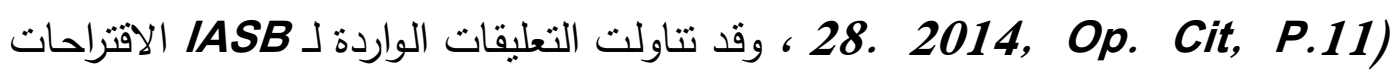

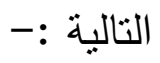

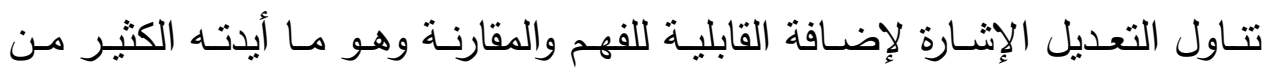
التعليقات ، ويؤيد الباحث ما عرضـا EY من أن الرغبة في دعم القابلية للفهم قد تصطدام

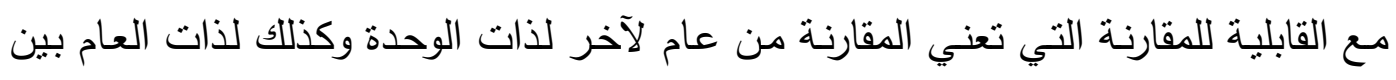

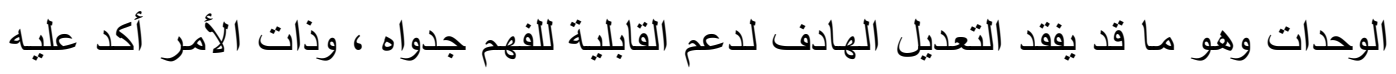
IASB

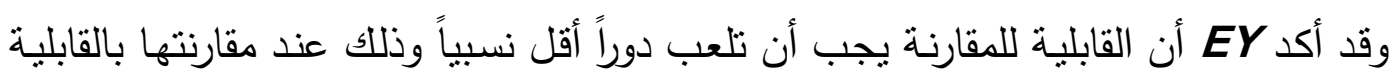
للفهم فالأولوية يجب أن تكون للقابلية للفهم. (EY, Jul 23, 2014, Op. Cit, P. 4)، وقد وردت ذات الملاحظة ضمن ملخص التعليقات الصادر عن IASB حيث طالب الكثير

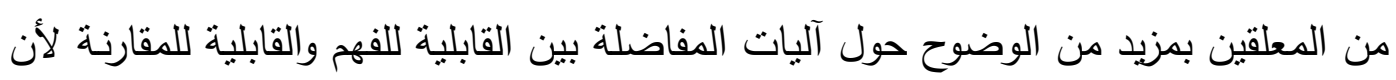

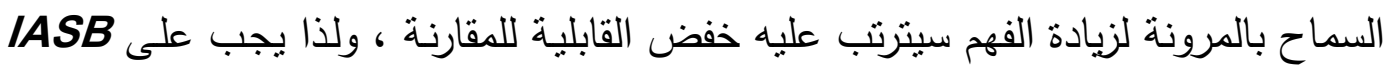

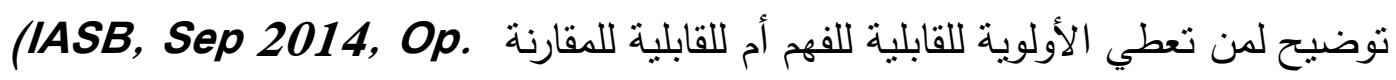
( Cit, P.p. 12 - 13)

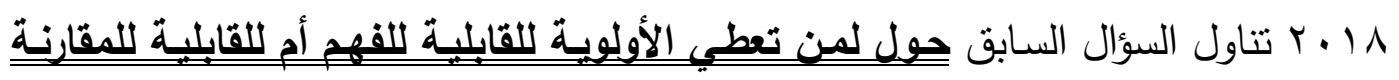

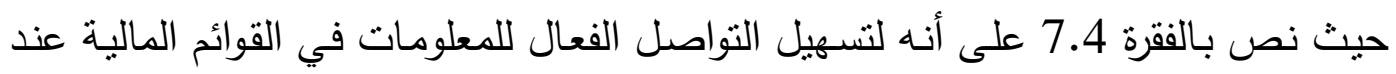

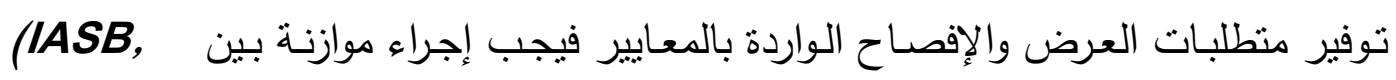
:March 2018, Op. Cit, P. 74) أ-إعطاء الوحدة المرونـة لتقديم معلومات ملائهـة ومعبرة بشكل صادق عن أصول الوحدة

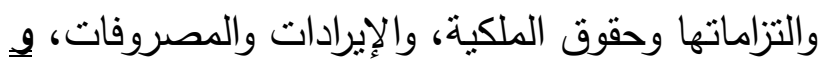

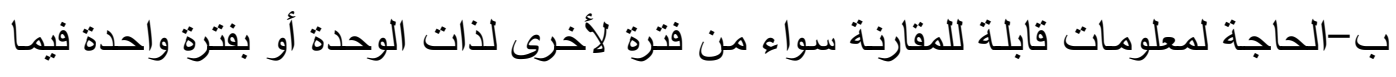
بين الوحدات. 
ويعتقد الباحث أن هذه الموازنـة المطلوبـة لم نظهر الأولويـة لمن للقابلية للفهم أم القابليـة

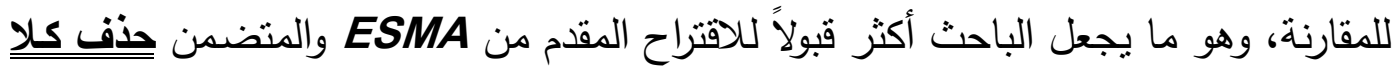

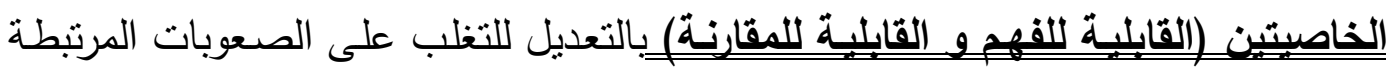

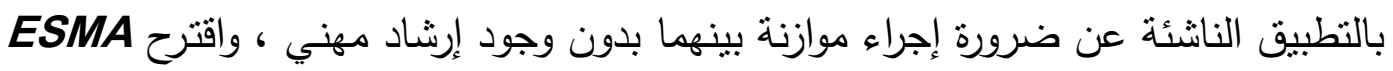

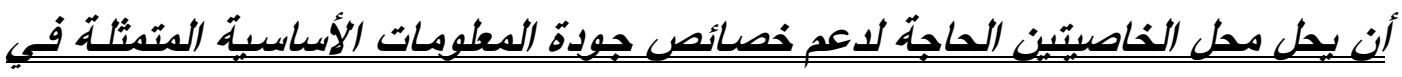
الملاعمة والثتعبير الصادق (ESMA, June 23. 2014, Op. Cit, P.5).

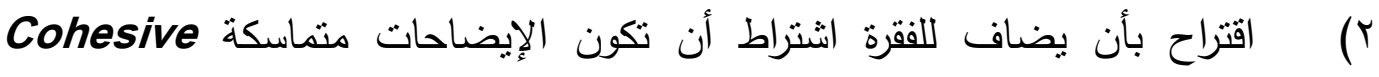

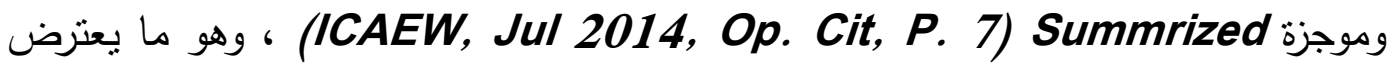
عليه الباحث اعتماداً على ما سبق ذكره بالمقترح السابق من الإثارة لتفعيل دور الخصائص النوعية للمعلومات عند إعداد الإيضاحات وهو ما سيكلل تحقق التماسك والإيجاز .

r) اقتراحات محدودة تتتاول ضرورة إدراج جدول محتويات (فهرس) قبل الملاحظـات لإعطاء لمحة سريعة لعناصر الإيضـاحات لتسـيل الوصول للإيضـاح الذي يرغبه القارئ (IASB, Sep 2014, Op. Cit, P. 13) لإدراجه بالفقرة باعتباره تعديل شكلي غالباً ما يتواجد بالتقارير المصدرة فعلاً.

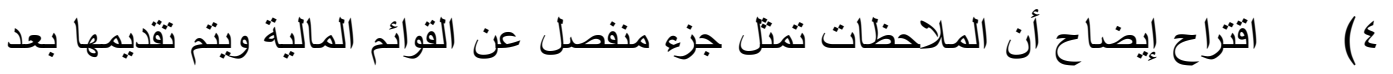
القوائم المالية. (ESMA, June 3, 2014, Op. Cit, P. 6)، ويتفق الباحث مع هذا عذات التعديل وسيرد بيان أهميـة هذا الفصل بين القوائم المالية والملاحظـات ضمن التعديلات المقترحة من الباحث على IAS1 والتي لم ترد في المبادرة.

بناءاً علبه تكون الصباغة المقترحة للققرة س ال كما بلي:

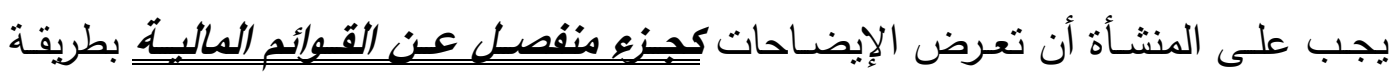

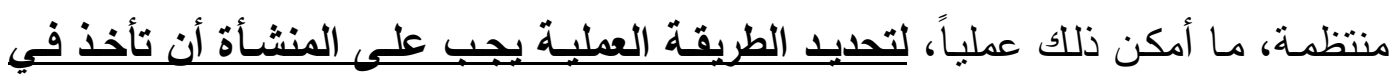

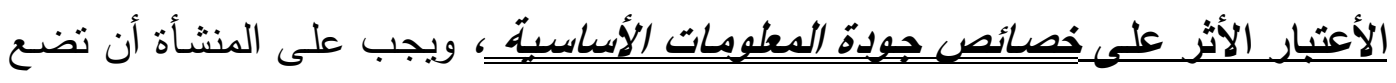

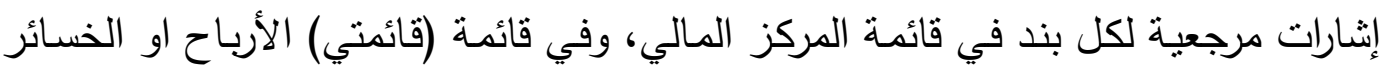


والدخل الثـامل الأخر ، وفي قائمتي التغيرات في حقوق الملكية والتدفقات النقدية إلى أي معلومات متعلقة به في الإيضاحات.

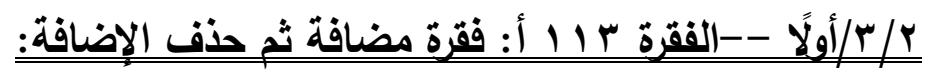
الإصدار الأول:

عند تحديد النظام المنهجي لعرض الإيضـاحات بجب إعطاء الأولويـة للإفصـاحات التي

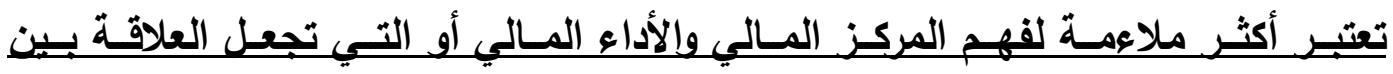
الإفصاحات مفهومة، على سبيل المثال بمكن للمنثأة تنظيم الإبضاحات بجمع الإيضاحات

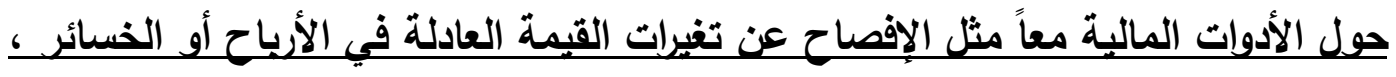

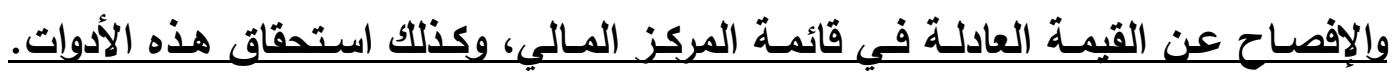
تجميع الإيضاحات بهذه الطريقة سوف بجعل العلاقات بين أنواع المعلومات المفصح عنهيا

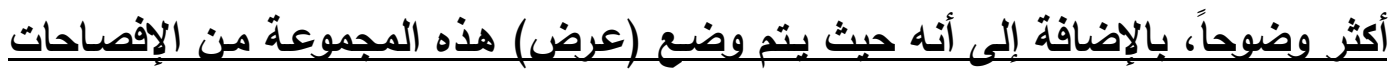
في القوائم المالبة بمكن تحدبد كيف تنظر الثركة للأهمبة النسيبة للأدوات المالبية كأداة لفهم المركز المالي والأداء المالي. الإصدار النهائي: تم حذف الفقرة ولم تدرج ضمن التعديلات النهائية على IAS1 تقييم وتطوير الفقرة س ا I أ :

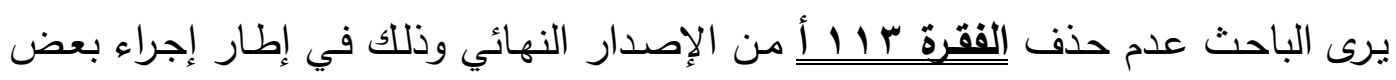

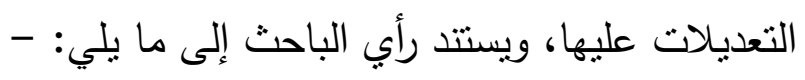

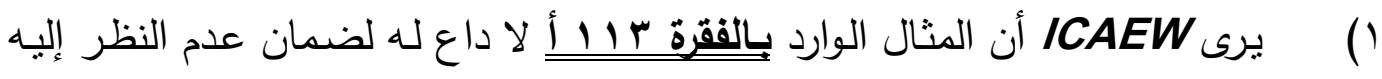
(ICAEW, July 2014, Op. باعتباره تطبيق إلزامي بتجميع ملاحظات الأدوات المالية لئل .Cit, P.6)

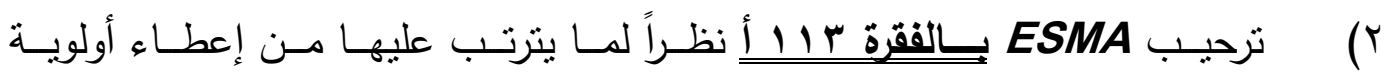

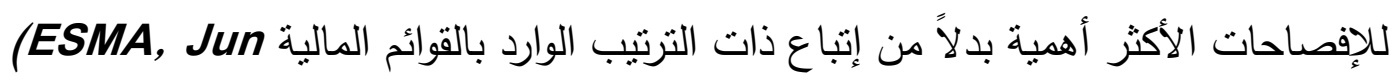
.23. 2014, Op. Cit, P. 5) - rqT L 


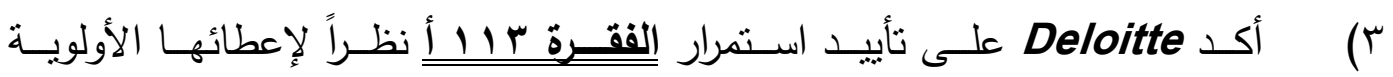

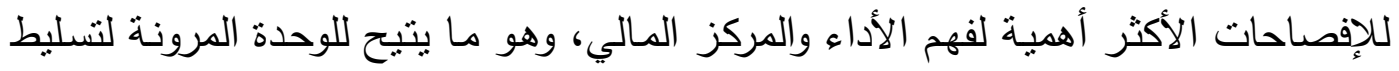

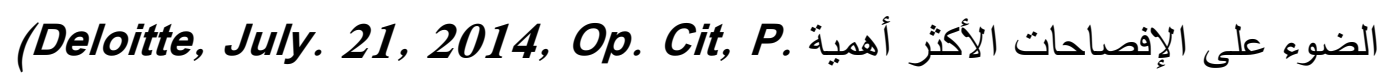

في إطار ما سبق يقترح الباحث عدم حذف الفقرة س ب11 11 أ بالإصدار النهائي وأن تستمر كفقرة بـ IAS1 نظراً لتنأييد معظم التعليقات لها نظرا لدورها في بيان عدم وجود نموذج ملزم

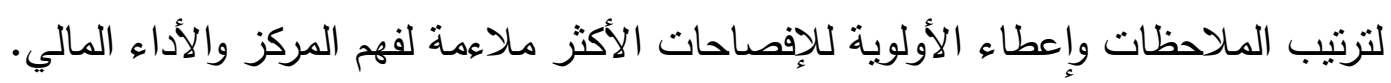

بناعاً علبه تكون الصباغة المقترحة للفقرة س 11 أ كما بإي:

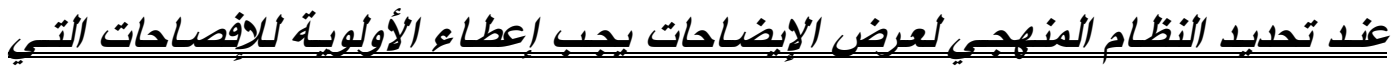

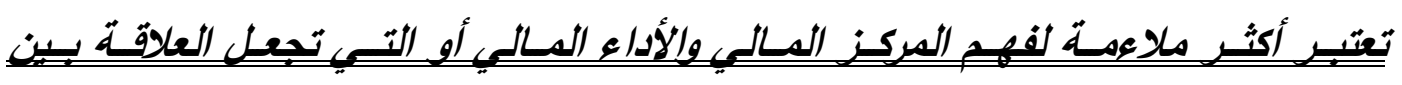
الإفصاحات مفهوية.

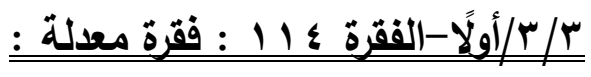
الإصدار الأول:

بدلا من ذلك، عند تحديد النظام المنهجي لترتيب الملاحظات، يجب أن تعرض المنشأة =

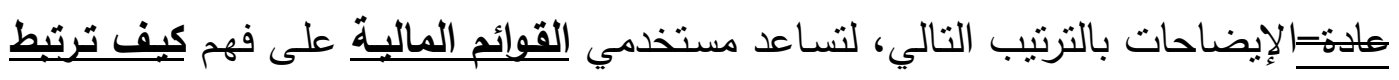

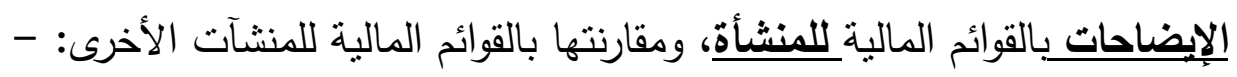
أ-بيان بالالتزام بالمعايير الدولية للتقرير المالي (انظر الفقرة 7 (1).

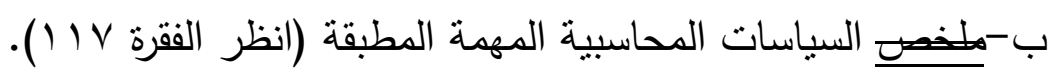

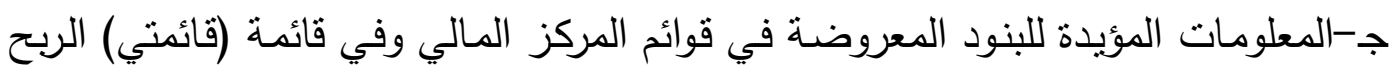

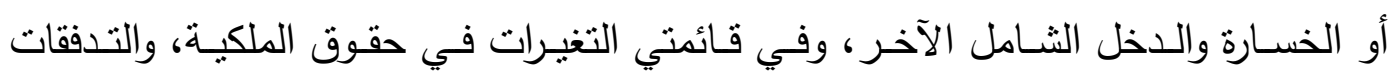

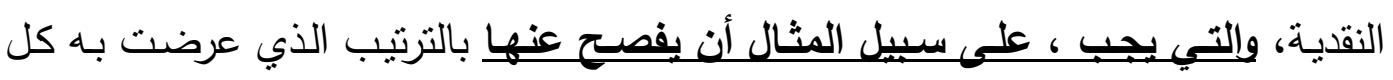
قائمة وكل بند مستقل

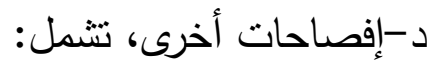


1-الالتزامـات المحتملـة (انظـر معيـار المحاسبة الدولي Vr) والارتباطـات التعاقديـة غير المثنتة. ץ-الإفصـاحات غير الماليـة، مثل أهداف وسياسـات إدارة المخاطر المالية للمنشـأة (انظر

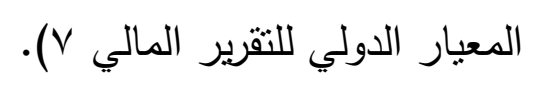

الإصدار النهائي: تثمل الأمثلة علي الترتيب المنظم أو تجميع الإيضاحات ما بليـيـ

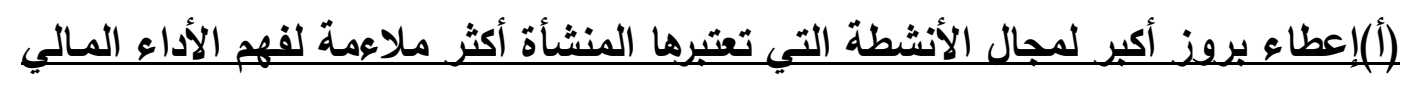
والمركز المالي، مثل تجميع المطومات مع بعضها عن أنثطة تثثغلية معينة؛

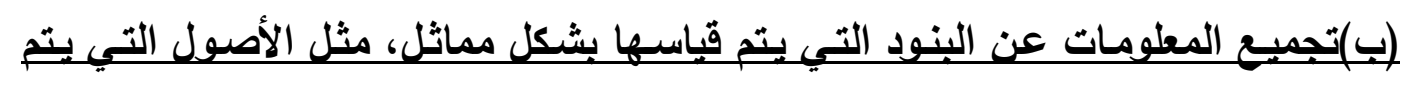

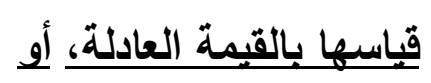
(ج)|تبـاع ترتبـب البنـود في قائمـة (قائمتي) الأربـاح أو الخسـائر واللـخل الثـامل الأخر وقائمة المركز المالي، مثل: (i) فقرة نوضح الالتزام بنطبيق المعايير الدولية للتقرير المالي (انظر الفقرة "ج ا").

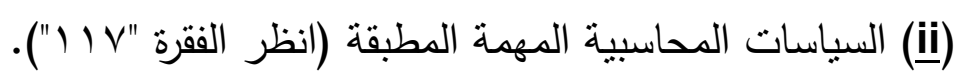
(اiii)

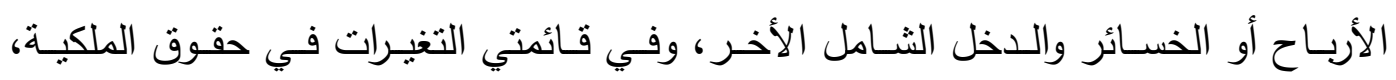
والتدفقات النقدية بالترتيب الذي عرضت باته وله كل قائمة وكل بند مستقل. (د)-إفصاحات أخرى، تشمل ما يلي: (1) -الالتزامات المحتملة (انظر معيار المحاسبة الدولي 37) والارتباطات التعاقدية غير المثنتة؛ (r) -الإفصـاحات غير الماليـة، مثل أهداف وسياسات المنشأة في إدارة المخاطر المالية

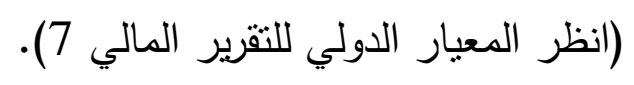

تقبيم الفقرة ك

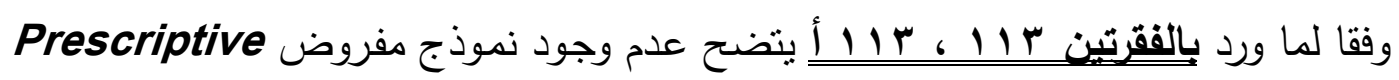
عند توفير الإيضاحات وهو ما يعتبر أمر على درجة مرتفعة من الأهمية باعتباره ينزع صفية

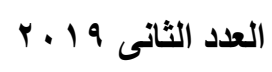
- r90 _

مجلة المحاسبة والمراجعة 


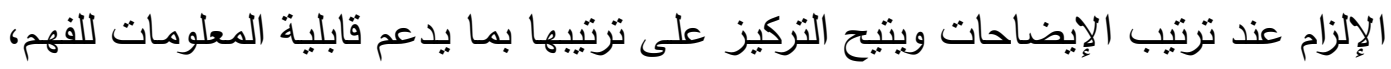

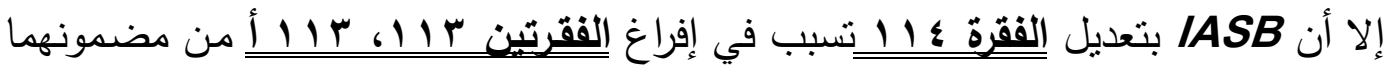

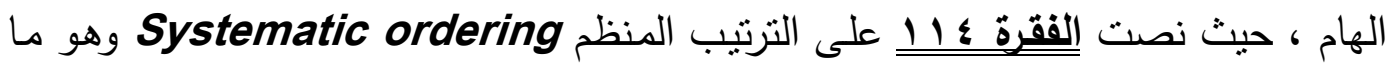

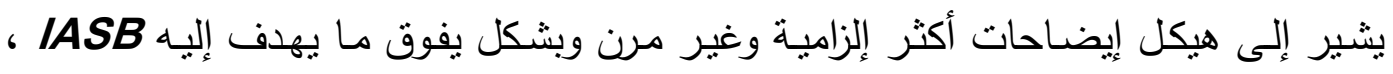
وبالتالي فإن حذف هذه العبارة الترتبب المنظ Systematic ordering سيؤدي لتجنب

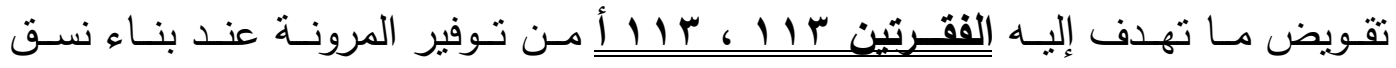

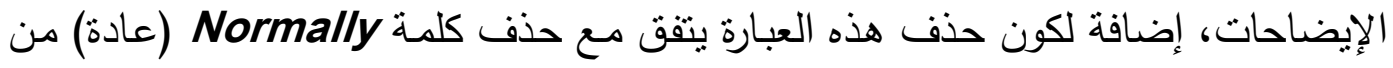

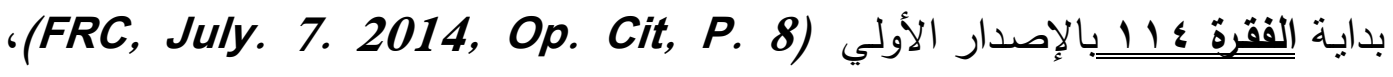
وذات الأمر تتاولته الكثير من التعليقات التي أوردها IASB حيث ألكد المعلقون أن الطريقة .

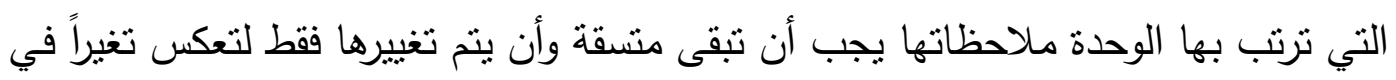

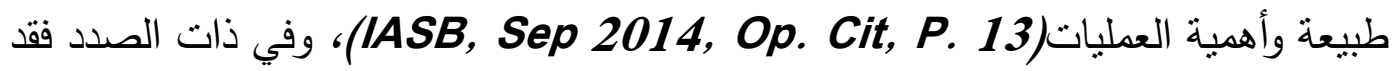

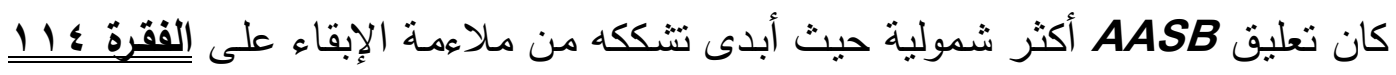

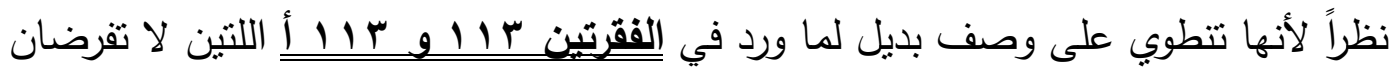

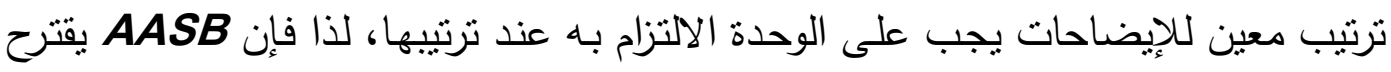

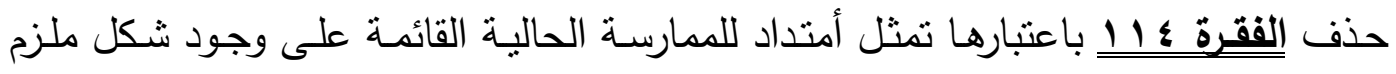

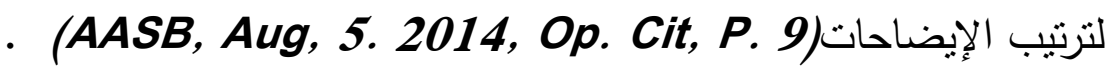

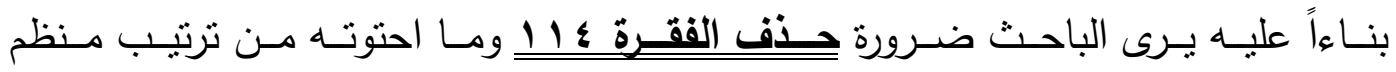
Systematic ordering وس 11 1أ المتمثل في التخلي عن صيغة الإلزام عند تحديد ترتيب الإيضـاحات، والاتجاه لترتيبها بما يلبي احتياجات المستخدمين ويدعم مسنوى تحقق الخصائص النوعية لجودة

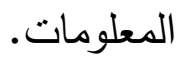

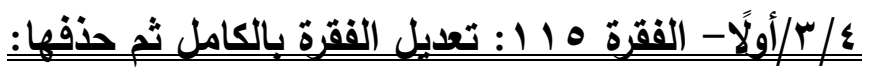
الإصدار الأول: 
يجب على المنشأة توفير إثشارات مرحية لكل بند معرض في قائمة المركز المالي وقائمة

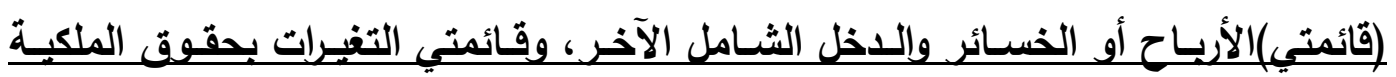
والتدفقات النقدية، وذلك إلى أي معلومات ذات صلة بالإيضاحات. الإصدار النهائي: تم حذف التعديل وحذف الفقرة الأصلية بالكامل.

تقييم الفقرة تضمنت الفقرة هـ 11 بالإصدار الأول الربط بين معلومات القوائم المالية وما يرتبط بها من

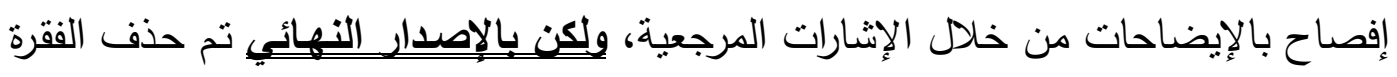
110 برتبط بها من إفصاح بالإيضـاحات من خلال الإثـارات المرجعية، ويالتالي يؤئيـا الباحث

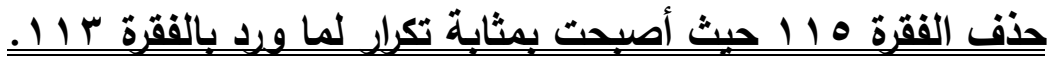

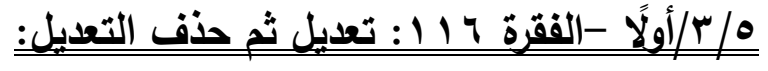
الإصدار الأول:

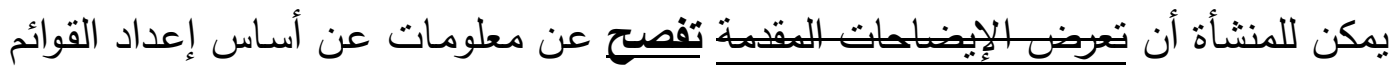
المالية، وعن سياسات محاسبية محددة كايضاحات في قسم منفصل بالقوائم المالية أو كجزع العادئ من الإيضاحات. الإصدار النهائي: تم حذف التعديل المقترح وظلت الفقرة كما هي.

تقييم الققرة 119: يؤيد الباحث استبدال كلمة عرض بكلمة إفصاح وفقاً للحاجة لضبط المصطلحات المستخدمة بالمعيار حيث أن ما يدرج بالإيضاحات هو إفصاح وليس عرض، ولكن بلكن بحد من القدرة

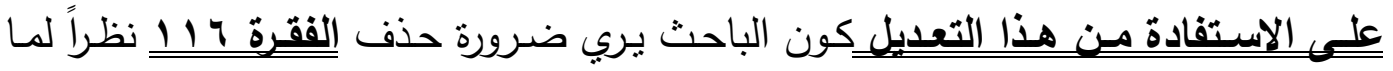
تضمنته من السماح بالإفصاح عن جزء من السياسات بشكل منفصل عن باقي السياسات

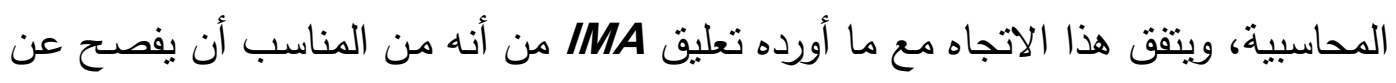

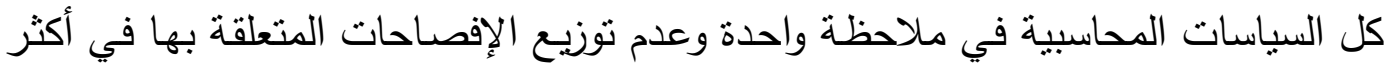

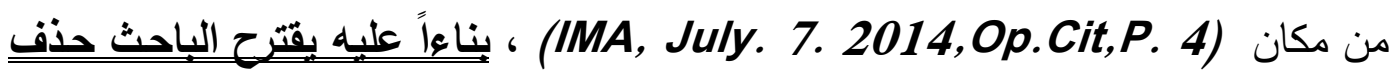


الفقـرة 1111 لضـمان عـرض مـا يتعلـق بالإفصـاح عن السياسـات المحاسبية بفقرة واحدة بالإيضـاحات منعـاً لتشـتت قـارىء الإيضـاحات وفقـاً لمـا سـيرد إيضـاحه في الجـزء التـالي بالبحث.

\section{ع /أولًا: التعديلات المرتبطة بالإفصاح عن السباسات المحاسبية :}

يمثن الجزء الخـاص بالسياسـات المحاسبية الوارد بالإيضـاحات واحداً مـن الأجزاء المفيدة للغاية بالنسبة للمستثرين، وهو ما بحتم أن يتم إعداد هذا الجزء بقدر عال من الدقة وذلك لك

(CFA, بما يكفل توفير معلومات للمستثرين عن السياسات الهامة التي تتبعها الوحدة Aug 28. 2014 Op.Cit,P. 12) الأعمـال تحتم تبنـي اتجاه أكثر انفتاحـاً فيمـا يتعلق بالإفصـاح عن السياسـات المحاسبية، ويرتبط تحقق هذا الاتجاه بكون المعلومات عن السياسات المحاسبية المفصح عنها معلومات محدة (خاصة بالوحدة) ومتسمة بالملاعمة بعيداً عن الطول الهائل لهذه المعلومات إضافة لضـرورة تجنب تكرار الإفصـاحات مـن سـنة لأخـرى لمـا يترتب على هذا التكـرارمن منـع المستخدمين من الإستفادة من هذة المعلومات على نحو فعال ,ICAEW, July 2014

.Op.Cit,P. 7)

وقد تتاولت التعديلات الـواردة بمبـادرة الإفصـاح-تعديلات IAS1 فيمـا بتعلـق بالسياسـات المحاسبية الفقرات التالية: - الماتية

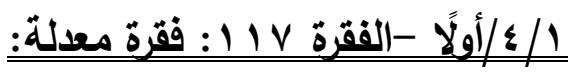
الإصدار الأول:

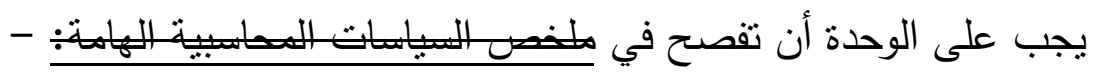
أ-أساس (أو أسس) القياس المستخدم في إعداد القوائم المالية. ب-السياسات المحاسبية الأخرى المستخدمة والتي تكون ملائمة لفهم القوائم المالية. الإصدار النهائي:

يجب على المنشأة أن تفصح في ملخصل عن سياساتها المحاسبية الهامة لنشمل: أ-أساس (أو أسس) القياس المستخدم في إعداد القوائم المالية. ب-السياسات المحاسبية الأخرى المستخدمة والتي تكون ملائمة لفهم القوائم المالية. $-r 91$. 


\section{تقبيم وتطوير الفقرة \\ 1-}

يراعى أن الإصدار الأولي للفقرة IV حلف كلمة (الهامـة) في حين أن الإصدار النهائي

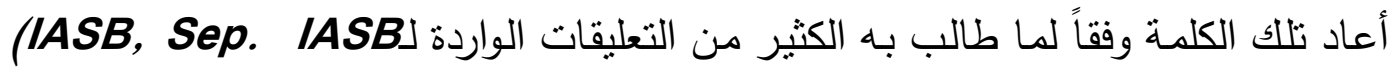
2014, Op.Cit,P.15)

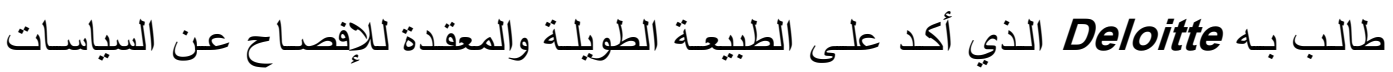
المحاسبية وهو ما يحتم إعطاء الأولوية للتركيز على السياسات الهامة وهوما سيكون أكثر ملاءمة للمستخدمين(Deloitte, Jul. 21, 2014, Op.Cit,P..p. 4 - 4 (D)، ويعتقد

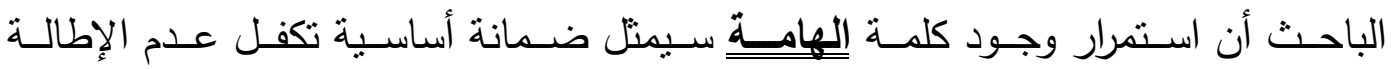
بالإفصاحات عن السياسات المحاسبية أو تكرار ذات الإفصاحات من عام لآخر من خلاد

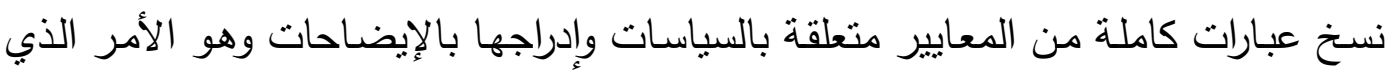

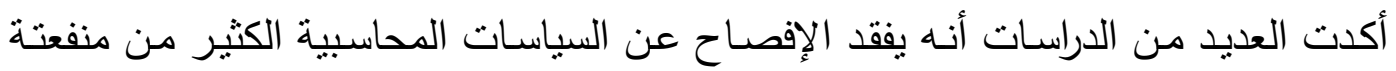

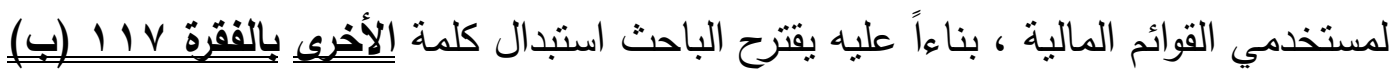

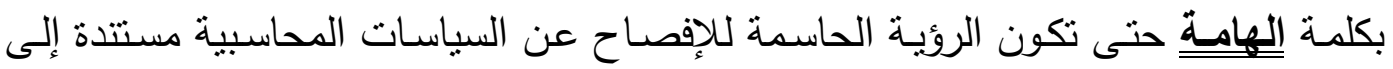
أساس واحد وهو مدى أهميتها.

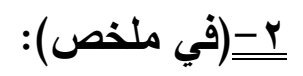

جاء حذف (في ملخص) بالإصدارين الأول والنهائي بهدف النأكيد على أنه ليس من الإلزام الإفصاح عن السياسات المحاسبية الهامة بملخص واحد ولكن يمكن الإفصاح عنها كجزء الإهاء

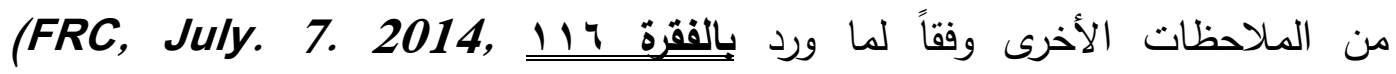
(OP.Cit,P.9)

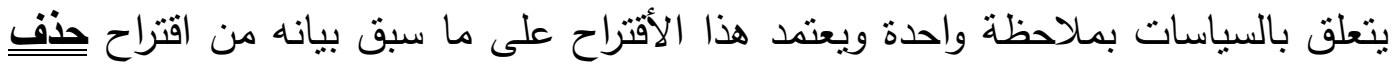
الفقرة 119 لضمان الإقصاح عن ما يتعلق بالسياسات المحاسبية في ملاحظة واحدة بالإيضاحات منعاً لنتشت القارئ.

بناءاً عليه تكون الصياغة المقترحة للفقرة V V

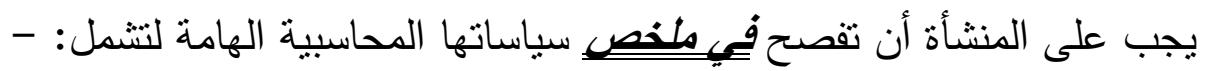
- - 99 - 
أ-أساس (أو أسس) القياس المستخدم في إعداد القوائم المالية. ب-السياسات المحاسبية الههامة المستخدمة والتي تكون ملائمة لفهم القوائم المالية.

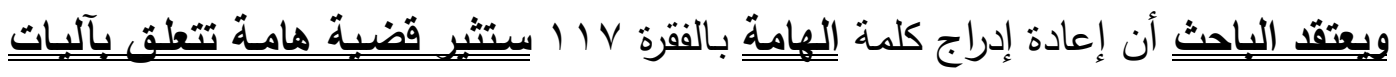

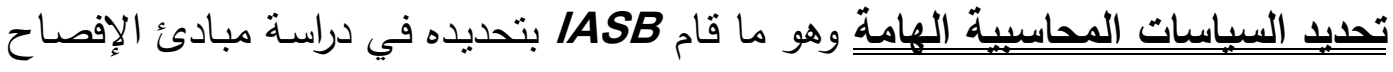

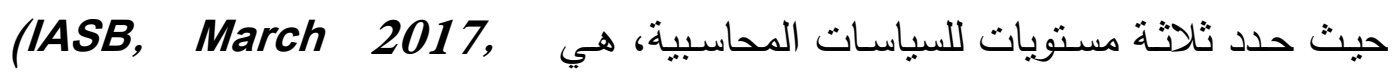
Op.Cit,P.p. 61 - 63) المستوى الأول: السياسات اللازمة لفهم المعلومات الواردة بالقوائم المالية وتتمثل في: أ-السياسات التي تغيرت خلال فترة التقرير .

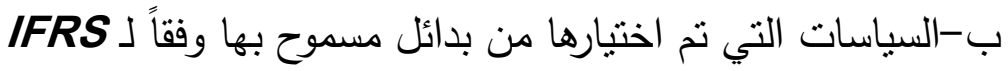

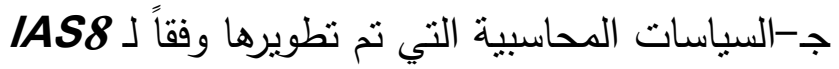
د-السياسات المحاسبية التي تتطلب من الوحدة بناء تقديرات هامة و (أو) افتراضات وفقا لهات لهات

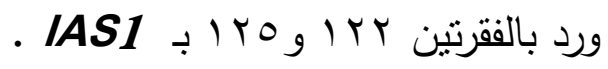
المستوى الثاني: واني هي السياسات المحاسبية الني لبست ضمن المستوى الأول لكنها تتعلق بالبنود والأحداث والمعاملات التي تعتبر جوهرية للقوائم المالية لسبب مبالغها أو طبيعتها.

المستوى الثالث:

السياسات المستخدمة من قبل الوحدة بإعداد القوائم المالية وغير مدرجة بالمستويين الأول والثاني، وتتعلق بمعاملات أو أحداث غير هامة.

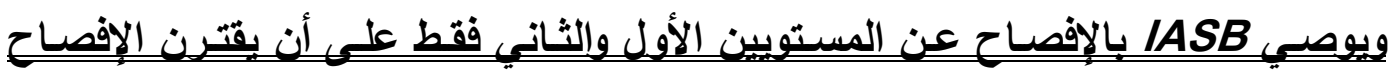
عنها بييان: أ-إن هدف الإفصاح عن السياسات المحاسبية هو تقديم توصيف حول: -السياسات المطبقة خلال إعداد القوائم المالية. - السياسات الضرورية لفهم القوائم المالية. 
ب-توضيح طبيعة الثلاثة مستويات من السياسات، وتوضيح الإلزام بنوفير المستوبين الأول والثناني.

ج-توضيح عدم إلزام الوحدة بالإفصاح عن المستوى الثالث من السياسات المحاسبية حتى

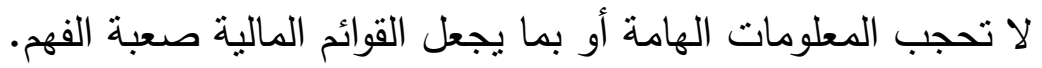

ويؤيد الباحث إدراج هذا التحديد لمستويات الإفصاح عن السباسات المحاسبية ضمن

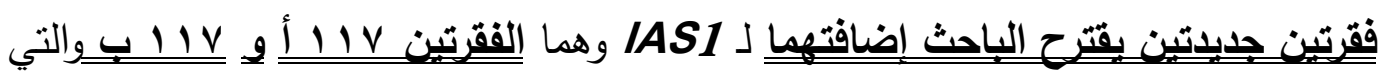
يقترح الباحث أن يكونا بمثابة مرشد مهني لمعدي التقارير يتيح لهم إصدار أحكام مهنية دقيقة حول كيفية تحديد السياسات المحاسبية الهامة.

بناعاً عليه تكون الصياغة المقترحة للفقرة V V ا أ كما يلي:

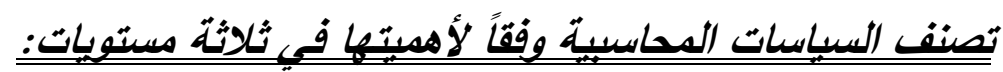

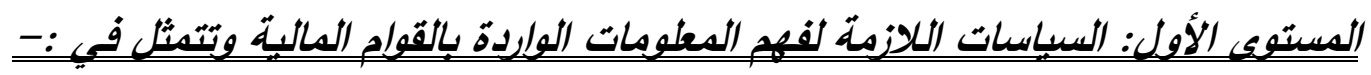
أ -السباسات التي تغيرت خلال فترة التقبير.

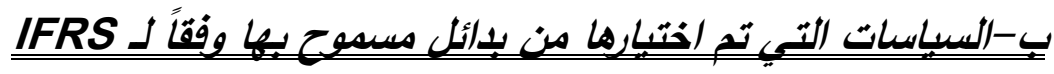

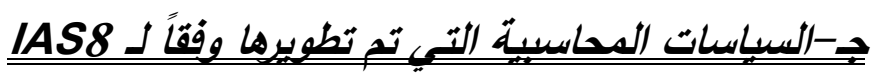

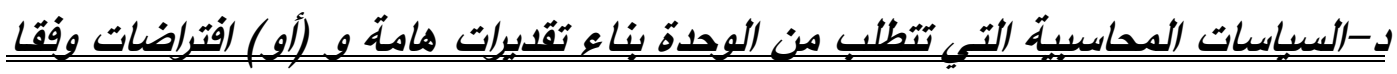

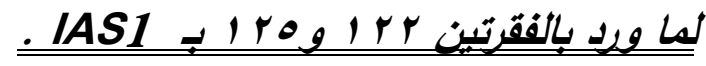
المستوى الثاني: هي السباسات المحاسيية التي لبيت ضمن المستوى الأول لكنها تتعلق بالبنول والأحداث والمعاملات التي تعتبر جوهية للقوائم المالية بسبب مبالغها أو طبينتها. المستوى الثالث:

السياسات المستخدمة من قبل الوحدة بإعداد القوائم المالية وغير مدرجة المستويين الأول والثاني وتتعق بمعاملات أو أحداث غير هامة.

وتكون الصياغة المقترحة للفقرة VI V ب كما يلي: 
يحب علمى الوحدة أن ثفصح عن السباسات المحاسبية الـولدة بالمستوبين الأول والثانسي بالفقرة V 11 أٔ، كما تفصح الوحدة عما بلي: أ-إن هدف الإفصاح عن السباسات المحاسبية هو تقليم توصبف حول: -السباسات المطبقة خلال اعداد القوائم المالبة. -السباسات الضرورية لفهم القوائم المالبة. ب-بيان طبيعة مستويات السباسات المحاسبية الثلاثتة وتوضبح الإلنزم بتوفير معلومات عن المستوبين الأول والثانهي.

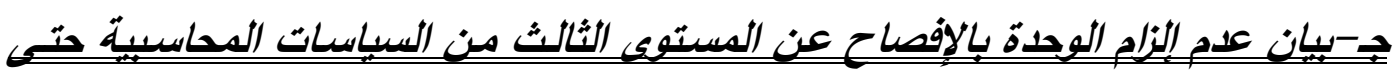
لو تحبب المعلومات الـهامة وذلك ما قد بترتب علبه أن تكون القوائم المالبة صعبة الفهر.

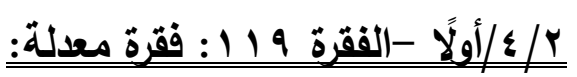
الإصدار الأولِ: تم عرض الفقرة بدون تعديل. الإصدار النهائي: عند تحديـ مـا إذا كـان ينبغـي أن يفصـح عن سياسـة محاسبية معينـة، تأخذذ الإدارة في الحسبان مـا إذا كـان الإفصـاح سيسـاعد المسـتخدمين في فهم الكيفيـة التي انعكسـت بهـا المعاملات والأحداث والظروف الأخرى في الأداء المسالي والمركز المـالي الذي تم التقرير عنه. تأخذ كل منشـأة في الحسبلن طبيعة عملياتها وسباسـاتها التي بيتوقع مستخدمو القوائم المالية الإفصاح عنها لنوع هذه المنشأة. يعد الإفصاح عن سياسات محاسبية معينة مفيداً للمستخدمين - بصفة خاصـة - عند اختيار تلك السياسات من بدائل مسموح بها في المعايير الدولية للتقربر المالي. مثنال ذللك، الإفصاح عما إذا كانت منشأة ما نطبق نموذج القيمة العادلة أو نموذج التكلفة على عقاراتها الاستثمارية (انظر معيار المحاسبة الدولي . ع "العقارات الاستتمارية") تتطلب بعض المعايير الدوليـة للتقريـر المـالي - بصفة خاصـة الإفصاح عن سياسـات محاسبية معينة، بما في ذلك الاختيارات التي قامت بها الإدارة بين السياسات المختلفة التي تسمح بها تللك المعايير • فعلى سبيل المثال، يتطلب معيار المحاسبة الدولي 11 الإفصاح عن أسس القياس المستخدمة لفئات العقارات والآلات والمعدات.

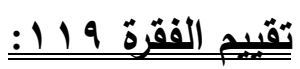
تتتاول الفقرة الاعتبارات الواجب مراعاتها عند الإفصاح عن سياسة محاسبية معينة وهو ما

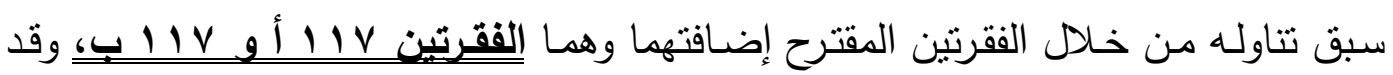
- r. r -

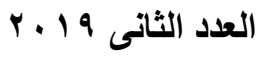
مجلة المحاسبة والمراجعة 
أنشـار ICAEW إلـى كـون IASB يخطط لصـياغة مشـروع منفصـل يتــاول السياسـات

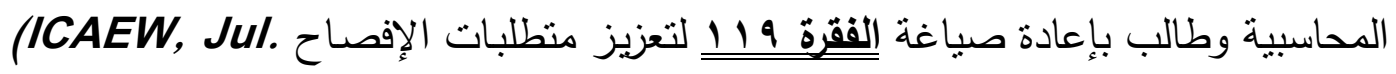
2014, Op.Cit,P. 7) IASB

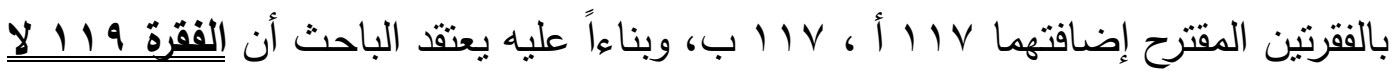

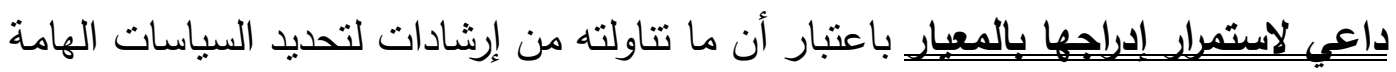

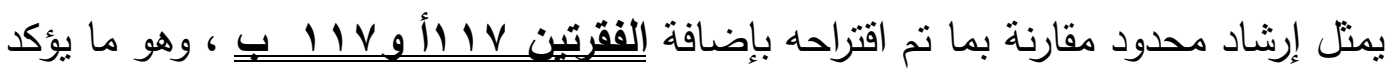
على عدم جدوى استمرار الفقرة 91 (ا ويؤكد على ضرورة حذفها.

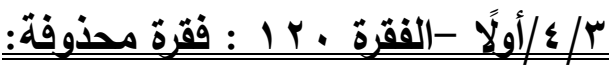

$$
\begin{aligned}
& \text { الإصدار الأول: حذف. } \\
& \text { الإصدار النهائي: حذف. } \\
& \text { تقييم الفقرة • P I }
\end{aligned}
$$

تناولت الفقرة أمتلة على السياسات المحاسبية الهامة التي يتوقع مستخدمو القوائم المالية أن

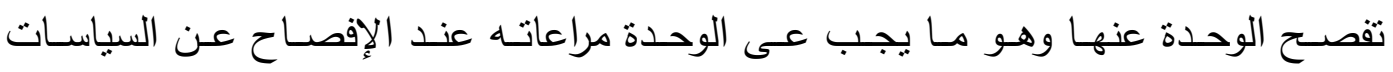
المحاسبية، وقد أكد IASB في ملخص النعليقات أن معظم المعلقين وافقوا على حذف الته الفقرة

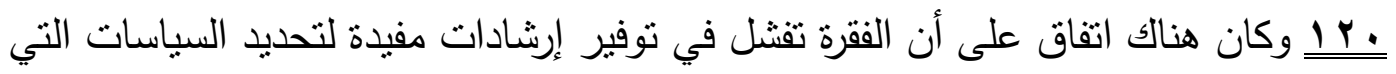

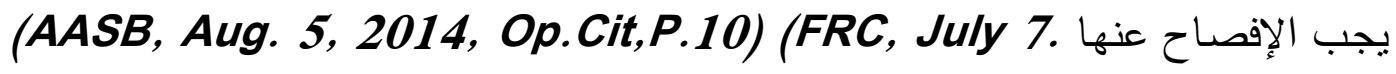
2014, Op.Cit, P.11)

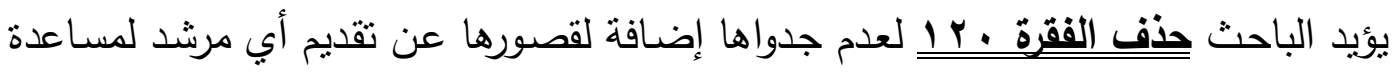
المعدين عند تصنيف السياسات الدحاسبية.

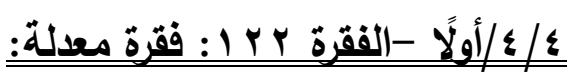
الإصدار الأول: لم تعرض ضمن التعديلات في الإصدار الأولي للمبادرة.

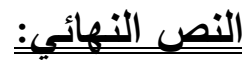
يجب على المنشأة أن تقصح في ملثصـ السياسات المحاسبية الهامة، أو في الإيضاحات الأخرى عن الأحكام التي اتخذتها الإدارة، بخلاف تلأك التي تتطوي على تقديرات (انظر 
الفقرة 0Y (1) ، في سياق تطبيق السياسات المحاسبية للمنشأة ، والتي يكون لها الأثر الأهم على المبالغ المثبتة في القوائم المالية.

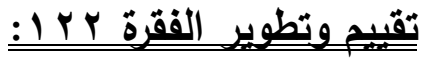

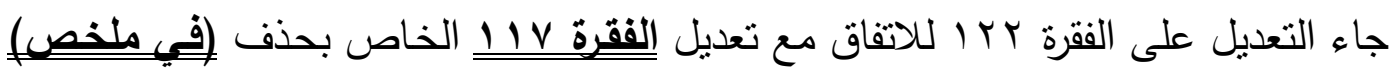

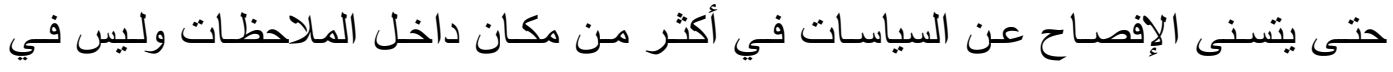

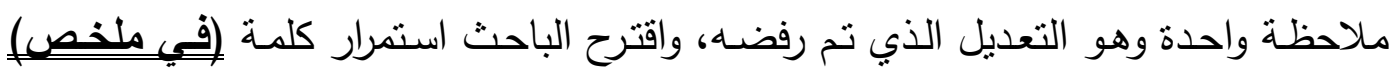

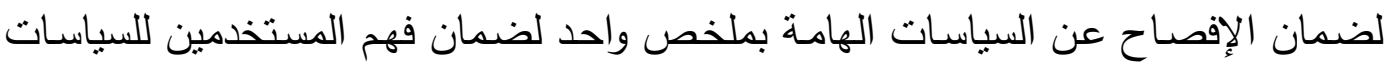

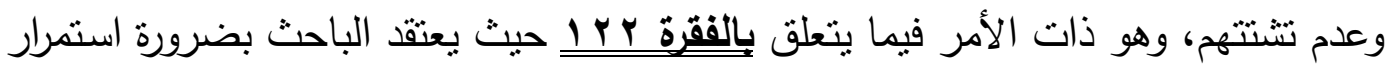

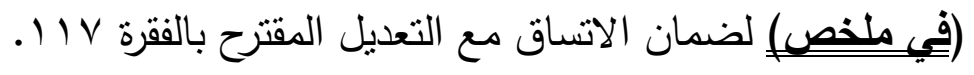

بناءاً عليه تكون الصياغة المقترحة للققرة V V يجب على المنشأة أن تقصح في ملفص السياعه السترجهات المحاسبية الهامة، أو في الإيضاحات الأخرى عن الأحكام التي اتخذتها الإدارة، بخلاف تلك التي تتطوي على تقديرات (انظر الفقرة 0Y (1) ، في سياق تطبيق السياسات المحاسبية للمنشأة ، والتي يكون لها الأثر الأهم على المبالغ المثبتة في القوائم المالية.

هـأولًَ: التعديل المتعلق بالمجموعة الكاملة من القوائم المالبة: الإصدار الأول:

لم يتم تتاول أي تعديل متعلق بالمجموعة الكاملة للقوائم المالية بالفقرة ـ1. الإصدار النهائي:

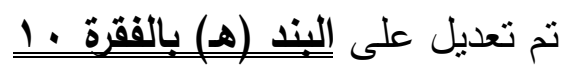

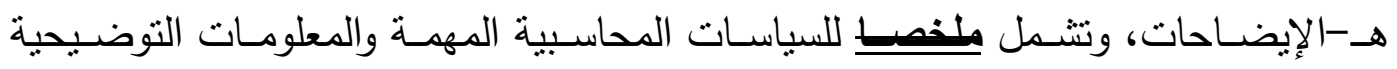

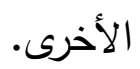

تقييم وتطوير الفقرة • (1) تم حذف كلمهة ملخصـا قبل السياسـات الهامـة وذلك لضمان الاتسـاق مع التعديل المقترح

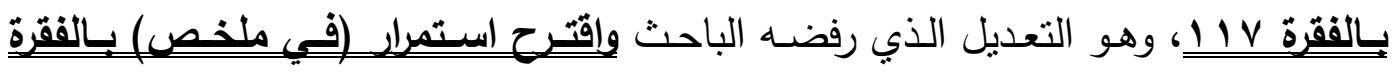

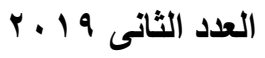
$-r \cdot \varepsilon$ -

مجلة المحاسبة والمراجعة 


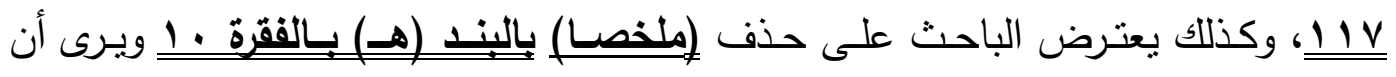

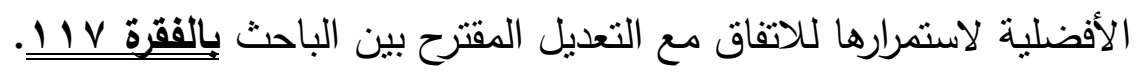

بناء عليه تكون الصياغة المقترحة للند هـ بالققرة ـ ـ كما يلي:

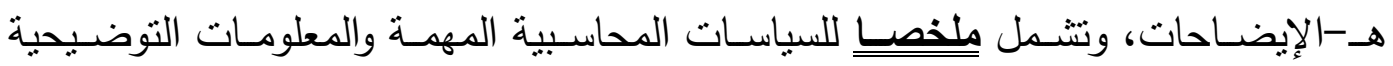

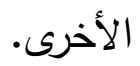

ثانياً: التعديلات المقترحة على فقرات بـ IAS1 لم ترد ضمن مبادرة الإفصاح-تعديلات IAS1 يعتقد الباحث أن الرغبة في إيجاد علاج لمشكلة الإفصاح تقتضي حزمة من التعديلات يجب

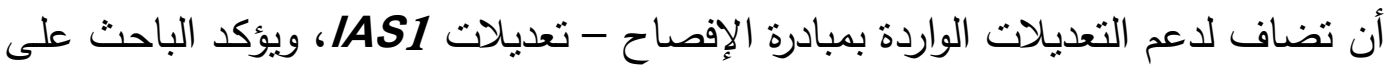

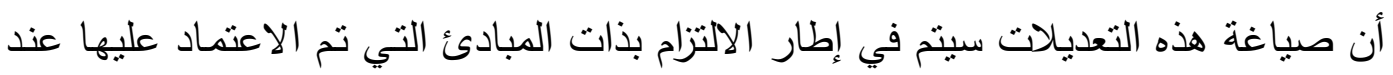

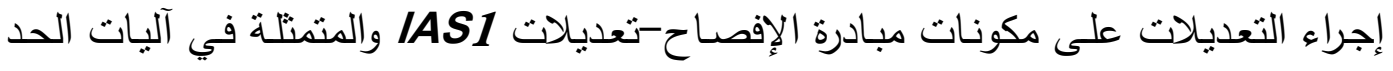

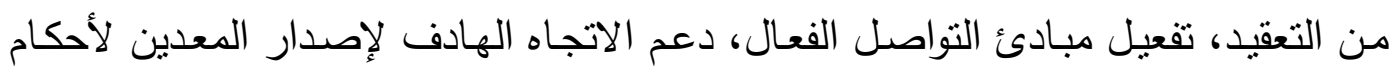

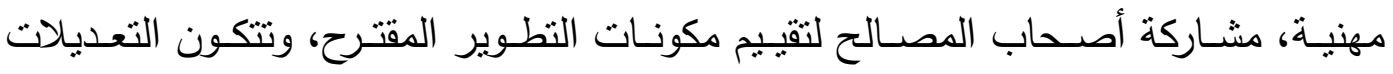

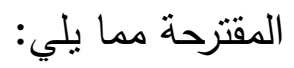

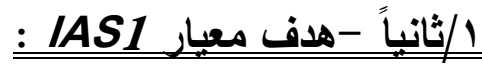

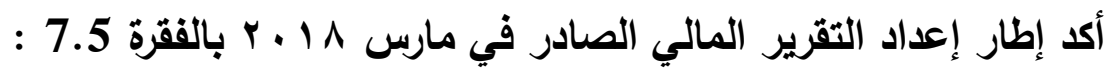
أن إدراج أهداف للعرض والإفصـاح بالمعايير سيسـاعد على دعم التواصل الفـل الفعال بـالقوائم

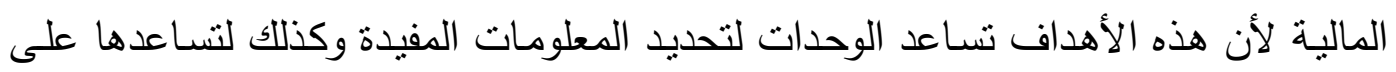
(IASB, March 2018, Op. تحديد كيفية نوصيل المعلومات بالوسيلة الأكثر فعالية لالئل

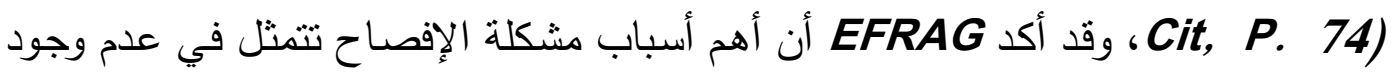
أهداف واضحة بالمعايير بما يساعد المعدين على إعداد قوائم مالية تتفق مع هدف المعيار

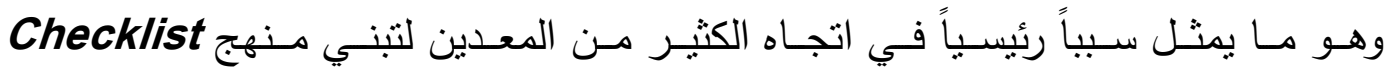
.(EFRAG, Oct. 12, 2017, Op. Cit, P.24) وقد ورد هدف معيار IAS1 في الفقرة الأولى، وينص على . - T.O. 
يحدد هذا المعيار أسـاس عرض القوائم الماليـة ذات الغرض العـام، وذلك لضمان قابليـة

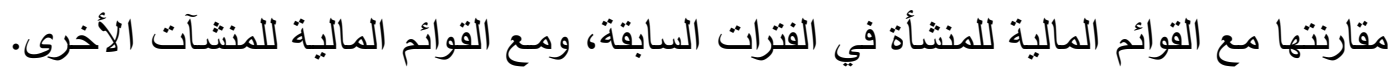

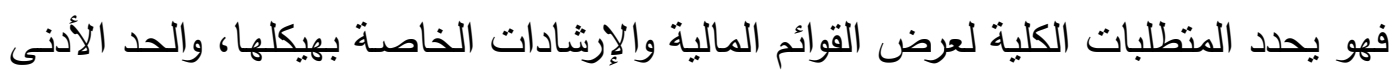
من المتطلبات المتعلقة بتلك بمحتوياتها. يعتقد الباحث أن العرض الدقيق يجب أن يكون كفيلاً بدعم تحقق كافة خصائص جودة

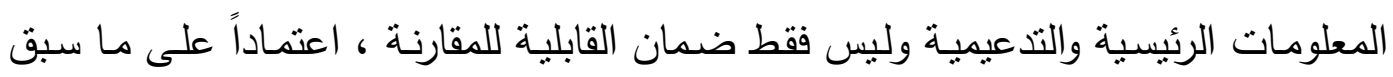

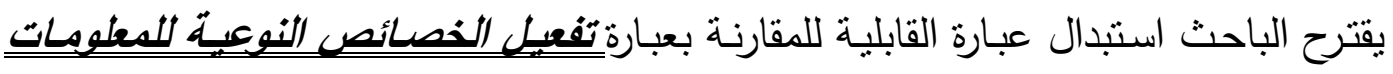

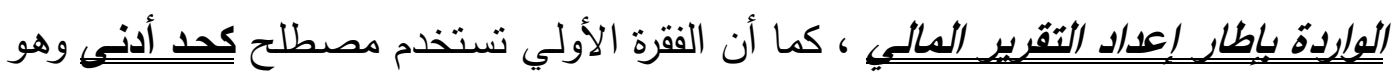

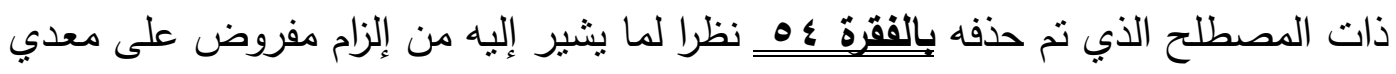

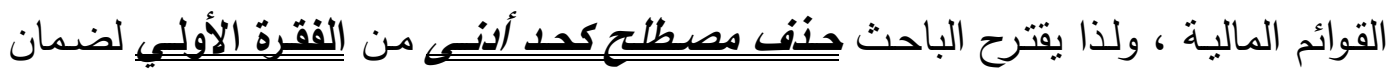

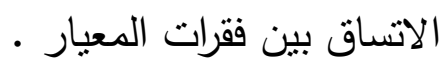

بناءاً علبه تكون الصباغة المقترحة للفقرة الأولي كما بليِ

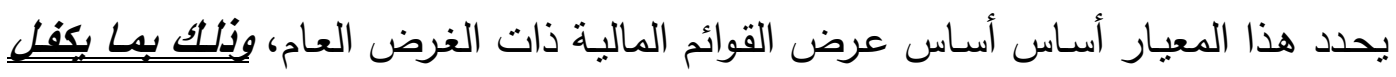

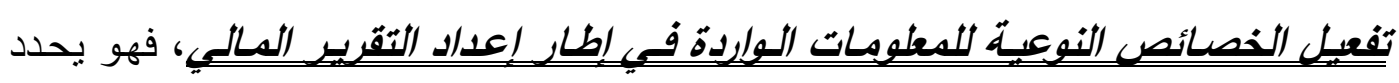
المنطلبات الكلية لعرض القوائم المالية ومحتوياتها والإرشادات الخاصة بهيكلها.

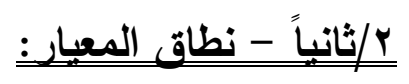

تنص الفقرة الثانية المتضمنة لنطاق المعيار على أن: -

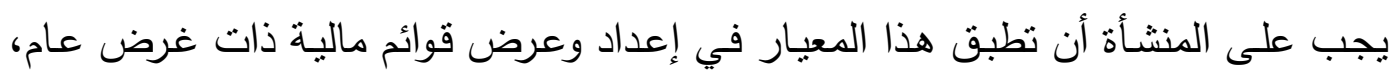
وفقاً للمعايير الدولية للتقرير المالي (IFRSs).

وقد ورد بالعديد من الدراسـات الحاجة لضبط المصطلحات المستخدمة بالمعيار بما يتيح

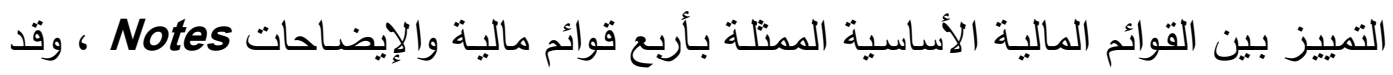

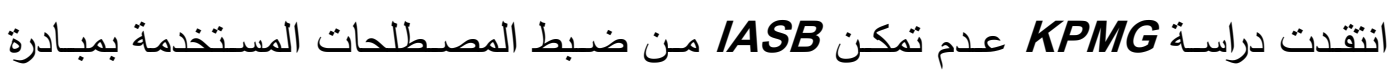

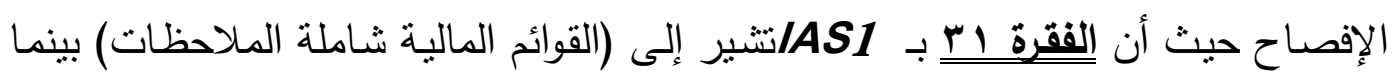

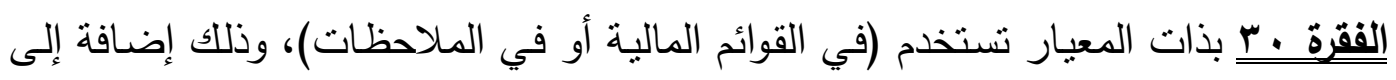


استخدام الفقرة العاشرة مصطلح (المجموعة الكاملة للقوائم المالية)، وأكد KPMG أنه من

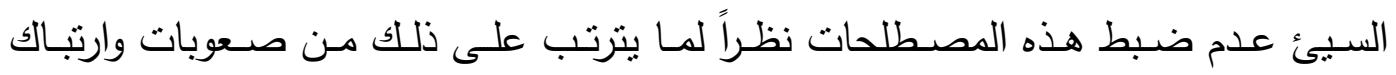

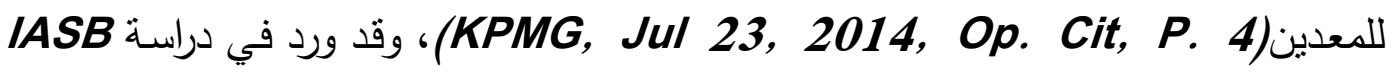
الخاصة بمبادئ الإفصاح التأكيد على ضرورة التفرقة بين مصطلحي القوائم المالية الأساسية

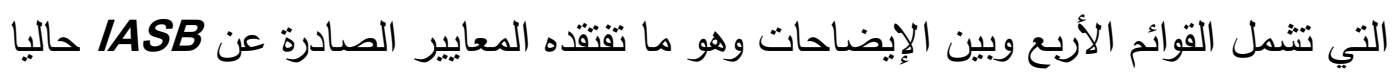
حيث لا ينم استخدام مصطلحات واضحة نساعد المعدين على التمييز بين كلا المصطلحين

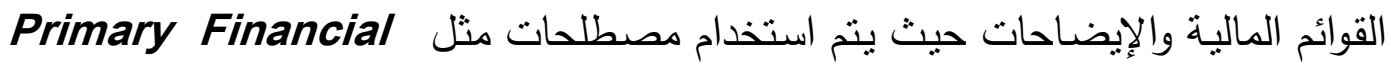
Statements \& Face of Financial Statements

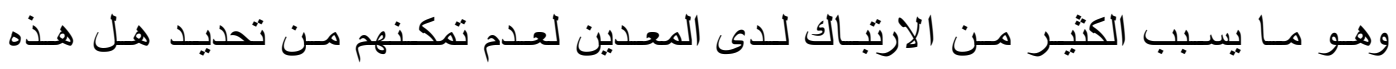

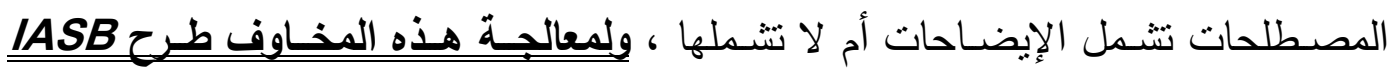

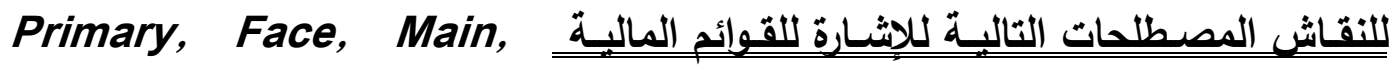
IASB Statements, Set of Statements إليه إلى فعالية مصطلح Primary financial statements للإشارة للقوائم الأربع نظراً لكونه :- البه

أ-مصطلح مفهوم جيداً ومستخدم على نطاق واسع بالمجتمع المالي.

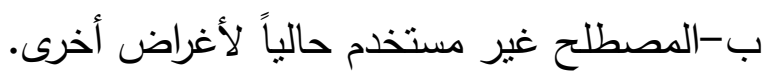
ج-تقديم مصطلح جديد قد يسبب ارتباك.

وأكد IASB أن استخدام مصطلح Primary للإثارة للقوائم المالية لا يعني أن الإيضاحات Notes

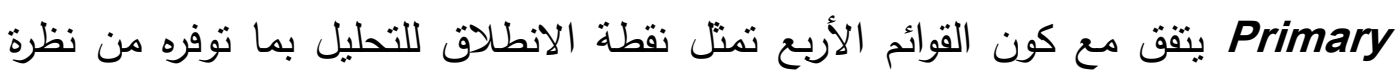

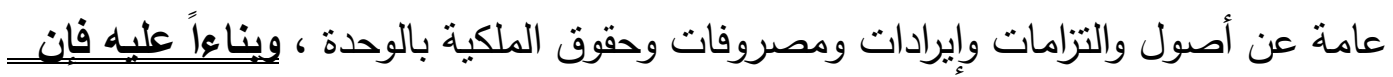
IASB الأساسبة (أريع قوائم) والـ Notes لتعني الإيضاحات، بحيث بطلق عليهما معاً المجموعة

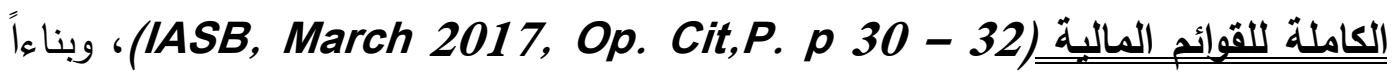
عليه يقترح الباحث أن تتم إعادة صياغة الفقرة الثانية للتمييز بين القوائم المالية الأساسية

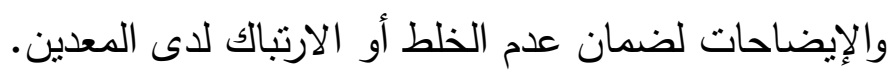
$-r \cdot \nu$ - 
بناءاً علبه تكون الصباغة المقترحة للققرة الثانبة نطاق المعباركما بلي؛

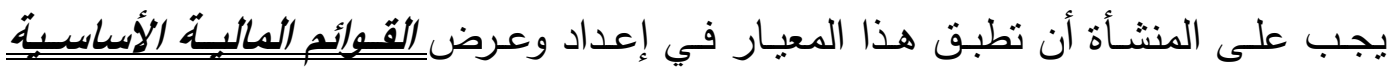

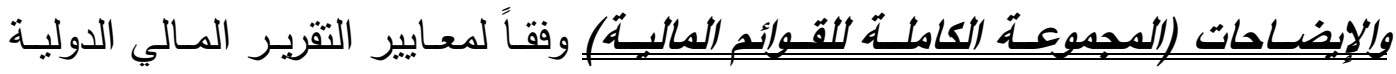
.IFRSs

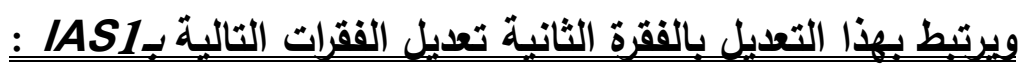
1-الفقرة 9 بـ IAS1:

عنوانها الرئيسي القوائم المالية يقترح تعديله إلى القوائم المالبة الأساسبةِ، كما يقترح تعديل

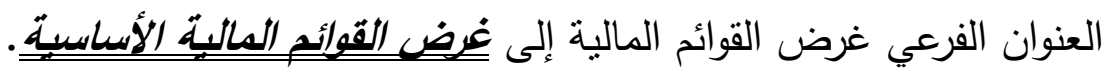

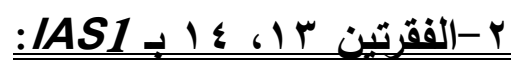

(الفقرة بr

تقوم الكثير من إدارات المنشآت بثقديم استعراض مالي خارج القوائم المالية، يصف ويوضح

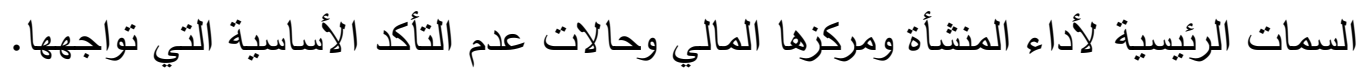

الفقرة ؟ 1:

تعرض كثبر من المنشآت أيضاً - خارج القوائم المالية-تقارير وقوائم مثل التقارير البيئية وقوائم القيمة المضافة، خاصة في الصناعات التي تكون فيها العوامل البيئية مهمة، وعندما يعد الموظفون مجموعة مهمة من المستخدمين. وتثثر هاتان الفقرتان الكثير من الخلط لدى المعدين فهل المقصود خارج القوائم المالية أن

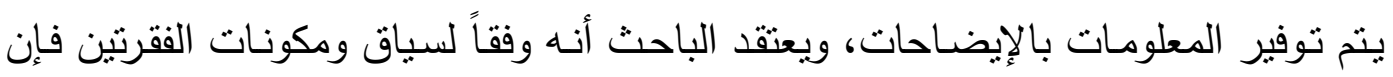

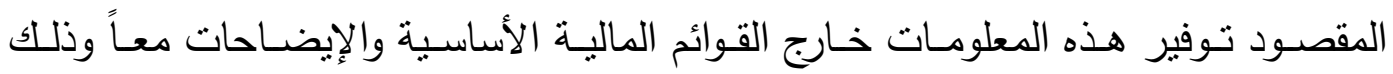

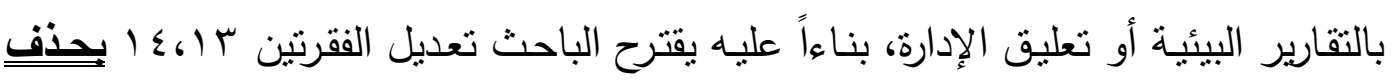

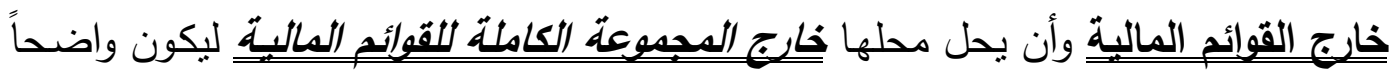

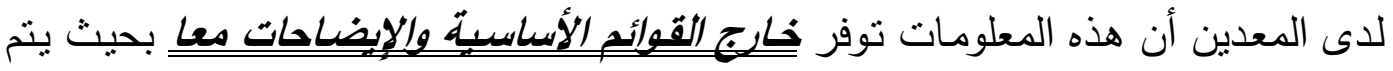

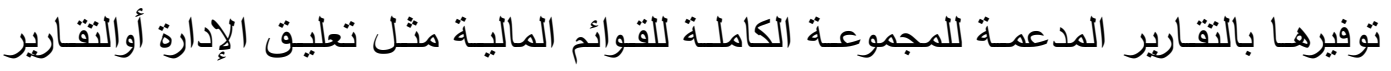

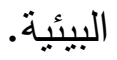




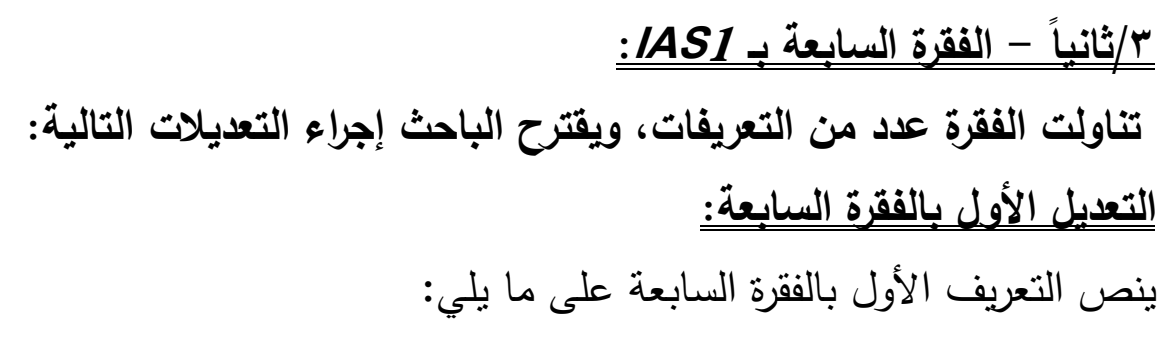

القوائم المالية ذات الغرض العام (يثار إليها بالقوائم المالية) هي تلاك القوائم التي يقصد منها

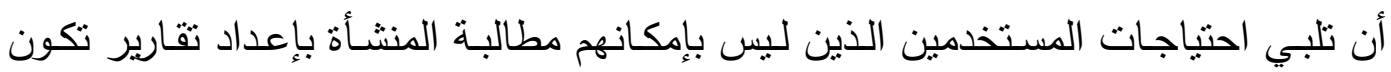
مصممة لنوفير احتياجاتهم المحددة من المعلومات. يقترح الباحث تعديل التعريف الأول بالفقرة السابعة لتكون صياغته منسقة مع التعديل الذي لتي

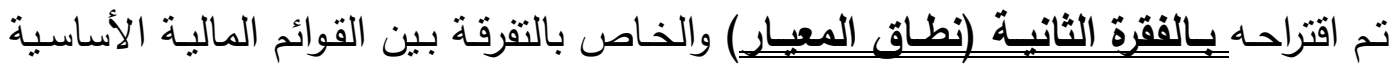
والإيضاحات لضمان ضبط المصطلحات والحد من ارتباك المعدين.

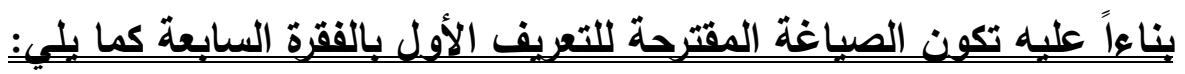

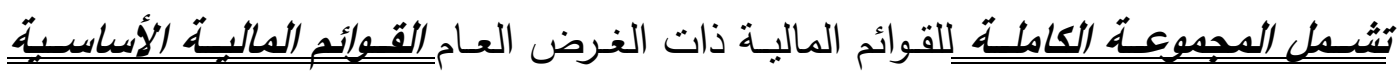
Primary financial statements

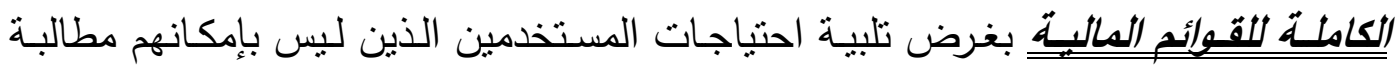
المنشأة بإعداد تقارير تكون مصممة لنوفير احتياجاتهم المحددة من المعلومات.

التعديل الثاني بالفقرة السابعة: تتـاول IASB بمبـادرة الإفصـاح-تعديلات IAS1 أهميـة التفرقـة بـين مصـطلح العـرض Presentation

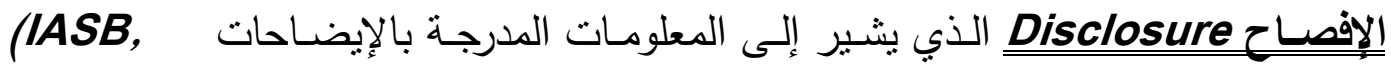
March 2014, Op. Cit,P. 17) ICAEW و FRC و KPMG التفرقة بين المصطلحين تقتضي مراجعة الكثير من فقرات IAS1 الأخرى.

بناءاً عليه يقترح الباحث أن يدرج بالفقرة السابعة ضمن التعريفات المدرجة بها تعريف لكلاً من العرض Dresentation والإفصاح Disclosure والتعريفان المقترحان هما :المعض: هو تقبيم المعلومات بالثقوائم المالبة الأساسبة. $-r \cdot 9$ - 


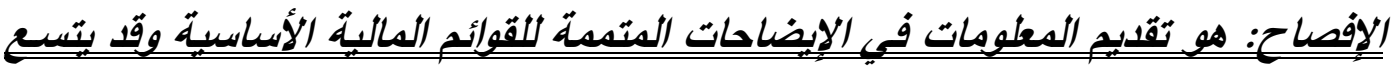

\section{المفهوم لبشمل المعلومات المدرجة بتعليق الإدارة وتحليل الععلبات والبيئة التنافسبة.}

ويتطلب التعديل السابق إجراء تعديلات أخرى على فقرات أخرى بـ IAS1 وذلك ليتحقق اتساق استخدام مصطلحى العرض Presentation والإفصاح Discloure عبر فقرات IAS1 بحيث لا يستخدم أب مصطلح منهما إلا للإثارة إلى ما تضمنه التعريفان المدرجان

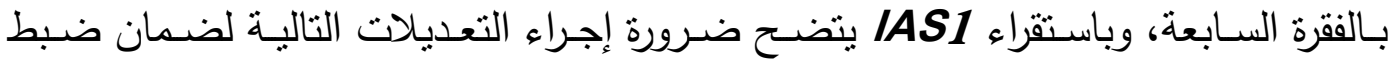

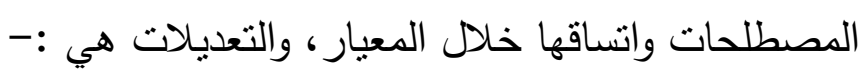
:IAS1 ب VV لفقرة

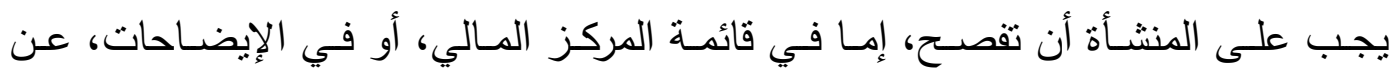
تصنيفات فرعية إضافية للبنود المستقلة المعروضة، مصنفة بطريقة تتاسب المنشأة. التعديل: يجب على المنشـأة أن تعـرض في قائمسة المركز المـالي أو تفصـح في الإيضـاحات، عن

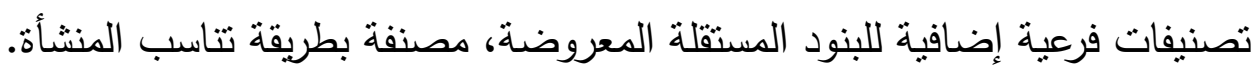

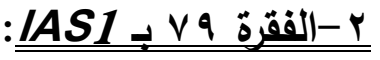

يجب على المنشأة أن تفصح عما يلي، أما في قائمة المركز المالي أو في قائمة التغيرات في حقوق الملكية، أو في الإيضاحات: ......... التعديل: يجب على المنشـأة أن تعـرض في قائمسة المركز المـالي أو في قائمـة التغيرات في حقوق الملكية، أو تفصح في الإيضاحات: .......

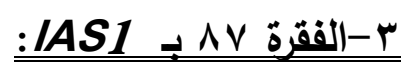

لا يجوز للمنشـأة أن تعرض أي بنود للـخل أو المصروف على أنها بنود استثنائية في

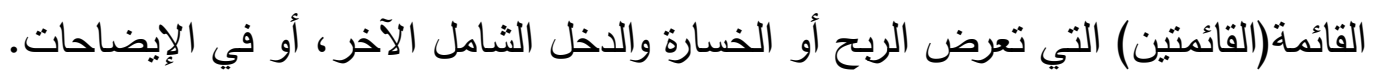

التعديل: 
لا يجوز للمنشأة أن تعرض أي بنود للاخل أو المصروف على أنها بنود استثنائية في

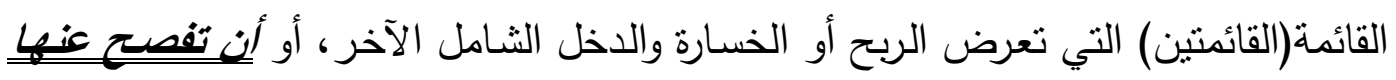
في الإيضاحات.

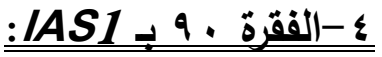

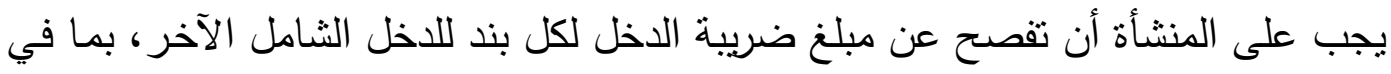

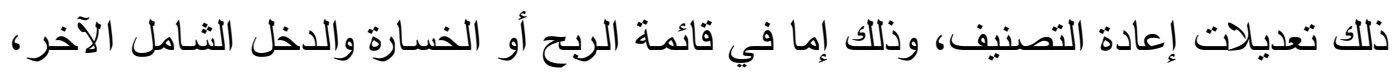
أو في الإيضاحات. التعديل: يجب على المنشأة أن تعرض مبلغ ضريبة الدخل لكل بند للاخل الثامل الآخر ، بما في ذللك

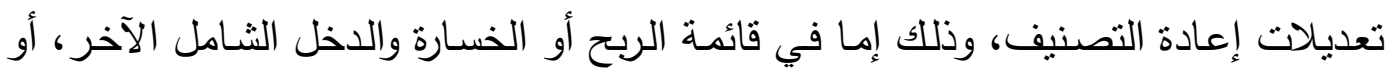
تفصح عنه الإيضاحات.

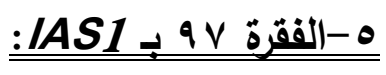

عنوان الفقرة: المعلومات التي تعرض في قائمة (قائمتي) الربح أو الخسارة والدخل الثشامل الآخر أو في الإيضاحات. نصص الفقرة: يجب على المنشأة أن تفصح عن طبيعة ومبلغ بنود الدخل أو المصروف بشكل منفصل - عندما تكون ذات أهمية نسبية. التعديل:

عنوان الفقرة: المعلومات التي تعرض في قائمة (قائمتي) الربح أو الخسارة والدخل الثـامل الآخر أو بفصح عنهي في الإيضاحات.

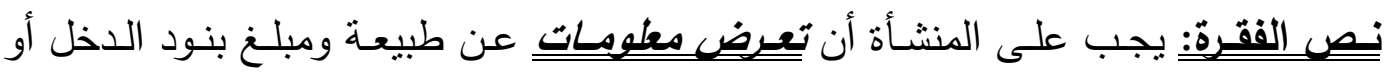

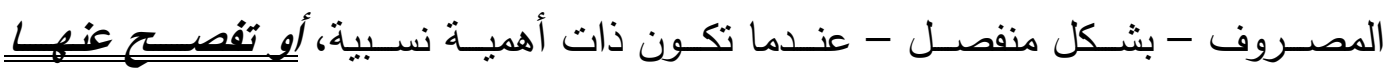
بالإيضاحات.

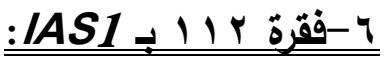

$$
\begin{aligned}
& \text { الإيضاحات يجب أن: - }
\end{aligned}
$$

أ-تعـرض معلومـات عـن أسـاس إعـداد القـوائم الماليــة والسياسـات المحاسبية المحـددة

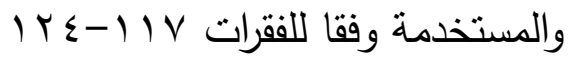


ب-تفح عن المعلومات المطلوبة بموجب المعايير الدولية للتقرير المالي، والتي لن تعرض في مكان آخر في القوائم المالية. ج-توفر المعلومات التي لن تُعرض في مكان آخر في القوائم المالية، ولكنها ملائمة لفهم أي منها. التعديل:

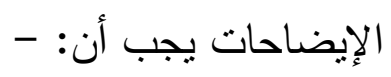

أ-تفصـح عـن معلومـات عن أسـاس إعداد القوائم الماليـة والسياسـات المحاسبية المحددة

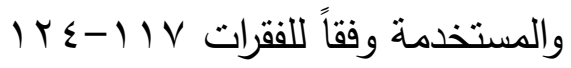

ب-تصحح عن المعلومات المطلوبة بموجب المعايير الدولية للتقرير المالي، والتي لن تعرض آلتر في مكان آخر في القوائم المالية.

ج-تفصح عن المعلومات الني لن تُعرض في مكان آخر في القوائم المالية، ولكنها ملائمة لفهم أبي منها.

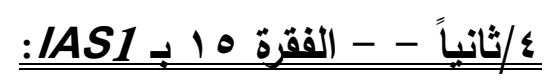

جاءت الفقرة بعنوان السمات العامة -العرض العادل والالنزام بالمعايير الدولية للتقرير

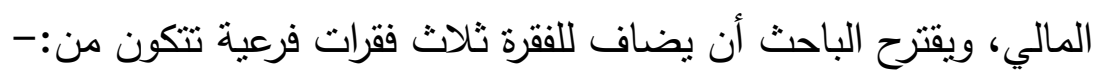
مـ/1/أ: أهداف العرض العادل بالقوائم المالية 10/1/ب: مبادئ العرض العادل.

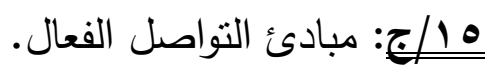

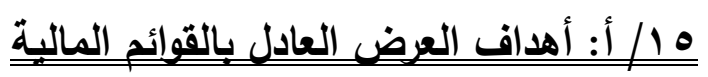

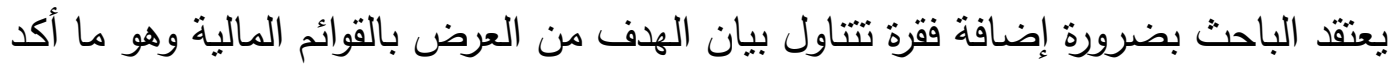

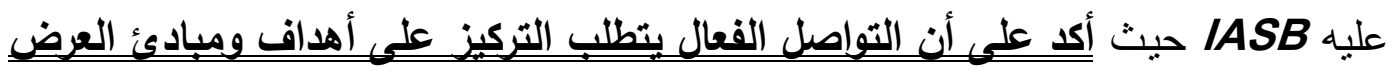
(IASB, March 2018, Op. Cit, P. 74)

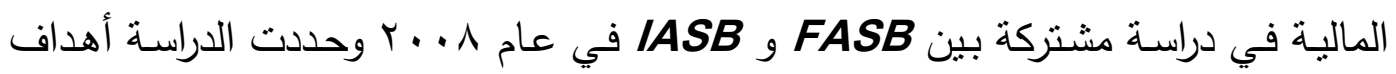
العرض بالقوائم المالية بما يلي (32) - 28 (IASB, FASB, Oct 2008,P.p.

$$
\begin{aligned}
& \text { العدد الثانى } 9 \text { ب ب r } \\
& \text { - MIT }
\end{aligned}
$$$$
\text { مجلة المحاسبة والمراجعة }
$$ 
الهـف الأول: التماسك Cohesiveness Objective؛

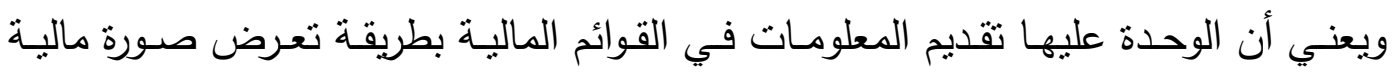

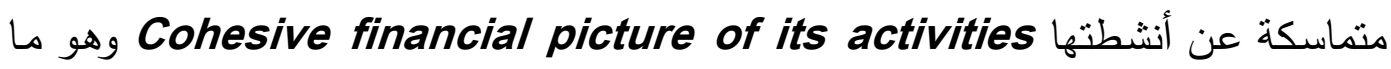
يعني أن العلاقات بين العناصر عبر القوائم المالية يجب أن تكون مترابطة بما يدعم من

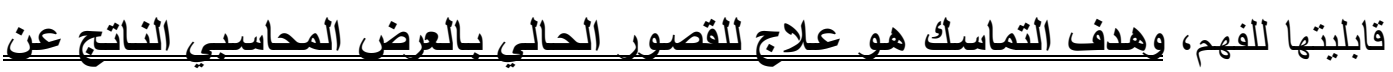
فصل الأنشطة وفقاً لطيعتها بقائمة التدفقات النقدية وهو ما لا بتم بياقي القوائم المالبة.

\section{الهُف الثاني: هاف التفصيل Disaggregation Objective:}

يجب على الوحدة أن تفصل المعلومات في القوائم المالية بالطريقة التي تجعلها مفيدة في

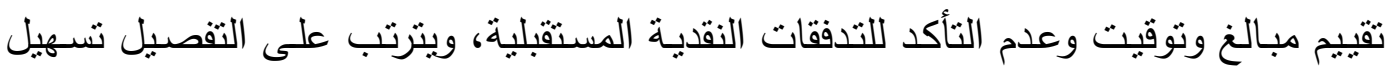

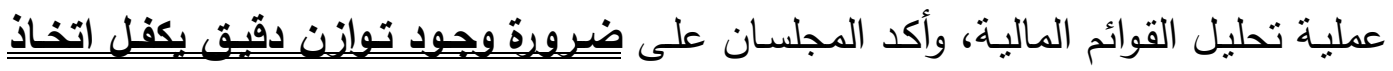

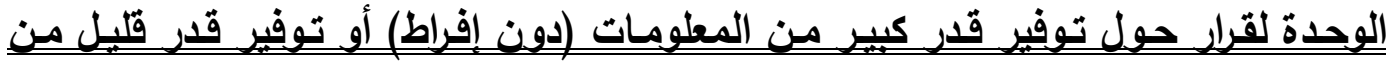
المعلومات، ولذا فمن الأهمبة إدراج التفصيل كهرفئ.

\section{Liquidity and financial اللهـف الثالث: هـف السـيولة والمرونـة المالبـة}

flexibility objective

يجب على الوحدة عرض المعلومات بالقوائم المالية بطريقة تساعد المستخدمين على تقييم

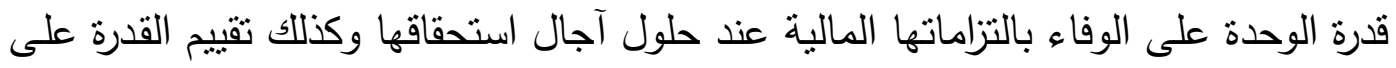

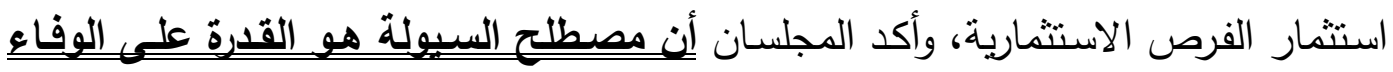
بالالتزامات في حين أن مصطلح المرونة المالبة بمثل A broader notion يرتبط بأكثر من مجرد وجود موارد لأداء الديون ولكن المرونة المالية ترتبط بقدرة الوحدة على: أ-تحقيق عوائد من الاستثمارات وتمويل النمو المستقبلي.

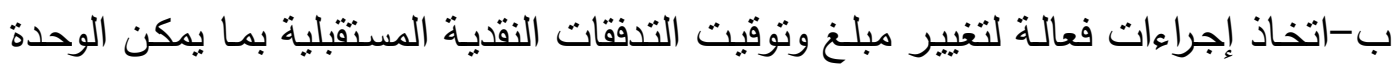
من الاستجابة للاحتياجات والفرص غير المتوقعة. تقييم الأهداف المقترحة للعرض: 
أكد Deloitte دعمـه لأهداف العرض السابقة حيث أن هدف التماسك سبقلل من ذاتيـة

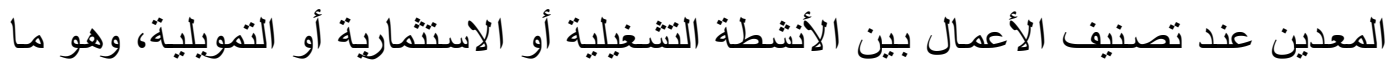
كان يمثل عائقاً غالباً ما برتبط بممارسات غير منسقة، إضـافة إلى تأييد هدف التقصيل المترتب عليه توفير معلومات مفيدة وهو ما يستلزم وجود مؤشرات من المجلسين لتحديد

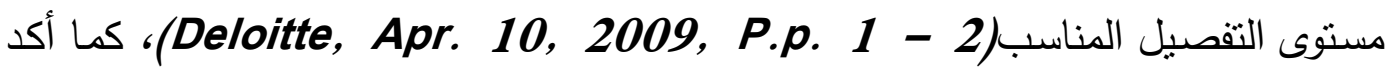
ICAEW باعتباره هدف لا غنى عنه خاصة في ظل المجال الاقتصادي الحالي . . 20, 2009, P. 7)

وفي إطار رغبة الباحث في تحقق المبادئ الحاكمة للنطوير المقترح (السابق بيانها بقسم

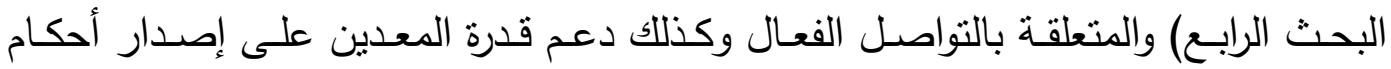

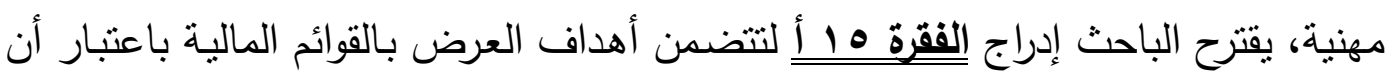

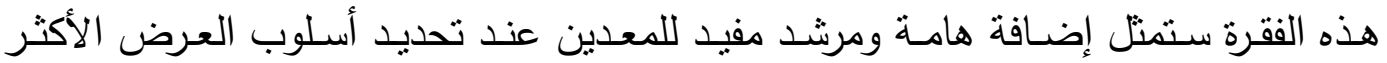
ملاءمة لاحتباجات المستخدمين.

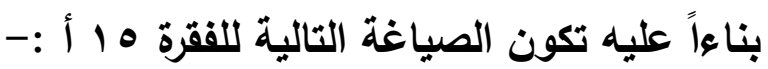

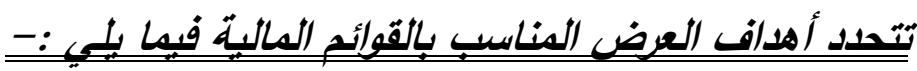

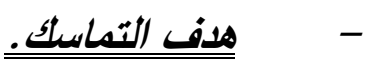
- - مدف التفصيل.

\section{هلف السبيولة والمرونية المالية.}

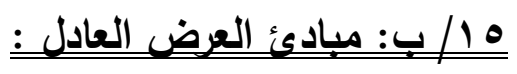
أكد IASB أن التركيز على مبادئ العرض بمتل أداة هامة لاعم التواصل الفعال وذلك بدلاًا من التركيز على القواعد(IASB, March 2018, Op. Cit, P. 74)، وقد ورد تحديد مبادئ العرض بدراسة مشتركة بين IASB, FASB تتاولت تحديد المبادئ التالية كمبادى

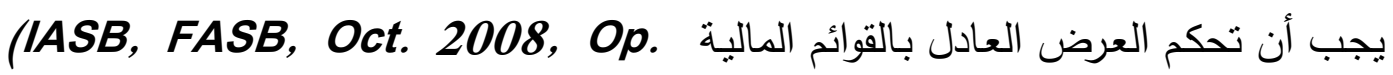




\section{المبدأ الأول: عرض قوائع مالبة متماسكة:}

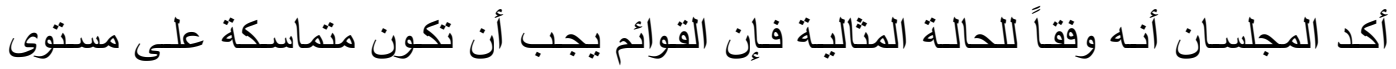
العناصر الرئيسية لأن ذلك سيدعم مستوى الثفافية بما يمكن المستخدم من تحديد الأصول

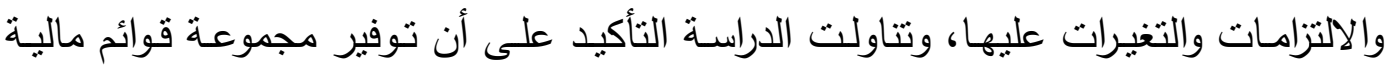
متماسكة يتطلب أحداث نوافق بين العناصر الرئيسية وترتيب المعلومات في القوائم المالية.

\section{المبدأ الثاني: فصل المعلومات إلى أقسام وفئًات:}

يجب على الوحدة أن تعرض المعلومات حول طريقة تحقق القيمة (أنشطة الأعمال) بشكل منفصل عن المعلومات حول طريقة تمويل هذه الأنشطة.

\section{المبدأ الثالث: تقديج مجامبع فرعية ذات مغزى:}

يجب على الوحدة تقديم المجاميع الفرعية والعناوين الأكثر تعبيراً عما تتجه لعرضده في كل

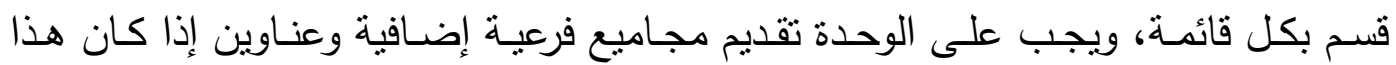

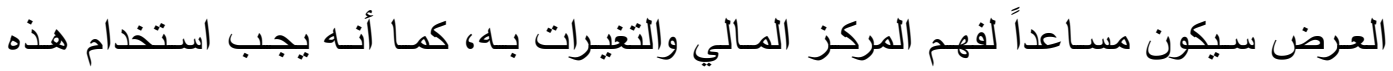
المجاميع الفرعية والعناوين بشكل متسق عبر القوائم المالية.

وقدأكد Deloitte أن أهداف ومبادئ العرض المحدة بالدراسة المشتركة IASB , FASB إذا تم تتفيذهما بشكل مناسب فسيكونا إضـافة لصالح المستخدمين لمساعدتهما على فهم

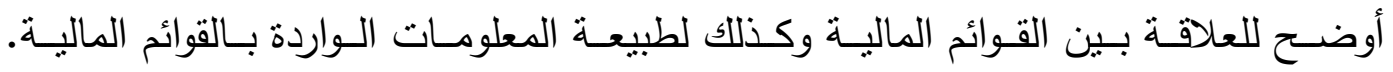
(Deloitte, Apr. 10, 2009, Op. Cit,P.2) القانونيين A/CPA أن الأهداف والمبادئ المحددة للعرض سوف يساهمان في رفع مستوى جودة القوائم المالية وهو ما يتوقع أن يؤدي لمساعدة المستخدمين إلى اتخاذ قرارات أفضل (A/CPA, Apr. 14, 2009, P.p. 1 - 2)، ويعتقد الباحث أن إدراج هذه المبادئ

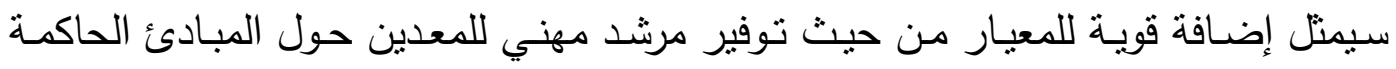
لعمهم عند تحديد أسلوب العرض الأكثر قدرة على تلبية حاجات المستخدمين، إضافة لكون

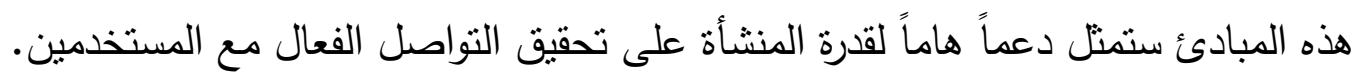

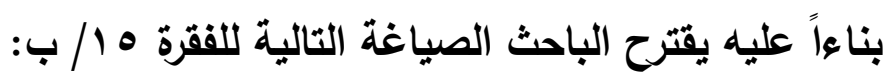




\section{يتحد أسلوب العرض العادل في ضوع المبادئ التالبية: - أ-عرض قوائم مالبة متماسكة. ب-فصل المعلومات إلى أقسام وفئات. ج-تقليم مجامبع فرعبة ذات مغزع.}

10/ ج: مبادئ التواصل الفعال: تتاول الباحث عرض لمبادىء التواصل الفعال الصادرة عن IASB ضمن المبادئ الحاكمة

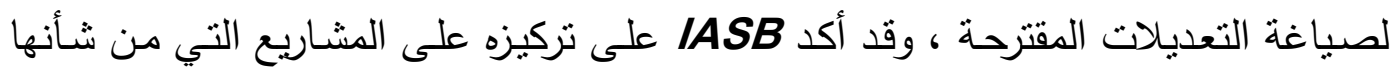

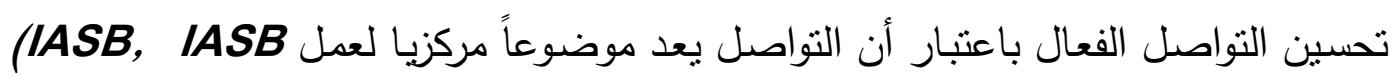
IASB وقد تضمنت الردود الواردة على مقترحل March 2017, Op. Cit, p. 4) بصياغة مبادئ للتواصل الفعال تأكيد ICAEW على تأييده لمبادئ التواصل الفعال التي

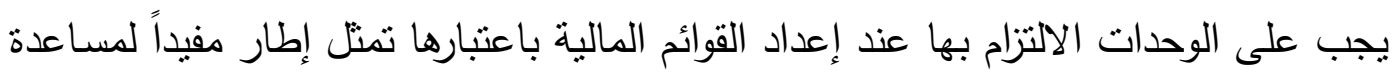

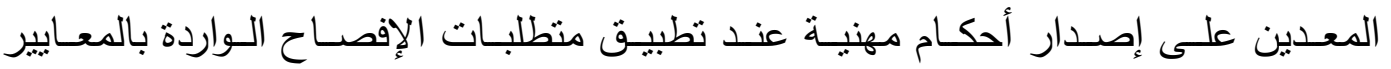
(ICAEW, Oct. 2. 2017 , P.p. 4 - 5)

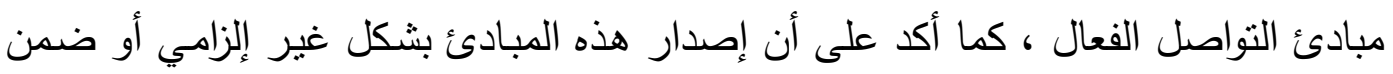

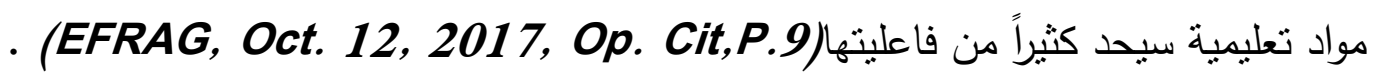

وفيمـا بتعلق بآلبـة إصدار مبـادئ التواصل الفعال وهل تكون إلزامبـة أم غير إلزامبة أكد IASB

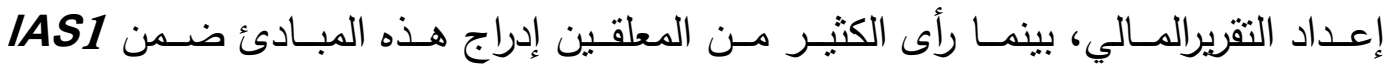

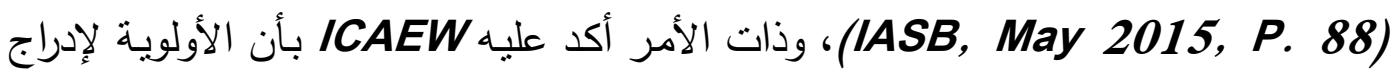

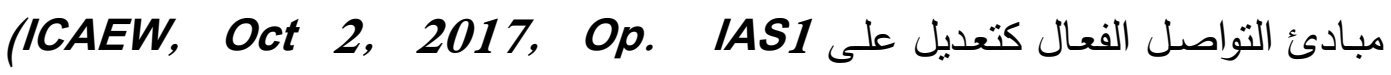

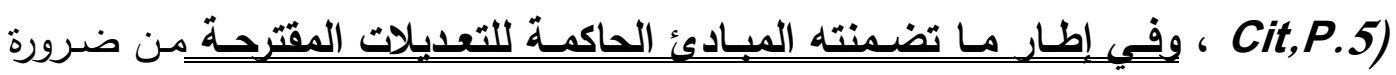
الالتزام بمبادئ التواصل الفعال المكونـة من عشرة مبادئ وردت في دراستين منفصلتين لـ

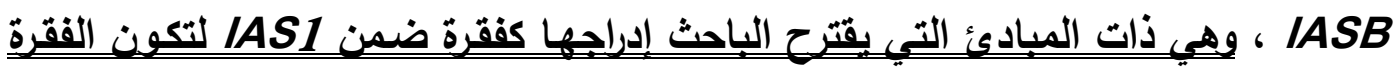

$$
\text { ج/10 }
$$




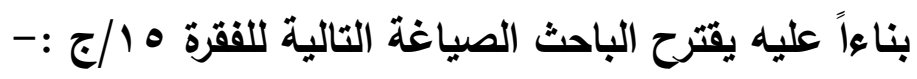
يعتد تحقق التواصل الفعال مع مستخدمي المجموعة الكاملة للقوائم المالية على المبادئ التالبة :-

| أن الكون المعلومات المفصح عنها خاصة بالوحدة ومصاغه وفقاً لظروفها.

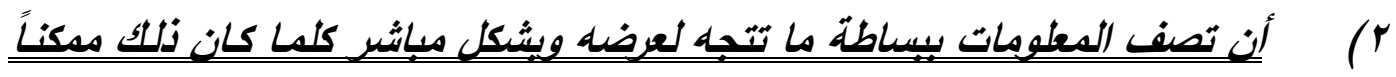
ويليون فقدان أي معلومات هامة .

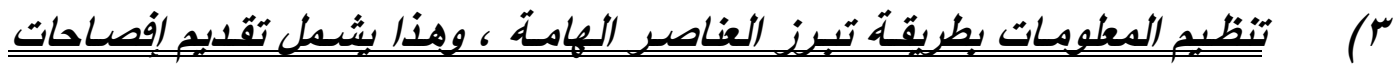

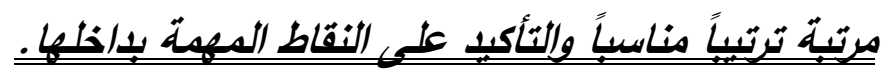

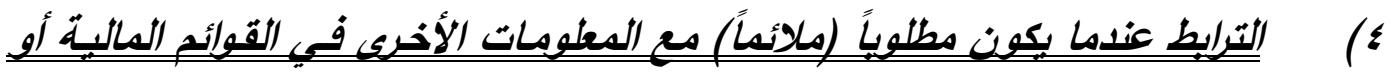
بالأجزاء الأخزى بالتقرير السنوي.

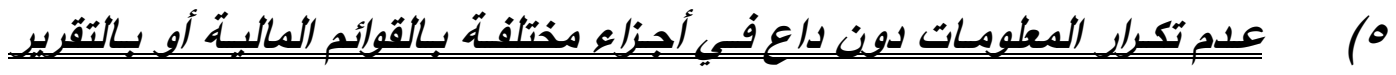
السنوي.

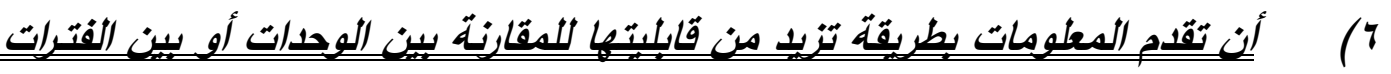
لنات الوحةة. ） أن تقدم المعلومات بشكل مناسب لهئا النوع في المعلومات ، على سبيل المثال

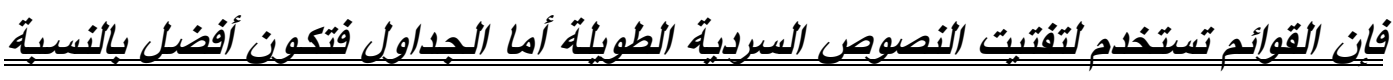
للمعلومات كثبة البيانات مثل تطليل آحال الاستحقاق.

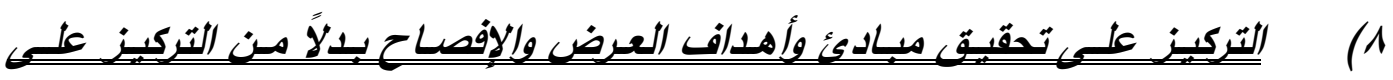
الرقواعد.

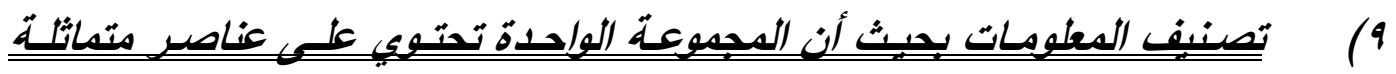
وفصل العناصس غير المتعاثلة.

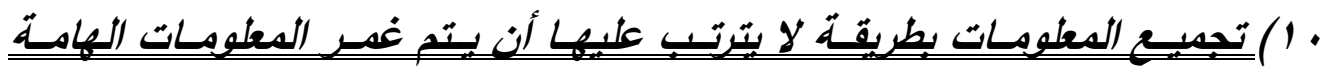
بالتقاصيل غير

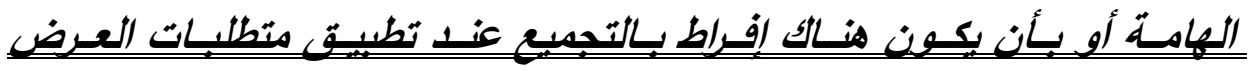


تضمن النطوير المقترح على الفقرة ؛ـٍ : 1-اقتراح حذف كل ما يشير إلى وجود قائمة إششادية للبنود الواجب إدراجها بقائمة المركز

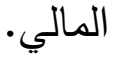
r-إضافة إلى حذف عبارة كحد أدنى لما كان يترتب عليها من تجاوز حدود النسبية وتوفير المعدين لكافة العناصر الواردة بالفقرة ؟ه بغض النظر عن مدى أهميتها. r-إضافة عبارة عندما تكون هامة.

وقد أكد IASB بالفقرة 7.9 من إطار إعداد التقرير المالي أنه قد يكون من المناسب أحياناً

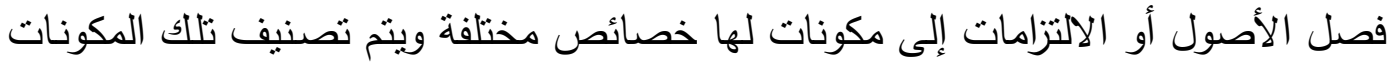
بشكل منفصل، ومن شأن ذلك أن يكون مناسباً عندما يؤدي هذا التصنيف بشكل منفصل إلى تعزيز فائدة المعلومـات وعلى سبيل المثال فقد يكون من المناسب تقسيم الأصسول

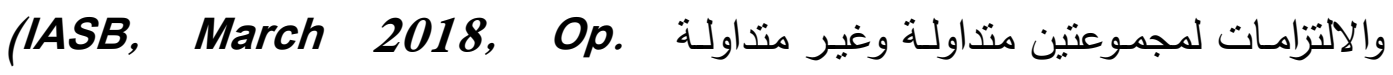

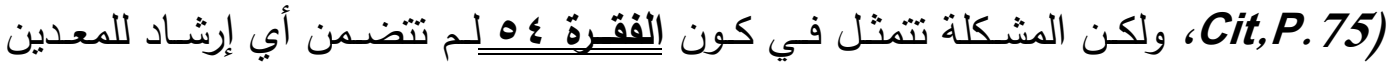
لكساعدتهم على تحديد التصنيف المناسب لعناصر الفقرة، وهو مـا بظهير الحاجـة لمرشـد

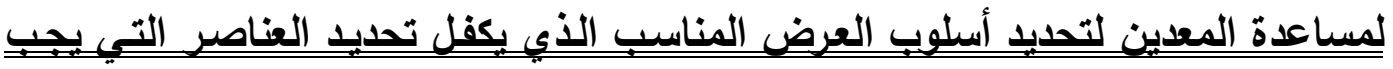
أن تعرض كعناصر رئيسية والأخرى التي يجب أن تعرض كمجاميع فرعية، وقد تضمنت دراسة لـ FASB حول العرض بيان الاعتبارات الضرورية الني تجب مراعاتها عند تحديد العناصر الرئيسية التي يجب أن تظهر في بيان مالي محدد وكذلك عند تحديد العناصر الفرعية التي ستدرج كمكونات بالعناصر الرئيسية، وتتحدد هذه الاعتبارات الضرورية فيما لتانيا يلي (FASB,August, 11.2016,P.p.12-13):أ-الحدث الذي تسبب في التعرف على عنصر ما، مثلاً معاملة أو تغيير في الظروف. ب-النشاط الذي يرتبط به عنصر ما. ج-التثابهات والاختلافات في نكرار (الأحداث) والتي من المتوقع أن تؤدي لمكونات مماتلة بالاخل الثامل وبمبالغ مماثلة سيعترف بها بالمستقبل. د-الوقت المتوقع حتى يتحقق الأصل أو يسدد الالتزام.

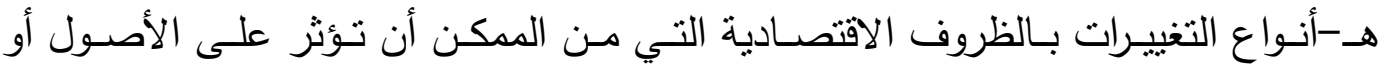
الخصوم أو الإيرادات أو المصروفات أو المكاسب، الخسائر في المستقبل. 


\section{ويقترح الباحث أن بضاف لتلك الاعتبارات ما يلي:-}

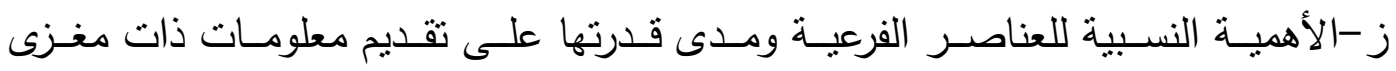
للمستخدمين. ح-مدى تجانس العناصر الفرعية المكونة للعنصر الرئيسي.

اعتمادا على ما سبق يعتقد الباحث ضرورة إضافة الفقرة ؛ه/أ لتضضمن الاعتبارات السابقة والتي يرى الباحث أنها ستمثل مرشد مهني لمساعدة المعدين على تحديد آليات تحديد

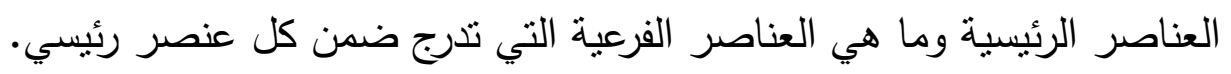

بناعاً عليه يقترح الباحث الصياغة التالية للفقرة ؛ ه/أ:

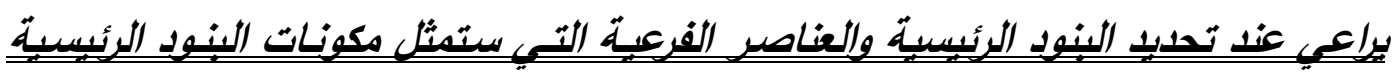

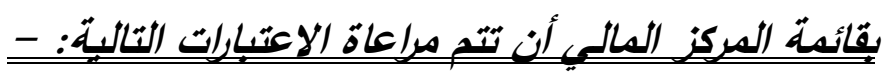
أر-الحلث الذي تسبب في التعرف على عنصر ما، مثلاً معاملة أو تغيير في الظروف.

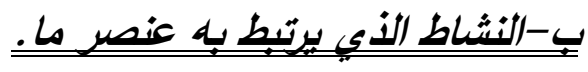

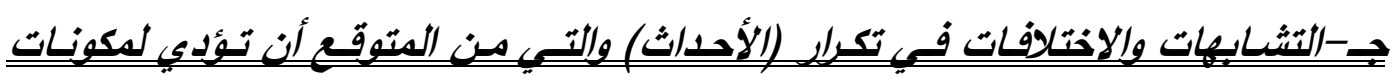

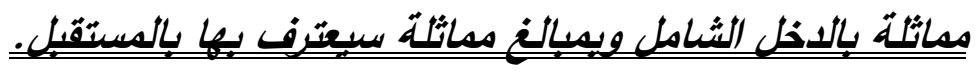

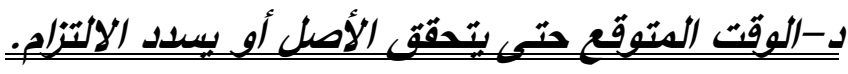

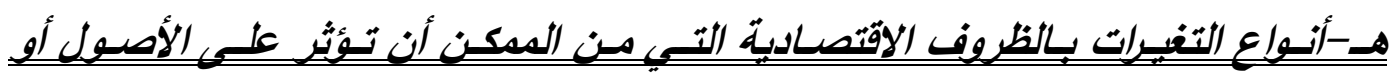
الخصوم أو الإيرادات أو المصروفات أو المكاسب، الخسائر في المستقبل. و -التشابهات أو الاختلافات بأسالبب القياس.

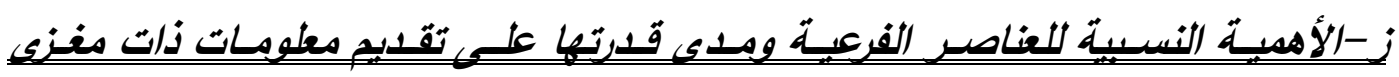
للمستخدمين. ح-مدى تجانس العناصر الفرعبة المكونتة للعنصر الئيسي. ثالثاً: التعدبلات على IAS1 المرتبطة باصدارIASB الإطار الفكري للتقرير المالي في - T19 _ 


\section{مارس ^1 .}

عقب إصدار الثكل الكامل لإطار إعداد التقرير المالي في مارس 1 إ. ب اصدر IASB دراسـة تحدد التعديلات الواجب إجراؤها على IAS1 ، وتضمنت هذه التعديلات ما يلي : (IASB, March 2018, P.p.9-12) :IAS1 + V لأققرة في الجزء المتعلق بالأهمية النسبية: أ-حذف ينص إطار إعداد وعرض القوائم المالية بالفقرة ه أن المستخدمين. يحل محلِها: المستخدمون ب-حذف الإشارة المرجعية رقم (ب).

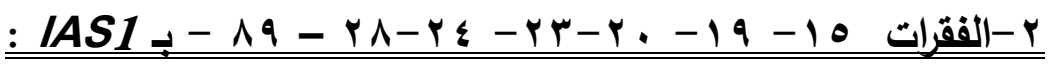
أ-حذف كلمة الإطار . - أن يحل محلها: الإطار الفكري للتقرير المالي (الإطار الفكري). ب-حذف الإشارات المرجعية رقم (ع)، رقم (0)، رقم (T).

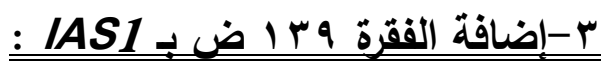

لتشير لكون التعديلات أعلاه ستطبق بداية من //// • • ب مع السماح بالتطبيق المبكر حالة تطبيق الوحدة لباقي التعديلات على المعايير الأخرى المرتبطة بإصدار الإطار وهي IFRS2, IFRS 3, IFRS 6, , IAS1,IAS8,IAS34,IAS37,IAS38, المعايير

\section{القسم السادس: الدراسة الاختبارية:؛}

يتتاول الباحث فيما يلى التحقق من صحة فروض البحث من خلال تصميم قائمة استقصاء.

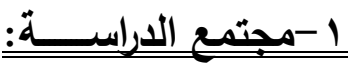
يرى الباحث أن يتكون المجتمع المستقصى أرائه من الفئات التالية:

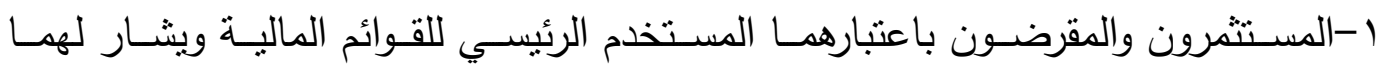
بالمستخدمين. r-معدو القوائم المالية بالثركات المساهمة المصرية. 
r-مراجعو القوائم المالية للشركات المساهمة المصرية. ع-المنظمون بالهيئة العامة لسوق المال والبورصة المصرية (مسئولي إدارات الإفصاح).

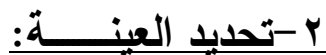

1-المستخدمون وُجه لهم عدد 77 قائمة استقصاء. r-معدو القوائم المالية وُجه لهم عدد ب-مراجعو القوائم المالية وُجه لهم عدد •ـ قائمة استقصاء. ع -المنظمون وُجه لهم عدد r ا قائمة استقصاء.

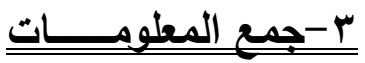
تم جمع المعلومات بعد إرسال قوائم الاستقصاء. ع -نسبة الاستجابة

تلقى الباحث ردود عن 90 قائمة من إجمالي • V ا قائمة بنسبة استجابة بلغت 00.11 \% . ه-التحقق من صحة الفروض:

يتم التحقق من صحة الفروض من خلال تحليل إجابات عينة الدراسة على الأسئلة الواردة بقائمة الاستقصاء.

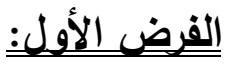

تتضح الحاجة لتطوير نموذج الإفصاح المحاسبي في إطار تعدد أبعاد مشكلة الإفصاح من

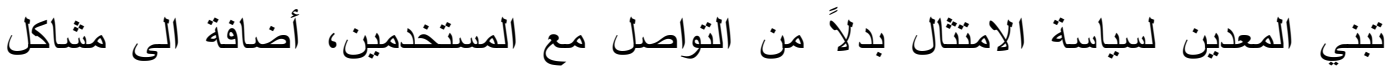
العرض المحاسبي وكذللك انخفاض جودة المعلومات المفصح عنها.

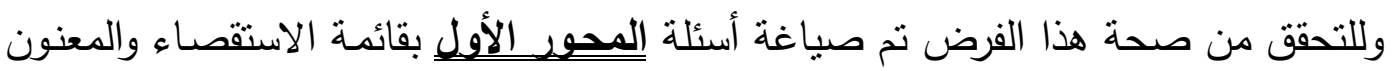
بتحبد أبعاد مشكلة الإفصاح المحاسبي، وعدد أسئلة هذا المحور ست أسئلة. القفرض الثاني:

يمنل إصدار IASB لمبادرة الإفصاح - تعديلات IAS1 استجابة تنظيمية للأزمة المالية العالمية تهدف إلى إيجاد حلول لمشاكل نموذج الإفصاح المحاسبي.

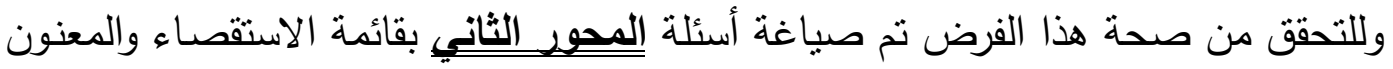

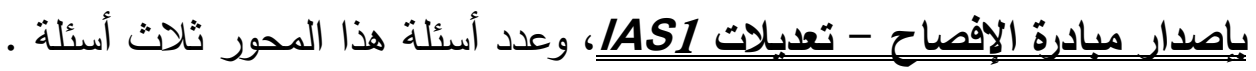




\section{الفرض الثالث:}

يجب أن يستند النطوير المقترح على مبادرة الإفصاح - تعديلات IAS1 على مجموعة من المبادئ التي تكفل الدد من التعقيد الحالي بالتقارير المالية، ودعم مستوى التواصل الفئل الفعال

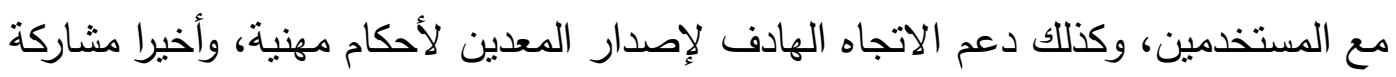

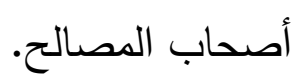
وللتحقق من صحة هذا الفرض نم صباغة أسئلة المحور الثالث بقائمة الاستقصاء والمعنون المبادئ التي بستند عليها التطوير المقترح؛ وعدد أسئلة هذا المحور ست أسئلة. الفرض الرابع: تمتل التعديلات المقترحة على مبادرة الإفصاح - تعديلات IAS1 المرنبطة بقائمة المركز

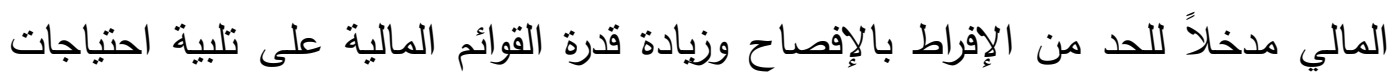
مستخدميها. وللتحقق من صحة هذا الفرض تم صياغة أسئلة المحور الرابيع بقائمة الاستقصاء والمعنون التطوير المقترح على مكونات مبادرة الإفصاح - تعليلات IAS1 (التعديلات المرتبطة

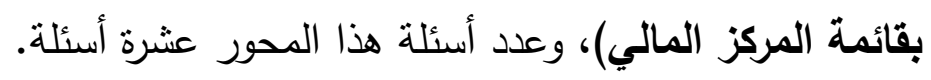

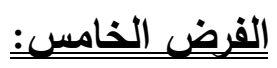
تمثل التعديلات المقترحة على مبادرة الإفصاح - تعديلات IAS1 المرتبطة بقائمة (قائمتي)

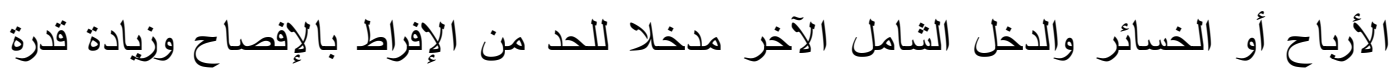
القوائم المالية على تلبية احتياجات مستخدميها. وللتحقق من صحة هذا الفرض نم صياغة أسئلة المحور الخامس بقائمة الاستقصاء

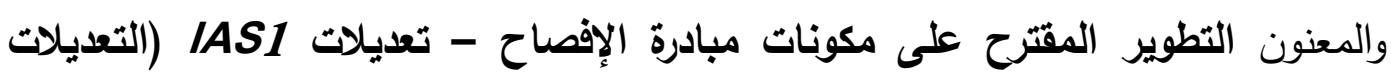

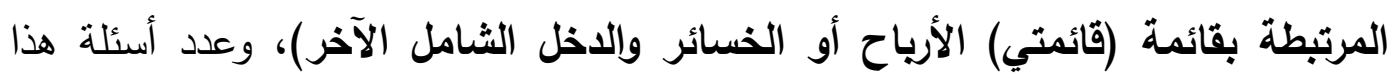
المحور ستة عثر سؤالًا. |لفرض السادس: 
تمثل التعديلات المقترحة على مبادرة الإفصاح - تعديلات IAS1 المرتبطة بالإيضاحات مدخلا للحد من الإفراط بالإفصاح وزيادة قدرة القوائم المالية على تلبية احتياجات مستخدميها.

وللتحقق من صحة هذا الفرض نم صياغة أسئلة المحور السادس بقائمة الاستقصاء

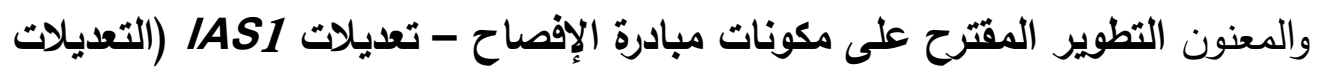

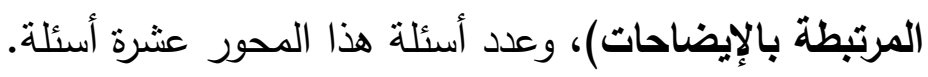

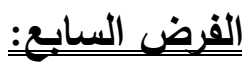
تمنل التعديلات المقترحة على مبادرة الإفصاح - تعديلات IAS1 المرتبطة بالإفصاح عن

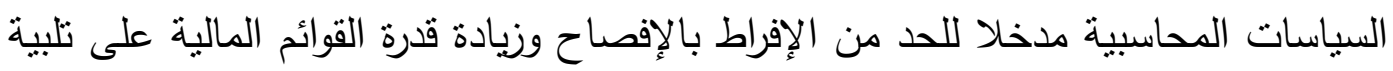
احتياجات مستخدميها. وللتحقق من صحة هذا الفرض تم صباغة أسئلة المحور السابع بقائمة الاستقصاء والمعنون التطوير المقترح على مكونات مبادرة الإفصاح- تعديلات IAS1 التعديلات المرتبطة بالإفصاح عن السياسات المحاسبية)، وعدد أسئلة هذا المحور أحد عشر سؤاتِالأ. الفرض الثامن التعديلات الواردة ضمن مبادرة الإفصاح- تعديلات IAS1 تمثل تعديلات محدودة النطاق

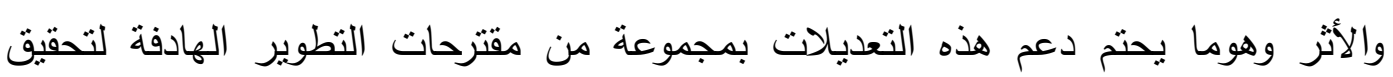
الأهداف المرجو تحققها من إصدار المبادرة. وللتحقق من صحة هذا الفرض تم صياغة أسئلة المحور الثامن بقائمة الاستقصاء والمعنون محدوية أثر مكونات مبادرة الإفصاح - تعديلات IAS1، وعدد أسئلة هذا المحور سؤالان.

الفرض التاسع تؤدي التعديلات المقترحة على فقرات IAS1 التي لم ترد ضمن مبادرة الإفصاح- تعديلات IAS1 وزيادة قدرة القوائم المالية على تلبية احتياجات مستخدميها. 
وللتحقق من صحة هذا الفرض تم صياغة أسئلة المحور التاسيع بقائمة الاستقصاء والمعنون

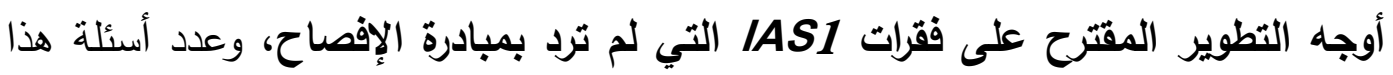
المحور ثناثة وعثرين سؤالا.

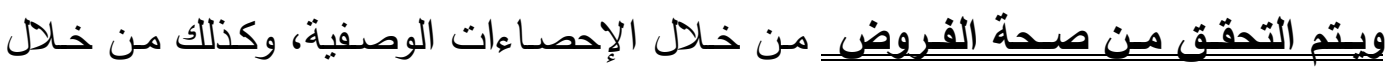
استخدام اختبار Chi-Square Test، وهو أحد الاختبارات اللامعلمية الهامة، وله العديد

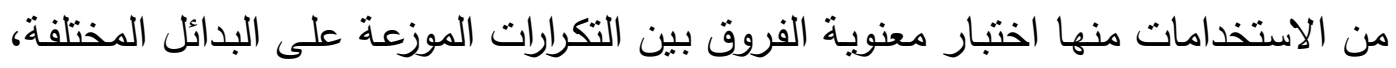
ولذلك يمكن استخدامه لاختبار معنوية الفروق بين التكرارات الموزعة على الدرجات المختلفة

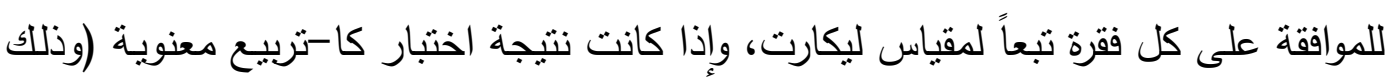

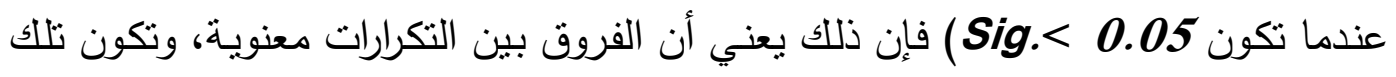
الفروق لصالح الآراء التي حصلت على النسبة الكبرى من التكرارات. أولًا-الإحصاءعات الوصفية:

يتضمن الجدول ( ) الإحصاءات الوصفية (الوسط الحسابي والانحراف المعياري) لإجابات

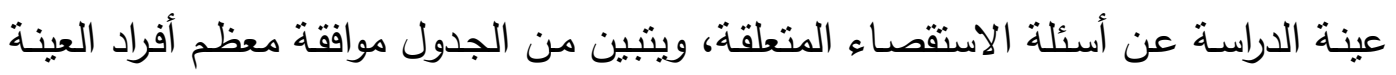

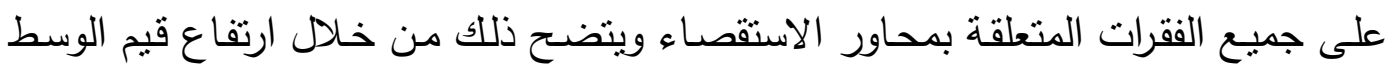

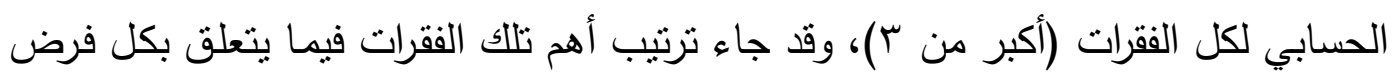

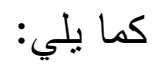

جدول (1) الإحصاءات الوصفية

\begin{tabular}{|c|c|c|}
\hline الانحراف المعياري & الوسط الحسابي & 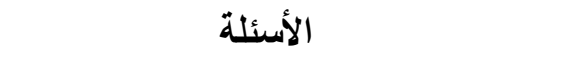 \\
\hline & & مجموعة الأسئلة المرتبطة بالفرض الأول: \\
\hline 0.925 & 4.26 & Q1_r \\
\hline 0.974 & 4.20 & Q1_1 \\
\hline \multirow[t]{2}{*}{1.041} & 4.18 & Q1_7 \\
\hline & & مجموعة الأسئلة المرتبطة بالفرض الثاني: \\
\hline 0.878 & 4.32 & Qr_r \\
\hline \multirow[t]{2}{*}{0.931} & 4.20 & Qr_r \\
\hline & & مجموعة الأسئلة المرتطة بالفرض الثالث: \\
\hline 0.881 & 4.38 & $Q r_{-} 1$ \\
\hline
\end{tabular}

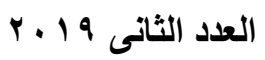

مجلة المحاسبة والمراجعة 


\begin{tabular}{|c|c|c|}
\hline 0.746 & 4.36 & Qr_r \\
\hline \multirow[t]{2}{*}{0.774} & 4.33 & Qr_Y \\
\hline & & مجموعة الأسئلة المرتبطة بالفرض الرابيع: \\
\hline 0.782 & 4.44 & Q4_10 \\
\hline 0.842 & 4.39 & Q4_2 \\
\hline \multirow[t]{2}{*}{0.824} & 4.36 & Q4_7 \\
\hline & & مجموعة الأسئلة المرتبطة بالقرض الخامس: \\
\hline 0.650 & 4.48 & Q5_7 \\
\hline 0.712 & 4.46 & Q5_12 \\
\hline \multirow[t]{2}{*}{0.712} & 4.44 & Q5_2 \\
\hline & & مجموعة الأسئلة المرتبطة بالفرض السادس: \\
\hline 0.649 & 4.45 & Q6_1 \\
\hline 0.768 & 4.44 & Q6_2 \\
\hline \multirow[t]{2}{*}{0.724} & 4.43 & Q6_10 \\
\hline & & مجموعة الأسئلة المرتبطة بالفرض السابع: \\
\hline 0.727 & 4.50 & Q7_7 \\
\hline 0.741 & 4.54 & Q7_2 \\
\hline \multirow[t]{2}{*}{0.756} & 4.48 & Q7_5 \\
\hline & & مجموعة الأسئلة المرتبطة بالقرض الثامن: \\
\hline 0.770 & 4.48 & Q^_2 \\
\hline \multirow[t]{2}{*}{0.797} & 4.47 & Q^_1 \\
\hline & & مجموعة الأسئلة المرتبطة بالقرض التاسع: \\
\hline 0.678 & 4.58 & Q9_19 \\
\hline 0.740 & 4.55 & Qq_V \\
\hline 0.727 & 4.54 & Qq_ir \\
\hline
\end{tabular}

Chi-Square ثانياً-نتيجة الاختبار الإحصائي لفروض الاراسة باستخدام اختبار

:. Test 
يوضح جدول (r) نتائج التحليل ((فيما يتعلق بالأسئلة المحققة لأعلى وسط حسابي وفقاً لما

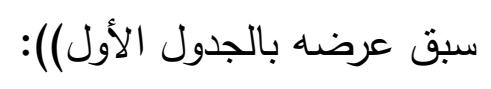

Chi-Square Test جدول (ץ) نتائج اختبار كا-تربيع

\begin{tabular}{|c|c|c|}
\hline \multicolumn{2}{|c|}{$\begin{array}{c}\text { اختبار كا-تربيع } \\
\text { Chi-square Test }\end{array}$} & \multirow[t]{2}{*}{ 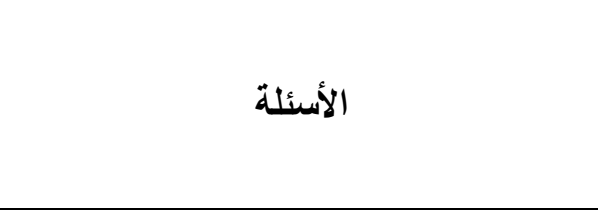 } \\
\hline 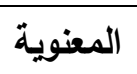 & القيمة & \\
\hline & & مجموعة الأسئلة المرتبطة بالفرض الأول: \\
\hline 0.000 & 88.211 & Q1_r \\
\hline 0.000 & 79.789 & Q1_1 \\
\hline \multirow[t]{2}{*}{0.000} & 80.421 & Q1_4 \\
\hline & & مجموعة الأسئلة المرتبطة بالفرض الثاني: \\
\hline 0.000 & 97.158 & Qr_r \\
\hline \multirow[t]{2}{*}{0.000} & 87.579 & Qr_r \\
\hline & & مجموعة الأسئلة المرتبطة بالفرض الثالث: \\
\hline 0.000 & 98.526 & Qr_l \\
\hline 0.000 & 100.316 & $Q^{r} r^{r}$ \\
\hline \multirow[t]{2}{*}{0.000} & 107.895 & Qr_t \\
\hline & & مجموعة الأسئلة المرتبطة بالفرض الرابع: \\
\hline 0.000 & 116.947 & Q4_10 \\
\hline 0.000 & 109.895 & Q4_2 \\
\hline \multirow[t]{2}{*}{0.000} & 102.000 & Q4_7 \\
\hline & & مجموعة الأسئلة المرتبطة بالفرض الخامس: \\
\hline 0.000 & 122.421 & Q5_7 \\
\hline 0.000 & 122.000 & Q5_12 \\
\hline 0.000 & 122.000 & Q5_2 \\
\hline
\end{tabular}




\begin{tabular}{|c|c|c|}
\hline & & مجموعـــة الأســـئلة المرتبطـــة بــالفرض \\
\hline 0.000 & 118.000 & Q6_1 \\
\hline 0.000 & 118.421 & Q6_2 \\
\hline \multirow[t]{2}{*}{0.000} & 115.263 & Q6_10 \\
\hline & & مجموعة الأسئلة المرتبطة بالفرض السابع: \\
\hline 0.000 & 140.421 & Q7_7 \\
\hline 0.000 & 142.316 & Q7_2 \\
\hline \multirow[t]{2}{*}{0.000} & 125.684 & Q7_5 \\
\hline & & مجموعة الأسئلة المرتبطة بالفرض الثامن: \\
\hline 0.000 & 128.000 & Q^_2 \\
\hline \multirow[t]{2}{*}{0.000} & 128.105 & Q^_1 \\
\hline & & مجموعة الأسئلة المرتبطة بالفرض التاسع: \\
\hline 0.000 & 150.526 & Q9_19 \\
\hline 0.000 & 146.000 & Qq_V \\
\hline 0.000 & 140.526 & Qq_ir \\
\hline
\end{tabular}

ومن الجدول السابق يتضح أنه توجد فروق بين التكرارات الموزعة على درجات الموافقة على

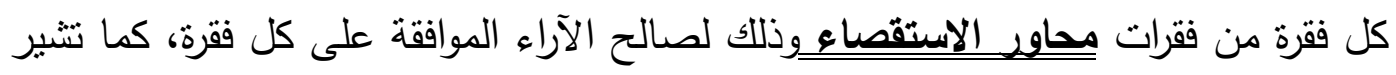

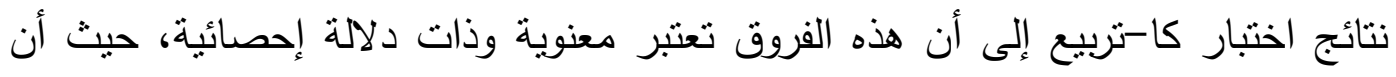

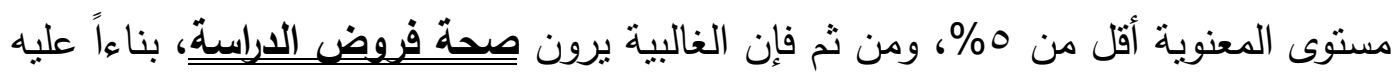
يتم قبول فروض الدراسة.

\section{ثالثا-المقارنة بين أراءع فئات الاراسية:}

لاختبار معنوية الفروق بين آراء فئات الدراسة الأربعة (مستخدمين - معدين - مراجعين منظمين) حول الحاجة لنطوير نموذج الإفصاح المحاسبي، وقد نم استخدام اختبار كروسكال - واليس Krusskal-Wallis، ويستخدم هذا الاختبارلاختبار معنوية الفروق بين أكثر من فئتين، ويعتبر البديل اللامعلمي لتحليل التباين ANOVA واختبار ف كانت نتيجة اختبار كروسكال - واليس معنوية (وذللك عندما تكون 0.05 > Sig) فإن ذللك 
يعني أن الفروق بين الفئات الأربع معنوية ، وتكون تلاك الفروق لصالح الفئة ذات أكبر

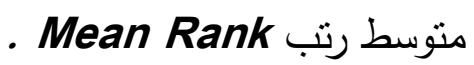

وقد نبين أن نتيجة اختبار كروسكال كواليس غير معنوية حيث أن مستوى المعنوية أكبر

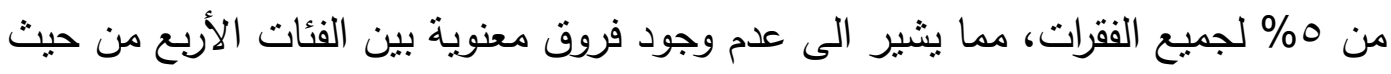

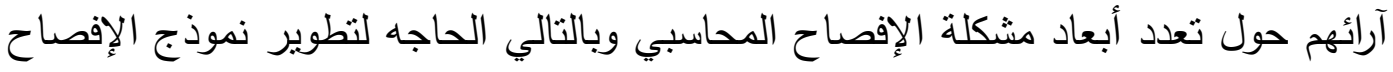
المحاسبي، ويستثى من ذلك الفقرة الثامنة بالفرض السابع، إضافة إلى الفقرتين الثانية والثامنة بالفرض التاسع حيث أن قيمة المعنوية أقل من 0\% مما يثير لوجود فروق معنوية

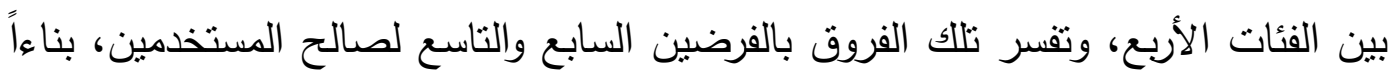

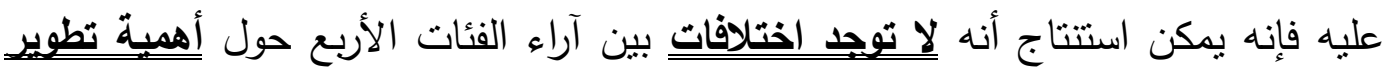

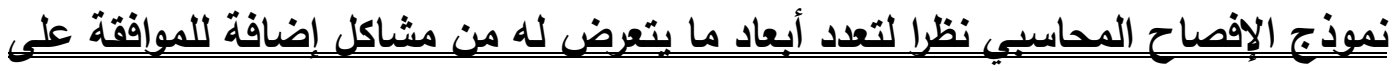

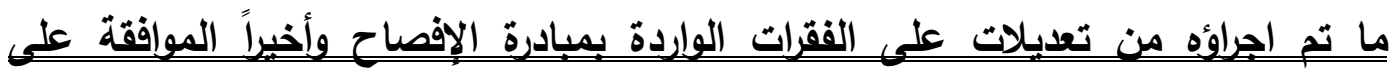

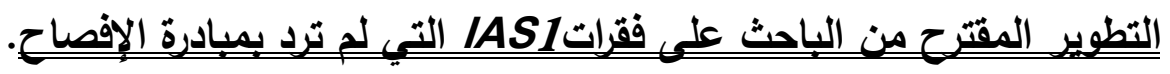

القسم السابع: الخلاصة والنتائج والتوصبات خلاصة البحث: تمثل هدف البحث في تقييم مستوى جودة مكونـات مبادرة الإفصساح - تعديلات IASB الصادرة عن IASB وذلك بهدف تحديد قدرتها على علاج المشاكل التي يتعرض لها نموذج

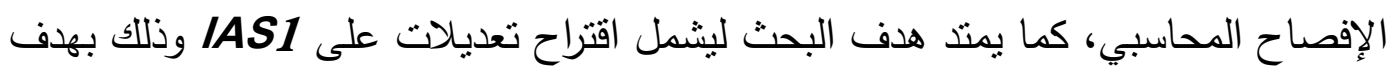

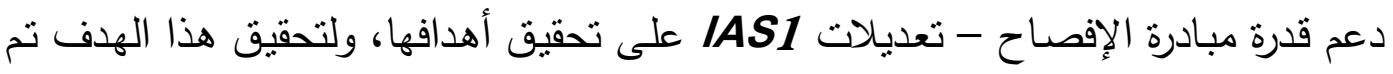
تقسيم البحث إلى سبعة أقسام على النحو التالي: دادئ القسم الأول: منهجية البحث القسم الثاني: إصدار مبادرة الإفصاح

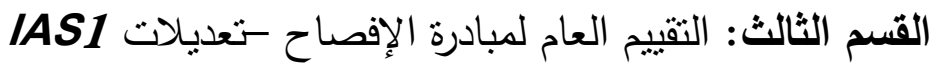
القسم الرابع: المبادئ التي يستند عليها التطوير المقترح على مبادرة الإفصاح- تعديلات IAS1

القسم الخامس: تقييم وتطوير مبادرة الإفصاح -تعديلات IAS1 - TrA - 
القسم السادس: الدراسة الاختبارية القسم السابع: الخلاصة والنتائج والتوصيات

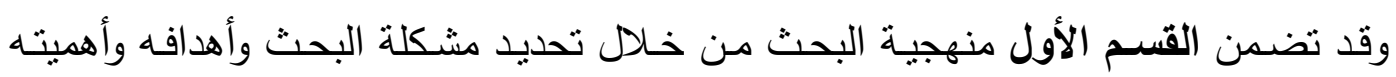

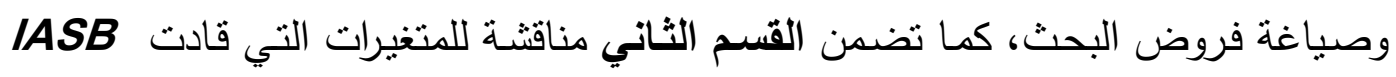

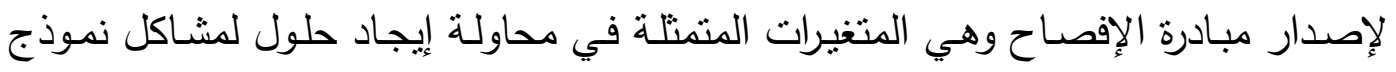
الإفصاح المحاسبي وكذلك حاجه مجتمع التقرير المالي لمبادرة تمثل إطاراً شاملاً للإفصـاح

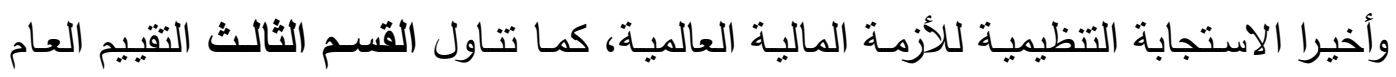

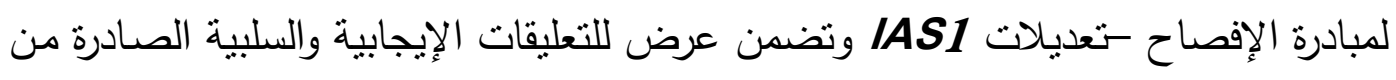

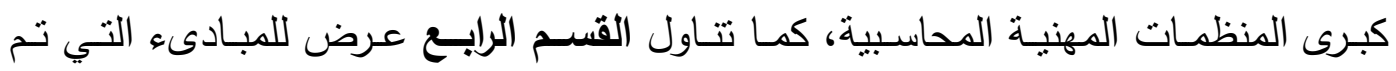

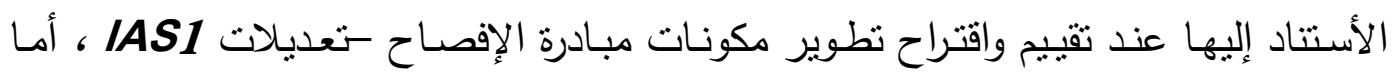

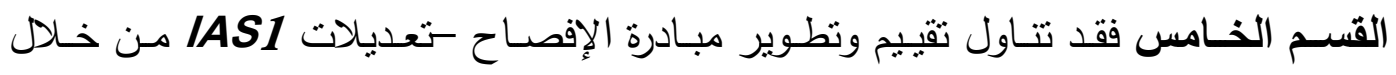

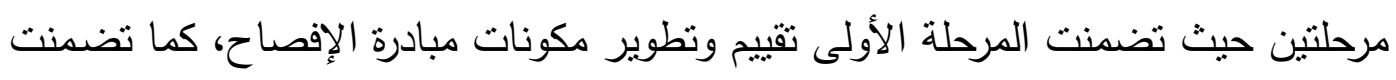

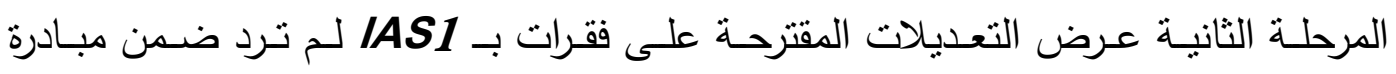

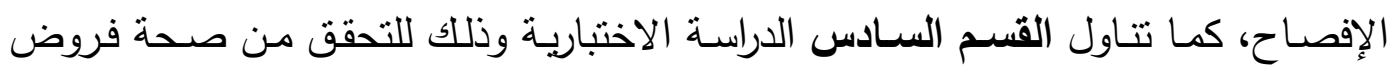

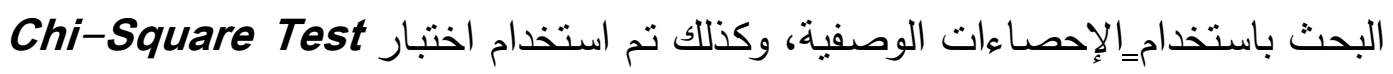

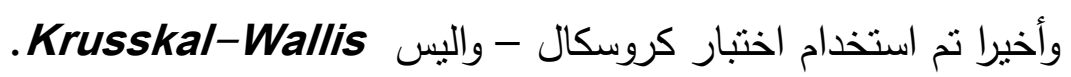

\section{نتائج البحث:}

توصل الباحث من خلال الاراستين النظرية والاختبارية إلى النتائج التالية: -

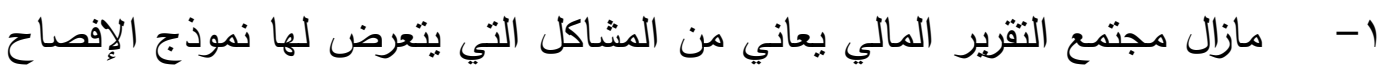

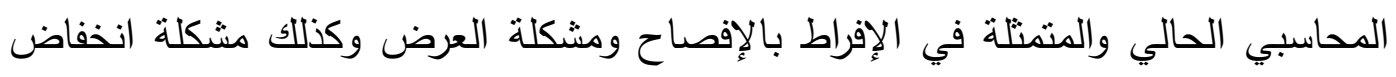
جودة المعلومات وأخيرا مشكلة عدم تمانل المعلومات. r أهمية اصدار IASB لمبادرة الإفصاح باعتبارها استجابة تنظيمية للأزمة المالية العالمية تهدف إلى تطوير نموذج الإفصاح المحاسبي.

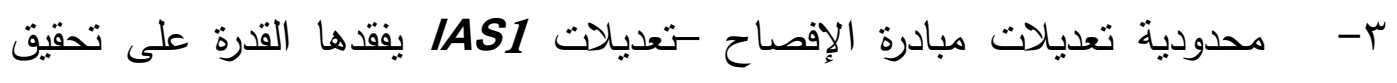

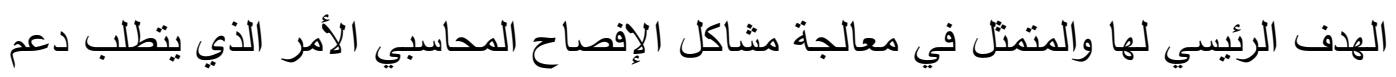


هذه التعديلات بمجموعة من مقترحات التطوير الهادفة لتحقيق الأهداف المرجو تحققها من إصدار المبادرة.

ع - تمتل التعديلات المقترحة على مبادرة الإفصاح - تعديلات IAS1 المرتبطة بكلا من قائمة المركز المالي وقائمة (قائمتي) الأرباح أو الخسائر والدخل الثنامل الآخر مدخلاً

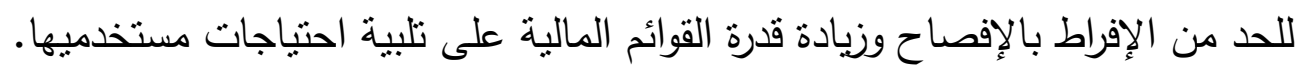

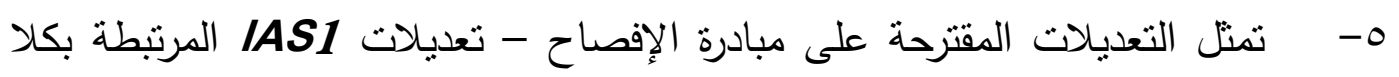
من الإيضاحات والإفصاح عن السياسات المحاسبية مدخلاً للحد من الإفراط بالإفصاح وزيادة قدرة القوائم المالية على تلبية احتياجات مستخدميها.

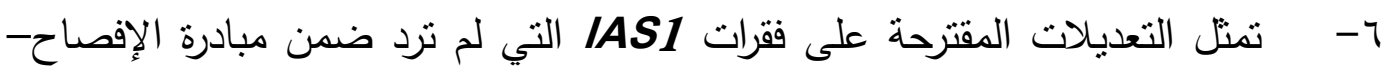

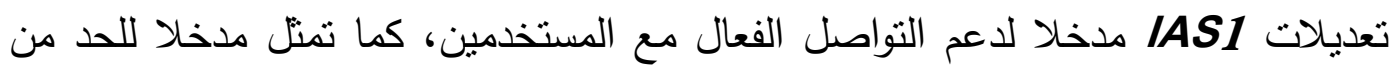
الإفراط بالإفصاح وزيادة قدرة القوائم المالية على تلبية احتباجات مستخدميها.

\section{التوصبيات:}

1- ضرورة البدء بإصدار إطار متكامل للإفصاح المحاسبي يؤدى دوره في تنظيم وترشيد الإفصاح المحاسبي وكذللك توفير آليات لمساعدة المعدين على إصدار أحكام مهنية.

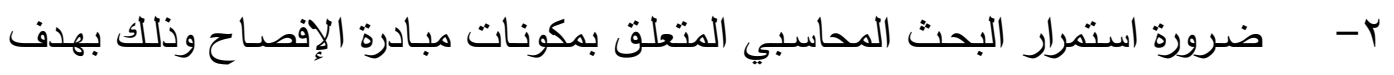
التقييم أو تقديم مقترحات للنطوير تنساعد على تحقق الهـف الرئيسي لمبادرة الإفصـاح والمتمتل في علاج مشاكل نموذج الإفصاح المحاسبي.

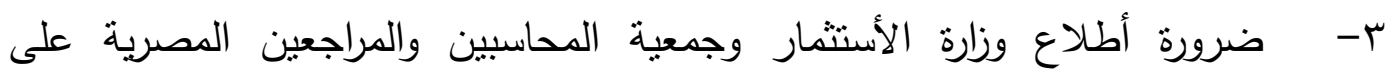

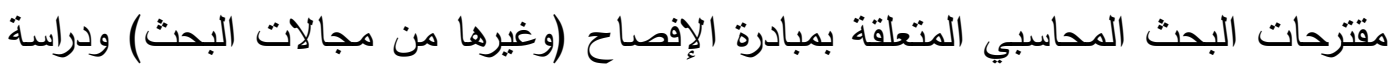

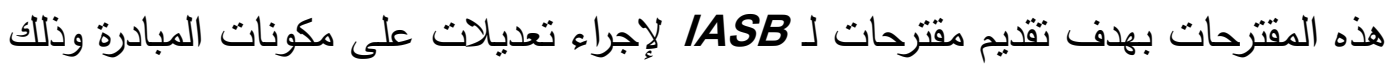

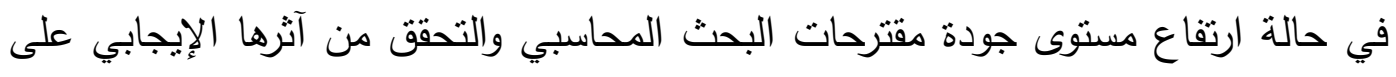

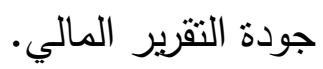




\section{Periodicals:}

- American Accounting Association AAA, Response to the Financial Accounting Standards Board's and the InternationalAccounting Standard Board's Joint Discussion Paper Entitled Preliminary Views on Financial Statement Presentation, Accounting Horizons, American Accounting Association, Vol. 24, No. 1,2010 .

- $\quad$ Brian P. Miller, The Effects of Reporting Complexity on Small and Large Investor Trading, 2010, The Accounting Review, Vol. 85, No. 6, 2010.

Erik F. Gerding, Disclosure 2.0: Can Technology Solve Overload, Complexity, and Other Information Failures?, $U$ of Colorado Law Legal Studies Research Paper No. 17-12, Tulane Law Review, Vol. 90, No. 5, U of Colorado Law Legal Studies Research, 2016. 
- Itay Goldstein and liyan Yang, Information Disclosure in Financial Markets, Annual Review of Financial Economics, 9,2017 .

James Guthrie, Leed. Parker, Accounting, Auditing \& Accountability, Journal,Vol. 29 No. 1, 2016.

Omaima Hassan, Claire Marston, Disclosure Measurement in the Empirical Accounting Literature - $\boldsymbol{A}$ Review Article, Working Paper No. 10-18, Economics and Finance Working Paper Series, July $\quad 15, \quad 2010, \quad$ Available at SSRN: $\underline{\text { https://ssrn.com/abstract=1640598 or http://dx.doi.org/10.21 }}$ 39/ssrn.1640598.

- Tom Berglund, Incentives for complexity in financial regulation, The Journal of Risk Finance, Vol. 15 No. 2, 2014.

- Youchaotan, Yuyuliu, How do investors view information disclosure quality rating? The effect of FNFI on corporate investment efficiency, Nankai Business Review International, Vol. 8 No. 2, 2017.

\section{Others:}

- Chartered Accountants Ireland CAI,The Accounting Committee, Comments on Exposure Draft ED/2014/1: Disclosure Initiative - Proposed amendments to IAS 1 July 2014.

- Deloitte\&Touch, Comments on Exposure Draft ED 2014/1 Disclosure Initiative: Proposed amendments to IAS 1, July. 21, 2014.

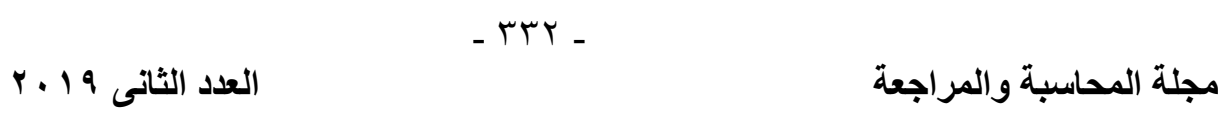


- Deloitte\&Touch, Proposed Statement of Financial Accounting Concepts, Concepts Statement 8 - Conceptual Framework for Financial Reporting - Chapter 7: Presentation Nov. 9. 2016.

- $\quad$ Ernst \& Young Global Limited EY, Comments on Exposure Draft ED/2014/1 Disclosure Initiative (Proposed amendments to IAS 1), July 23. 2014.

- Ernst \& Young Global Limited EY,, Improving disclosure effectiveness, July 2014.

- $\quad$ Ernst \& Young Global Limited EY, Invitation to comment Exposure Draft ED/2014/1 Disclosure Initiative (Proposed amendments to IAS 1), July 23, 2014.

- European Financial Reporting Advisory Group EFRAG, Comment Letter on Discussion Paper DP/2017/1 Disclosure Initiative - Principles of Disclosure, Oct12, 2017.

- European Financial Reporting Advisory Group EFRAG, Re:

Disclosure Initiative (Proposed amendments to IAS 1), July. 22. 2014.

- $\quad$ Financial Accounting Standards Board, FASB, Chairman

Russ Golden, Georgia Society of CPAs Southeastern Accounting Show, Atlanta, Georgia, August 31, 2017.

- $\quad$ Financial Accounting Standards Board FASB, Concepts

Statement 8-Conceptual Framework for Financial Reporting:

Chapter 7: Presentation, August 11, 2016.

- Financial Accounting Standards Board, FASB, International Accounting Standards Board, IASB,, Discussion Paper: Preliminary Views on

Financial Statement Presentation, 2008

$$
\begin{aligned}
& \text { العدد الثانى } 9 \text { 1. } \\
& \text { - } \\
& \text { مجلة المحاسبة والمراجعة }
\end{aligned}
$$


- $\quad$ Financial Accounting Standards Board FASB, Remarks of

Russ Golden Chairman of Financial Accounting Standards Board, August. 31, 2017.

- $\quad$ Financial Reporting Council FRC, Cutting clutter: Combating clutter in annual reports.

- $\quad$ Financial Reporting Council, FRC,, Feedback Statement Thinking about disclosures in a broader context - A roadmap for a disclosure framework, June 2013.

- $\quad$ Financial Reporting Council, FRC, Louder than Words -

Principles and actions for making corporate reports less complex and more relevant, 2009.

- $\quad$ Financial Reporting Council FRC, Response to Exposure Draft 'Disclosure Initiative (Proposed amendments to IAS 1), July 7. 2014.

- $\quad$ Financial Reporting Council, FRC, Thinking about

disclosures in a broader context A road map for a disclosure framework, Oct 2012.

- $\quad$ Financial Reporting Council FRC, True and Fair, June 2014.

- International Accounting Standards Board, IASB,

Amendments to IAS 1 Presentation of Financial Statements A Revised Presentation, March 2006.

- International Accounting Standards Board, IASB,

Conceptual Framework for Financial Reporting, March 2018.

- International Accounting Standards Board, IASB,

Disclosure Initiative amendments to IAS 1, Dec.2014.

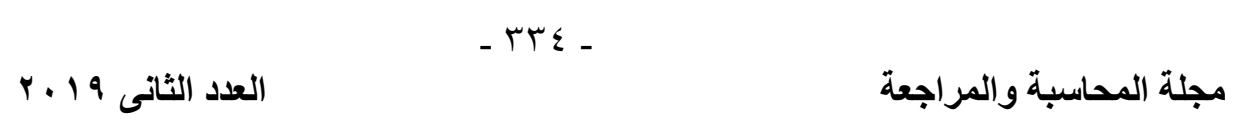


- International Accounting Standards Board, IASB,

Disclosure Initiative: Amendments to IAS 1: due process steps \& balloting, Oct. 2014.

- International Accounting Standards Board, IASB,

Disclosure initiative An overview, Sep 2013.

- International Accounting Standards Board, IASB,

Disclosure Initiative-Principles of Disclosure, March 2017.

- International Accounting Standards Board, IASB,

Disclosure Initiative: Proposed amendments to IAS 1: feedback summary Sep.2014.

- International Accounting Standards Board, IASB,

Disclosure Initiative: Proposed amendments to IAS 1, March, 2014.

- International Accounting Standards Board, IASB,

Discussion Forum-Financial Reporting Disclosure Feedback Statement, May 2013.

- International Federation of Accountants (IFAC), INTERNATIONAL GOOD PRACTICE GUIDANCE PRINCIPLES FOR EFFECTIVE BUSINESS REPORTING PROCESSES: EXECUTIVE SUMMARY, September 2013.

- $\quad$ KPMG IFRG Limited, Comments on Exposure Draft:

Disclosure Initiative - Proposed amendments to IAS 1, July. 23. 2014.

- KPMG IFRG Limited, The future of corporate reporting: towards a common vision, 2013.

- $\quad$ Sergio Gilotta, The Conflict between Disclosure in Securities Markets and the Firm's Need for Confidentiality: Theoretical

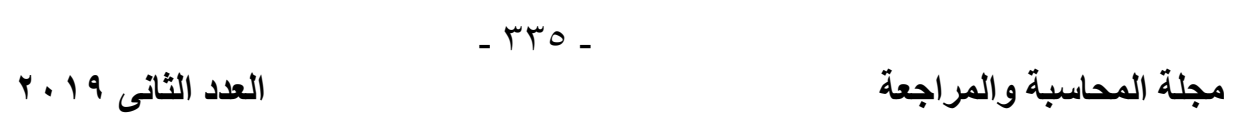


Framework and Regulatory Analysis, Working Paper, August 2, 2010, Available at

SSRN: https://ssrn.com/abstract=1709334 or http://dx.doi.org/10.21 39/ssrn.709334.

- The Association of Chartered Certified Accountants ACCA, Complexity in Financial Reporting2009.

- The Australian Accounting Standards Board AASB, Comments on Exposure Draft ED/2014/1 Disclosure Initiative, August. 5. 2014.

- $\quad$ The Chartered Financial Analyst Institute, CFA, A Comprehensive Business Reporting Model Financial Reporting for Investors, 2007 .

- $\quad$ The Chartered Financial Analyst Institute, CFA, Financial Reporting Disclosures Investor Perspectives on Transparency, Trust, and Volume, July.2013.

- $\quad$ The Chartered Financial Analyst Institute, CFA, Janes

Allen, Mathew Waldron, 2011.

- $\quad$ The Chartered Financial Analyst Institute, CFA, Re:

Disclosure Initiative: Proposed Amendments to IAS 1, August. 28. 2014.

- The European Corporate Governance Institute, ECGI,

Christian Leuz, Peterwys oscki, The Economics of Disclosure and Financial Reporting Regulation: Evidence and Suggestions for Future Research, Law Working Paper N³06/2016, Chicago Booth Research Paper No. 16-03. Available at

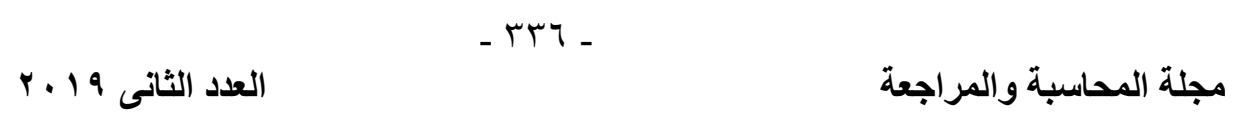


SSRN: https://ssrn.com/abstract=2733831 or http://dx.doi.org/10.21 39/ssrn.2733831.

- $\quad$ The European Securities and Markets Authority ESMA,

Comments on The IASB's Exposure Draft Proposed Amendments to IAS 1 - Presentation of Financial Statements under the Disclosure Initiative, June 23, 2014.

- The Institute of Chartered Accountants in England and Wales ICAEW, Comments on Disclosure Initiative - Principles of Disclosure Oct. 2. 2017.

- $\quad$ The Institute of Chartered Accountants in England and Wales ICAEW, Disclosure Initiative Proposed amendments to IAS 1, 2014.

- $\quad$ The Institute of Chartered Accountants in England and Wales , ICAEW, Financial Reporting Disclosures: Market and Regulatory Failure information for better markets initiative, Dec.2013.

- $\quad$ The Institute of Chartered Accountants in England and Wales ICAEW, ICAEW Rep 96/14 - Disclosure Initiative: Proposed Amendments to IAS 1, July 2014.

- $\quad$ The Institute of Chartered Accountants of Scotland, ICAS, Making corporate reports readable- time to cut the Chase, 2010.

- $\quad$ The Institute of Chartered Accountants of Scotland, ICAS, Making corporate Reports Relevant, 2013.

- $\quad$ The Institute of Chartered Accountants of Scotland, ICAS, The New Zealand Institute of Chartered Accountants, NZICA, Losing the excess baggage - reducing disclosures in financial statements to what is important, 2011.

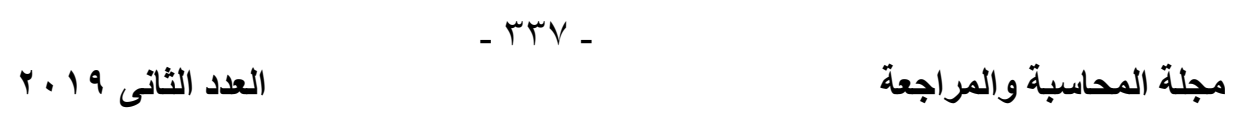


- $\quad$ The Institute of Management Accountants IMA, Comment Letter on IASB Disclosure Initiative: Proposed amendments to IAS 1, July. 7. 2014.

الملاحق

ملحق (1) : الثكل الكامل للتعديلات على IAS1

\begin{tabular}{|c|c|c|c|}
\hline ديسمبر \& ا بـ باري & 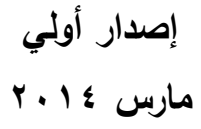 & الفقرة & الموضوع \\
\hline حذف التعديل & تعديل & rq & \multirow{4}{*}{ والأهمية النسبية } \\
\hline حذف التعديل & تعديل & $r$. & \\
\hline مضافة & مضافة & ir. & \\
\hline تعديل & تعديل & $\mu$ & \\
\hline تعديل & تعديل & 0 & \multirow{3}{*}{ قائمة المركز المالي } \\
\hline تعديل & لم تعدل & 00 & \\
\hline مضافة & مضافة & 100 & \\
\hline حذف التعديل & تعديل & Ar & \multirow[b]{2}{*}{ قائمة (قائمتي) الأرياح } \\
\hline تعديل & تعديل & I Ar & \\
\hline
\end{tabular}

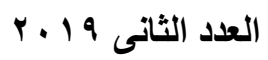

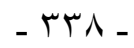

مجلة المحاسبة والمراجعة 


\begin{tabular}{|c|c|c|c|}
\hline تعديل & لم تعدل & 10 & \multirow{3}{*}{ أو الخسائر واللاخل } \\
\hline مضافة & مضافة & i 10 & \\
\hline مضنافة & مضافة & هی ب & \\
\hline تعديل & تعديل & $11 r$ & \multirow{5}{*}{ الإيضاحات } \\
\hline حذف الإضافة & مضافة & I & \\
\hline تعديل & تعديل & $11 \leq$ & \\
\hline حذف & تعديل بالكامل & 110 & \\
\hline حذف التعديل & تعديل & 117 & \\
\hline تعديل & تعديل & $11 \mathrm{~V}$ & \multirow{4}{*}{ الإفصاح عن السياسات } \\
\hline تعديل & لم تعدل & 119 & \\
\hline حذف & حذف & $1 \%$. & \\
\hline تعديل & لم تعدل & Irr & \\
\hline تعديل & لم تعدل & 1. & المجموعة الكاملة للقوائم \\
\hline
\end{tabular}

ملحق (r) نتائج الإحصاءات الوصفية واختبار Chi-Square Test لكل فروض البحث الفرض الأول: - الي

\begin{tabular}{|c|c|c|c|}
\hline $\begin{array}{c}\text { Chi-square } \\
\text { Test }\end{array}$ & العتبار كارات & & \\
\hline
\end{tabular}

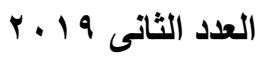

مجلة المحاسبة والمراجعة 


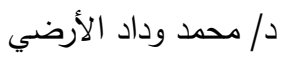

تقييم وتطوير مبادرة الإفصاح لعلاج مشاكل الإفصاح المحاسبي

\begin{tabular}{|c|c|c|c|c|c|c|c|c|c|c|}
\hline المعنوية & القيمة & الانحراف & الكسابى & بشئ & غوافق & محايل & موافق & موافق & & \\
\hline \multirow{2}{*}{0.000} & \multirow{2}{*}{79.789} & \multirow{2}{*}{0.974} & \multirow{2}{*}{4.20} & 2 & 6 & 7 & 36 & 44 & عدد & \multirow{2}{*}{ Q1_1 } \\
\hline & & & & 2.1 & 6.3 & 7.4 & 37.9 & 46.3 & $\%$ & \\
\hline \multirow{2}{*}{0.000} & \multirow{2}{*}{88.211} & \multirow{2}{*}{0.925} & \multirow{2}{*}{4.26} & 2 & 4 & 7 & 36 & 46 & عدد & \multirow{2}{*}{ Q1_2 } \\
\hline & & & & 2.1 & 4.2 & 7.4 & 37.9 & 48.4 & $\%$ & \\
\hline \multirow{2}{*}{0.000} & \multirow{2}{*}{71.368} & \multirow{2}{*}{0.984} & \multirow{2}{*}{4.11} & 2 & 7 & 8 & 40 & 38 & عدد & \multirow{2}{*}{ Q1_3 } \\
\hline & & & & 2.1 & 7.4 & 8.4 & 42.1 & 40.0 & $\%$ & \\
\hline \multirow{2}{*}{0.000} & \multirow{2}{*}{76.105} & \multirow{2}{*}{1.055} & \multirow{2}{*}{4.16} & 4 & 5 & 7 & 35 & 44 & عدد & \multirow{2}{*}{ Q1_4 } \\
\hline & & & & 4.2 & 5.3 & 7.4 & 36.8 & 46.3 & $\%$ & \\
\hline \multirow{2}{*}{0.000} & \multirow{2}{*}{77.789} & \multirow{2}{*}{0.989} & \multirow{2}{*}{4.15} & 3 & 5 & 7 & 40 & 40 & عدد & \multirow{2}{*}{ Q1_5 } \\
\hline & & & & 3.2 & 5.3 & 7.4 & 42.1 & 42.1 & $\%$ & \\
\hline \multirow{2}{*}{0.000} & \multirow{2}{*}{80.421} & \multirow{2}{*}{1.041} & \multirow{2}{*}{4.18} & 3 & 7 & 5 & 35 & 45 & عدد & \multirow{2}{*}{ Q1_6 } \\
\hline & & & & 3.2 & 7.4 & 5.3 & 36.8 & 47.4 & $\%$ & \\
\hline
\end{tabular}

الفرض الثانى:

\begin{tabular}{|c|c|c|c|c|c|c|c|c|c|c|}
\hline \multicolumn{2}{|c|}{$\begin{array}{c}\text { اختبار كا-تربيع } \\
\text { Chi-square } \\
\text { Test }\end{array}$} & \multicolumn{2}{|c|}{ الإحصاءات الوصفية } & \multicolumn{5}{|c|}{ آراء عينة الدراسة } & & \multirow{2}{*}{ العبارات } \\
\hline المعنوية & القيمة & الالمعراف & الحسابى & بشدة & موافق & 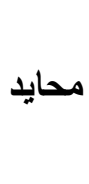 & موافق & موافق & & \\
\hline \multirow{2}{*}{0.000} & \multirow{2}{*}{87.263} & \multirow{2}{*}{1.008} & \multirow{2}{*}{4.24} & 3 & 5 & 6 & 33 & 48 & عدد & \multirow{2}{*}{ Q2_1 } \\
\hline & & & & 3.2 & 5.3 & 6.3 & 34.7 & 50.5 & $\%$ & \\
\hline \multirow{2}{*}{0.000} & \multirow{2}{*}{97.158} & \multirow{2}{*}{0.878} & \multirow{2}{*}{4.32} & 1 & 5 & 5 & 36 & 48 & عدد & \multirow{2}{*}{ Q2_2 } \\
\hline & & & & 1.1 & 5.3 & 5.3 & 37.9 & 50.5 & $\%$ & \\
\hline \multirow{2}{*}{0.000} & \multirow{2}{*}{87.579} & \multirow{2}{*}{0.931} & \multirow{2}{*}{4.24} & 1 & 7 & 5 & 37 & 45 & عدد & \multirow{2}{*}{ Q2_3 } \\
\hline & & & & 1.1 & 7.4 & 5.3 & 38.9 & 47.4 & $\%$ & \\
\hline
\end{tabular}


الفرض الثالث:

\begin{tabular}{|c|c|c|c|c|c|c|c|c|c|c|}
\hline \multicolumn{2}{|c|}{$\begin{array}{c}\text { اختبار كا-تربيع } \\
\text { Chi-square } \\
\text { Test }\end{array}$} & \multicolumn{2}{|c|}{ الإحصاءات الوصفية } & \multicolumn{5}{|c|}{ آراء عينة الدراسة } & & \multirow{2}{*}{ العبارات } \\
\hline المعنوية & القيمة & الانحراف & الحسابى الوسط & بشدير & غوافق & محايد & مواقق & موافق & & \\
\hline \multirow{2}{*}{0.000} & \multirow{2}{*}{98.526} & \multirow{2}{*}{0.881} & \multirow{2}{*}{4.33} & 1 & 5 & 5 & 35 & 49 & عدد & \multirow{2}{*}{ Q3_1 } \\
\hline & & & & 1.1 & 5.3 & 5.3 & 36.8 & 51.6 & $\%$ & \\
\hline \multirow{2}{*}{0.000} & \multirow{2}{*}{105.579} & \multirow{2}{*}{0.854} & \multirow{2}{*}{4.32} & 2 & 3 & 3 & 42 & 45 & عدد & \multirow{2}{*}{ Q3_2 } \\
\hline & & & & 2.1 & 3.2 & 3.2 & 44.2 & 47.4 & $\%$ & \\
\hline \multirow{2}{*}{0.000} & \multirow{2}{*}{100.316} & \multirow{2}{*}{0.746} & \multirow{2}{*}{4.38} & 0 & 2 & 9 & 35 & 49 & عدد & \multirow{2}{*}{ Q3_3 } \\
\hline & & & & 0.0 & 2.1 & 9.5 & 36.8 & 51.6 & $\%$ & \\
\hline \multirow{2}{*}{0.000} & \multirow{2}{*}{88.842} & \multirow{2}{*}{0.997} & \multirow{2}{*}{4.24} & 3 & 5 & 5 & 35 & 47 & عدد & \multirow{2}{*}{ Q3_4 } \\
\hline & & & & 3.2 & 5.3 & 5.3 & 36.8 & 49.5 & $\%$ & \\
\hline \multirow{2}{*}{0.000} & \multirow{2}{*}{94.632} & \multirow{2}{*}{0.939} & \multirow{2}{*}{4.27} & 3 & 3 & 5 & 38 & 46 & عدد & \multirow{2}{*}{ Q3_5 } \\
\hline & & & & 3.2 & 3.2 & 5.3 & 40.0 & 48.4 & $\%$ & \\
\hline \multirow{2}{*}{0.000} & \multirow{2}{*}{107.895} & \multirow{2}{*}{0.774} & \multirow{2}{*}{4.38} & 1 & 2 & 5 & 39 & 48 & عدد & \multirow{2}{*}{ Q3_6 } \\
\hline & & & & 1.1 & 2.1 & 5.3 & 41.1 & 50.5 & $\%$ & \\
\hline
\end{tabular}

الفرض الرابع:

\begin{tabular}{|c|c|c|c|c|c|c|c|c|c|c|}
\hline \multicolumn{2}{|c|}{$\begin{array}{c}\text { اختبار كا-تربيع } \\
\text { Chi-square } \\
\text { Test }\end{array}$} & \multicolumn{2}{|c|}{ الإحصاءات الوصفية } & \multicolumn{5}{|c|}{ آراء عينة الاراسة } & & \multirow{2}{*}{ العبارات } \\
\hline المعنوية & القيمة & الانحراف & الحسابى & موافق & غوافق & محايل & موافق & بشدة موافق & & \\
\hline \multirow{2}{*}{0.000} & \multirow{2}{*}{92.947} & \multirow{2}{*}{0.864} & \multirow{2}{*}{4.31} & 1 & 4 & 7 & 36 & 47 & عدد & \multirow{2}{*}{ Q4_1 } \\
\hline & & & & 1.1 & 4.2 & 7.4 & 37.9 & 49.5 & $\%$ & \\
\hline
\end{tabular}




\begin{tabular}{|c|c|c|c|c|c|c|c|c|c|c|}
\hline \multicolumn{2}{|c|}{$\begin{array}{c}\text { اختبار كا-تربيع } \\
\text { Chi-square } \\
\text { Test }\end{array}$} & \multicolumn{2}{|c|}{ الإحصاءات الوصفية } & \multicolumn{5}{|c|}{ آراء عينة الاراسة } & & \multirow{2}{*}{ العبارات } \\
\hline المعنوية & القيمة & الانحراف & الحسابى & غشير & غوافير & محايد & موافق & بشدة موافق & & \\
\hline \multirow{2}{*}{0.000} & \multirow{2}{*}{109.895} & \multirow{2}{*}{0.842} & \multirow{2}{*}{4.39} & 1 & 4 & 4 & 34 & 52 & عدد & \multirow{2}{*}{ Q4_2 } \\
\hline & & & & 1.1 & 4.2 & 4.2 & 35.8 & 54.7 & $\%$ & \\
\hline \multirow{2}{*}{0.000} & \multirow{2}{*}{87.263} & \multirow{2}{*}{0.922} & \multirow{2}{*}{4.25} & 2 & 4 & 7 & 37 & 45 & عدد & \multirow{2}{*}{ Q4_3 } \\
\hline & & & & 2.1 & 4.2 & 7.4 & 38.9 & 47.4 & $\%$ & \\
\hline \multirow{2}{*}{0.000} & \multirow{2}{*}{100.211} & \multirow{2}{*}{0.904} & \multirow{2}{*}{4.33} & 1 & 6 & 4 & 34 & 50 & عدد & \multirow{2}{*}{ Q4_4 } \\
\hline & & & & 1.1 & 6.3 & 4.2 & 35.8 & 52.6 & $\%$ & \\
\hline \multirow{2}{*}{0.000} & \multirow{2}{*}{99.263} & \multirow{2}{*}{0.878} & \multirow{2}{*}{4.32} & 2 & 3 & 5 & 38 & 47 & عدد & \multirow{2}{*}{ Q4_5 } \\
\hline & & & & 2.1 & 3.2 & 5.3 & 40.0 & 49.5 & $\%$ & \\
\hline \multirow{2}{*}{0.000} & \multirow{2}{*}{97.263} & \multirow{2}{*}{0.900} & \multirow{2}{*}{4.31} & 1 & 6 & 4 & 36 & 48 & عدد & \multirow{2}{*}{ Q4_6 } \\
\hline & & & & 1.1 & 6.3 & 4.2 & 37.9 & 50.5 & $\%$ & \\
\hline \multirow{2}{*}{0.000} & \multirow{2}{*}{102.000} & \multirow{2}{*}{0.824} & \multirow{2}{*}{4.36} & 1 & 3 & 6 & 36 & 49 & عدد & \multirow{2}{*}{ Q4_7 } \\
\hline & & & & 1.1 & 3.2 & 6.3 & 37.9 & 51.6 & $\%$ & \\
\hline $0 \Omega 0$ & $88 \Omega \cap 0$ & 0045 & 125 & 2 & 5 & 6 & 36 & 46 & عدد & $\Omega 48$ \\
\hline 0.000 & 00.000 & $0.74 J$ & $4.2 J$ & 2.1 & 5.3 & 6.3 & 37.9 & 48.4 & $\%$ & Q4__o \\
\hline م & 02401 & 0010 & 40 & 2 & 4 & 6 & 36 & 47 & عدد & 010 \\
\hline 0.000 & 32.421 & (1) & 7.20 & 2.1 & 4.2 & 6.3 & 37.9 & 49.5 & $\%$ & X_t \\
\hline م & & 0700 & $414-1$ & 0 & 4 & 5 & 31 & 55 & عدد & \\
\hline 0.000 & 110.947 & 0.102 & 4.44 & 0.0 & 4.2 & 5.3 & 32.6 & 57.9 & $\%$ & Q4_10 \\
\hline
\end{tabular}

الفرض الخامس :

\begin{tabular}{|c|c|c|c|}
\hline $\begin{array}{c}\text { Chi-square } \\
\text { Test }\end{array}$ & اختبار كا-تربيعة العبارات & \\
\hline
\end{tabular}




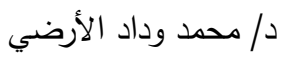

تقييم وتطوير مبادرة الإفصاح لعلاج مشاكل الإفصاح المحاسبي

\begin{tabular}{|c|c|c|c|c|c|c|c|c|c|c|}
\hline المعنوية & القيمة & الانحراف & الحسابى & بشير & غوافق & محايا & موافق & بشدة موافق & & \\
\hline \multirow{2}{*}{0.000} & \multirow{2}{*}{109.158} & \multirow{2}{*}{0.830} & \multirow{2}{*}{4.40} & 1 & 3 & 6 & 32 & 53 & عدد & \multirow{2}{*}{ Q5_1 } \\
\hline & & & & 1.1 & 3.2 & 6.3 & 33.7 & 55.8 & $\%$ & \\
\hline \multirow{2}{*}{0.000} & \multirow{2}{*}{122.000} & \multirow{2}{*}{0.712} & \multirow{2}{*}{4.46} & 0 & 3 & 3 & 36 & 53 & عدد & \multirow{2}{*}{ Q5_2 } \\
\hline & & & & 0.0 & 3.2 & 3.2 & 37.9 & 55.8 & $\%$ & \\
\hline \multirow{2}{*}{0.000} & \multirow{2}{*}{92.421} & \multirow{2}{*}{0.959} & \multirow{2}{*}{4.26} & 2 & 6 & 4 & 36 & 47 & عدد & \multirow{2}{*}{ Q5_3 } \\
\hline & & & & 2.1 & 6.3 & 4.2 & 37.9 & 49.5 & $\%$ & \\
\hline \multirow{2}{*}{0.000} & \multirow{2}{*}{113.895} & \multirow{2}{*}{0.723} & \multirow{2}{*}{4.42} & 0 & 3 & 4 & 38 & 50 & عدد & \multirow{2}{*}{ Q5_4 } \\
\hline & & & & 0.0 & 3.2 & 4.2 & 40.0 & 52.6 & $\%$ & \\
\hline \multirow{2}{*}{0.000} & \multirow{2}{*}{99.474} & \multirow{2}{*}{0.844} & \multirow{2}{*}{4.33} & 1 & 4 & 5 & 38 & 47 & عدد & \multirow{2}{*}{ Q5_5 } \\
\hline & & & & 1.1 & 4.2 & 5.3 & 40.0 & 49.5 & $\%$ & \\
\hline \multirow{2}{*}{0.000} & \multirow{2}{*}{98.737} & \multirow{2}{*}{0.928} & \multirow{2}{*}{4.33} & 2 & 4 & 6 & 32 & 51 & عدد & \multirow{2}{*}{ Q5_6 } \\
\hline & & & & 2.1 & 4.2 & 6.3 & 33.7 & 53.7 & $\%$ & \\
\hline & & & 410 & 0 & 1 & 5 & 36 & 53 & عدد & \\
\hline 0.000 & 122.421 & 0.030 & 4.40 & 0.0 & 1.1 & 5.3 & 37.9 & 55.8 & $\%$ & $U_{-}$ \\
\hline & & & & 1 & 4 & 2 & 38 & 50 & عدد & \\
\hline 0.000 & דטסלת & 0.010 & & 1.1 & 4.2 & 2.1 & 40.0 & 52.6 & $\%$ & _o \\
\hline (مOA & 05.174 & 0800 & 127 & 1 & 5 & 6 & 34 & 49 & عدد & 050 \\
\hline 0.000 & 30.414 & 0.030 & $4 . J 2$ & 1.1 & 5.3 & 6.3 & 35.8 & 51.6 & $\%$ & W_ \\
\hline 0 & 06040 & 0 & 40 & 2 & 5 & 4 & 36 & 48 & عدد & 0510 \\
\hline 0.000 & 30.042 & (20) & 4.25 & 2.1 & 5.3 & 4.2 & 37.9 & 50.5 & $\%$ & US_U \\
\hline & & & & 1 & 4 & 6 & 36 & 48 & عدد & \\
\hline 0.000 & 91.205 & 0.050 & $4 . J J$ & 1.1 & 4.2 & 6.3 & 37.9 & 50.5 & $\%$ & US_I1 \\
\hline (مOA & חمח 2 ר & 0712 & 146 & 0 & 3 & 3 & 36 & 53 & عدد & 55 \\
\hline 0.000 & 122.000 & 0.112 & 4.40 & 0.0 & 3.2 & 3.2 & 37.9 & 55.8 & $\%$ & $x J_{-1}$ \\
\hline & & & & 1 & 4 & 4 & 36 & 50 & عدد & \\
\hline 0.000 & 100.020 & 0.057 & ו & 1.1 & 4.2 & 4.2 & 37.9 & 52.6 & $\%$ & US_15 \\
\hline 0.000 & 98.526 & 0.881 & 4.33 & 1 & 5 & 5 & 35 & 49 & عدد & Q5_14 \\
\hline
\end{tabular}




\begin{tabular}{|c|c|c|c|c|c|c|c|c|c|c|}
\hline \multicolumn{2}{|c|}{$\begin{array}{c}\text { اختبار كا-تربيع } \\
\text { Chi-square } \\
\text { Test }\end{array}$} & \multicolumn{2}{|c|}{ الإحصاءات الوصفية } & \multicolumn{5}{|c|}{ آراء عينة الدراسة } & & \multirow{3}{*}{ العبارات } \\
\hline \multirow[t]{2}{*}{ المعنوية } & القيمة & الالمعراف & الحسابى الوسط & بثير & غير & محايا & موافق & بثدة & & \\
\hline & & & & 1.1 & 5.3 & 5.3 & 36.8 & 51.6 & $\%$ & \\
\hline \multirow{2}{*}{0.000} & \multirow{2}{*}{91.895} & \multirow{2}{*}{0.983} & \multirow{2}{*}{4.27} & 3 & 4 & 6 & 33 & 49 & عدد & \multirow{2}{*}{ Q5_15 } \\
\hline & & & & 3.2 & 4.2 & 6.3 & 34.7 & 51.6 & $\%$ & \\
\hline \multirow{2}{*}{0.000} & \multirow{2}{*}{115.474} & \multirow{2}{*}{0.740} & \multirow{2}{*}{4.44} & 0 & 3 & 5 & 34 & 53 & عدد & \multirow{2}{*}{ Q5_16 } \\
\hline & & & & 0.0 & 3.2 & 5.3 & 35.8 & 55.8 & $\%$ & \\
\hline
\end{tabular}

الفرض السادس:

\begin{tabular}{|c|c|c|c|c|c|c|c|c|c|c|}
\hline \multicolumn{2}{|c|}{$\begin{array}{c}\text { اختبار كا-تربيع } \\
\text { Chi-square } \\
\text { Test }\end{array}$} & \multicolumn{2}{|c|}{ الإحصاءات الوصفية } & \multicolumn{5}{|c|}{ آراء عينة الدراسة } & & \multirow{2}{*}{ العبارات } \\
\hline المعنوية & القيمة & الانحراف & الحسابى & بشدير & غوافق & محايد & موافق & موافق & & \\
\hline \multirow{2}{*}{0.000} & \multirow{2}{*}{118.000} & \multirow{2}{*}{0.649} & \multirow{2}{*}{4.45} & 0 & 1 & 5 & 39 & 50 & عدد & \multirow{2}{*}{ Q6_1 } \\
\hline & & & & 0.0 & 1.1 & 5.3 & 41.1 & 52.6 & $\%$ & \\
\hline \multirow{2}{*}{0.000} & \multirow{2}{*}{118.421} & \multirow{2}{*}{0.768} & \multirow{2}{*}{4.44} & 1 & 2 & 4 & 35 & 53 & عدد & \multirow{2}{*}{ Q6_2 } \\
\hline & & & & 1.1 & 2.1 & 4.2 & 36.8 & 55.8 & $\%$ & \\
\hline \multirow{2}{*}{0.000} & \multirow{2}{*}{100.632} & \multirow{2}{*}{0.848} & \multirow{2}{*}{4.35} & 0 & 6 & 5 & 34 & 50 & عدد & \multirow{2}{*}{ Q6_3 } \\
\hline & & & & 0.0 & 6.3 & 5.3 & 35.8 & 52.6 & $\%$ & \\
\hline \multirow{2}{*}{0.000} & \multirow{2}{*}{111.684} & \multirow{2}{*}{0.660} & \multirow{2}{*}{4.41} & 0 & 1 & 6 & 41 & 47 & عدد & \multirow{2}{*}{ Q6_4 } \\
\hline & & & & 0.0 & 1.1 & 6.3 & 43.2 & 49.5 & $\%$ & \\
\hline \multirow{2}{*}{0.000} & \multirow{2}{*}{110.316} & \multirow{2}{*}{0.779} & \multirow{2}{*}{4.41} & 0 & 4 & 5 & 34 & 52 & عدد & \multirow{2}{*}{ Q6_5 } \\
\hline & & & & 0.0 & 4.2 & 5.3 & 35.8 & 54.7 & $\%$ & \\
\hline 0.000 & 103.684 & 0.813 & 4.37 & 0 & 5 & 5 & 35 & 50 & عدد & Q6_6 \\
\hline
\end{tabular}




\begin{tabular}{|c|c|c|c|c|c|c|c|c|c|c|}
\hline \multicolumn{2}{|c|}{$\begin{array}{c}\text { اختبار كا-تربيع } \\
\text { Chi-square } \\
\text { Test }\end{array}$} & \multicolumn{2}{|c|}{ الإحصاءات الوصفية } & \multicolumn{5}{|c|}{ آراء عينة الدراسة } & & \multirow{3}{*}{ العبارات } \\
\hline \multirow[t]{2}{*}{ المعنوية } & القيمة & الالمعيارى & الحسابى الوسط & بثير & غوافير & محايد & موافق & موافق & & \\
\hline & & & & 0.0 & 5.3 & 5.3 & 36.8 & 52.6 & $\%$ & \\
\hline \multirow{2}{*}{0.000} & \multirow{2}{*}{107.684} & \multirow{2}{*}{0.800} & \multirow{2}{*}{4.37} & 1 & 3 & 4 & 39 & 48 & عدد & \multirow{2}{*}{ Q6_7 } \\
\hline & & & & 1.1 & 3.2 & 4.2 & 41.1 & 50.5 & $\%$ & \\
\hline \multirow{2}{*}{0.000} & \multirow{2}{*}{94.421} & \multirow{2}{*}{0.849} & \multirow{2}{*}{4.29} & 1 & 4 & 6 & 39 & 45 & عدد & \multirow{2}{*}{ Q6_8 } \\
\hline & & & & 1.1 & 4.2 & 6.3 & 41.1 & 47.4 & $\%$ & \\
\hline \multirow{2}{*}{0.000} & \multirow{2}{*}{96.737} & \multirow{2}{*}{0.794} & \multirow{2}{*}{4.34} & 0 & 4 & 7 & 37 & 47 & عدد & \multirow{2}{*}{ Q6_9 } \\
\hline & & & & 0.0 & 4.2 & 7.4 & 38.9 & 49.5 & $\%$ & \\
\hline \multirow{2}{*}{0.000} & \multirow{2}{*}{115.263} & \multirow{2}{*}{0.724} & \multirow{2}{*}{4.43} & 0 & 3 & 4 & 37 & 51 & عدد & \multirow{2}{*}{ Q6_10 } \\
\hline & & & & 0.0 & 3.2 & 4.2 & 38.9 & 53.7 & $\%$ & \\
\hline
\end{tabular}

الفرض السابع:

\begin{tabular}{|c|c|c|c|c|c|c|c|c|c|c|}
\hline \multicolumn{2}{|c|}{$\begin{array}{c}\text { اختبار كا-تربيع } \\
\text { Chi-square } \\
\text { Test }\end{array}$} & \multicolumn{2}{|c|}{ الإحصاءات الوصفية } & \multicolumn{5}{|c|}{ آراء عينة الاراسة } & & \multirow{2}{*}{ العبارات } \\
\hline المعنوية & القيمة & الانحراف & الحسابى & بثير & غوافق & محايد & موافق & بشدة موافق & & \\
\hline \multirow{2}{*}{0.000} & \multirow{2}{*}{102.211} & \multirow{2}{*}{0.811} & \multirow{2}{*}{4.36} & 0 & 5 & 5 & 36 & 49 & عدد & \multirow{2}{*}{ Q7_1 } \\
\hline & & & & 0.0 & 5.3 & 5.3 & 37.9 & 51.6 & $\%$ & \\
\hline \multirow{2}{*}{0.000} & \multirow{2}{*}{142.316} & \multirow{2}{*}{0.741} & \multirow{2}{*}{4.54} & 1 & 2 & 2 & 30 & 60 & عدد & \multirow{2}{*}{ Q7_2 } \\
\hline & & & & 1.1 & 2.1 & 2.1 & 31.6 & 63.2 & $\%$ & \\
\hline \multirow{2}{*}{0.000} & \multirow{2}{*}{104.421} & \multirow{2}{*}{0.773} & \multirow{2}{*}{4.37} & 0 & 4 & 5 & 38 & 48 & عدد & \multirow{2}{*}{ Q7_3 } \\
\hline & & & & 0.0 & 4.2 & 5.3 & 40.0 & 50.5 & $\%$ & \\
\hline
\end{tabular}




\begin{tabular}{|c|c|c|c|c|c|c|c|c|c|c|}
\hline \multicolumn{2}{|c|}{$\begin{array}{c}\text { اختبار كا-تربيع } \\
\text { Chi-square } \\
\text { Test }\end{array}$} & \multicolumn{2}{|c|}{ الإحصاءات الوصفية } & \multicolumn{5}{|c|}{ آراء عينة الدراسة } & & \multirow{2}{*}{ العبارات } \\
\hline المعنوية & القيمة & الانحراف & الحسابى & بثير & غوافير & محايد & موافق & بشدة موافق & & \\
\hline \multirow{2}{*}{0.000} & \multirow{2}{*}{100.526} & \multirow{2}{*}{0.837} & \multirow{2}{*}{4.36} & 1 & 3 & 7 & 34 & 50 & عدد & \multirow{2}{*}{ Q7_4 } \\
\hline & & & & 1.1 & 3.2 & 7.4 & 35.8 & 52.6 & $\%$ & \\
\hline \multirow{2}{*}{0.000} & \multirow{2}{*}{125.684} & \multirow{2}{*}{0.756} & \multirow{2}{*}{4.48} & 0 & 3 & 6 & 28 & 58 & عدد & \multirow{2}{*}{ Q7_5 } \\
\hline & & & & 0.0 & 3.2 & 6.3 & 29.5 & 61.1 & $\%$ & \\
\hline \multirow{2}{*}{0.000} & \multirow{2}{*}{97.158} & \multirow{2}{*}{0.860} & \multirow{2}{*}{4.35} & 0 & 5 & 9 & 29 & 52 & عدد & \multirow{2}{*}{ Q7_6 } \\
\hline & & & & 0.0 & 5.3 & 9.5 & 30.5 & 54.7 & $\%$ & \\
\hline \multirow{2}{*}{0.000} & \multirow{2}{*}{140.421} & \multirow{2}{*}{0.727} & \multirow{2}{*}{4.54} & 0 & 2 & 7 & 24 & 62 & عدد & \multirow{2}{*}{ Q7_7 } \\
\hline & & & & 0.0 & 2.1 & 7.4 & 25.3 & 65.3 & $\%$ & \\
\hline \multirow{2}{*}{0.000} & \multirow{2}{*}{126.211} & \multirow{2}{*}{0.836} & \multirow{2}{*}{4.46} & 1 & 3 & 6 & 26 & 59 & عدد & \multirow{2}{*}{ Q7_8 } \\
\hline & & & & 1.1 & 3.2 & 6.3 & 27.4 & 62.1 & $\%$ & \\
\hline \multirow{2}{*}{0.000} & \multirow{2}{*}{105.789} & \multirow{2}{*}{0.748} & \multirow{2}{*}{4.39} & 0 & 3 & 6 & 37 & 49 & عدد & \multirow{2}{*}{ Q7_9 } \\
\hline & & & & 0.0 & 3.2 & 6.3 & 38.9 & 51.6 & $\%$ & \\
\hline \multirow{2}{*}{0.000} & 105700 & 0740 & 120 & 0 & 3 & 6 & 37 & 49 & عدد & Q7_10 \\
\hline & 100.67 & 0.140 & לעכ. & 0.0 & 3.2 & 6.3 & 38.9 & 51.6 & $\%$ & \\
\hline ( $0 \Omega$ & 102011 & 0811 & 426 & 0 & 5 & 5 & 36 & 49 & عدد & \\
\hline 0.000 & 102.211 & 0.011 & 4.00 & 0.0 & 5.3 & 5.3 & 37.9 & 51.6 & $\%$ & $x_{-11}$ \\
\hline
\end{tabular}

القرض الثامن:

\begin{tabular}{|c|c|c|c|}
\hline $\begin{array}{c}\text { اختبار كا-تربيع } \\
\text { Chi-square } \\
\text { Test }\end{array}$ & الإحصاءات الوصفية & آراء عينة الدراسة & العبارات \\
\hline
\end{tabular}




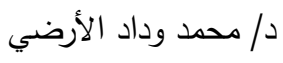

تقييم وتطوير مبادرة الإفصاح لعلاج مشاكل الإفصاح المحاسبي

\begin{tabular}{|c|c|c|c|c|c|c|c|c|c|c|}
\hline المعنوية & القيمة & الانحراف & الحسابى & بشير & غوافق & محايد & موافق & بشدة موافق & & \\
\hline \multirow{2}{*}{0.000} & \multirow{2}{*}{128.105} & \multirow{2}{*}{0.797} & \multirow{2}{*}{4.47} & 0 & 5 & 3 & 29 & 58 & عدد & \multirow{2}{*}{ Q8_1 } \\
\hline & & & & 0.0 & 5.3 & 3.2 & 30.5 & 61.1 & $\%$ & \\
\hline \multirow{2}{*}{0.000} & \multirow{2}{*}{128.000} & \multirow{2}{*}{0.770} & \multirow{2}{*}{4.48} & 0 & 4 & 4 & 29 & 58 & عدد & \multirow{2}{*}{ Q8_2 } \\
\hline & & & & 0.0 & 4.2 & 4.2 & 30.5 & 61.1 & $\%$ & \\
\hline
\end{tabular}

الفرض التاسع:

\begin{tabular}{|c|c|c|c|c|c|c|c|c|c|c|}
\hline \multicolumn{2}{|c|}{$\begin{array}{c}\text { اختبار كا-تربيع } \\
\text { Chi-square } \\
\text { Test }\end{array}$} & \multicolumn{2}{|c|}{ الإحصاءات الوصفية } & \multicolumn{5}{|c|}{ آراء عينة الدراسة } & & \multirow{2}{*}{ العبارات } \\
\hline المعنوية & القيمة & الانحراف & الوسط الحسى & موافق & غوافق & محايد & موافق & موافق & & \\
\hline \multirow{2}{*}{0.000} & \multirow{2}{*}{100.632} & \multirow{2}{*}{0.824} & \multirow{2}{*}{4.36} & 0 & 5 & 6 & 34 & 50 & عدد & \multirow{2}{*}{ Q9_1 } \\
\hline & & & & 0.0 & 5.3 & 6.3 & 35.8 & 52.6 & $\%$ & \\
\hline \multirow{2}{*}{0.000} & \multirow{2}{*}{133.474} & \multirow{2}{*}{0.797} & \multirow{2}{*}{4.49} & 1 & 3 & 3 & 29 & 59 & عدد & \multirow{2}{*}{ Q9_2 } \\
\hline & & & & 1.1 & 3.2 & 3.2 & 30.5 & 62.1 & $\%$ & \\
\hline \multirow{2}{*}{0.000} & \multirow{2}{*}{104.421} & \multirow{2}{*}{0.773} & \multirow{2}{*}{4.37} & 0 & 4 & 5 & 38 & 48 & عدد & \multirow{2}{*}{ Q9_3 } \\
\hline & & & & 0.0 & 4.2 & 5.3 & 40.0 & 50.5 & $\%$ & \\
\hline \multirow{2}{*}{0.000} & \multirow{2}{*}{100.526} & \multirow{2}{*}{0.837} & \multirow{2}{*}{4.36} & 1 & 3 & 7 & 34 & 50 & عدد & \multirow{2}{*}{ Q9_4 } \\
\hline & & & & 1.1 & 3.2 & 7.4 & 35.8 & 52.6 & $\%$ & \\
\hline \multirow{2}{*}{0.000} & \multirow{2}{*}{130.421} & \multirow{2}{*}{0.797} & \multirow{2}{*}{4.48} & 1 & 3 & 3 & 30 & 58 & عدد & \multirow{2}{*}{ Q9_5 } \\
\hline & & & & 1.1 & 3.2 & 3.2 & 31.6 & 61.1 & $\%$ & \\
\hline \multirow{2}{*}{0.000} & \multirow{2}{*}{114.737} & \multirow{2}{*}{0.808} & \multirow{2}{*}{4.43} & 0 & 4 & 7 & 28 & 56 & عدد & \multirow{2}{*}{ Q9_6 } \\
\hline & & & & 0.0 & 4.2 & 7.4 & 29.5 & 58.9 & $\%$ & \\
\hline \multirow{2}{*}{0.000} & & & & 0 & 3 & 5 & 24 & 63 & عدد & \\
\hline & & 0.140 & $4.5 J$ & 0.0 & 3.2 & 5.3 & 25.3 & 66.3 & $\%$ & Q9_? \\
\hline 0.000 & 126.211 & 0.836 & 4.46 & 1 & 3 & 6 & 26 & 59 & عدد & Q9_8 \\
\hline
\end{tabular}




\begin{tabular}{|c|c|c|c|c|c|c|c|c|c|c|}
\hline \multicolumn{2}{|c|}{$\begin{array}{c}\text { اختبار كا-تربيع } \\
\text { Chi-square } \\
\text { Test }\end{array}$} & \multicolumn{2}{|c|}{ الإحصاءات الوصفية } & \multicolumn{5}{|c|}{ آراء عينة الدراسة } & & \multirow{3}{*}{ العبارات } \\
\hline \multirow[t]{2}{*}{ المعنوية } & القيمة & الانعراف & الحسابى & بشير & غوافير & محايد & موافق & بشدة موافق & & \\
\hline & & & & 1.1 & 3.2 & 6.3 & 27.4 & 62.1 & $\%$ & \\
\hline \multirow{2}{*}{0.000} & \multirow{2}{*}{105.789} & \multirow{2}{*}{0.748} & \multirow{2}{*}{4.39} & 0 & 3 & 6 & 37 & 49 & عدد & \multirow{2}{*}{ Q9_9 } \\
\hline & & & & 0.0 & 3.2 & 6.3 & 38.9 & 51.6 & $\%$ & \\
\hline \multirow{2}{*}{0.000} & \multirow{2}{*}{102.632} & \multirow{2}{*}{0.760} & \multirow{2}{*}{4.38} & 0 & 3 & 7 & 36 & 49 & عدد & \multirow{2}{*}{ Q9_10 } \\
\hline & & & & 0.0 & 3.2 & 7.4 & 37.9 & 51.6 & $\%$ & \\
\hline \multirow{2}{*}{0.000} & \multirow{2}{*}{113.158} & \multirow{2}{*}{0.830} & \multirow{2}{*}{4.40} & 1 & 4 & 3 & 35 & 52 & عدد & \multirow{2}{*}{ Q9_11 } \\
\hline & & & & 1.1 & 4.2 & 3.2 & 36.8 & 54.7 & $\%$ & \\
\hline \multirow{2}{*}{0.000} & \multirow{2}{*}{104.421} & \multirow{2}{*}{0.773} & \multirow{2}{*}{4.37} & 0 & 4 & 5 & 38 & 48 & عدد & \multirow{2}{*}{ Q9_12 } \\
\hline & & & & 0.0 & 4.2 & 5.3 & 40.0 & 50.5 & $\%$ & \\
\hline \multirow{2}{*}{0.000} & \multirow{2}{*}{140.526} & \multirow{2}{*}{0.727} & \multirow{2}{*}{4.54} & 0 & 3 & 4 & 27 & 61 & عدد & \multirow{2}{*}{ Q9_13 } \\
\hline & & & & 0.0 & 3.2 & 4.2 & 28.4 & 64.2 & $\%$ & \\
\hline 0 & 07360 & 0024 & 40 & 1 & 4 & 5 & 42 & 43 & عدد & 14 \\
\hline 0.000 & 91.508 & 0.834 & 4.28 & 1.1 & 4.2 & 5.3 & 44.2 & 45.3 & $\%$ & Q9_14 \\
\hline & & & & 0 & 3 & 2 & 33 & 57 & عدد & \\
\hline 0.000 & 134.000 & ( & $4 . J 2$ & 0.0 & 3.2 & 2.1 & 34.7 & 60.0 & $\%$ & W_IJ \\
\hline م & 11547 & م 7.19 & 4 & 0 & 3 & 5 & 34 & 53 & عدد & (r) \\
\hline 0.000 & $115.4 / 4$ & 0.140 & 4.44 & 0.0 & 3.2 & 5.3 & 35.8 & 55.8 & $\%$ & Q9_16 \\
\hline & & & & 0 & 3 & 4 & 27 & 61 & عدد & \\
\hline 0.000 & 140.526 & 0.727 & 4.54 & 0.0 & 3.2 & 4.2 & 28.4 & 64.2 & $\%$ & Q9_17 \\
\hline & 07570 & م o o & 1 0 & 1 & 3 & 6 & 43 & 42 & عدد & 10 \\
\hline 0.000 & $91.5 / 9$ & 0.808 & 4.28 & 1.1 & 3.2 & 6.3 & 45.3 & 44.2 & $\%$ & Q9_18 \\
\hline 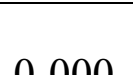 & 150526 & 0678 & 158 & 0 & 2 & 4 & 26 & 63 & عدد & 10 \\
\hline 0.000 & $150.5<0$ & 0.010 & 4.00 & 0.0 & 2.1 & 4.2 & 27.4 & 66.3 & $\%$ & Q9_19 \\
\hline
\end{tabular}


د/ محمد وداد الأرضي

تقييم وتطوير مبادرة الإفصاح لعلاج مشاكل الإفصاح المحاسبي

\begin{tabular}{|c|c|c|c|c|c|c|c|c|c|c|}
\hline \multicolumn{2}{|c|}{$\begin{array}{c}\text { اختبار كا-تربيع } \\
\text { Chi-square } \\
\text { Test }\end{array}$} & \multicolumn{2}{|c|}{ الإحصاءات الوصفية } & \multicolumn{5}{|c|}{ آراء عينة الدراسة } & & \multirow{2}{*}{ العبارات } \\
\hline المعنوية & القيمة & الانحراف & الوسط & بثير & غوافق & محايد & موافق & بثدة موافق & & \\
\hline \multirow{2}{*}{0.000} & \multirow{2}{*}{134.211} & \multirow{2}{*}{0.727} & \multirow{2}{*}{4.51} & 0 & 4 & 1 & 33 & 57 & عدد & \multirow{2}{*}{ Q9_20 } \\
\hline & & & & 0.0 & 4.2 & 1.1 & 34.7 & 60.0 & $\%$ & \\
\hline \multirow{2}{*}{0.000} & \multirow{2}{*}{100.632} & \multirow{2}{*}{0.848} & \multirow{2}{*}{4.35} & 0 & 6 & 5 & 34 & 50 & عدد & \multirow{2}{*}{ Q9_21 } \\
\hline & & & & 0.0 & 6.3 & 5.3 & 35.8 & 52.6 & $\%$ & \\
\hline \multirow{2}{*}{0.000} & \multirow{2}{*}{120.000} & \multirow{2}{*}{0.796} & \multirow{2}{*}{4.45} & 0 & 4 & 6 & 28 & 57 & عدد & \multirow{2}{*}{ Q9_22 } \\
\hline & & & & 0.0 & 4.2 & 6.3 & 29.5 & 60.0 & $\%$ & \\
\hline \multirow{2}{*}{0.000} & \multirow{2}{*}{122.000} & \multirow{2}{*}{0.847} & \multirow{2}{*}{4.44} & 1 & 4 & 4 & 29 & 57 & عدد & \multirow{2}{*}{ Q9_23 } \\
\hline & & & & 1.1 & 4.2 & 4.2 & 30.5 & 60.0 & $\%$ & \\
\hline
\end{tabular}


ملحق (بَ): نتائج اختبار كروسكال Krusskal-Wallis للمقارنة بين آراء فئات الاراسة الأربع

\begin{tabular}{|c|c|c|c|c|c|c|c|}
\hline \multicolumn{2}{|c|}{ كروسكال - واليس } & \multicolumn{4}{|c|}{ متوسط الرتب حسب الفئة } & \multirow[t]{2}{*}{ العبارات } & \multirow[b]{2}{*}{ الفروض } \\
\hline المعنوية & القيمة & المنظمون & المراجعون & المعدون & المستخدمون & & \\
\hline 0.453 & 2.624 & 53.20 & 45.91 & 43.25 & 52.23 & Q1_1 & \\
\hline 0.344 & 3.328 & 46.40 & 39.28 & 46.96 & 52.58 & Q1_2 & \\
\hline 0.786 & 1.065 & 39.00 & 48.84 & 46.37 & 50.18 & Q1_3 & الفرض الأول \\
\hline 0.462 & 2.574 & 40.20 & 46.31 & 44.43 & 52.69 & Q1_4 & \\
\hline 0.760 & 1.170 & 45.60 & 42.16 & 50.12 & 48.84 & Q1_5 & \\
\hline 0.946 & 0.371 & 51.80 & 46.94 & 46.44 & 49.28 & Q1_6 & \\
\hline 0.364 & 3.184 & 42.20 & 40.03 & 47.32 & 52.49 & Q2_1 & \\
\hline 0.751 & 1.208 & 49.60 & 47.94 & 44.49 & 50.81 & Q2_2 & الفرض الثاني \\
\hline 0.671 & 1.548 & 60.60 & 46.94 & 45.88 & 48.65 & Q2_3 & \\
\hline 0.290 & 3.747 & 49.20 & 45.94 & 42.41 & 53.43 & Q3_1 & \\
\hline 0.675 & 1.533 & 42.40 & 45.38 & 45.84 & 51.59 & Q3_2 & \\
\hline 0.372 & 3.131 & 41.40 & 46.91 & 43.54 & 53.05 & Q3_3 & الفرض الثالث \\
\hline 0.585 & 1.941 & 51.60 & 44.31 & 44.74 & 51.80 & Q3_4 & \\
\hline 0.268 & 3.938 & 55.70 & 38.84 & 46.21 & 52.23 & Q3_5 & \\
\hline 0.516 & 2.283 & 62.80 & 45.41 & 45.90 & 48.98 & Q3_6 & \\
\hline 0.628 & 1.742 & 42.80 & 53.41 & 49.82 & 44.94 & Q4_1 & \\
\hline 0.996 & 0.058 & 47.70 & 49.25 & 48.03 & 47.51 & Q4_2 & \\
\hline 0.603 & 1.855 & 60.40 & 44.94 & 49.84 & 46.11 & Q4_3 & \\
\hline 0.377 & 3.093 & 48.90 & 45.63 & 43.12 & 52.99 & Q4_4 & \\
\hline 0.751 & 1.208 & 42.20 & 45.00 & 46.66 & 51.06 & Q4_5 & الفرض الرابع \\
\hline 0.657 & 1.610 & 49.70 & 47.69 & 44.00 & 51.31 & Q4_6 & \\
\hline 0.892 & 0.618 & 49.80 & 47.13 & 45.71 & 50.08 & Q4_7 & \\
\hline
\end{tabular}




\begin{tabular}{|c|c|c|c|c|c|c|c|}
\hline 0.252 & 4.091 & 56.10 & 39.41 & 45.43 & 52.61 & Q4_8 & \\
\hline 0.736 & 1.273 & 37.70 & 47.00 & 47.18 & 50.39 & Q4_9 & \\
\hline 0.151 & 5.306 & 46.30 & 42.84 & 42.85 & 54.65 & Q4_10 & \\
\hline 0.950 & 0.351 & 48.20 & 45.09 & 47.75 & 49.35 & Q5_1 & \\
\hline 0.598 & 1.881 & 47.30 & 46.72 & 44.21 & 51.83 & Q5_2 & \\
\hline 0.565 & 2.034 & 50.40 & 44.03 & 44.79 & 52.01 & Q5_3 & \\
\hline 0.933 & 0.435 & 48.70 & 44.34 & 48.50 & 48.95 & Q5_4 & \\
\hline 0.581 & 1.961 & 42.20 & 49.41 & 44.07 & 51.50 & Q5_5 & الفرض الخامس \\
\hline 0.824 & 0.904 & 48.60 & 46.56 & 45.41 & 50.70 & Q5_6 & \\
\hline 0.515 & 2.288 & 38.20 & 44.19 & 46.76 & 51.80 & Q5_7 & \\
\hline 0.926 & 0.469 & 48.30 & 44.22 & 48.50 & 49.05 & Q5_8 & \\
\hline 0.460 & 2.584 & 58.70 & 46.16 & 43.75 & 51.01 & Q5_9 & \\
\hline 0.745 & 1.234 & 49.80 & 43.34 & 46.54 & 50.88 & Q5_10 & \\
\hline 0.540 & 2.159 & 42.10 & 49.19 & 43.88 & 51.76 & Q5_11 & \\
\hline 0.316 & 3.540 & 60.10 & 41.34 & 45.51 & 51.26 & Q5_12 & \\
\hline 0.860 & 0.757 & 49.30 & 50.19 & 45.07 & 49.45 & Q5_13 & \\
\hline 0.465 & 2.559 & 58.60 & 47.19 & 43.50 & 50.83 & Q5_14 & \\
\hline 0.641 & 1.680 & 49.70 & 42.22 & 46.60 & 51.29 & Q5_15 & \\
\hline 0.888 & 0.636 & 56.40 & 47.53 & 47.26 & 47.76 & Q5_16 & \\
\hline 0.605 & 1.845 & 61.60 & 49.66 & 46.29 & 47.09 & Q6_1 & \\
\hline 0.789 & 1.052 & 47.50 & 44.38 & 46.43 & 50.85 & Q6_2 & \\
\hline 0.795 & 1.026 & 48.70 & 45.50 & 45.65 & 50.91 & Q6_3 & \\
\hline 0.369 & 3.151 & 40.90 & 48.53 & 43.25 & 52.71 & Q6_4 & \\
\hline 0.828 & 0.888 & 47.50 & 45.28 & 46.15 & 50.73 & Q6_5 & الفرض السادس \\
\hline 0.371 & 3.135 & 49.50 & 46.75 & 42.71 & 52.81 & Q6_6 & \\
\hline 0.869 & 0.717 & 49.10 & 49.56 & 45.13 & 49.68 & Q6_7 & \\
\hline 0.736 & 1.273 & 43.30 & 52.91 & 49.29 & 45.53 & Q6_8 & \\
\hline 0.507 & 2.328 & 49.70 & 43.91 & 44.54 & 52.36 & Q6_9 & \\
\hline
\end{tabular}




\begin{tabular}{|c|c|c|c|c|c|c|c|}
\hline 0.733 & 1.284 & 52.40 & 52.22 & 44.69 & 48.58 & Q6_10 & \\
\hline 0.293 & 3.724 & 62.50 & 41.56 & 51.40 & 45.88 & Q7_1 & \\
\hline 0.052 & 7.728 & 43.90 & 40.19 & 43.22 & 55.70 & Q7_2 & \\
\hline 0.862 & 0.747 & 54.30 & 45.69 & 49.74 & 46.66 & Q7_3 & \\
\hline 0.779 & 1.091 & 48.60 & 45.59 & 45.50 & 51.01 & Q7_4 & \\
\hline 0.897 & 0.599 & 45.00 & 52.00 & 47.66 & 47.06 & Q7_5 & \\
\hline 0.734 & 1.280 & 48.10 & 48.97 & 44.29 & 50.75 & Q7_6 & الفرض السابع \\
\hline 0.083 & 6.675 & 44.20 & 41.06 & 43.44 & 55.13 & Q7_7 & \\
\hline 0.024 & 9.404 & 44.90 & 41.47 & 41.29 & 56.70 & Q7_8 & \\
\hline 0.645 & 1.664 & 40.90 & 48.16 & 51.90 & 45.51 & Q7_9 & \\
\hline 0.645 & 1.664 & 40.90 & 48.16 & 51.90 & 45.51 & Q7_10 & \\
\hline 0.293 & 3.724 & 62.50 & 41.56 & 51.40 & 45.88 & Q7_11 & \\
\hline 0.605 & 1.844 & 57.80 & 42.25 & 48.22 & 48.89 & Q8_1 & الفرض الثامن \\
\hline 0.715 & 1.361 & 45.00 & 43.47 & 51.34 & 47.35 & Q8_2 & \\
\hline 0.722 & 1.330 & 53.70 & 45.41 & 51.12 & 45.68 & Q9_1 & \\
\hline 0.018 & 10.027 & 44.60 & 36.31 & 44.12 & 56.40 & Q9_2 & \\
\hline 0.676 & 1.529 & 54.30 & 51.06 & 49.74 & 44.51 & Q9_3 & \\
\hline 0.779 & 1.091 & 48.60 & 45.59 & 45.50 & 51.01 & Q9_4 & \\
\hline 0.984 & 0.157 & 45.00 & 48.97 & 47.32 & 48.56 & Q9_5 & \\
\hline 0.991 & 0.109 & 46.10 & 46.59 & 48.50 & 48.38 & Q9_6 & الفرض التاسع \\
\hline 0.127 & 5.699 & 43.70 & 43.81 & 42.87 & 54.58 & Q9_7 & \\
\hline 0.024 & 9.404 & 44.90 & 41.47 & 41.29 & 56.70 & Q9_8 & \\
\hline 0.645 & 1.664 & 40.90 & 48.16 & 51.90 & 45.51 & Q9_9 & \\
\hline 0.647 & 1.655 & 41.20 & 47.06 & 52.09 & 45.75 & Q9_10 & \\
\hline 0.621 & 1.771 & 47.60 & 47.88 & 43.96 & 51.54 & Q9_11 & \\
\hline 0.440 & 2.703 & 54.30 & 41.66 & 52.40 & 46.01 & Q9_12 & \\
\hline 0.064 & 7.267 & 43.60 & 40.25 & 43.56 & 55.43 & Q9_13 & \\
\hline
\end{tabular}




\begin{tabular}{|l|l|l|l|l|l|l|l|}
\hline 0.986 & 0.141 & 51.40 & 48.06 & 48.40 & 47.21 & Q9_14 & \\
\hline 0.436 & 2.725 & 45.00 & 40.59 & 47.37 & 51.88 & Q9_15 & \\
\hline 0.450 & 2.645 & 47.70 & 39.13 & 49.25 & 50.53 & Q9_16 & \\
\hline 0.064 & 7.267 & 43.60 & 40.25 & 43.56 & 55.43 & Q9_17 & \\
\hline 0.983 & 0.167 & 44.10 & 48.38 & 48.79 & 47.66 & Q9_18 & \\
\hline 0.029 & 9.038 & 46.20 & 34.13 & 47.32 & 54.35 & Q9_19 & \\
\hline 0.987 & 0.138 & 45.10 & 48.91 & 47.40 & 48.51 & Q9_20 & \\
\hline 0.894 & 0.610 & 48.70 & 50.56 & 49.35 & 45.74 & Q9_21 & \\
\hline 0.991 & 0.106 & 46.60 & 49.69 & 47.71 & 47.75 & Q9_22 & \\
\hline 0.920 & 0.495 & 46.50 & 49.59 & 45.85 & 49.38 & Q9_23 & \\
\hline
\end{tabular}

